\title{
Lift up of Lowlands: \\ Beneficial use of dredged sediments to \\ reverse land subsidence
}

Bruna Raquel Figueiredo Oliveira 


\section{Thesis committee}

\section{Promotor}

Prof. Dr H.H.M. Rijnaarts

Professor of Environment Technology

Wageningen University

\section{Co-Promotor}

Dr J.T.C. Grotenhuis

Associate professor, Sub-department of Environmental Technology

Wageningen University

\section{Other members}

Prof. Dr. R.N.J. Comans, Wageningen University

Prof, Dr T.J. Heimovaara, Delft University of Technology

Dr J.J. Keizer, University of Aveiro, Portugal

Prof. Dr P.J.G.J. Hellegers, Wageningen University

This research was conducted under the auspices of the Graduate School for Socio-Economic and Natural Sciences of the Environment (SENSE) 


\title{
Lift up of Lowlands:
}

\section{Beneficial use of dredged sediments to reverse land subsidence}

\author{
Bruna Raquel Figueiredo Oliveira
}

\section{Thesis}

submitted in fulfilment of the requirements for the degree of doctor at Wageningen University

by the authority of the Rector Magnificus

Prof. Dr A.P.J. Mol

in the presence of the

Thesis Committee appointed by the Academic Board

to be defended in public

on Wednesday 15 February 2017

at 1.30 p.m. in the Aula. 
Bruna Raquel Figueiredo Oliveira

Lift up of Lowlands: Beneficial use of dredged sediments to reverse land subsidence, 229 pages.

PhD thesis, Wageningen University, Wageningen, NL (2017)

With references, with summaries in English, Dutch and Portuguese

ISBN: 978-94-6257-883-8

DOI: http://dx.doi.org/10.18174/387316 


\section{Contents}

Chapter 1

General introduction and state of the art on the beneficial use of dredged sediments to reverse land subsidence

Chapter 2

Functional properties of soils formed from biochemical ripening of dredged sediments - subsidence mitigation in delta areas

Chapter 3

Impact of compost and manure on the ripening of dredged sediments

Chapter 4

Subsidence of organic dredged sediments - mesoscale experiments with different water levels

Chapter 5

Subsidence of organic dredged sediments in an upland deposit in Wormer- en Jisperveld - North Holland, the Netherlands

General Discussion

Future perspectives and opportunities for the beneficial use of dredged sediments to reverse land subsidence

References

Appendices

Appendix 1: Summary of case studies

Appendix 2: Non-invasive determination of $\mathrm{O}_{2}$ and $\mathrm{CO}_{2}$ in laboratorial-scale experiments with dredged material

Lift of Figures

List of Tables

Summary

English

Nederlandse

Português

Publications and communication of the results

About the author

SENSE certificate

Financial support 



\section{Chapter 1}

General introduction and state of the art on the beneficial use of dredged sediments to reverse land subsidence 



\begin{abstract}
The beneficial use of dredged sediments is presented here with special emphasis to reverse the process of land subsidence. The major constraints for beneficial use are the contaminants concentrations in the sediments as well as managing the supply and demand. The perspectives of beneficial use of dredged sediments to reverse the process of land subsidence in lowlands and delta areas is feasible and should be integrated in water basins management plans.
\end{abstract}

\title{
Keywords
}

Dredged sediments; Land subsidence; Beneficial use 


\subsection{Introduction}

Land subsidence is occurring in many low lying and delta areas worldwide, for instance in the Netherlands (Oliveira et al. 2016, Querner et al. 2012, van Asselen 2011), U.S.A. (Aich et al. 2013, Kolker et al. 2011), Italy (Teatini et al. 2011), Egypt (Wöppelmann et al. 2013), Indonesia (Hooijer et al. 2012), New Zealand (Pronger et al. 2014). Land subsidence in these areas is, in addition to long term geological effects, mostly a consequence of anthropogenic interference such as drainage which results in shrinkage due to the loss of volume occupied by the water and rearrangement of the particles (Oleszczuk et al. 2003), and in organic matter oxidation (Sanei et al. 2005). There are studies with contrasting results regarding the individual contribution of shrinkage and organic matter oxidation to the total land subsidence: some report that the high subsidence rates observed in the layer above the groundwater level is mostly oxidation of organic matter (Dawson et al. 2010, Hoogland et al. 2012, Schothorst 1977); others relate land subsidence mainly with shrinkage (Teatini et al. 2011); and other studies concluded that the contribution of oxidation of organic matter and shrinkage is variable in time (Hooijer et al. 2012, Pronger et al. 2014, van Asselen 2011).

The dense networks of waterways needed to regulate the water level in lowlands and Delta areas is perpetuating the subsidence and is becoming increasingly costly (Querner et al. 2012). Periodical dredging of the waterways is generally performed to maintain their nautical and hydrological functions and improve water quality. A beneficial use of non-contaminated dredged sediments is to spread these on the land adjacent to the waterway. This might be a solution to reverse land subsidence by rising the land surface level (Bramley \& Rimmer 1988, Harmsen 2007) especially considering that in some areas the sediments and water flow are restrained, by dams and ponds, which limits the 
natural restoration through sediment accumulation in the delta areas (Kolker et al. 2011). Furthermore, since the sediments mostly originate from erosion of soils in the same water basin, and therefore the characteristics of the sediments are often identical to the soils in the adjacent lands, the impacts on the ecosystem of using sediments locally should be minimal when compared to relocation outside the water basin or import of sediments from other locations (Harmsen 2007, Salomons 2008).

When flood-induced inundation occurs, the sediments are naturally spread on land, which increases the soil fertility, compensates for nutrient and organic matter losses and offsets subsidence or flooding due to the sea-level rise (Canet et al. 2003, Fonseca et al. 1998, Leue \& Lang 2012).

The industrialization and population growth around waterways in the $19^{\text {th }}$ century led to the contamination of sediments with heavy metals, oils and grease, pesticides, PCBs and hydrocarbons from domestic and industrial sources (von Gunten et al. 1997). As a consequence, some European countries classify dredged sediments as a waste (Apitz 2010) and contaminated sediments were isolated from the environment in confined land disposal areas which were generally located near the dredging projects as the most economical alternative (Walsh 1977). Nowadays there are many Directives, Conventions, Regulations and country-specific policies that apply to dredged sediments and complicate the scenario (Mink et al. 2006), starting by the classification of dredged sediments as a waste or a resource (Apitz 2010, Mink et al. 2006). Still, with the decrease in sources of pollution, the development of remediation and treatment technologies (Förstner \& Salomons 2010, Rulkens 2005), and the current policies demanding more sustainable and environmental friendly practices for sediment management (International Maritime Organization 1972, The European Parliament 
and The Council of the European Union 2008), there are increasing possibilities for the beneficial use of dredged sediments.

Both scientific literature and European policies favor the beneficial use of sediments to reverse land subsidence. The stakeholders involved in dredging and sediments management, and the general public should be involved in the planning of the water basins to increase the acceptance and feasibility of beneficial uses of dredged sediments (Bortone et al. 2004a).

The objective of this overview is to present the state of the art on perspectives for the beneficial use of dredged sediments to reverse the process of land subsidence.

\subsection{Beneficial use of dredged sediments}

Dredging has come a long way since the shoveling a ditch or digging a canal with horse-drawn bucket dredgers, to the dredging of the Suez and Panama canals or the building of the Hong Kong Airport (IADC 1999). A common destination for sediments dredged from small waterways was spreading on the land adjacent to the waterways (Harmsen et al. 2012). The spreading of sediments on land is also naturally done through flooding of the waterways (Slobbe et al. 2013).

In 1973, the Dredged Material Research Program (DMRP) was created by the United States Army Corps of Engineers (USACE) with the objective of exploring dredged material as a resource (Walsh 1977). In 1987 a manual based on case studies was released with guidance for planning, designing, developing, and managing dredged sediments for beneficial uses ranging from habitat development to construction (USACE 1987). Later, in 1992, the World Association for Waterborne Transport Infrastructure released a practical guide, based on the USACE publications, in which the beneficial uses of dredged sediments with different textures are divided in engineered uses, agricultural and 
product uses, and environment enhancement (PIANC 1992). Most scientific publications on the beneficial use of sediments are descriptions of case studies and a more detailed description of studies not dealing with spreading sediments on land is given on Appendix 1.

Engineered uses refers to construction for commercial, industrial or institutional purposes. In these cases dredged sediments are a resource and reduce the need for other primary resources. Usually coarse sediments, such as gravel and sand, are more suitable for these uses than fine sediments (PIANC 1992). Some examples of engineered uses of dredged sediments are land creation, improvement and restoration (Yozzo et al. 2004), offshore berms and shore protection (Coulet et al. 2014, Malasavage et al. 2012), replacement fill (Perrodin et al. 2012) and capping (Brose et al. 2016, Eek et al. 2007).

Agricultural uses refers to the use of mainly silt and soft clays, originating from water basin erosion (PIANC 1992), as topsoil or medium for plant growth (Canet et al. 2003, Fonseca et al. 1998, Sheehan et al. 2010b).

Product uses refer to the incorporation of mainly clayey sediments (PIANC 1992) in construction materials, such as cement (Aouad et al. 2012, Dang et al. 2013), bricks (Chiang et al. 2008, Samara et al. 2009), ceramics (Giulio Bernstein et al. 2002, Torres et al. 2009), and road construction (Miraoui et al. 2012, Wang et al. 2012).

Environmental Enhancement includes restoration of habitats (Augustin et al. 2011, Yozzo et al. 2004), fisheries (Reine et al. 2013), and wetlands (French \& Burningham 2009, van der Wal et al. 2011).

The International Association of Dredging Companies and the International Association of Ports and Harbors (IADC \& IAPH 2010) and some harbors around the world have also prepared specific guidelines in order to maximize the potential of beneficial use of dredged sediments 
(Garcia Navarro 2010, The Innovative Reuse Committee 2007, USACE 2008, Vellinga \& Eisma 2005, Wagner 2000, Yozzo et al. 2004).

Even though the growing scientific and engineering knowledge of using dredged sediments as a valuable resource has emphasized this practice for a variety of applications (Parson \& Swafford 2012), there are still constraints to be beneficial uses. For instance, in Spain, from 1994 to $2004,76 \%$ of the total volume dredged has been used for land reclamation or beach nourishment. The remaining $24 \%$ were dumped at high sea (Vidal 2006). The USACE estimates that 20 to $30 \%$ of the total volume dredged is currently used beneficially in the USA, even though the percentage varies from year to year (EPA \& USEPA 2007). The beneficial use of sediments is only $20 \%$ in the Republic of Ireland (Sheehan et al. 2009) and 25\% in the Netherlands (Palumbo 2007). In contrast, in Japan, up to $90 \%$ of dredged sediments have been beneficially used (PIANC 2009).

The major constraints for an efficient beneficial use of dredged sediments are (Apitz 2010, USACE 2008, Vellinga \& Eisma 2005): contamination of dredged sediments; coordination of supply and demand in terms of quality (organic matter content and particle size distribution), quantity, distance and time; and legislative restrictions and public acceptance.

In recent years, a new approach is being developed of looking for opportunities in nature to answer engineering challenges which can cope with changing conditions such as sea level rise and climate change has emerged, which is in line with the Green Adaptation (EU, UNEP, FAO, WWF, and Conservation International) (EEA 2013). This is a flexible and self-adjusting way of aligning natural processes with engineering practices to achieve economic, environmental, and social benefits, and has been named "Building with nature" (van Slobbe \& Lulofs 2011), "Working with Nature" (PIANC 2011), or "Engineering with nature" 
(Banks et al. 2013). In the case of sediments, these concepts are translated as the management of dredged sediments within the water basin as a resource, and as engineered changes in hydrodynamics and natural processes to manage the sediments without the need to dredge (for example, in flood-induced inundations) (de Vriend \& van Koningsveld 2012).

\subsection{Beneficial use of dredged sediments to reverse land subsidence}

Land subsidence is becoming more urgent in the last decade as the effects of climate change and higher temperatures leading to increased organic matter oxidation are accelerating the subsidence especially of inland peaty and lowlands (Brouns et al. 2015, Hoogland et al. 2012, Ritzema \& Stuyt 2015).

Constructed barriers along the water basins block sediment transport and if the sediment is dredged and transported to a disposal site, the bed of the water basin behind the barrier will not accompany the rising of the outer delta (due to rising sea level) (Slobbe et al. 2013). Increasing the level of dikes will only continue to work if vertical aggradation is implemented. Furthermore, increasing energy scarcity will make energy intensive management strategies (such as building and maintaining dikes and pumping sediments) less affordable and feasible (Ibáñez et al. 2014). Therefore, spreading sediment is increasingly being used for coastal protection and in anticipation of climate change (Slobbe et al. 2013).

Since inland sediment mostly originate from eroded agricultural soils within the same water basin, the sediment is usually rich in nutrients, organic carbon, and clay minerals. So, spreading these dredged sediments on land can not only offset subsidence or sea-level rise but also increase the soil fertility and compensate for nutrient and organic 
matter losses (Canet et al. 2003, Fonseca et al. 1998, Leue \& Lang 2012).

When dredged sediments with a clay content higher than $8 \%$ and/or an organic matter content higher than $3 \%$, are transferred from water to upland conditions, sedimentation, consolidation and ripening occur (Pons \& Zonneveld 1965). Sedimentation refers to the settling and rearrangement of the smaller fractions of the particles into multi-particle conglomerates, and takes place within hours or days, depending on the texture of the sediments. During consolidation the weight of the sediments forces out the pore water of deeper layers, i.e., the extent of consolidation will depend on the thickness of the layer and on the permeability of the sediments and boundaries (Terzaghi et al. 1996). When thick layers of sediments are spread on land the consolidation and compaction of the underlying soil can add to the land subsidence (van Asselen 2011) and therefore the impact of the weight of the sediments on the underlying soil should be evaluated. Ripening is a soil forming process that converts the waterlogged sediments into soil. Ripening can be subdivided into physical, chemical, and biological, even though the three proceed simultaneously and interact with each other (Vermeulen et al. 2003).

A possible consequence of spreading dredged sediments on land is that the addition of fresh organic matter to soil provides substrates for energy and growth to microorganisms which then stimulate the decomposition of carbonaceous compounds. This effect is called the positive priming effect and is mostly an acceleration of native soil organic matter mineralization by using the fresh organic matter as a source of energy (Fontaine et al. 2011, Guenet et al. 2012). There are, however, also studies reporting a negative priming effect, i.e., the native soil organic matter mineralization can be reduced. The positive or negative priming effect is mostly determined by the soil microbial 
biomass response to the addition of different substances (Kuzyakov et al. 2000). If a positive priming effect occurs, land subsidence due to organic matter mineralization could potentially increase. A solution to decrease organic matter mineralization is the management of the groundwater level (Querner et al. 2012, Schouwenaars 2000). In fact, raising the groundwater level, and consequently decreasing the aerobic layer of the soil, should be done together with the spreading of dredged sediments.

Another example of land subsidence due to shrinkage and organic matter mineralization is the increasing thawing of the permafrost (Shiklomanov et al. 2013). Also in that case, a solution to decrease the subsidence rates when related to mineralization of organic matter is to keep high groundwater levels since the anaerobic mineralization of organic matter is in general much slower than the aerobic mineralization (Knoblauch et al. 2013), and shrinkage due to drainage will also decrease (Lewis et al. 2012).

\subsection{Constraints to the beneficial use of sediments to reverse land subsidence}

The multiple sources of contamination within a water basin result in a mixture of contaminants more difficult to treat than industrial wastes (Jacobs \& Förstner 2001). Sediments act as sinks for Persistent Organic Pollutants (POP) such as Polychlorinated biphenyls (PCB), dioxins, and DDT; Hydrophobic Organic Contaminants (HOC) such as Polycyclic Aromatic Hydrocarbons (PAH) and Hexachlorocyclohexane ( $\mathrm{HCH}$ ) (Smit 2009); and pesticides and heavy metals (Kronvang et al. 2003). In addition, in some cases of sediments originating from agricultural areas, the nutrients concentration can be very high which can cause eutrophication of the waterways (Carpenter 2005), especially when the sediments are re-suspended when dredging (Lohrer \& Wetz 2003). 
Considering the legislation and regulations regarding not only contaminants but also waste minimization, environmental protection and the protection of aquatic ecosystems and services, lead to the preference for a management of dredged sediments that minimize risks and waste (Apitz 2010). In this way, bioavailability and water basin management give a more realistic appraisal of the potential risks that contaminants pose to environment and human health than traditional quantity-oriented, site specific policies (Förstner \& Salomons 2010, Harmsen 2007). The bioavailability principles have in consideration that the biological effects are not related with the total concentration of a contaminant in the soil and soil-like materials but with the response of organisms to the fraction that is biologically available. Bioavailability principles are more attractive in terms of both costs and in situ management of contaminated sites than traditional concentration-based principles (Harmsen 2007, Semple et al. 2003). For instance, the Dutch Ministry of Health, Welfare and Sport produced a report with advice for the implementation of bioavailability in soil policies (RIVM 2012).

For remediation purposes the application of the principles of bioavailability can result in practices that reduce bioavailability and consequently the risk of contaminants (Harmsen \& Naidu 2013), and the literature gives enough evidence to recognize bioavailability as a promising tool in risk assessment (Harmsen 2007, Naidu et al. 2015). As an example, when spreading dredged sediments on land, compost, manure or other biological materials can also be added which will not only enhance biodegradation of organic pollutants through the priming effect (d'Errico et al. 2013).

Whilst the use of risk-based decision criteria is established in Europe for soil remedial decisions, these principles have not yet been translated to generally applied decision frameworks or guidance for contaminated sediment management in Europe (Apitz 2008). The first step on that 
direction was the development of an International Standard for the selection and application of methods for the assessment of bioavailability of contaminants in soil and soil materials (ISO 17402:2008 2008).

The successful beneficial use of dredged sediments depends not only on science but also on the stakeholders (dredgers, farmers, recreation entrepreneurs, nature conservation agencies) involved in a dredging project who should be identified and work together (IADC \& IAPH 2010), and on the evaluation of the appropriate legislation and guidelines, and the use of risk assessment and societal cost-benefit analysis (Owens 2005). For instance, scientific knowledge and the identification of economic and social benefits, may help overcome some public opposition to the beneficial use of dredged sediments (Bortone et al. 2004b).

The beneficial use of dredged sediments can be more practical, cost effective, and environmentally advantageous when it is integrated in the water basin planning processes and regional strategies for managing sediment resources (Netzband 2007, USACE 1987).

When the supply of dredged sediments is not enough to fulfil the demand for the compensation of land subsidence, other resources like stabilized compost and manure can be added. The spreading on agricultural soils of organic amendments, such as compost and manure, together with the dredged sediments, can improve plant growth and yield, soil carbon content, and microbial biomass and activity (Thangarajan et al. 2013) and even on the biodegradation of organic contaminants (Mattei et al. 2016). The use of organic amendments together with sediments will further increase the surface level of the lands suffering from subsidence (Brils et al. 2014, Hoogland et al. 2012). 


\subsection{Conclusions}

Land subsidence is occurring in many lowlands and delta areas worldwide. These areas are often characterized by dense networks of drainage waterways which have to be periodically dredged. A beneficial use of the dredged sediments is to spread these on land to reverse the process of land subsidence. The spreading of sediments on land is naturally occurring in flood plains and is known to increase the productivity of agricultural soils. Still, in some places the contamination level of the sediments might hinder this beneficial use. When this is the case, the contamination should be evaluated in terms of bioavailability and remediation techniques are available to enable the beneficial use of sediments within the water basin from where these originate.

In many countries the legislation already allows the use of dredged sediments as a resource and the dredging industry starts to make use of the huge potential of dredged material. Still, the known percentages of beneficially used dredged sediments are still low and therefore in principle large volumes of sediments are available to be beneficially used to reverse land subsidence, which should be included in the water basin management plans.

\subsection{Outlook of the thesis}

In general, most studies reporting the beneficial use of dredged sediments, either in engineering, products or environmental enhancement, lack a proper characterization of the sediments used. More particularly in the case of the beneficial use of dredged sediments on land, there are not many scientific publications of this practice

Land subsidence in drained lowlands and delta areas is mainly caused by shrinkage and organic matter oxidation. There are studies reporting that organic matter contributes more to subsidence than shrinkage while other studies report that shrinkage is the major contributor. When 
sediments are transferred from the waterways to upland conditions, there is a significant loss in volume. Both the particle size distribution and the organic matter content might have an important role on the behaviour of dredged sediments during dewatering and biochemical ripening. Therefore in Chapter 2 laboratory experiments were performed under well-defined conditions to determine:

What is the relative contribution of shrinkage and organic matter oxidation to the overall subsidence rate of sediments?

Since the sediments in the waterways in lowlands and Delta areas mainly originate from erosion within the water basin, no external material is imported and therefore the volume of sediments dredged might not be sufficient to reverse land subsidence. Since many of these areas are agricultural areas, it is expected that also green-wastes, such as compost and manure, are locally produced. Therefore in the laboratory experiments reported in Chapter 3 we answer the question:

Can compost and manure be added to dredged sediments to reverse land subsidence?

As the laboratory experiments impose strict boundary conditions, also mesoscale experiments, in $1 \mathrm{~m}^{3}$ containers, were performed to study physical/chemical and biological processes closer to application scale. In the mesoscale experiments, the water level in the containers could be regulated and therefore two scenarios were tested: upland deposit, and underwater deposit. The containers with the upland deposit scenario were allowed to dry with time, and the underwater deposits of the second scenario were kept with a layer of approximately $1 \mathrm{~cm}$ on top of sediments to prevent oxidation. These two scenarios would help answering the question (Chapter 4):

What is the influence of the water level on the oxidation of organic matter during ripening of dredged sediments? 
To complete the research, a real, field-scale upland deposit was monitored for 17 months with the objective of answering the question (Chapter 5):

How do the controlled laboratory results compare with the uncontrolled field results? 


\section{Chapter 2}

\section{Functional properties of soils formed from biochemical ripening of dredged sediments - subsidence mitigation in delta areas}

This Chapter has been published as:

Bruna R. F. Oliveira; Martijn P. J. Smit; Leon A. van Paassen; Tim Grotenhuis; Huub H. M. Rijnaarts (2016): Functional properties of soils formed from biochemical ripening of dredged sediments - subsidence mitigation in delta areas. Journal of Soils and Sediments, 17(1), 286-298, doi: 10.1007/s11368016-1570-7. 



\section{Abstract}

Purpose: In delta areas dense networks of canals have been developed through time and have to be periodically dredged. Lowering the groundwater level in delta areas deepens the aerobic zone, leading to the oxidation of organic matter and possibly to land subsidence. The use of the dredged sediments on land can be a solution to mitigate land subsidence in delta areas.

Materials and methods: Five types of dredged sediments with different organic matter content and particle size distribution were dewatered for 7 days and then submitted to biochemical ripening during 141 days on a laboratorial scale with constant temperature and relative humidity. The functional properties analysed were the type and content of organic matter, $\mathrm{pH}$, total $\mathrm{C}, \mathrm{N}, \mathrm{P}$ and $\mathrm{S}$, dry bulk density, water retention capacity, aggregate stability and load-bearing capacity.

Results and discussion: After biochemical ripening there was no significant loss in the mass of organic matter but there was an increase in the fraction of stable organic compounds, observed by an increase in oxygen-bearing compounds and decrease in hydrocarbons during biochemical ripening. The $\mathrm{pH}$ was not affected by biochemical ripening, and the total $\mathrm{C}, \mathrm{N}, \mathrm{P}$ and $\mathrm{S}$ concentrations are high and therefore the dredged sediments can improve the quality of the land. Most volume lost during dewatering and biochemical ripening can be attributed to the loss of water. The water retention capacity of the dredged sediments changed with biochemical ripening. The soils formed from biochemical ripening have very stable aggregates and its load-bearing capacity is enough to sustain cattle and tractors.

Conclusions: Most volume lost during dewatering and biochemical ripening can be attributed to the loss of water and not organic matter. Therefore, the studied dredged sediments have potential to mitigate land subsidence in delta areas when spread on land.

\section{Keywords}

Beneficial use; Biochemical ripening; Dredged sediments; Land subsidence 


\subsection{Introduction}

In many delta areas, dense networks of ditches and canals have been developed through time to regulate the water level, to avoid flooding, and to facilitate navigation, transport, agriculture and infra-structure construction. Lowering the groundwater level in these areas deepens the aerobic zone of the soil, leading (especially in peatlands) to the oxidation of organic matter and further land subsidence (Querner et al. 2012).

Some studies report that the high subsidence rates observed in the layer above the groundwater level in low moor peat soils is $15 \%$ ascribed to shrinkage and $85 \%$ to oxidation of organic matter (Schothorst 1977), whereas others relate land subsidence mainly with consolidation (Teatini et al. 2011). Other authors concluded that the contribution of oxidation of organic matter and compaction to land subsidence is variable in time (van Asselen et al 2011). Land subsidence as a result of water discharging is occurring in many low lying areas and delta areas worldwide (Kolker et al. 2011, Teatini et al. 2011, van Asselen 2011, Wöppelmann et al. 2013) and many attempts are made to attenuate or reverse this process (Querner et al. 2012).

Periodical dredging of ditches and canals is generally performed to maintain their nautical and hydrological functions and improve water quality. Spreading the dredged sediments on land might be a solution to reverse land subsidence by rising the land surface level (Bramley \& Rimmer 1988). The practice of spreading dredged sediments on land has been carried out for many years and all reported studies about this practice refer to the behavior of contaminants (Bedell et al. 2003, Ohimain et al. 2004, Perrodin et al. 2006, Vandecasteele et al. 2002), without detailed characterization of the properties and behavior of the sediments. 
Dredged sediments are frequently stored in upland deposits and when the clay content is higher than $8 \%$ and/or the organic matter content is higher than $3 \%$, sedimentation, consolidation and ripening occur (Pons \& Zonneveld 1965). Sedimentation refers to the settling and rearrangement of the smaller fractions of the particles into multi-particle conglomerates. Sedimentation is a relatively fast process that takes place within hours or days. Coarse or high-density particles have higher sedimentation rates than small or low-density particles. Sedimentation is followed by consolidation during which the weight of overlying sediment forces out the pore water. The volume occupied by the sediments will only be reduced if the water is able to drain. Therefore, the consolidation rate depends on the permeability of the sediments, the permeability of the boundaries of the deposit and on the height of the sediments layer (Terzaghi et al. 1996). The ripening process is a soil forming process that converts waterlogged sediments into soils. Ripening of dredged sediments can be subdivided into physical, chemical, and biological ripening, even though the three ripening processes proceed simultaneously and interact with each other (Vermeulen et al. 2003).

Previous studies have shown that multiple processes affect the ripening of dredged sediments and subsequent soil formation (Lafrenz et al. 2013, Sheehan et al. 2010a, Vermeulen 2007). Some of the functional properties that play an important role in the nature of ripening and affect the properties of the soil are the type of organic matter (Aich et al. 2013, Akker et al. 2008, Berglund \& Berglund 2011, Guenet et al. 2012, Schmidt et al. 2011, Urbanek et al. 2011), pH and nutrients content (Ayuke et al. 2011, Knicker 2011, Leue \& Lang 2012), water retention capacity (Berglund \& Berglund 2011, Bolte et al. 2011, Querner et al. 2012), dry bulk density (van Asselen 2011), aggregate stability (Amézketa 1999, Deviren Saygın et al. 2012, Elmholt et al. 2008, Munkholm 2011, Six et al. 2004) and load-bearing capacity (Gui 
et al. 2011). The objective of this study is to relate these functional properties of soils formed from different types of dredged sediments after dewatering and biochemical ripening at laboratory scale. In separate studies the behavior of sediments was characterized on mesoscale (Oliveira et al. submitted-a) and field scale (Oliveira et al. submitted-b).

Soil organic matter is associated with soil fertility for plant growth, soil and water quality, soil resistance to erosion and it stores at least three times more carbon than the atmosphere or in living plants (Aich et al. 2013, Kirkels et al. 2014, Schmidt et al. 2011). When dredged sediments are transferred to upland deposits, the oxidation of organic matter begins. Due to oxidation, the type of organic matter will change with time to form stable organic matter compounds. Determination of the type of soil organic matter before and after biochemical ripening will lead to quantification of the stable soil organic matter (Sanei et al. 2005). Furthermore, the total mass of organic matter before and after ripening will lead to insight in the role of organic matter oxidation in land subsidence (Schothorst 1977).

Soil pH is affected by the soil air, liquid and solid components. The solid components buffer soils to $\mathrm{pH}$ changes caused by natural and anthropic processes. Soil $\mathrm{pH}$ affects a wide range of soil biochemical properties, such as the surface charge of organic matter, clay, and mineral particles; the solubility, mobility, and toxicity of contaminants; the relative binding of positively charged ions to the cation exchange sites; calcium carbonate equivalents; ion mobility; precipitation and dissolution equilibria and kinetics; oxidation-reduction equilibria; and nutrients availability (Sumner 2000, Winfield \& Lee 1999). Soil pH also affects the decomposition of organic matter by determining the microbial activity and growth (Delaune et al. 1981, Madigan et al. 2010). 
Soil organic matter is a source of energy and nutrients for soil biota and plants. The more stable fraction of soil organic matter has a near constant carbon $(\mathrm{C})$, nitrogen $(\mathrm{N})$, phosphorus $(\mathrm{P})$, and sulphur $(\mathrm{S})$ ratio and has higher $\mathrm{N}, \mathrm{P}$, and $\mathrm{S}$ content per unit of $\mathrm{C}$ than less stable organic matter (Kirkby et al. 2013, Kramer et al. 2003). Some authors hypothesized that the availability of $\mathrm{N}, \mathrm{P}$ and $\mathrm{S}$ may limit the stabilization of organic matter (Kirkby et al. 2013, Knicker 2011, Lal 2008). In addition, changes in the structure of the organic matter significantly alter the soil texture and structure, and the nutrients dynamics leads to organic matter with varying $C: N: P: S$ ratios (Sumner 2000). Dredged sediments are a source of nutrients that can decrease the decomposition of organic matter and increase the fertility of the receiving soil (Fontaine et al. 2011, Leue \& Lang 2012). When sulphur compounds that were stable under anaerobic conditions are transferred to an aerobic layer, these can be oxidized and cause acidification which increases the vulnerability of soil to erosion (Bramley \& Rimmer 1988, Vermaat et al. 2012). Also, the sulphate released can cause soil organic matter degradation with the formation of $\mathrm{CO}_{2}$ (Tichý 1998).

The water content of dredged sediments decreases with time when these are transferred to upland deposits. The removal of water gradually allows oxygen to penetrate through the dredged sediments, changing the conditions from anaerobic to aerobic. The more water removed from the matrix, the more void spaces are available for oxygen penetration which increases organic matter oxidation. The water content affects the properties and behavior of soils, as the water causes soil particles to swell or shrink, to adhere to each other, and to form structural aggregates (Brady \& Weil 2008).

Dewatering begins when the dredged sediments are deposited on land or in ripening basins. Soil water potential can be divided in 3 components: matric or hydrostatic potential, depending if it refers to the 
saturated or unsaturated zone, osmotic potential and gravitational potential. All of these components act simultaneously and affect water behavior in soils (Brady \& Weil 2008). In this study, the gravitational potential and osmotic potential are considered constant. Only the matric potential is operational in unsaturated samples and results from adhesive forces and capillarity (Brady \& Weil 2008). A matric potential of $-100 \mathrm{hPa}$, or pF 2, corresponds to field capacity, i.e., the matric potential at which the plants are regarded to have their optimal water intake and a pF 4.2 corresponds to wilting point after which plants can no longer extract water from the soil and microbial activity is inhibited by $80 \%$ (Koorevaar et al. 1983, Vermeulen 2007 ).

In this study the term biochemical ripening refers to the combination of biological and chemical processes that take place after dewatering, when the amount of air-filled pores increases. The major biochemical ripening process is the aerobic mineralization of organic matter (Vermeulen et al. 2007).

Soil aggregate stability is an indicator of soil degradation which can be defined as the resistance of the soil against external mechanical and physicochemical destructive forces, including the effects of rainfall, runoff, tillage, heavy machinery, treading by animals, slaking, swelling and shrinkage (Amézketa 1999, Deviren Saygın et al. 2012, Kemper \& Rosenau 1986, Munkholm 2011). A soil aggregate is a naturally formed assemblage of mineral particles and organic matter that cohere to each other more strongly than to other surrounding particles, usually by natural forces and substances derived from root exudates and microbial activity. Furthermore, stable soil aggregates can protect occluded soil organic matter (SOM) against decomposition, leading to a possible longterm stabilization of soil carbon (Baldock \& Skjemstad 2000, Bossuyt et al. 2005, Chaplot \& Cooper 2015, Pulleman et al. 2005, van Lützow et al. 2006, Wei et al. 2014). 
The undrained shear strength is a mechanical characteristic that, given a certain texture, depends on changing parameters such as degree of humidity, density and the strength of the connection between mineral particles (Hamza \& Anderson 2005). Soil compaction increases soil load-bearing capacity and decreases soil physical fertility through decreasing storage and supply of water and nutrients (Hamza \& Anderson 2005). Soil compaction refers to the rearrangement of the soil particles, decreasing the void space and increasing the soil bulk density (European Soil Portal 2012). Soil compaction also alters the spatial arrangement, size and shape of the soil aggregates (Comoss et al. 2002). When sediments are dredged the water content is high and behave as a liquid since there is no structure. During ripening, the waterlogged sediments gradually develop a structure, increasing the permeability and shear strength (Bramley \& Rimmer 1988). The soil undrained shear strength can be used to calculate the soil load-bearing capacity, and therefore to determine which forces it can sustain without failure. Therefore, to define what use can be given to the newly formed soil, it is necessary to determine its load-bearing capacity.

Several studies regarding the use of dredged sediments characterized only part of the parameters described above, leading to a risk of nonoptimal performance of ripened sediments in its beneficial use (Dang et al. 2013, Giulio Bernstein et al. 2002, Malasavage et al. 2012, Perrodin et al. 2012, Torres et al. 2009, Zentar et al. 2009). The objective of this study is to characterize the functional properties of five types of dredged sediments before and after dewatering and biochemical ripening in order to assess their suitability to mitigate land subsidence in agriculturaldelta areas. In addition, the contribution of shrinkage and organic matter oxidation to the overall volume lost by the sediments when transferred from water to upland conditions is determined. 


\subsection{Material and methods}

\subsubsection{Collection of samples}

Sampling points S1 to S4 were selected within the Green Heart area, province Zuid-Holland, the Netherlands. According to the World Reference Base for soil resources classification, this area is very heterogeneous and mainly composed by fluvisols and histosols (WRB 2014); http://eusoils.jrc.ec.europa.eu/2. Using monitoring data from the water board Hoogheemraadschap van Schieland en de Krimpenerwaard (HHSK), the sampling points S1 to S4 were selected with the objective of having distinct particle size distribution and organic matter content, preferably extremes in clay and/or organic matter content. Approximately 60 liters of each sample were dredged from small ditches using a bucket.

Sample S5 was dredged in the Wormer- and Jisperveld nature area in the province Noord-Holland. According to the World Reference Base for soil resources classification, the area surrounding S5 is classified as histosols (WRB 2014); http://eusoils.jrc.ec.europa.eu/). Currently the area is a protect wetland and is mostly used for animal husbandry and various recreational activities (Natuurmonumenten 2015). Sample S5 was dredged by the water board Hoogheemraadschap Hollands Noorderkwartier (HHNK) from one of this small ditches using a crane, placed in an one cubic meter container and sent to the laboratory.

In the laboratory, all dredged sediment samples were manually wetsieved and the fraction smaller than $2 \mathrm{~mm}$ was stored in airtight containers under anaerobic conditions (under water) at $4^{\circ} \mathrm{C}$ until used in the experiments. The fractions larger than $2 \mathrm{~mm}$ were discarded since soil classification systems only consider fractions smaller than $2 \mathrm{~mm}$ to be soil (Sumner 2000). The fractions larger than $2 \mathrm{~mm}$ were estimated to be less than $15 \%$ of the total mass by observation. 


\subsubsection{Organic matter content, particle size distribution and fiber content of the dredged sediments}

The organic matter content (Table 2-1) was calculated following the loss on ignition ( $4 \mathrm{~h}$ at $550^{\circ} \mathrm{C}$ ) method (ISO/TS 17892-1:2014). To facilitate the interpretation of the results, the samples will be presented from S5 to $\mathrm{S} 1$ which is from higher to lower organic matter content.

The fibers content (Table 2-1) was determined following the standard test method for laboratory determination of the fibers content of peat samples by dry mass ASTM D1997-91 (2008).

For determination of the particle size distribution of the mineral fraction (Table 2-1), the samples were first air-dried and then the organic matter was removed with $\mathrm{H}_{2} \mathrm{O}_{2}$ and the $\mathrm{CaCO}_{3}$ with $\mathrm{HCl}$. The particle size distribution was determined following the ISO standard ISO/TS 178924:2014. Fractions $<2 \mu \mathrm{m}, 2-16 \mu \mathrm{m}$, and $16-50 \mu \mathrm{m}$ were determined by the pipet method and fraction 50-63 $\mu \mathrm{m}$ was determined by wet sieving at the Soil Chemical Biological Soil Laboratory (CBLB) of Wageningen UR. The fractions 63-150 $\mu \mathrm{m}, 150-420 \mu \mathrm{m}$, and 420-2000 $\mu \mathrm{m}$ were determined by dry sieving by the Soil Physics laboratory of Wageningen UR. 
Table 2-1: Organic matter content, Fibers content, and Particle size distribution, and classification according to the USDA classification system (USDA 1987) and according to the ISO/TS 17892-4:2014

\begin{tabular}{|c|c|c|c|c|c|c|}
\hline & S5 & s4 & S3 & $\mathbf{S 2}$ & S1 \\
\hline \multicolumn{2}{|c|}{$\begin{array}{l}\text { Organic matter } \\
\left(\%, g_{\text {ом }} \cdot \mathrm{g}^{-1} \text { dry matter }\right)\end{array}$} & 45.6 & 16.1 & 11.8 & 11.8 & 6.0 \\
\hline \multicolumn{2}{|c|}{$\begin{array}{l}\text { Fibers } \\
\left(\%, g_{\text {fibers }} \cdot g^{-1} \text { dry matter }\right)\end{array}$} & 25.9 & 19.6 & 56.5 & 4.1 & 8.2 \\
\hline \multirow{6}{*}{ 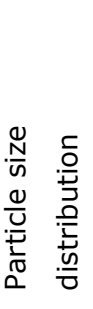 } & $<2 \mathrm{~mm}$ & 47.9 & 10.2 & 9.8 & 25.1 & 13.9 \\
\hline & $2-16 \mathrm{~mm}$ & 17.6 & 3.4 & 3.5 & 16.1 & 4.6 \\
\hline & $16-63 \mathrm{~mm}$ & 2.8 & 5.2 & 5.1 & 21.4 & 10.8 \\
\hline & $63-150 \mathrm{~mm}$ & 9.3 & 20.2 & 17.4 & 33.1 & 58.5 \\
\hline & $150-420 \mathrm{~mm}$ & 15.1 & 58.1 & 62.6 & 4.1 & 11.6 \\
\hline & $420-2000 \mathrm{~mm}$ & 7.2 & 3.0 & 1.7 & 0.2 & 0.6 \\
\hline \multicolumn{2}{|c|}{ USDA classification } & Clay & $\begin{array}{l}\text { Loamy } \\
\text { sand }\end{array}$ & $\begin{array}{l}\text { Loamy } \\
\text { sand }\end{array}$ & Loam & $\begin{array}{l}\text { Sandy } \\
\text { loam }\end{array}$ \\
\hline \multicolumn{2}{|c|}{ ISO/TS 17892-4:2014 } & $\begin{array}{c}\text { Fine } \\
\text { grained }\end{array}$ & $\begin{array}{l}\text { Mixed } \\
\text { grained }\end{array}$ & $\begin{array}{l}\text { Mixed } \\
\text { grained }\end{array}$ & $\begin{array}{c}\text { Fine } \\
\text { grained }\end{array}$ & $\begin{array}{l}\text { Mixed } \\
\text { grained }\end{array}$ \\
\hline
\end{tabular}

\subsubsection{Experimental procedure}

\subsubsection{Dewatering}

To dewater the dredged sediments samples, suction chambers were used where a suction pressure of $-100 \mathrm{hPa}$ was applied below the sample to achieve the matric potential corresponding to field capacity. To retain the fine particles in the suction chambers, a nylon filter with pore size of $0.45 \mu \mathrm{m}$ was used. It was assumed that equilibrium between the matric potential of the sample and the applied suction is reached when the water outflow from the sample ceases (Klute \& Dirksen 1986). This was generally observed within 7 days. This method was previously tested and reported by Vermeulen et al. (2005). 
Dewatering was done at $20 \pm 1{ }^{\circ} \mathrm{C}$ and the suction chambers were completely closed to the atmosphere, i.e., evaporation was avoided using a lid on the setup. The water removed from the sample was collected in a tube for quantification by weighing. Periodically a plug on top of the suction chamber was open to release the pressure due to the decrease of the volume by removed water from the sample.

The internal diameter of the suction chambers was $5 \mathrm{~cm}$ and the amount of sample poured in the suction chambers was calculated for each sample individually with the objective of achieving a final height of 1.5 $\mathrm{cm}$, i.e., after dewatering all samples had $1.5 \mathrm{~cm}$ in height and $5 \mathrm{~cm}$ in diameter. The volume of sample lost during dewatering was calculated from the initial and final mass of the sample, density of water and dry bulk density of the sample.

After dewatering, some samples were sacrificed in order to determine the water and organic matter content. This was done to determine the homogeneity in water content in samples of the same type of dredged sediments.

\subsubsection{Biochemical ripening}

After dewatering, nine samples of each type of dredged sediments were submitted to biochemical ripening in specifically designed batch bottles (BBs) (Figure 2-1). Each sample was placed in one of these BBs which allowed monitoring of individual variations. The BBs were closed to the atmosphere and the gas phase was periodically monitored to assure that there was biological activity and that there was no oxygen limitation, i.e., oxygen concentration in the headspace was always above $10 \%$ $(\mathrm{v} / \mathrm{v})$. To avoid condensation and keep the relative humidity constant in the BBs, a saturated solution of potassium nitrate $\left(\mathrm{KNO}_{3}\right)$ with a concentration of $360 \mathrm{g.l}^{-1}$ was kept inside the $\mathrm{BBs}$. The $\mathrm{KNO}_{3}$ has neutral $\mathrm{pH}$, absorbs about $0.03 \%$ water in $80 \%$ relative humidity over 50 days, 


\section{Chapter 2}

and in a closed environment at $20^{\circ} \mathrm{C}$ keeps the relative humidity constant at $94.5 \%$. The BBs were operated for 141 days at $20 \pm 1{ }^{\circ} \mathrm{C}$.

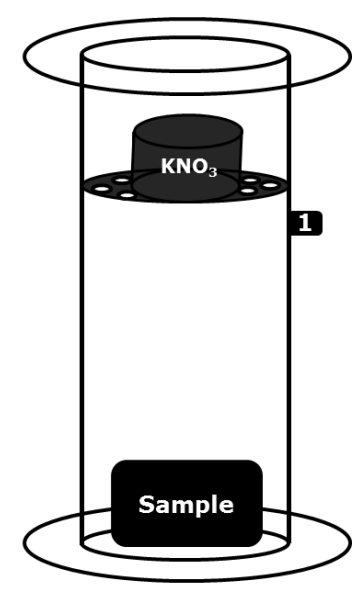

Figure 2-1: Schematic representation of the Batch Bottles (BBs)

To obtain a better insight on the aerobic degradation of organic matter and $\mathrm{O}_{2}$ transport through the samples during biochemical ripening, a PreSens imaging system was used as a non-invasive method (PreSens 2013). This system combines an imaging technology by a digital camera with fluorescent chemical optical sensor foils to visualize 2D distributions of $\mathrm{O}_{2}$ at a specific surface of heterogeneous samples. The sensor foils were calibrated in the BBs without sample and with and without the saturated salt solution of $\mathrm{KNO}_{3}$, following the multipoint calibration described in the manual (PreSens 2013). From the results of the calibration, the $\mathrm{O}_{2}$ sensor foils did not prove to be suitable for measurement of $\mathrm{O}_{2}$ diffusion rate through the samples under the described experimental conditions. More detailed information regarding the sensors can be found in Appendix 2 . 


\subsubsection{Analytical methods}

The geotechnical water content was calculated from the oven dry weight of the samples (ISO/TS 17892-1:2014). The samples were oven dried at $105^{\circ} \mathrm{C}$ for 24 hours since it is the most common practice in soil sciences (Soil and Plant Analysis Council Inc. 1999, Sumner 2000).

$\mathrm{O}_{2}$ and $\mathrm{CO}_{2}$ in the $\mathrm{BBs}$ headspace were measured with gas chromatography (Shimadzy GC-2010) with a thermal conductivity detector (TCD).

The $\mathrm{pH}$ of the dredged sediments was determined directly by immersing the electrode in the wet sediments since the water content was above $70 \%$ for all samples. The $\mathrm{pH}$ of the biochemically ripened sediments was determined on an a 1:1 soil-water suspension using a glass electrode (Soil and Plant Analysis Council Inc. 1999).

The total C, N, P, and S were determined at the Chemical Biological Soil Laboratory of Wageningen UR, The Netherlands. The dredged sediments samples were centrifuged to separate the solid fraction from the supernatant. The supernatant was then filtrated and the colloid fraction collected in the filter was added to the solid fraction. One sub-sample of the solid fraction was digested with the DigiPrep (aquaregia method, according to NEN-69610) and analysed with a Thermo (type iCAP) ICPAES. Another sub-sample of the solid fraction was used to analyse total organic $\mathrm{C}$ and total $\mathrm{N}$ with a Leco $\mathrm{C} / \mathrm{N}$ analyser. The total $\mathrm{P}$ and total $\mathrm{S}$ of the liquid fraction were analysed with a Varian ICP-AES and the total organic carbon and total nitrogen were analysed with a Skalar Segmented Flow Analyser (SFA).

The type of organic matter was characterized with the Rock-Eval $6^{\circledR}$ method. The samples of $20 \mathrm{mg}$ of sediments are heated in pyrolysis and oxidation ovens at a heating rate of $25^{\circ} \mathrm{C} / \mathrm{min}$ of the Rock Eval $6^{\circledR}$ apparatus. The pyrolysis occurs between 100 and $650^{\circ} \mathrm{C}$ under an inert 
atmosphere of $\mathrm{N}_{2}$. During the pyrolysis, the free hydrocarbons present in the sample and the hydrocarbons released by the thermal cracking of organic matter are detected by the Flame Ionization Detector. Simultaneously, the $\mathrm{CO}$ and $\mathrm{CO}_{2}$ released during thermal cracking of oxygen-bearing organic compounds are measured by Infrared detectors. The measurement of $\mathrm{CO}$ is conducted up to $570{ }^{\circ} \mathrm{C}$ to avoid interference from the release of inorganic $\mathrm{CO}$ at higher temperatures. The measurement of $\mathrm{CO}_{2}$ is conducted up to $400{ }^{\circ} \mathrm{C}$ to avoid interference from the release of inorganic $\mathrm{CO}_{2}$ at higher temperatures. Following the pyrolysis stage, the sample is transferred to the oxidation oven and heated from 400 to $850^{\circ} \mathrm{C}$ in air, incinerating all the residual organic carbon. The $\mathrm{CO}$ and $\mathrm{CO}_{2}$ released during combustion of residual organic carbon are measured by online Infrared detectors. The HI (Hydrogen Index) is an indicative value for the amount of hydrocarbons released by thermal cracking of organic matter per gram of TOC (Total Organic Carbon), and the $\mathrm{OI}_{\mathrm{RE} 6}$ (Oxygen Index) is an indicative value for the amount of $\mathrm{CO}_{2}$ and $\mathrm{CO}$ by thermal cracking of oxygen-bearing organic compounds per gram of TOC (Supplementary material Table 2). Changes in the $\mathrm{HI}$ and $\mathrm{OI}_{\mathrm{RE} 6}$ are analyzed to evaluate a transition in the type of organic matter. Rock-Eval $6^{\circledR}$ analyses were performed at Deltares, the Netherlands.

The water retention curve determination was performed by the Soil Physics Laboratory of Wageningen UR, the Netherlands. The water retention curve determination was performed in a climatized room, at 16 $\pm 1{ }^{\circ} \mathrm{C}$ and a relative humidity of $60 \pm 5 \%$, using pressure plates, according to the ISO $11274: 1998$. The non-treated samples were filtered and further dried in a $100 \mathrm{~cm}^{3}$ sample ring at height of $2.5 \mathrm{~cm}$ of suction. 
The water retention curve is presented in terms of water potential ( $\mathrm{pF}$ ) vs volumetric moisture ratio $(\mathrm{cm} 3 . \mathrm{cm}-3)$. The volumetric moisture ratio, $\theta$, is:

$\theta=\frac{\mathrm{v}_{1}}{\mathrm{v}_{\mathrm{t}}}$ Equation 2-1

in which $V_{1}$ the volume of liquid; $V_{t}$ the volume of saturated sample.

Since the starting $\mathrm{pF}$ for the biochemically ripened samples was pF 2 (previously dewatered to this $\mathrm{pF}$ ), the volumetric moisture ratio was normalized to the volume of the sample at $\mathrm{pF} 2, \theta_{\mathrm{pF} 2 \text { normalized: }}$ :

$\theta_{p F 2 \text { normalised }}=\frac{V_{l}}{V_{t, p F 2}}$

Equation 2-2

This normalization was chosen because ripening is an irreversible process (Vermeulen et al 2003) and re-wetting the samples would lead to unrealistic results. Hence, to compare the water retention curve of the dredged sediments samples (a) with the biochemically ripened samples (c) also the water retention curve of the dredged sediments samples was referenced to the volume of the sample at $\mathrm{pF} 2$.

The volume of the biochemically ripened samples was calculated from the measured dimensions using a marking gauge. The water retention was determined until pF 4.2 since this corresponds to the conditions when plants can no longer extract water from the soil (Vermeulen 2007).

The dry bulk density was determined after air drying a sample and following the linear measurement method described in the standard ISO 17892-2:2014

The aggregate stability was determined according to the method described by Kemper and Rosenau for wet aggregates stability determination. The calculated aggregate stability varies from 0 - 


\section{Chapter 2}

unstable - to 1 - very stable (Kemper \& Rosenau 1986). This method measures the breakdown of aggregates upon rapid wetting (slaking) and the subsequent breakdown of aggregates due to the mechanical sieving action. The wet sieving apparatus from Eijkelkamp was used for the mechanical sieving.

The undrained shear strength was determined with the fall cone method of the biochemically ripened samples, following the procedure described in the ISO/TS 17892-6:2004. The measured undrained shear strengths were used to calculate the bearing capacity in order to evaluate whether the soil is accessible for cattle and tractors. The bearing capacity of the soil is calculated according to the method described e.g. in Terzaghi et al (1996).

$q=s_{c} d_{c} c_{u} N_{c}+s_{q} d_{q} \gamma D N_{q}+s_{\gamma} 0.5 \gamma B N_{\gamma}$ Equation 2-3

in which $\mathrm{q}$ is the bearing capacity in $[\mathrm{kPa}], \mathrm{c}_{\mathrm{u}}$ is the undrained shear strength in $[\mathrm{kPa}], \mathrm{Y}$ is the bulk unit weight of the soil in $\left[\mathrm{kN} \cdot \mathrm{m}^{-3}\right], D$ is the depth at which the load is applied below surface level in $[m], B$, is the width of the load surface in [m] assuming an infinitely long strip footing, $\mathrm{N}_{\mathrm{c}}, \mathrm{N}_{\mathrm{q}}$ and $\mathrm{N}_{\mathrm{Y}}$ are so-called bearing capacity factors, which are related the friction angle of the soil, $\mathrm{s}_{\mathrm{c}}, \mathrm{s}_{\mathrm{q}}$ and $\mathrm{s}_{\mathrm{Y}}$ are shape factors which are used to correct for the shape of the surface on which the load is applied, $d_{c}$ and $d_{q}$ are depth factors which need to be taken into account when the load is applied below surface level. Considering that the load of cattle or tractors is applied at surface level and only for a short period of time at the same location, $\mathrm{D}=0 \mathrm{~m}, \mathrm{~N}_{\mathrm{Y}}=0, \mathrm{~N}_{\mathrm{q}}=1$ and $\mathrm{N}_{\mathrm{c}}=5.14$ (Barnes 2000), the equation above can be simplified to:

$\mathrm{q}=\left(1+\frac{\mathrm{N}_{\mathrm{q}}}{\mathrm{N}_{\mathrm{c}}}\right) \mathrm{c}_{\mathrm{u}} \mathrm{N}_{\mathrm{c}}=6.14 \mathrm{c}_{\mathrm{u}}$

Equation 2-4

In this empirical approach the soil is presumed to be infinitely stiff and homogeneous in both horizontal and vertical directions, which are 
considered to be valid presumptions when the load is applied in the open field. In case a tractor or cow is standing close to a ditch the bearing capacity may be significantly lower and that scenario was not considered in this study.

The load applied by cattle on the soil was calculated considering an average weight of $600 \mathrm{~kg}$, and considering that the weight is evenly distributed by the 4 paws with a surface area of $0.01 \mathrm{~m}^{2}$ each. For tractors, it was considered an average weight of $2900 \mathrm{~kg}$ per front wheel and an average weight of $6000 \mathrm{~kg}$ per rear wheel. The values on Table 2-2 correspond to cattle and tractors operating at the Wormer- and Jisperveld nature area and may vary from place to place.

Table 2-2: Estimation of load applied on the soil by cattle and tractors

\begin{tabular}{lcccc} 
& $\begin{array}{c}\text { Mass } \\
(\mathrm{kg})\end{array}$ & $\begin{array}{c}\text { Surface area } \\
\left(\mathrm{m}^{2}\right)\end{array}$ & $\begin{array}{c}\text { Number paws } \\
\text { or wheels }\end{array}$ & $\begin{array}{c}\text { Load } \\
{[\mathrm{kPa} /(\text { paw or wheel })]}\end{array}$ \\
\hline Cattle & 600 & 0.01 & 4 & 147 \\
Tractor front & 2900 & 0.12 & 2 & 118 \\
Tractor rear & 6000 & 0.24 & 2 & 123 \\
\hline
\end{tabular}

12 replicates of each sample were dewatered. Of these 12, 3 were used to confirm heterogeneity through water and organic matter content analysis, and 9 were submitted to biochemical ripening. The biochemically ripened samples (c) had to be divided for the different analyses. The verification of the water and organic matter content allowed to conclude that the samples were relatively homogenous for this type of biological samples. Based on that, it was decided to use mixtures of three samples to do the analysis. The accuracy of the analytical methods is guaranteed by the certified laboratories where the analyzes were performed.

The total mass of dredged sediments and organic matter content before dewatering, after dewatering and after biochemical ripening are summarized on Supplementary material Figures 2-1 and 2-3. 


\subsection{Results}

The mass of organic matter content determined following the loss on ignition method did not change significantly for any of the five samples during the 7 days of dewatering and during the 141 days of biochemical ripening (Figure 2-2). Even though, there was oxygen $\left(\mathrm{O}_{2}\right)$ consumption and carbon dioxide $\left(\mathrm{CO}_{2}\right)$ production (Figure 2-3) evidencing that there was microbial activity in the BBs.

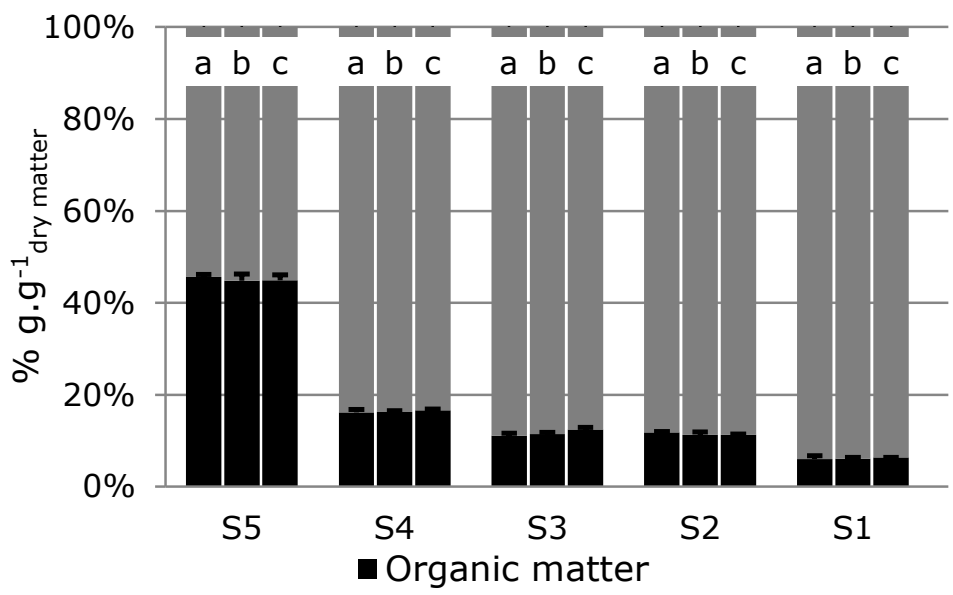

Figure 2-2: Dry matter distribution a) before dewatering; b) after dewatering; c) after biochemical ripening

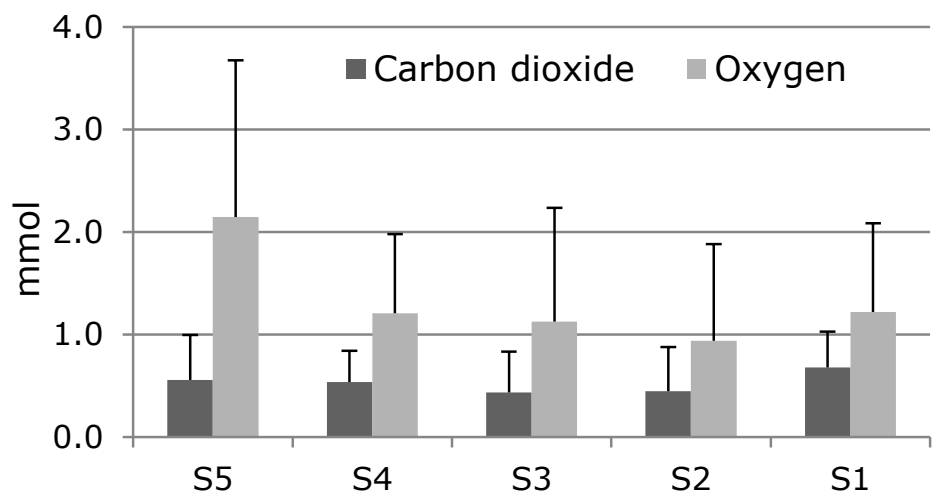

Figure 2-3: Average total $\mathrm{CO}_{2}$ produced and $\mathrm{O}_{2}$ consumed (mmol) during the 141 of biochemical ripening. Error bars represent standard deviation of 9 replicates 
The results of $\mathrm{O}_{2}$ consumption and $\mathrm{CO}_{2}$ production have significant error bars which might be justified not only by the natural heterogeneity between biological systems but also by the possible leakage of some of the BBs, since no differences were observed in the organic matter content between replicates. The results in Figure 2-3 reflect the total cumulative $\mathrm{CO}_{2}$ production and $\mathrm{O}_{2}$ consumption during 141 days of biochemical ripening. Considering that the samples had $5 \mathrm{~cm}$ in diameter, that biochemical ripening took 141 days, and that the rate of $\mathrm{CO}_{2}$ production was constant during biochemical ripening, the average $\mathrm{CO}_{2}$ released from the samples ranged from $6.8 \mathrm{gc} \cdot \mathrm{m}^{-2} \cdot \mathrm{yr}^{-1}$ for $\mathrm{s} 3$ (lowest) to $10.8 \mathrm{gc} \cdot \mathrm{m}^{-2} \cdot \mathrm{yr}^{-1}$ for $\mathrm{S} 1$ (highest). Assuming that the samples are not oxygen limited, these rates can be corrected for the $1.5 \mathrm{~cm}$ height of the samples, and therefore the average $\mathrm{CO}_{2}$ released ranged from $456.9 \mathrm{gc} \cdot \mathrm{m}^{-3} \cdot \mathrm{yr}^{-1}$ for $\mathrm{S} 3$ to $716.6 \mathrm{gc} \cdot \mathrm{m}^{-3} \cdot \mathrm{yr}^{-1}$ for $\mathrm{S} 1$.

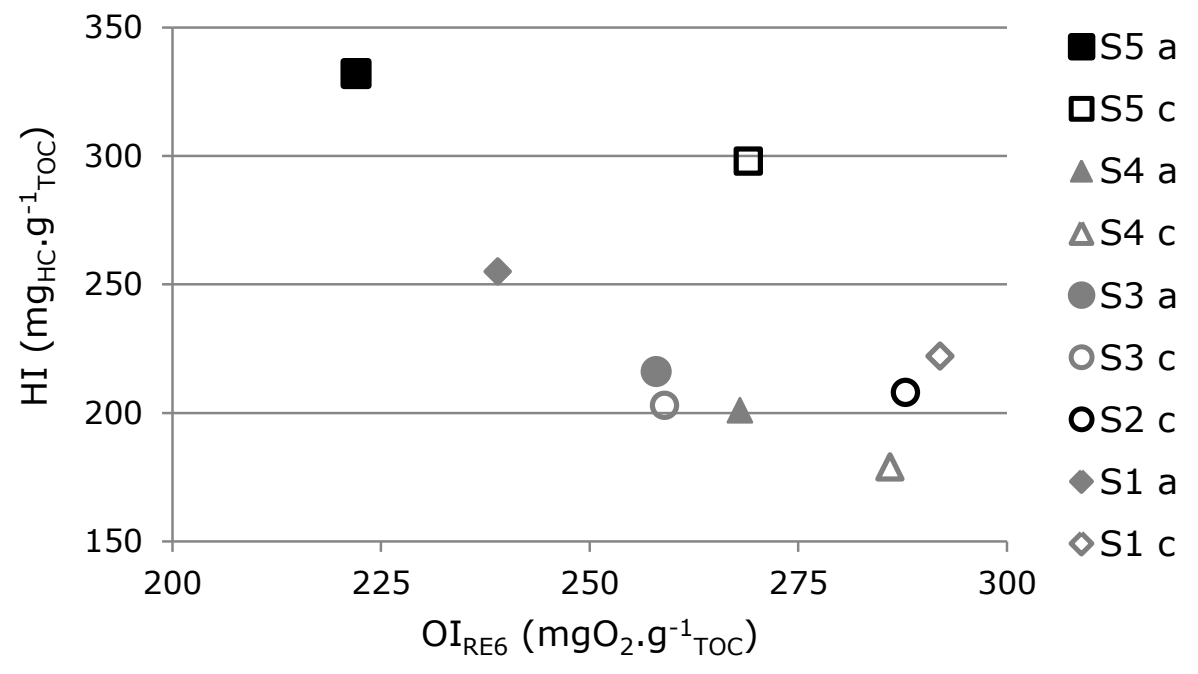

Figure 2-4: Hydrogen index ( $\left.\mathrm{mg} \mathrm{Hс}_{\mathrm{HC}} \mathrm{g}^{-1} \mathrm{Tоc}\right)$ and oxygen index $\left(\mathrm{mg}_{\mathrm{Oz}} \cdot \mathrm{g}^{-1} \mathrm{Toc}\right)$ of the dredged sediments a) before dewatering and $c$ ) after biochemical ripening. Hydrogen and oxygen indexes of S2. S2 a) gave a faulty measurement 
Regarding the type of organic matter, biochemical ripening resulted in a decrease in the HI and an increase in OIRE6 for all the samples, i.e., a decrease in hydrocarbons and an increase in oxygen-bearing compounds (Figure 2-4). The percentage of decrease in $\mathrm{HI}$ and percentage of increase in $\mathrm{OI}_{\mathrm{RE} 6}$ seem to be dependent of the composition of each sample and are not proportional. Sample S5 had 27\% increase (highest) in the $\mathrm{OI}_{\text {REG }}$ while sample $\mathrm{S} 3$ had $3 \%$ increase (lowest) in the $\mathrm{OI}_{\mathrm{RE} 6}$. The decrease in $\mathrm{HI}$ was highest for S4 with $13 \%$ and lowest for S3 with $6 \%$. The smallest increase in OIRE6 and smallest decrease in $\mathrm{HI}$ was observed for sample S3 which has the highest fiber content (Table 2-1).

The $\mathrm{pH}$ (Table 2-3) of the samples was stable during biochemical ripening. The $\mathrm{pH}$ of sample S5, from North-Holland, was lower than the samples from South-Holland.

The dry bulk density increases with decreasing organic matter content (Table 2-3), except for $\mathrm{S} 2$ which might be caused by the high clay (Table 2-1).

Table 2-3: $\mathrm{pH}$; dry bulk density; aggregate stability index; undrained shear strength and calculated bearing capacity, a) before dewatering and c) after biochemical ripening

\begin{tabular}{|c|c|c|c|c|c|}
\hline Sample & S5 & 54 & S3 & S2 & S1 \\
\hline $\begin{array}{l}\mathrm{pH} \\
\text { a) and c) }\end{array}$ & 4.28 & 7.40 & 7.42 & 7.22 & 7.37 \\
\hline $\begin{array}{l}\text { Dry bulk density } \\
\left.\left(\mathrm{g} \cdot \mathrm{cm}^{-3}\right) \mathbf{a}\right)\end{array}$ & 0.21 & 0.55 & 0.61 & 0.55 & 0.70 \\
\hline $\begin{array}{l}\text { Dry bulk density } \\
\left.\left(\mathrm{g} \cdot \mathrm{cm}^{-3}\right) \mathbf{c}\right)\end{array}$ & 0.32 & 0.81 & 0.88 & 0.69 & 1.07 \\
\hline $\begin{array}{l}\text { Aggregate stability index } \\
\left.\left(\mathrm{g}_{\text {stable aggregates }} \cdot \mathrm{g}^{-1} \text { sample }\right) \mathrm{C}\right)\end{array}$ & 0.94 & 0.94 & 0.90 & 0.97 & 0.95 \\
\hline $\begin{array}{l}\text { Undrained shear strength } \\
(\mathrm{kPa}) \mathrm{c})\end{array}$ & 125 & 183 & 226 & 481 & 370 \\
\hline $\begin{array}{l}\text { Bearing capacity } \\
(\mathrm{KPa}) \mathrm{c})\end{array}$ & 770 & 1125 & 1388 & 2954 & 2273 \\
\hline
\end{tabular}


Table 2-4: Total Carbon (TC), Total Nitrogen (TN), Total Phosphorus (TP), and Total Sulphur (TS) content a) before dewatering; and c) after biochemical ripening

\begin{tabular}{lccccc} 
& TC & TN & TP & TS & $\begin{array}{c}\text { C:N:P:S } \\
\text { (molar ratio) }\end{array}$ \\
\cline { 2 - 4 } S5 a) & 238.60 & 14.66 & 1.21 & 23.48 & $511: 27: 1: 19$ \\
S5 c) & 232.00 & 17.70 & 1.21 & 20.13 & $497: 33: 1: 16$ \\
& & & & & \\
S4 a) & 88.82 & 6.44 & 1.05 & 10.56 & $218: 14: 1: 10$ \\
S4 c) & 89.10 & 7.20 & 1.25 & 10.93 & $184: 12: 1: 8$ \\
& & & & & \\
S3 c) & 75.60 & 6.04 & 0.65 & 9.48 & $300: 21: 1: 14$ \\
& & & & & \\
S2 a) & 67.34 & 4.92 & 1.50 & 6.58 & $116: 7: 1: 4$ \\
S2 c) & 67.80 & 5.60 & 1.63 & 5.51 & $108: 8: 1: 3$ \\
& & & & & \\
S1 a) & 44.49 & 2.30 & 0.46 & 7.57 & $248: 11: 1: 16$ \\
S1 c) & 48.40 & 2.76 & 0.55 & 7.86 & $229: 11: 1: 14$
\end{tabular}

Regarding the total C, N, P, and S (Table 2-4), the observed variations might not be significant due to the heterogeneity of the samples.

The water balance for the dewatering process (Table 2-5) is closed for 93 to $98 \%$ and therefore losses of water are not significant. Dewatering resulted in the removal of 72 to $52 \%$ of the total water content of the dredged sediments. The sample with highest water dewatered was S1 which is the sample with lowest organic matter content. 


\section{Chapter 2}

Table 2-5: Water collected in the tubes during dewatering and water remaining in the sample after dewatering ( $\%$ of total mass of water present before dewatering)

\begin{tabular}{lcc} 
& $\begin{array}{c}\text { Water drained } \\
\text { (\% total weight of water) }\end{array}$ & $\begin{array}{c}\text { Water remaining in the sample } \\
\text { (\% of total weight of water) }\end{array}$ \\
\hline S5 & $54 \pm 6$ & $44 \pm 6$ \\
S4 & $52 \pm 3$ & $43 \pm 2$ \\
S3 & $58 \pm 4$ & $35 \pm 1$ \\
S2 & $59 \pm 3$ & $37 \pm 2$ \\
S1 & $72 \pm 5$ & $26 \pm 1$ \\
\hline
\end{tabular}

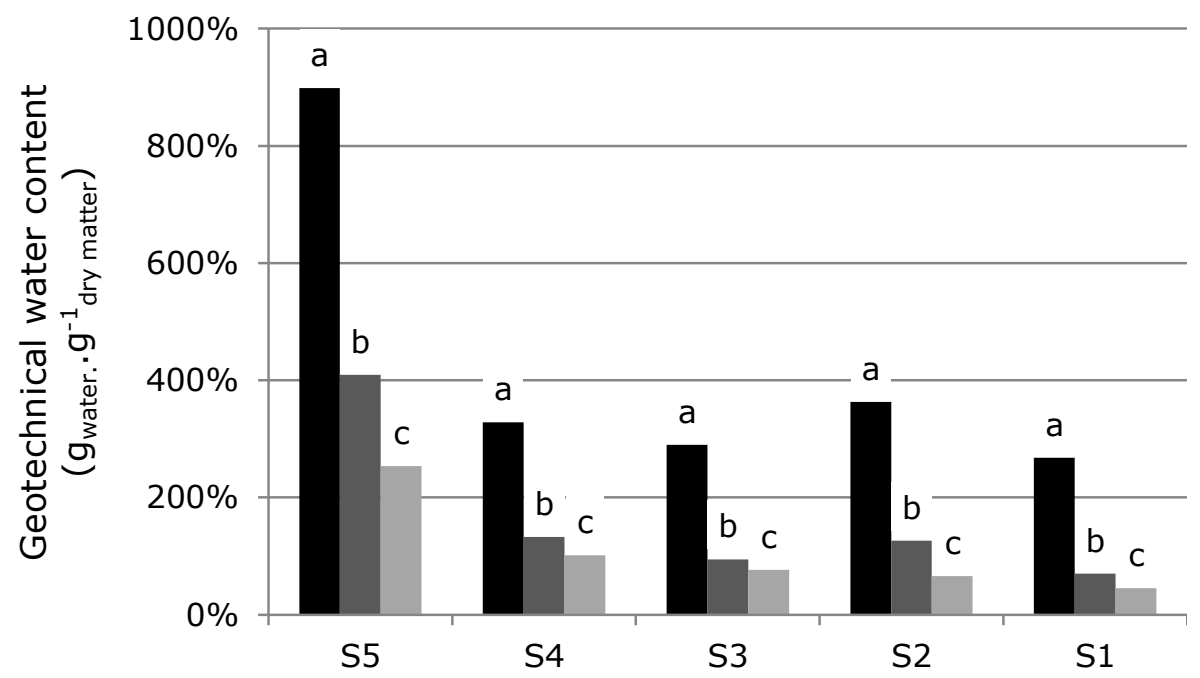

Figure 2-5: Geotechnical water content a) before dewatering; b) after dewatering; and c) after biochemical ripening

From Figure 2-5, most water was lost during the dewatering step, but during biochemical ripening also a significant amount of water was lost. Part of the water during biochemical ripening might be incorporated in the organic compounds or transferred to the $\mathrm{KNO}_{3}$ salt solution. The water content in $\mathrm{g}_{\text {water }} \cdot \mathrm{g}^{-1}$ sample is in Supplementary Material Figure 2-2. 


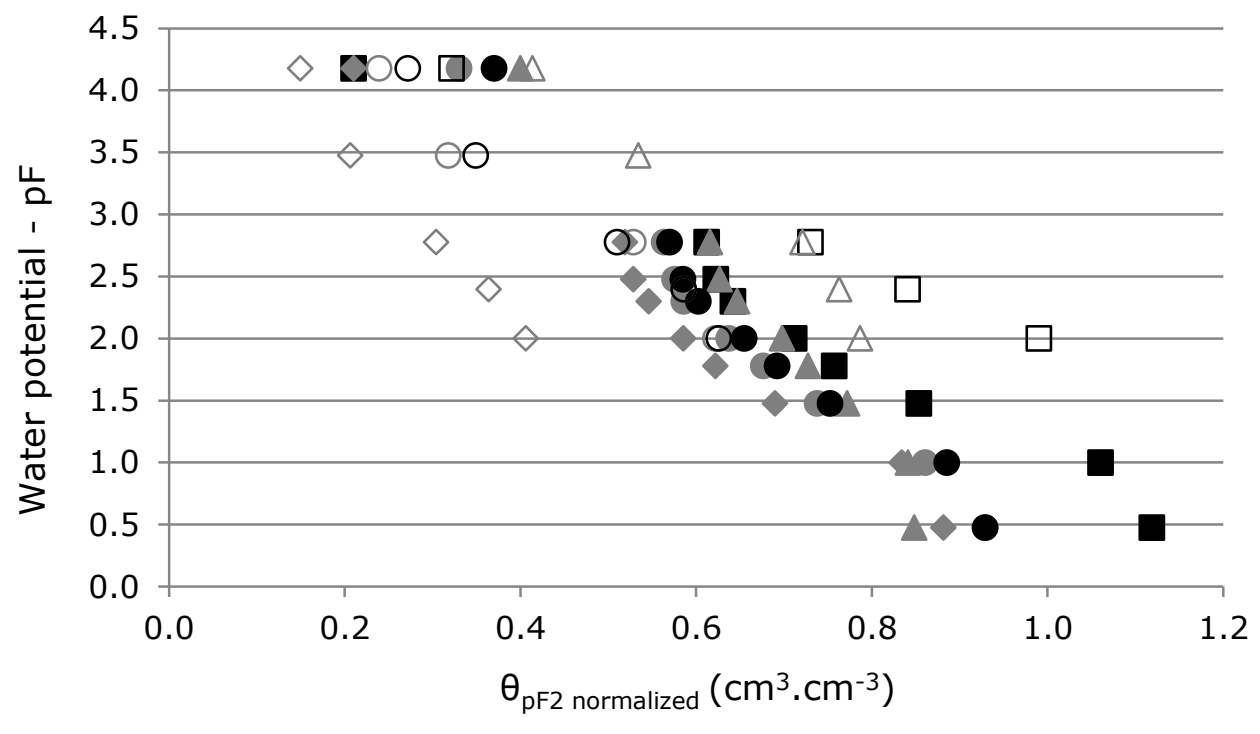

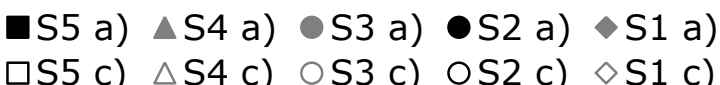

Figure 2-6: Water retention curve of the dredged sediments a) before dewatering; and c) after biochemical ripening.

The water retention curves of the dredged sediments are very similar (Figure 2-6). Sample S5 has the strongest water retention capacity while S1 has the weakest water retention capacity. The results suggest that the higher the organic matter content, the strongest the water retention capacity. S5 has a strong shrinkage behaviour, resulting in a normalized (Equation 2-2) volumetric moisture ratio higher than 1, due to the very high organic matter and clay content. Samples S2 and S3 have similar organic matter content and the difference in behaviour might be caused by highest clay content of S2 in relation to S3.

Dewatering and biochemical ripening resulted in an increase of the water retention capacity for samples S5 and S4 and in a decrease for samples S2, S1 and S3 (Figure 2-6). At pF 2, biochemical ripening resulted in $43 \%$ increase in the water retention capacity for S5 and $31 \%$ decrease for $\mathrm{S} 1$. At pF 4.2 , biochemical ripening resulted in $53 \%$ 
decrease in the water retention capacity for S5 and $29 \%$ increase for $\mathrm{S} 1$. The change in the composition of the organic matter might explain the variations in the water retention capacity of the soil samples in relation to the dredged sediments (Figure 2-6). The higher the water retention capacity, the less air-filling pores which results in less oxygen diffusion and consequently less organic matter oxidation.

Regarding the type of organic matter, biochemical ripening resulted in a decrease in the $\mathrm{HI}$ and an increase in $\mathrm{OI}_{\mathrm{RE} 6}$ for all the samples, i.e., a decrease in hydrocarbons and an increase in oxygen-bearing compounds (Figure 2-4). The percentage of decrease in $\mathrm{HI}$ and percentage of increase in $\mathrm{OI}_{\mathrm{RE} 6}$ seem to be dependent of the composition of each sample and are not proportional. Sample S5 had 27\% increase (highest) in the $\mathrm{OI}_{\text {RE6 }}$ while sample $\mathrm{S} 3$ had $3 \%$ increase (lowest) in the $\mathrm{OI}_{\text {RE6 }}$. The decrease in $\mathrm{HI}$ was highest for S4 with $13 \%$ and lowest for S3 with $6 \%$. The smallest increase in $\mathrm{OI}_{\mathrm{RE} 6}$ and smallest decrease in $\mathrm{HI}$ was observed for sample S3 which has the highest fiber content (Table 2-1).

The $\mathrm{pH}$ (Table 2-3) of the samples was stable during biochemical ripening. The $\mathrm{pH}$ of sample S5, from North-Holland, was lower than the samples from South-Holland.

The dry bulk density increases with decreasing organic matter content (Table 2-3), except for $\mathrm{S} 2$ which might be caused by the high clay (Table 2-1).

The lowest undrained shear strength was observed for sample S5 which has the highest organic matter content whiles the highest undrained shear strength was observed for sample S2 which has the lowest fiber content (Table 2-1). The calculated bearing capacity of the samples indicates that the studied dredged sediments can sustain tractors and cattle (according to the calculation in Table 2-2). 


\subsection{Discussion}

The organic matter content of the samples did not vary significantly after 141 days of biochemical ripening. This result is opposite to earlier findings in which land subsidence of low moor peats in the Netherlands was monitored for 6 years in terms of surface elevation, bulk density, moisture and organic matter content, and was $85 \%$ attributed to organic matter degradation and $15 \%$ to shrinkage (Schothorst 1977).

The $\mathrm{CO}_{2}$ released from the samples during biochemical ripening, corrected to the $1.5 \mathrm{~cm}$ height of the samples, was $456.9 \mathrm{gc} \cdot \mathrm{m}^{-3} \cdot \mathrm{yr}^{-1}$ for S3 and $716.6 \mathrm{gc} \cdot \mathrm{m}^{-3} \cdot \mathrm{yr}^{-1}$ for $\mathrm{S} 1$. Therefore, the results suggest that the samples studied, without the presence of vegetation, are a source of $\mathrm{CO}_{2}$ to the atmosphere.

Field studies performed in the Netherlands, with an average annual precipitation of $800 \mathrm{~mm}$ and an average annual temperature of $9.8^{\circ} \mathrm{C}$, in which the gas fluxes from histosols to the atmosphere were monitored using eddy covariance systems and closed flux chambers, report varying fluxes:

- $330 \mathrm{gc} \cdot \mathrm{m}^{-2} \cdot \mathrm{yr}^{-1}$ from an abandoned agricultural field converted into a wetland nature reserve (Hendriks et al. 2007a);

- $130 \mathrm{gc} \cdot \mathrm{m}^{-2} \cdot \mathrm{yr}^{-1}$ from a peat pasture used for intensive dairy farming (Langeveld et al. 1997);

- $220 \mathrm{gc} \cdot \mathrm{m}^{-2} \cdot \mathrm{yr}^{-1}$ from grasslands (Jacobs et al. 2007);

- $113.18 \mathrm{gc} \cdot \mathrm{m}^{-2} \cdot \mathrm{yr}^{-1}$ from an intensively managed grassland (Schrier-Uijl et al. 2014);

- -409.09 gc. $\mathrm{m}^{-2} \cdot \mathrm{yr}^{-1}$ (minus signal means uptake) from a rewetted former agricultural peatland (Schrier-Uijl et al. 2014). 
In general organic soils are often sources of $\mathrm{CO}_{2}$ (Hendriks et al. 2007a, Jacobs et al. 2007, Langeveld et al. 1997, Schrier-Uijl et al. 2014) while mineral soils are often a sink of $\mathrm{CO}_{2}$ (Gilmanov et al. 2007, Jacobs et al. 2007). Since the groundwater level in the field varies significantly throughout the year and that the field cover also affects significant the gas and liquid fluxes, it is not easy to compare the results of our experiments with previously reported results since the samples used had a constant height of $1.5 \mathrm{~cm}$ and no vegetation was present. However, it seems that the potential of $\mathrm{CO}_{2}$ release from the studied samples is low compared with field studies.

The Rock-Eval $6{ }^{\circledR}$ method allows to follow the evolution of the humification process in sediments and soils with time. Our results confirm that there was a change in the type of organic matter since all the treated samples (soil) have lower $\mathrm{HI}$ and higher $\mathrm{OI}_{\mathrm{RE} 6}$ than the correspondent dredged sediments. This means that the treatment resulted in a decrease in free hydrocarbons and an increase in oxygenbearing organic compounds for all the samples, i.e., the treatment resulted in more stable organic matter. The formation of recalcitrant SOM compounds increases the stability of the organic matter (Six et al. 2002). The decrease in $\mathrm{HI}$ and increase in $\mathrm{OI}_{\mathrm{RE} 6}$ indicate an increase in the humification of the organic matter (Disnar et al. 2003, Lafargue et al. 1998).

More consumption of $\mathrm{O}_{2}$ than production of $\mathrm{CO}_{2}$ indicates the incorporation of oxygen in the organic matter, i.e., the increase in oxygen rich compounds. For instance, sample S5 has the highest $\left[\mathrm{CO}_{2}\right]:\left[\mathrm{O}_{2}\right]$ ratio and also the highest increase in oxygen rich compounds. The activity of communities of microorganisms are also influenced by the pH (Berg \& Laskowski 2005, Rousk et al. 2010, van Roon 2012), and, since S5 is acidic while the other samples are close to 
neutral, the active microorganisms can differ which also explains the difference in $\left[\mathrm{CO}_{2}\right]:\left[\mathrm{O}_{2}\right]$ ratios.

Considering the $\mathrm{CO}_{2}$ production, the $\mathrm{O}_{2}$ consumption and the Rock-Eval $6^{\circledR}$ results, it can be concluded that the loss on ignition method might not the best method to detect changes in organic matter under such experimental conditions.

The decrease in water content during biochemical ripening together with the insignificant loss in organic matter content during biochemical ripening, indicates that in 141 days of biochemical ripening most shrinkage was caused by water loss. Sample S1 had the highest loss in total weight during dewatering and biochemical ripening, due to water removal, and is the sample with the highest increase in dry bulk density. Sample S5 had the lowest loss in total weight during dewatering and biochemical ripening and was the sample with lowest increase in dry bulk density. Therefore, the higher the water removal, the higher the compaction of the sample which was also observed by (Teatini et al. 2011).

The water retention capacity of any material is related with the porosity and the nature of the bonding between water and soil. Fine grained soils need higher water potentials to release water than coarse grained materials. At any given water potential, organic soils usually retain more water than fine grained soils (Sumner 2000). Our results show that sample S1, with $6 \%$ (dry weight) organic matter and $14 \%$ (of the mineral fraction) clay content, is the sample that retains less water. Sample S5 has $46 \%$ (dry weight) organic matter and $48 \%$ (of the mineral fraction) clay content and is the sample that retains more water until pF 2.75. For higher water potentials, sample S4, with $16 \%$ organic matter and $10 \%$ clay content is the sample that retains more water. This might be due to the strong shrinkage behavior observed for sample S5 (laboratory observation). In general, the results confirm that the 
higher organic matter content results in more water retention capacity. Furthermore, the clay can also chemically protect organic matter from decomposition since the clay particles are active soil components in the production of organo-mineral complexes and the microorganisms are less efficient in decomposing the organic matter protected in these complexes (Krull et al. 2003, van Lützow et al. 2006, Wei et al. 2014). From the particle size distribution and the average total $\mathrm{CO}_{2}$ released and $\mathrm{O}_{2}$ consumed, there is no direct relation between the clay content of the samples and the organic matter decomposition.

The $\mathrm{pH}$ was not affected by dewatering and biochemical ripening.

The organic matter decomposition depends also on the availability of nitrogen, phosphorus, and sulphur. There is evidence for a constant stoichiometric ratio of $\mathrm{C}: \mathrm{N}: \mathrm{P}: \mathrm{S}$ for the stable portion of the soil organic material across a wide range of global soils. Such a ratio should provide a reliable basis with which to determine the fraction of stable organic matter in soils (Kirkby et al. 2011). In addition, sediments in ditches and canals can accumulate nutrients leached from the adjacent agricultural sites and therefore the agriculture land can benefit from the recycling of these nutrients. Sample S5, S4, S3 and S1 are very rich in carbon and can therefore be representative carbon sinks if the decomposition of organic matter is minimized. Other authors studying Dutch dredged sediments found TC varying from 118 to $53 \mathrm{~g} . \mathrm{kg}^{-1}$ dry matter, TN varying from 6.9 to $5.0 \mathrm{~g} \cdot \mathrm{kg}^{-1}$ dry matter, TP varying from 2.5 to $0.9 \mathrm{~g} \cdot \mathrm{kg}^{-1}$ dry matter and TS varying from 18 to $8 \mathrm{~g} \cdot \mathrm{kg}^{-1}$ dry matter.

The dredged sediments have a water content ranging from $898 \%$ for S5 to $268 \%$ for S1 (Figure 2-5) and, as a consequence, it is not possible to determine the stability and undrained shear strength. Since during dewatering and biochemical ripening of the dredged sediments the excess of water is removed, a structure is developed and the aggregate 
stability and undrained shear strength can be determined for the newly formed soil.

One indicator of soil degradation is the aggregate stability which can be defined as the resistance of the soil against the external destructive effects of water and wind (Deviren Saygın et al. 2012). The results obtained indicate that the soils formed from biochemical ripening dredged sediments are very stable to water erosion and, as a consequence, the organic matter occluded within the aggregates is protected against biochemical degradation. However, from the observation of the samples in the laboratory during the wet sieving with the dispersant solution, most material was retained in the sieves as if the cohesive forces of the aggregates could not be broken down by the dispersant solution. No literature was found addressing this topic and therefore these results should be interpreted carefully.

The load-bearing capacity of the biochemically ripened dredged sediments varies between $770 \mathrm{kPa}$ for S5 and $2954 \mathrm{kPa}$ for S1, which is enough to sustain cattle and tractors, meaning that the soil can be used for husbandry (crops and/or animals).

In general, the behaviour of S5 diverts from the behaviour of the other four samples which seems to be related with the very high organic and clay content that resulted in this sample behaving more as a slurry than a soil at the start of the ripening process. This could not be foreseen when the experiments were designed and future research should take this in consideration. 


\subsection{Conclusions}

The studied dredged sediments have the potential to mitigate land subsidence in delta areas when spread on land since:

- The mass of organic matter did not change after dewatering and biochemical ripening.

- Most volume lost during dewatering and biochemical ripening can be attributed to water loss and pore water reduction and not to organic matter loss.

- Biochemical ripening resulted in an increase in oxygen-bearing compounds and decrease in hydrocarbons which indicates an increase in the fraction of stable organic compounds.

- The water retention capacity is higher for samples with higher organic matter which is a valuable condition to decrease the oxygen diffusion through the matrix.

- The total C, N, P and S concentrations are high and therefore the dredged sediments can be considered as fertilizer when added to a soil.

- The aggregates formed during biochemical ripening are very stable to water erosion and can protect organic matter against oxidation.

- The load-bearing capacity after biochemical ripening is enough to sustain cattle and tractors, meaning that the soil can be used for husbandry (crops and/or animals). 


\section{Acknowledgements}

This research is supported by the Dutch Technology Foundation STW, which is part of the Netherlands Organisation for Scientific Research (NWO), and which is partly funded by the Ministry of Economic Affairs, via the perspective program BioGeoCivil (grant 11344). We would like to express gratitude to Guido Verweij from Hoogheemraadschap van Schieland en de Krimpenerwaard (HHSK) and Karsten Hopman from Hoogheemraadschap Hollands Noorderkwartier (HHNK) for the support with sampling; to Gerben Bakker Soil Physics Laboratory Wageningen University and Research Centre for all the input about laboratorial methods about soil sciences; and to Vinnie de Wilde from the sub-department of Environmental Technology Wageningen University and Research Centre for all the support designing the experimental setup. 


\section{Supplementary Material of Chapter 2}

Supplementary Material Table 2-1: Rock-Eval ${ }^{\circledR}$ parameters. Adapted from (Lafargue et al. 1998, Sanei et al. 2005)

\begin{tabular}{|c|c|c|c|}
\hline $\begin{array}{l}\text { Parameters m } \\
\text { Designation }\end{array}$ & $\begin{array}{l}\text { asured } \\
\text { Oven }\end{array}$ & Parameter & Units \\
\hline $\mathrm{S} 1$ & Pyrolysis & Free, "volatile" hydrocarbons & ( $\mathrm{mg}_{\text {hydrocarbons }} \cdot \mathrm{g}^{-1} \mathrm{~s}$ \\
\hline $\mathrm{S} 2$ & Pyrolysis & $\begin{array}{l}\text { Hydrocarbons released by } \\
\text { thermal cracking of organic } \\
\text { matter }\end{array}$ & ( $\mathrm{mg}_{\text {hydrocarbons }} \cdot \mathrm{g}^{-1} \mathrm{~s}$ \\
\hline $\mathrm{S}_{\mathrm{CO} 2}$ & Pyrolysis & $\begin{array}{l}\mathrm{CO}_{2} \text { released during thermal } \\
\text { cracking of oxygen-bearing } \\
\text { organic compounds }\end{array}$ & $\left(\mathrm{mg}_{\mathrm{CO} 2} \cdot \mathrm{g}_{\text {sample }}^{-1}\right)$ \\
\hline $\mathrm{S} 3_{\mathrm{CO}}$ & Pyrolysis & $\begin{array}{l}\text { CO released during thermal } \\
\text { cracking of oxygen-bearing } \\
\text { organic compounds }\end{array}$ & $\left(\mathrm{mg}_{\mathrm{co}} \cdot \mathrm{g}^{-1}\right.$ sample $)$ \\
\hline $\mathrm{S} 4 \mathrm{CO}_{2}$ & Oxidation & $\begin{array}{l}\mathrm{CO}_{2} \text { released during the } \\
\text { combustion of the residual } \\
\text { organic carbon }\end{array}$ & $\left(\mathrm{mg}_{\mathrm{co} 2} \cdot \mathrm{g}^{-1}\right.$ sample $)$ \\
\hline $\mathrm{S} 4_{\mathrm{CO}}$ & Oxidation & $\begin{array}{l}\text { CO released during the } \\
\text { combustion of the residual } \\
\text { organic carbon }\end{array}$ & $\left(\mathrm{mg}_{\mathrm{co}} \cdot \mathrm{g}^{-1}\right.$ sample $)$ \\
\hline
\end{tabular}

\begin{tabular}{|c|c|c|c|}
\hline $\begin{array}{l}\text { Parameters c } \\
\text { Designation }\end{array}$ & $\begin{array}{l}\text { culated } \\
\text { Parameter }\end{array}$ & Formula & Units \\
\hline $\mathrm{OI}_{\mathrm{RE} 6}$ & $\begin{array}{l}\text { Oxygen } \\
\text { Index }\end{array}$ & $\mathrm{OI}_{\mathrm{RE} 6}=\frac{\mathrm{S} 3 \mathrm{CO} 2^{\mathrm{C}} \times 100}{\mathrm{TOC}} \times \frac{32}{44}+\frac{\mathrm{S}^{3} \mathrm{CO} \times 100}{\mathrm{TOC}} \times \frac{16}{28}$ & $\left(\mathrm{mgo2}_{\mathrm{O}} \cdot \mathrm{g}^{-1}\right.$ TOC) \\
\hline TOC & $\begin{array}{l}\text { Total Organic } \\
\text { Carbon }\end{array}$ & $\mathrm{TOC}=\mathrm{PC}+\mathrm{RC}$ & $\left(\%, g_{c} \cdot g^{-1}\right.$ sample $)$ \\
\hline PC & $\begin{array}{l}\text { Pyrolysable } \\
\text { Carbon }\end{array}$ & $\begin{array}{l}\mathrm{PC}=(\mathrm{S} 1+\mathrm{S} 2) \times 0.083+\mathrm{S} 3_{\mathrm{CO} 2} \times \\
\frac{12}{440}+\mathrm{S} 3_{\mathrm{CO}} \times \frac{12}{280}\end{array}$ & $\left(\%, g_{c} \cdot g^{-1}\right.$ sample $)$ \\
\hline RC & $\begin{array}{l}\text { Residual } \\
\text { Carbon }\end{array}$ & $\mathrm{RC}=\mathrm{S} 4_{\mathrm{CO} 2} \times \frac{12}{440}+\mathrm{S} 4_{\mathrm{CO}} \times \frac{12}{280}$ & $\left(\%, g_{c} g^{-1}\right.$ sample $)$ \\
\hline MINC & $\begin{array}{l}\text { Mineral } \\
\text { Carbon }\end{array}$ & $\mathrm{MINC}=\mathrm{S} 3_{\mathrm{CO} 2} \times \mathrm{S}_{\mathrm{CO} 2} \times \frac{12}{440}$ & $\left(\%, g_{c .} g_{\text {sample }}^{-1}\right)$ \\
\hline TC & Total Carbon & $\mathrm{TC}=\mathrm{TOC}+\mathrm{MINC}$ & $\left(\%, g_{c .} g^{-1}\right.$ sample $)$ \\
\hline
\end{tabular}



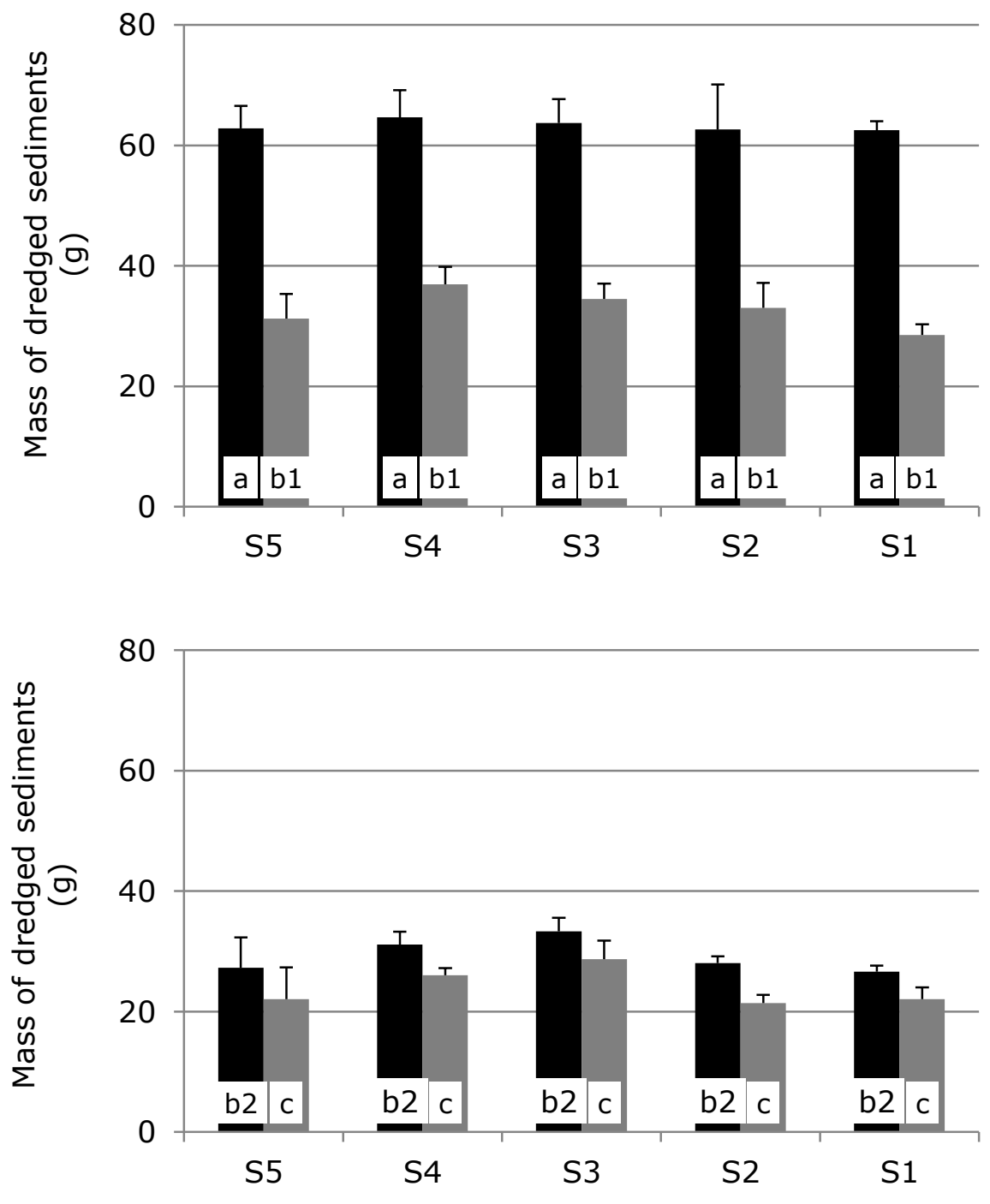

Supplementary Material Figure 2-1:Mass of dredged sediments a)before dewatering; b1) after dewatering; b2) before biochemical ripening; c) after biochemical ripening. The difference between $b 1$ and $b 2$ is consequence of the mass lost during the transfer from the suction chambers to the BBs 


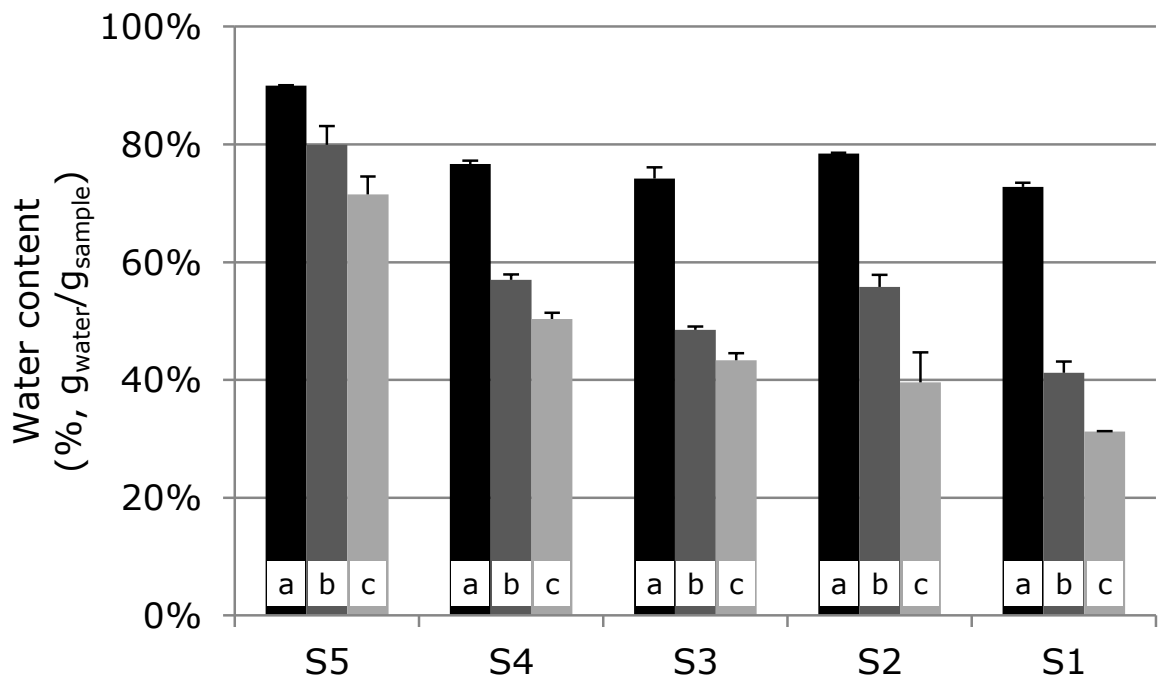

Supplementary Material Figure 2-2: Water content $\left(\%, g_{\text {water }} / g_{\text {sample }}\right)$

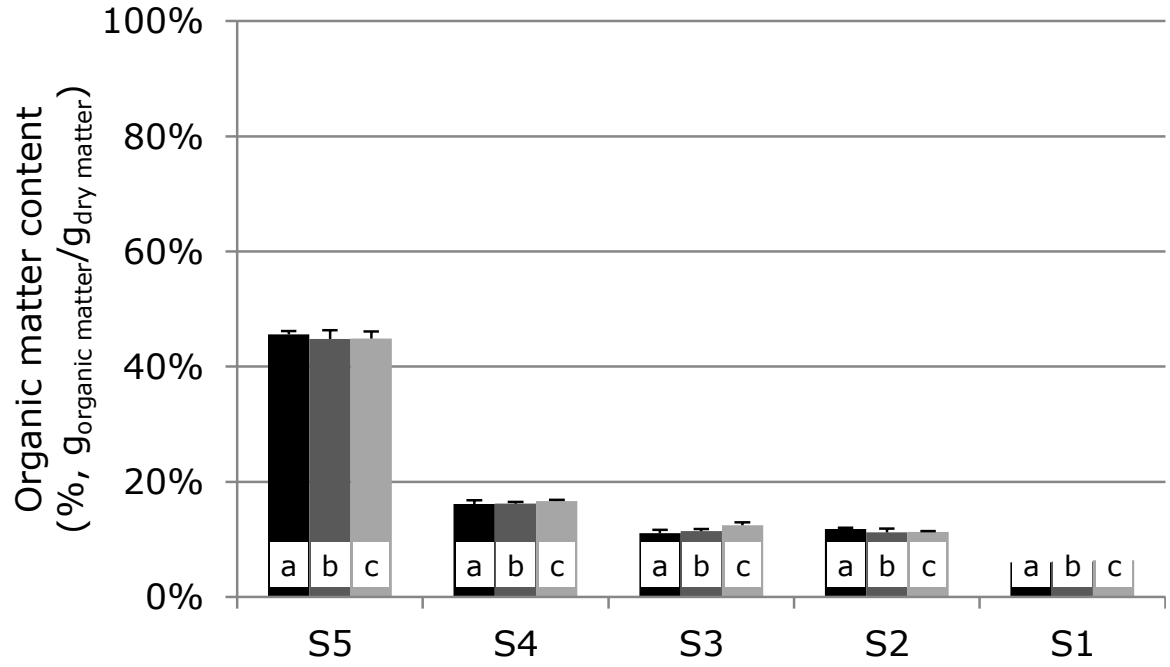

Supplementary Material Figure 2-3: Organic matter content ( $\%, g_{\text {organic matter }} / \mathrm{g}_{\text {dry matter }}$ ) 


\section{Chapter 3}

\section{Impact of compost and manure on the ripening of dredged sediments}

This Chapter has been published as:

Bruna R.F. Oliveira; Krisjan van Laarhoven; Martijn P.J. Smit; Huub H.M. Rijnaarts; Tim Grotenhuis (2916): Impact of compost and manure on the ripening of dredged sediments. Journal of Soils and Sediments, 17(2), 567-577, doi: 10.1007/s11368-016-1571-6. 



\section{Abstract}

Purpose: In low lying areas with dense networks of canals for land drainage, sediments accumulate in the waterways and have to be periodically dredged. These adjacent areas are mainly used for farming and agriculture and suffer from high rates of subsidence. The recycling of organic amendments, such as sediments, compost and manure, in agricultural soils can improve plant growth and yield, soil carbon content, and microbial biomass and activity, and have the potential to reverse the process of land subsidence.

Materials and methods: The effect of mixing bio-waste compost and the solid fraction of swine manure with dredged sediments before dewatering and biochemical ripening was investigated in terms of type and quantity of organic matter, $\mathrm{CO} 2$ production and $\mathrm{O} 2$ consumption, and N, P and S content. The water released during dewatering, the aggregate stability, and the undrained shear strength after ripening were also assessed since these areas have to be assessable by trucks and cattle.

Results and discussion: For the sediment with compost and manure the transformations in the type of organic matter, $\mathrm{CO} 2$ production and $\mathrm{O} 2$ consumption were larger compared to the individual fractions, indicating a positive priming effect. Most volume lost during ripening can be attributed to the loss of water and not to the loss of organic matter. In addition, the mixtures result in very stable aggregates and showed an undrained shear strength three times higher than measured for the sediments.

Conclusions: Sediments, compost and manure can be used and applied as beneficial use to reverse the process of land subsidence in low lying areas.

\section{Keywords}

Compost; Dredged sediments; Priming effect; Ripening; Rock-Eval; Swine manure; Undrained shear strength; Beneficial use 


\subsection{Introduction}

Soil organic matter (SOM), and the carbon (C) it contains, is associated with soil fertility for plant growth, soil and water quality, soil resistance to erosion, and thus stores at least three times more carbon than the atmosphere or living plants (Aich et al. 2013, Schmidt et al. 2011). The more stable fraction of SOM has a slower decomposition rate and slower release of nutrients than the more labile fractions of organic matter (Gruhn et al. 2000). The degradation of SOM significantly alters the soil texture and structure causing changes in soil hydrology and associated nutrient dynamics. Carbon (C), nitrogen ( $N)$, phosphorus ( $P$ ), and sulphur (S) cycling are intimately linked through soil, plant and microbial processes affecting the C:N:P:S ratios of the soil organic matter (Kirkby et al. 2011).

In low lying delta areas with dense networks of canals, sediments accumulate in the waterways and have to be dredged periodically for several reasons, including the maintenance of the water quality, ecological status and navigability, and to prevent flooding (Querner et al. 2012). A beneficial use of the dredged sediments is to spread these on the land adjacent to the drained waterway. When non-impacted dredged sediments are transferred to upland conditions, the ripening process begins and transforms the waterlogged sediments into an aerated soil (Pons \& Zonneveld 1965). During ripening, the previously anaerobic dredged sediments become aerobic which induces the oxidation of organic matter (Vermeulen et al. 2007). The oxidation of the organic matter can go in the direction of the humification or mineralization (Sanei et al. 2005). Humification can be defined as the transformation of SOM into amorphous humic compounds while mineralization refers to the transformation of organically bound elements (C, N, P, S) into inorganic compounds (Sumner 2000, Zech et al. 1997). 
The recycling of organic amendments, such as dredged sediments, compost and manure, in agricultural soils can improve plant growth and yield, soil carbon content, and microbial biomass and activity (Thangarajan et al. 2013) and also have the potential to increase the surface level of the land in low lying polder areas which suffer from high rates of subsidence (Brils et al. 2014, Hoogland et al. 2012). There is evidence that the addition of organic amendments to soil can induce mineralization of the more stable fraction of the SOM and reduce the overall carbon content. This induced mineralization of the SOM is mainly due to the increase of SOM decomposing microorganisms which sustain after the initial organic amendment input is exhausted, and then survive on the remaining soil organic matter (Fontaine et al. 2004). This effect is called the positive priming effect and is mostly an acceleration of native SOM mineralization by using the organic amendment as a source of energy (Fontaine et al. 2011, Guenet et al. 2012). There are, however, also studies reporting a negative priming effect, i.e., the native SOM mineralization can be reduced (Kuzyakov et al. 2000). The positive or negative priming effect is mostly determined by the soil microbial biomass response to the addition of different substances (Kuzyakov et al. 2000).

The humification or mineralization of the organic matter also depends on the nutrients availability (Kirkby et al. 2014). Priming effects were found not only for C but also for N (Dempster et al. 2012, Fontaine et al. 2011, Masayna et al. 1985), P (Kuzyakov et al. 2000) and S (O'Donnell et al. 1994). The recycling of dredged sediments, compost and manure in soils can therefore have varying impacts, depending mainly on the soil type, composition of the organic amendment, climate conditions and period over which measurements are made (Cely et al. 2014, Zimmerman et al. 2011). 
Even though there are many scientific references regarding the addition of compost and manure to soils, no literature was found regarding the mixture of compost and manure with dredged sediments. Therefore, the objective of this study is to evaluate the impact of adding compost of domestic bio-waste and the solid fraction of swine manure on the ripening of dredged sediments with the objective of doubling the organic matter content of the sediments. The impact was characterized in terms of type and quantity of organic matter, $\mathrm{CO} 2$ production and $\mathrm{O} 2$ consumption, and $\mathrm{N}, \mathrm{P}$ and $\mathrm{S}$ content. The water released during dewatering, the aggregate stability, and the undrained shear strength after ripening were determined to evaluate the possibility of use of these materials in agriculture lands where tractors have to be used and cattle graze.

\subsection{Material and methods}

\subsubsection{Collection of samples}

The sediment (S) samples were dredged in November 2012 from a ditch surrounded by greenhouses and small family houses, located in Gouda, Zuid-Holland, the Netherlands. One container of 30 I was filled with sediment from the ditch using a bucket of 20 liters for sampling. The airtight container of $30 \mathrm{I}$ was transported to the laboratory where the sediment was sieved and the fraction smaller than $2 \mathrm{~mm}$ was stored in the air-tight container at $4^{\circ} \mathrm{C}$ until used in the experiments. The larger fractions were discarded. The 30 I container was in a roller bank for 24 hours to homogenize before taking samples to use in the experiments.

The particle size distribution of the mineral fraction of the sediments was determined by first air-drying and then removing the organic matter with $\mathrm{H}_{2} \mathrm{O}_{2}$ and the $\mathrm{CaCO}_{3}$ with $\mathrm{HCl}$. The particle size distribution was determined following the ISO standard ISO/TS 17892-4:2014. Fractions $<2 \mu \mathrm{m}, 2-16 \mu \mathrm{m}$, and $16-50 \mu \mathrm{m}$ were determined by the pipet method 
and fraction 50-63 $\mu \mathrm{m}$ was determined by wet sieving at the Soil Chemical Biological Soil Laboratory (CBLB) of Wageningen UR. The fractions 63-105 $\mu \mathrm{m}, 105-150 \mu \mathrm{m}, 150-210 \mu \mathrm{m}, 210-420 \mu \mathrm{m}$, and 420$2000 \mu \mathrm{m}$ were determined by dry sieving by the Soil Physics laboratory of Wageningen UR. The sediments have $25 \%$ clay, 38\% silt, 37\% sand. The dredged sediments are classified as fine grained according to the ISO/TS 17892-4:2014 and classified as loam according to the USDA classification system of textural classes (USDA 1987).

The fiber content of the sediments was determined following the standard test method for laboratory determination of the fiber content of peat samples by dry mass ASTM D1997-91(2008). The fiber content of the sediments is $4.1 \% \mathrm{~g}_{\text {dry fibers }} / \mathrm{g}_{\text {dry matter }}$.

The compost of domestic bio-waste (C) was provided by the Dutch company Attero. The domestic bio-waste was primarily separated at source and secondarily at Attero facilities. According to the Green Paper on the management of bio-waste in the European Union, "bio-waste is defined as biodegradable garden and park waste, food and kitchen waste from households, restaurants, caterers and retail premises, and comparable waste from food processing plants. It does not include forestry or agricultural residues, manure, sewage sludge, or other biodegradable waste such as natural textiles, paper or processed wood (COM 2008).

The solid fraction of swine manure (M) used in this research was provided by the Dutch company AquaPurga. To obtain the solid fraction, the manure was mixed with the copolymer of acrylamide and quaternized cationic monomer Zetag ${ }^{\circledR} 8140$ and then the liquid and solid phases were mechanically separated using a belt press. The solid fraction used had a water content of $32 \%\left(g_{\text {water }} / g_{\text {sample }}\right)$.

$\mathrm{S}, \mathrm{C}$ and $\mathrm{M}$ were stored at $4^{\circ} \mathrm{C}$ in air-tight containers until used in the experiments. 


\subsubsection{Experimental procedure}

\subsubsection{Mixtures}

The mixtures were prepared with the objective of doubling the organic matter content of the sediments. The mixtures of sediments with compost $(S+C)$ and sediments with manure $(S+M)$ were prepared considering the following ratios (in dry weight):

$\frac{\mathrm{m}_{\mathrm{C}}}{\mathrm{m}_{\mathrm{S}}}=24 \%$

Equation 3-1

$\frac{\mathrm{m}_{\mathrm{M}}}{\mathrm{m}_{\mathrm{S}}}=14 \%$

Equation 3-2

where $\mathrm{m}_{\mathrm{C}}$ is the dry mass of $\mathrm{C} ; \mathrm{m}_{\mathrm{S}}$ the dry mass of $\mathrm{C}$; and $\mathrm{m}_{\mathrm{M}}$ the dry mass of $M$.

The ratios in Equations 3-1 and 3-2 were calculated from the water and organic matter content of $S, C$, and $M$ before dewatering. The mixtures $\mathrm{S}+\mathrm{C}$ and $\mathrm{S}+\mathrm{M}$ were prepared before dewatering of the sediments, using a magnetic stirrer.

The results of the mixtures $\mathrm{S}+\mathrm{C}$ and $\mathrm{S}+\mathrm{M}$ are later compared with the results that can be estimated from the controls $S, C$, and $M$, using Equations 3-1 and 3-2.

\subsubsection{Dewatering}

In order to dewater $\mathrm{S}, \mathrm{S}+\mathrm{C}$ and $\mathrm{S}+\mathrm{M}$, suction chambers (Vermeulen et al. 2005) were used where a suction pressure of $100 \mathrm{hPa}$ was applied below the sample. To retain the fine particles in the suction chambers, a nylon filter with pore size of $0.45 \mu \mathrm{m}$ was used. It was assumed that equilibrium between the matric potential of the sample and the applied suction is reached when the water outflow from the sample ceases (Klute \& Dirksen 1986). This was generally observed within 7 days.

Dewatering was done at $20 \pm 1{ }^{\circ} \mathrm{C}$ and the suction chambers were completely closed to the atmosphere, i.e., evaporation was avoided 
using a lid on the setup. Periodically a plug on top of the suction chamber was opened to release the suction pressure due to the decrease of the volume by removed water from the sample.

The diameter of the dewatered samples was $6.0 \pm 0.1 \mathrm{~cm}$ and the height of the $\mathrm{S}$ samples was $2.2 \pm 0.2 \mathrm{~cm}$, the height of the $\mathrm{S}+\mathrm{C}$ samples was $3.3 \pm 0.1 \mathrm{~cm}$ and the height of the $S+M$ samples was 2.8 $\pm 0.1 \mathrm{~cm}$.

The water content of samples $C$ and $M$ could not be decreased with a suction of $100 \mathrm{hPa}$, i.e., the samples were at a matric potential higher than $100 \mathrm{hPa}$. The $\mathrm{C}$ and $\mathrm{M}$ samples were molded by hand to a final diameter of $6.0 \pm 0.2 \mathrm{~cm}$ and a height of $3.3 \pm 0.2 \mathrm{~cm}$ for $C$ and $2.8 \pm$ 0.2 for $M$, to come to equivalent size of samples as $S+C$ and $S+M$, respectively.

After dewatering, three replicates of each sample were sacrificed to determine the water and organic matter content and therefore to control the homogeneity between samples.

\subsubsection{Biochemical ripening}

After dewatering of $\mathrm{S}, \mathrm{S}+\mathrm{C}$ and $\mathrm{S}+\mathrm{M}$, and molding $\mathrm{C}$ and $\mathrm{M}$ by hand, nine samples of each mixture and control were submitted to biochemical ripening in specifically designed batch bottles (BBs) (Figure 3-1). Each sample was placed in one of these BBs which allowed monitoring of individual variations. The BBs were closed to the atmosphere and the gas phase was periodically monitored to assure that there was biological activity and that there was no oxygen limitation, i.e., oxygen concentration in the headspace was always above $10 \%(\mathrm{v} / \mathrm{v})$. To be able to take a gas sample, the BBs were designed with a gas sampling port. To avoid condensation and keep the relative humidity constant in the BBs, a saturated solution of potassium nitrate $\left(\mathrm{KNO}_{3}\right)$ with a concentration of $360 \mathrm{~g} / \mathrm{L}$ was kept inside each of the BBs. The $\mathrm{KNO}_{3}$ has 
neutral $\mathrm{pH}$, absorbs about $0.03 \%$ water in $80 \%$ relative humidity over 50 days, and in a closed environment at $20^{\circ} \mathrm{C}$ keeps the relative humidity constant at $94.5 \%$. Biochemical ripening was done during 37 days for $\mathrm{S}$, and 35 days for $\mathrm{C}, \mathrm{M}, \mathrm{S}+\mathrm{C}$ and $\mathrm{S}+\mathrm{M}$.

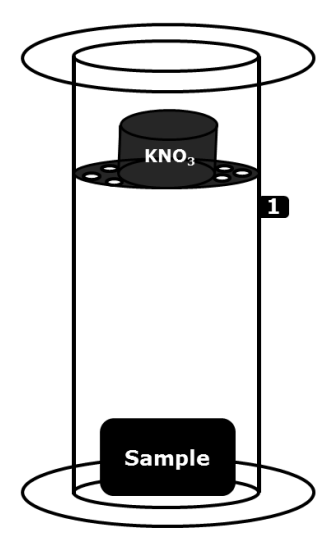

Figure 3-1: Scheme of the batch bottles (BBs) used for biochemical ripening, with a beaker with a saturated salt solution of $\mathrm{KNO} 3$ to keep constant relative humidity and a port (1) for gas sampling

\subsubsection{Analytical methods}

Since the samples were analyzed for different parameters at different phases of the experiment, the samples before dewatering will be referred to as phase a); after dewatering as phase b); and after biochemical ripening as phase $\mathrm{c}$ ).

The water removed from the samples during dewatering was collected in a tube for quantification by weighing.

The moisture content and organic matter content were calculated from the oven dry weight of the samples ( 24 hours at $105^{\circ} \mathrm{C}$ ) and the loss on ignition ( $4 \mathrm{~h}$ at $550^{\circ} \mathrm{C}$ ) of the samples (ISO/TS 17892-1:2014). The samples were oven dried at $105^{\circ} \mathrm{C}$ for 24 hours since it is the most common practice in soil sciences (Soil and Plant Analysis Council Inc. 1999, Sumner 2000). 
$\mathrm{O}_{2}$ and $\mathrm{CO}_{2}$ in the $\mathrm{BBs}$ headspace were measured with gas chromatography (Shimadzu GC-2010) with a thermal conductivity detector (TCD). For practical reasons, this was done for all samples on the same day. Since not all BBs started on the same day, the gas measurements are not done on the same intervals for all the samples.

The $\mathrm{pH}$ of the S sample before dewatering was determined directly since water content was above $70 \%$ for all samples. The $\mathrm{pH}$ of the $\mathrm{C}$ and $\mathrm{M}$ before ripening and $S, C, M, S+C$ and $S+M$ after biochemical ripening was determined on an a $1: 1$ sediment/manure/compost:water suspension using a glass electrode (Soil and Plant Analysis Council Inc. 1999).

The total N, P, and S were determined at the Chemical Biological Soil Laboratory of Wageningen University and Research Centre, The Netherlands. The samples were centrifuged to separate the solid fraction from the supernatant. The supernatant was then filtrated and the colloid fraction collected in the filter was added to the solid fraction. One subsample of the solid fraction was digested with the DigiPrep (aquaregia method, according to NEN-69610) and analyzed with a Thermo (type iCAP) ICP-AES. Another sub-sample of the solid fraction was used to analyze total $\mathrm{N}$ with a Leco $\mathrm{C} / \mathrm{N}$ analyzer. The total $\mathrm{P}$ and total $\mathrm{S}$ of the liquid fraction were analyzed with a Varian ICP-AES and the total organic carbon and total nitrogen were analyzed with a Skalar Segmented Flow Analyzer (SFA).

The type of organic matter was characterized with the Rock-Eval $6^{\circledR}$ method. The samples of $20 \mathrm{mg}$ of sediments are heated in pyrolysis and oxidation ovens at a heating rate of $25^{\circ} \mathrm{C} / \mathrm{min}$ of the Rock Eval $6^{\circledR}$ apparatus. The pyrolysis occurs between 100 and $650^{\circ} \mathrm{C}$ under an inert atmosphere of $\mathrm{N}_{2}$. During the pyrolysis, the free hydrocarbons present in the sample and the hydrocarbons released by the thermal cracking of organic matter are detected by the Flame Ionization Detector. 
Simultaneously, the $\mathrm{CO}$ and $\mathrm{CO}_{2}$ released during thermal cracking of oxygen-bearing organic compounds are measured by Infrared detectors. The measurement of $\mathrm{CO}$ is conducted up to $570{ }^{\circ} \mathrm{C}$ to avoid interference from the release of inorganic $\mathrm{CO}$ at higher temperatures. The measurement of $\mathrm{CO}_{2}$ is conducted up to $400^{\circ} \mathrm{C}$ to avoid interference from the release of inorganic $\mathrm{CO}_{2}$ at higher temperatures. Following the pyrolysis stage, the sample is transferred to the oxidation oven and heated from 400 to $850^{\circ} \mathrm{C}$ in air, incinerating all the residual organic carbon. The $\mathrm{CO}$ and $\mathrm{CO}_{2}$ released during combustion of residual organic carbon are measured by online Infrared detectors. The HI (Hydrogen Index) is an indicative value for the amount of hydrocarbons released by thermal cracking of organic matter per gram of TOC (Total Organic Carbon), and the $\mathrm{OI}_{\mathrm{RE} 6}$ (Oxygen Index) is an indicative value for the amount of $\mathrm{CO}_{2}$ and $\mathrm{CO}$ by thermal cracking of oxygen-bearing organic compounds per gram of TOC (Supplementary material Table 2-1). Changes in the $\mathrm{HI}$ and $\mathrm{OI}_{\mathrm{RE} 6}$ are analyzed to evaluate a transition in the type of organic matter. Rock-Eval $6^{\circledR}$ analyses were performed at Deltares, the Netherlands.

Aggregate stability was determined according to the method described by Kemper \& Rosenau for wet aggregate stability determination (Kemper \& Rosenau 1986). This method measures the breakdown of aggregates upon rapid wetting (slaking) and the subsequent breakdown of aggregates due to the mechanical sieving action. The wet sieving apparatus from Eijkelkamp was used for the mechanical sieving. The aggregate stability index goes from 0 to 1 , where 1 is very stable and 0 is absence of aggregates (Kemper \& Rosenau 1986).

The undrained shear strength was determined with the fall cone method of the biochemically ripened samples, following the procedure described in the ISO/TS 17892-6:2004. The measured undrained shear strengths were used to calculate the bearing capacity in order to evaluate whether 
the soil is accessible for cattle and tractors. The bearing capacity ( $q$ ) of the soil is calculated according to the method described e.g. in Terzaghi et al (1996):

$q=s_{c} d_{c} c_{u} N_{c}+s_{q} d_{q} \gamma D N_{q}+s_{\gamma} 0.5 \gamma B N_{\gamma}$

Equation 3-3

in which $\mathrm{q}$ is the bearing capacity in $[\mathrm{kPa}], \mathrm{C}_{\mathrm{u}}$ is the undrained shear strength in $[\mathrm{kPa}], \mathrm{Y}$ is the bulk unit weight of the soil in $\left[\mathrm{kN} / \mathrm{m}^{3}\right], D$ is the depth at which the load is applied below surface level in $[m], B$, is the width of the load surface in [m] assuming an infinitely long strip footing, $N_{c}, N_{q}$ and $N_{Y}$ are so-called bearing capacity factors, which are related the friction angle of the soil, $s_{c}, s_{q}$ and $s_{Y}$ are shape factors which are used to correct for the shape of the surface on which the load is applied, $\mathrm{d}_{\mathrm{c}}$ and $\mathrm{d}_{\mathrm{q}}$ are depth factors which need to be taken into account when the load is applied below surface level. Considering that the load of cattle or tractors is applied at surface level and only for a short period of time at the same location, $\mathrm{D}=0 \mathrm{~m}, \mathrm{~N}_{\mathrm{Y}}=0, \mathrm{~N}_{\mathrm{q}}=1$ and $\mathrm{N}_{\mathrm{c}}=5.14$ (Barnes 2000), the equation above can be simplified to:

$q=\left(1+\frac{N_{q}}{N_{c}}\right) c_{u} N_{c}=6.14 c_{u}$

Equation 3-4

In this empirical approach the soil is presumed to be infinitely stiff and homogeneous in both horizontal and vertical directions, which are considered to be valid presumptions when the load is applied in the open field. In case a tractor or cow is standing close to a ditch the bearing capacity may be significantly lower and that scenario was not considered in this study.

The load applied by cattle on the soil was calculated considering an average weight of $600 \mathrm{~kg}$, and considering that the weight is evenly distributed by the 4 hoofs with a surface area of $0.01 \mathrm{~m} 2$ each. For tractors, it was considered an average weight of $2900 \mathrm{~kg}$ per front wheel and an average weight of $6000 \mathrm{~kg}$ per rear wheel (Table 3-1). 
Table 3-1: Estimation of load applied on the soil by cattle and tractors

\begin{tabular}{lcccc} 
& $\begin{array}{c}\text { Mass } \\
(\mathrm{kg})\end{array}$ & $\begin{array}{c}\text { Surface area } \\
\left(\mathrm{m}^{2}\right)\end{array}$ & $\begin{array}{c}\text { Number of } \\
\text { hoofs or wheels }\end{array}$ & $\begin{array}{c}\text { Load } \\
{[\mathrm{kPa} /(\text { paw or wheel })]}\end{array}$ \\
\hline Cattle & 600 & 0.01 & 4 & 147 \\
Tractor front & 2900 & 0.12 & 2 & 118 \\
Tractor rear & 6000 & 0.24 & 2 & 123 \\
\hline
\end{tabular}

\subsection{Results}

In all samples the Total Organic Carbon, TOC (RC+PC), represents more than $70 \%$ of the Total Carbon, TC (TOC+MINC), for all samples, both before dewatering (a) and after biochemical ripening (c) (Figure 3-2). The TOC of $\mathrm{S}+\mathrm{Ca}$ ) and $\mathrm{S}+\mathrm{Ma}$ ) is approximately 2 times the TOC of $\mathrm{Sa}$ ), as desired with the mixtures. During biochemical ripening, the decrease in TOC was $26 \%$ for $S+C, 10 \%$ for $S+M$, and $25 \%$ for $S$. The decrease in MINC was $39 \%$ for $S+C, 42 \%$ for $S+M$, and $51 \%$ for $S$ (Figure 3-2).

The estimated TOC for $\mathrm{S}+\mathrm{Cc}$ ) from $\mathrm{Sc}$ ) and $\mathrm{Cc}$ ) (using Equation 3-1) is $6 \%$ higher than the measured and the estimated TOC for $\mathrm{S}+\mathrm{Mc}$ ) from $\mathrm{Sc}$ ) and $\mathrm{Mc}$ ) (using Equation 3-2) is $9 \%$ smaller than the measured.

During biochemical ripening, PC decreased $28 \%$ for $\mathrm{S}+\mathrm{C}$ and $5 \%$ for $\mathrm{S}+\mathrm{M}$ which is less than the $31 \%$ decrease for $\mathrm{S}$ (Figure 3-2). RC decreased $25 \%$ for $S+C$ and $12 \%$ for $S+M$ while $S$ had a decrease of $23 \%$ (Figure 3-2). The estimated PC for S+Cc) from Sc) and $\mathrm{Cc}$ ) (using Equation 3-1) was similar to the measured, and the estimated PC for $\mathrm{S}+\mathrm{Mc}$ ) from $\mathrm{Sc}$ ) and $\mathrm{Mc}$ ) (using Equation $3-2$ ) is $28 \%$ smaller than the measured. The estimated $\mathrm{RC}$ for $\mathrm{S}+\mathrm{Cc}$ ) from $\mathrm{Sc}$ ) and $\mathrm{Cc}$ ) (using Equation 3-1) was $9 \%$ higher than the measured and the estimated RC for $\mathrm{S}+\mathrm{Mc}$ ) from $\mathrm{Sc}$ ) and $\mathrm{Mc}$ ) (using Equation 3-2) was $2 \%$ higher than the measured. 


\section{Controls}

\section{Mixtures}

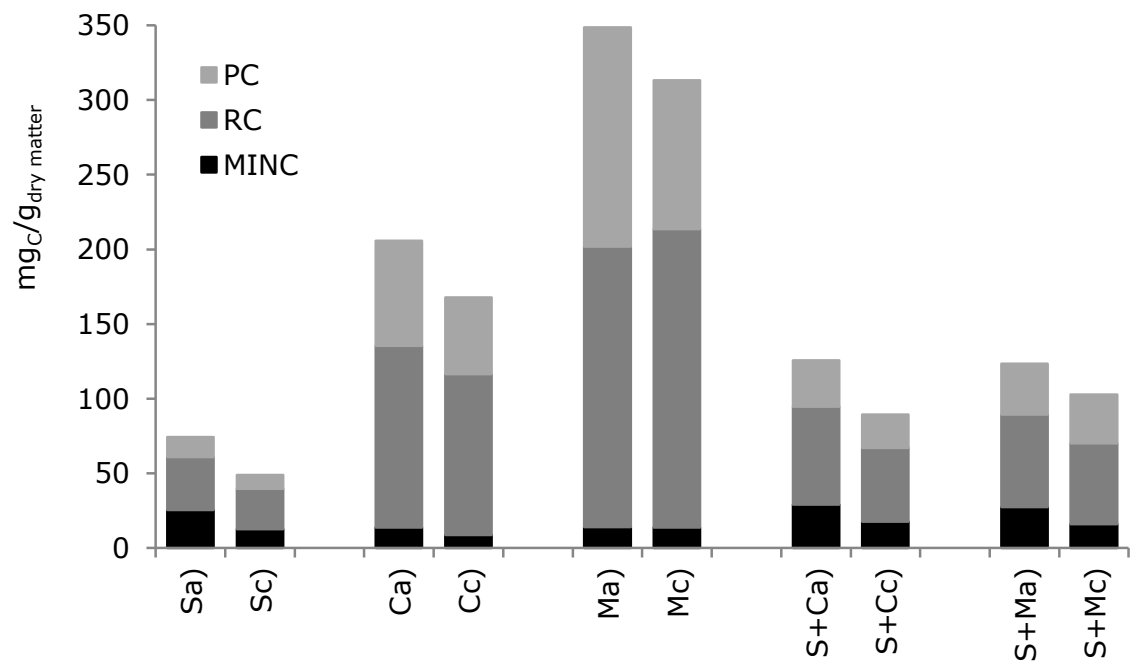

Figure 3-2: Total Carbon of samples as sum of MINC - Mineral Carbon, RC - Residual Carbon, and PC - Pyrolysable Carbon; a) before dewatering, and c) after biochemical ripening. TOC - Total Organic Carbon is the sum of RC and PC

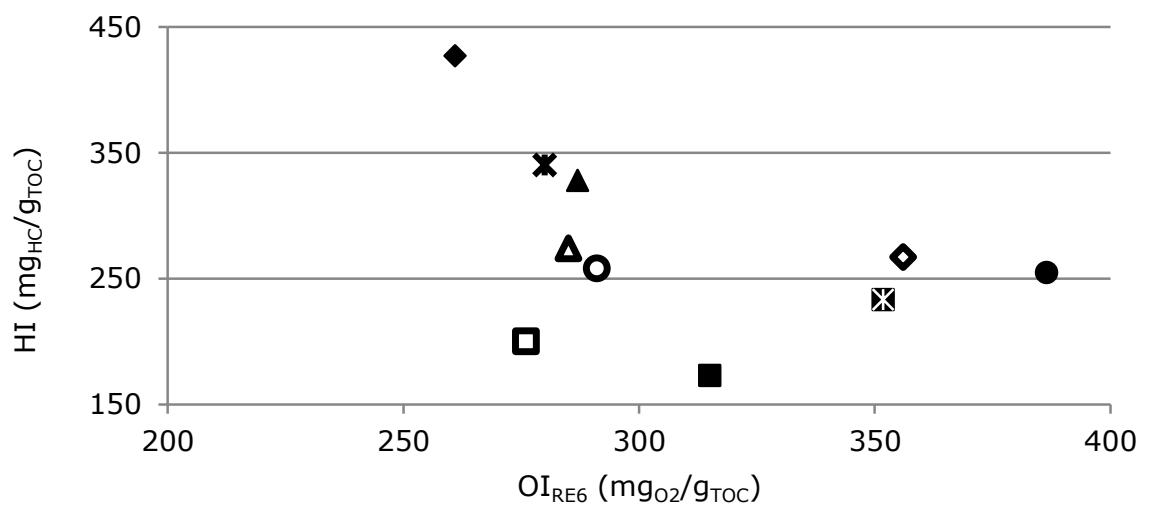

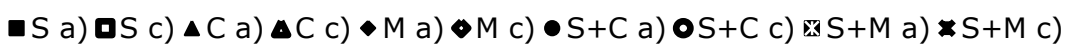

Figure 3-3: HI and OIRE6 a) before dewatering and c) after biochemical ripening 
The type of organic matter by Rock Eval analysis showed before dewatering, $\mathrm{S}+\mathrm{C}_{\mathrm{a}}$ and $\mathrm{S}+\mathrm{M}_{\mathrm{a}}$ had similar $\mathrm{HI}$ and $\mathrm{S}+\mathrm{C}_{\mathrm{a}}$ had higher $\mathrm{OI}_{\mathrm{RE} 6}$ than $S+M_{a}$ ). After biochemical ripening, $S+C$ had $1 \%$ increase in $\mathrm{HI}$ and $20 \%$ decrease in $\mathrm{OI}_{\mathrm{RE} 6}$, and $\mathrm{S}+\mathrm{M}$ had $46 \%$ increase in $\mathrm{HI}$ and $25 \%$ decrease in $\mathrm{OI}_{\mathrm{RE} 6}$, while $\mathrm{S}$ had $16 \%$ increase in $\mathrm{HI}$ and $12 \%$ decrease in $\mathrm{OI}_{\mathrm{RE6}}$. Therefore, $\mathrm{S}+\mathrm{C}, \mathrm{S}+\mathrm{M}$ and $\mathrm{S}$ all had an increase in $\mathrm{HI}$ and a decrease in $\mathrm{OI}_{\mathrm{RE} 6}$. The control $\mathrm{C}$ had a decrease in $\mathrm{HI}$ and decrease in $\mathrm{OI}_{\text {RE6 }}$. The control $M$ had a decrease in $\mathrm{HI}$ and increase in $\mathrm{OI}_{\mathrm{RE} 6}$ and $\mathrm{M}_{\mathrm{a}}$ ) was the sample with the highest $\mathrm{HI}$ and lowest $\mathrm{OI}_{\text {RE6 }}$ (Figure 3-3).

The $\mathrm{HI}$ of $\mathrm{S}+\mathrm{C}_{\mathrm{c}}$ ) was $4 \%$ smaller than the estimated from $\mathrm{S}_{\mathrm{c}}$ ) and $\mathrm{C}_{\mathrm{c}}$ ) (using Equation 3-1) while the $\mathrm{HI}$ for $\mathrm{S}+\mathrm{M}_{\mathrm{c}}$ ) was $30 \%$ higher than the estimated from $S_{c}$ ) and $M_{c}$ ( (using Equation 3-2). The $O I_{R E 6}$ for $S+C_{c}$ ) and $S+M_{c}$ was $19 \%$ and $16 \%$ smaller, respectively, than the estimated from the individual parts $\mathrm{S}_{\mathrm{c})}, \mathrm{C}_{\mathrm{c})}$ and $\mathrm{M}_{\mathrm{c} \text { ). }}$.

The TOC content before dewatering was used to normalise the results of $\mathrm{CO} 2$ production and $\mathrm{O} 2$ consumption during biochemical ripening (Figure 3-4). The results in Figure 3-4 confirm that there was microbial activity in the $\mathrm{BBs}$ and consistently show a higher $\mathrm{CO} 2$ production than $\mathrm{O} 2$ consumption. The mixtures $\mathrm{S}+\mathrm{C}$ and $\mathrm{S}+\mathrm{M}$ result in higher $\mathrm{CO} 2$ production and $\mathrm{O} 2$ consumption per gram of TOC than the observed for the controls $S, C$ and $M$. The mixture $S+M$ had higher total $\mathrm{CO} 2$ production and $\mathrm{O} 2$ consumption per gram of TOC than the mixture $\mathrm{S}+\mathrm{C}$. The $\mathrm{O} 2$ consumption of $\mathrm{S}+\mathrm{C}$ and $\mathrm{S}+\mathrm{M}$ was similar until 15 days and after that $\mathrm{S}+\mathrm{M}$ had higher $\mathrm{O} 2$ consumption than $\mathrm{S}+\mathrm{C}$ (Figure 3-4). 

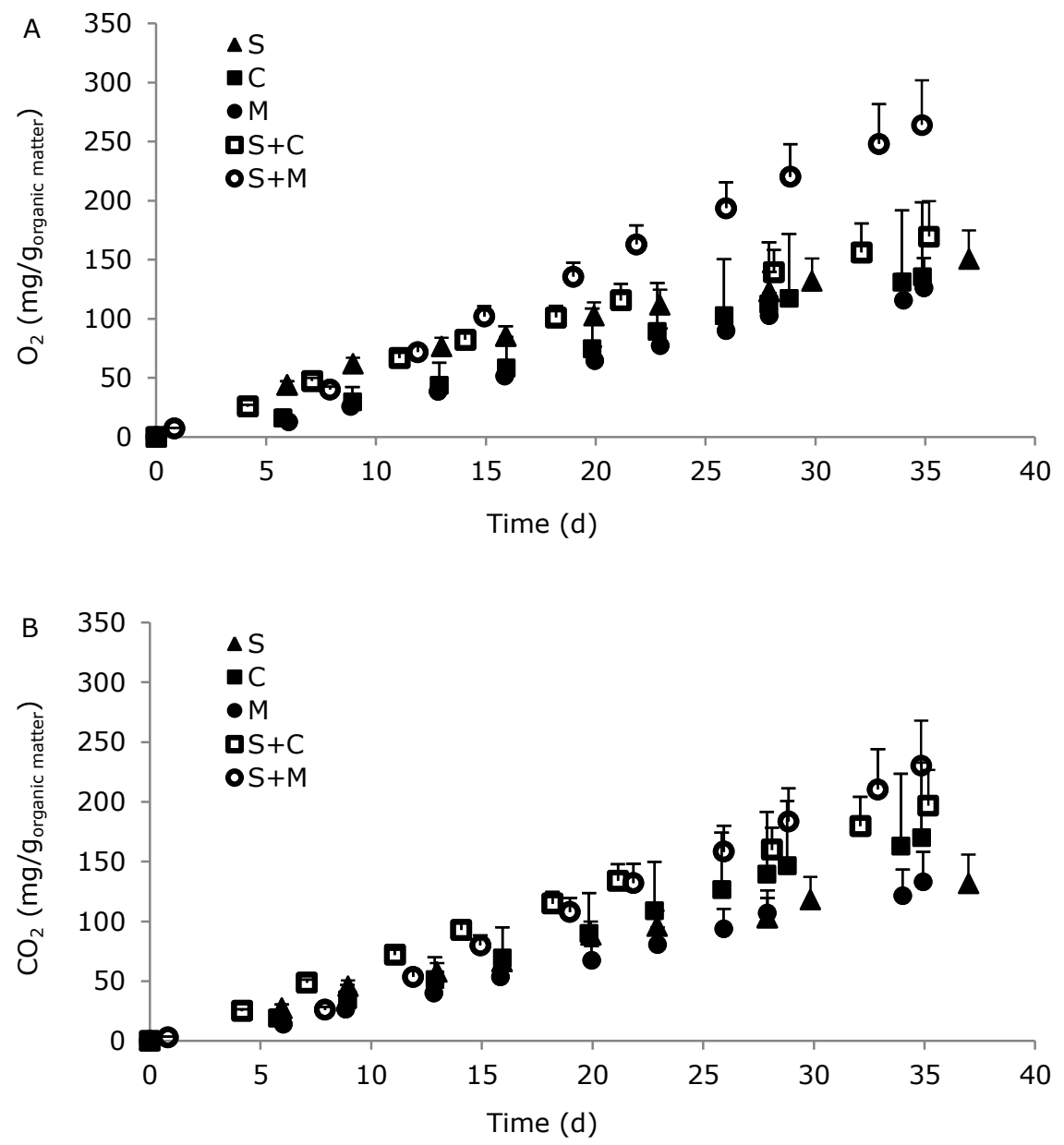

Figure 3-4: A) $\mathrm{O}_{2}$ consumption, and $\left.\mathrm{B}\right) \mathrm{CO}_{2}$ production during biochemical ripening per gram of TOC

Table 3-2: Carbon mass balance based on nutrients analysis and gas phase measurements during biochemical ripening. TCa - Total Carbon before dewatering; TCc - Total Carbon after biochemical ripening; TCa-c - Total Carbon released to the atmosphere during biochemical ripening

\begin{tabular}{lcccc} 
& $\begin{array}{c}\mathrm{TC}_{\mathrm{a}} \\
\left(\mathrm{mg} / \mathrm{g}_{\mathrm{om}}\right)\end{array}$ & $\begin{array}{c}\mathrm{TC}_{\mathrm{c}} \\
\left(\mathrm{mg}_{\mathrm{c}} / \mathrm{g}_{\mathrm{om}}\right)\end{array}$ & $\begin{array}{c}\mathrm{TC}_{\mathrm{a}-\mathrm{c}} \\
\left(\mathrm{mgc} / \mathrm{g}_{\mathrm{om}}\right)\end{array}$ & $\left|\left(\mathrm{TC}_{\mathrm{a}}-\mathrm{TC}_{\mathrm{c}}-\mathrm{TC}_{\mathrm{a}-\mathrm{c}}\right) / \mathrm{TC}_{\mathrm{a}}\right| * 100$ \\
\hline $\mathbf{S}$ & 639.67 & 624.44 & 19.91 & $0.7 \%$ \\
$\mathbf{C}$ & 488.43 & 490.78 & 20.89 & $4.8 \%$ \\
$\mathbf{M}$ & 464.04 & 449.58 & 15.95 & $0.3 \%$ \\
$\mathbf{S + C}$ & 545.57 & 445.55 & 26.19 & $14 \%$ \\
$\mathbf{S + M}$ & 582.86 & 507.49 & 30.25 & $8 \%$
\end{tabular}


The molar ratio [CO2]:[02] was almost constant with time for $\mathrm{C}$ and $\mathrm{M}$, and increased slightly with time for $\mathrm{S}, \mathrm{S}+\mathrm{C}$ and $\mathrm{S}+\mathrm{M}$ (Supplementary Material Figure 3-1).

The carbon mass balance (Table 3-2) has a gap of less than $8 \%$ for $\mathrm{S}$, C, M and $\mathrm{S}+\mathrm{M}$ and a gap of $14 \%$ for $\mathrm{S}+\mathrm{C}$. The carbon mass balance is not completely closed probably due to leakages in the BBs, i.e, the carbon released to the atmosphere during biochemical ripening was higher than the measured, and due to transport of atmospheric air to the BBs when sampling (invasive sampling method). Despite the decrease in TOC observed with the Rock-Eval method (Figure 3-2), the organic matter content determined by loss on ignition did not show a significant change during dewatering and biochemical ripening (Figure 35). The standard deviation of the organic matter content (Figure 3-5) confirmed that the replicates were homogeneous.

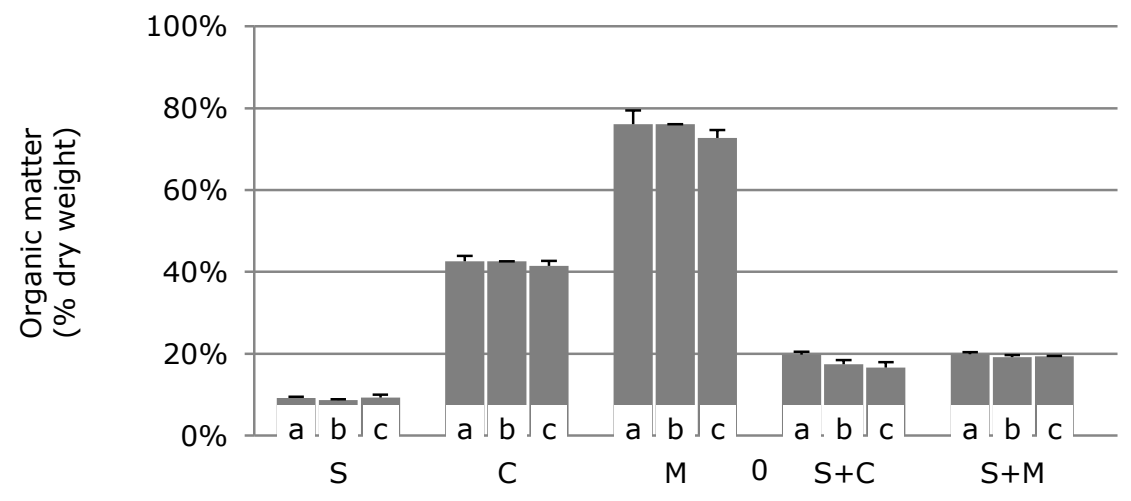

Figure 3-5: Organic matter content (\% dry weight) a) before dewatering; b) after dewatering; and c) after biochemical ripening 
Analysis of nutrients and $\mathrm{pH}$ in Table 3-3 showed that Total Nitrogen (TN) decreased $18 \%$ for $\mathrm{S}+\mathrm{C}$ and $22 \%$ for $\mathrm{S}+\mathrm{M}$ even though TN did not significantly change for the control samples $S, C$ and $M$. For Total Phosphorus (TP) and Total Sulphur (TS) all changes were less than 7\% (Table 3-3).

The $\mathrm{pH}$ (Table 3-3) did not significantly change during biochemical ripening.

Table 3-3: Total Nitrogen (TN), Total Phosphorus (TP), Total Sulphur (TS), and $\mathrm{pH}, \mathrm{a}$ ) before dewatering; and c) after biochemical ripening

\begin{tabular}{lcccc} 
& $\begin{array}{c}\mathrm{TN} \\
\left(\mathrm{mg} / \mathrm{g}_{\mathrm{om}}\right)\end{array}$ & $\begin{array}{c}\mathrm{TP} \\
\left(\mathrm{mg} / \mathrm{g}_{\mathrm{om}}\right)\end{array}$ & $\begin{array}{c}\mathrm{TS} \\
\left(\mathrm{mg} / \mathrm{g}_{\mathrm{om}}\right)\end{array}$ & \\
\hline S a) & 40.47 & 15.08 & 63.34 & 7.16 \\
S c) & 55.59 & 14.87 & 60.28 & 7.40 \\
& & & & \\
C a) & 35.69 & 7.15 & 4.99 & 8.43 \\
C c) & 37.34 & 7.46 & 5.18 & 8.26 \\
& & & & \\
M a) & 40.88 & 26.31 & 9.05 & 8.64 \\
M c) & 44.96 & 25.59 & 8.81 & 8.33 \\
& & & & \\
S+C a) & 36.07 & 9.45 & 24.69 & n.a. \\
S+C c) & 29.65 & 9.01 & 26.07 & 7.48 \\
& & & & \\
S+M a) & 43.11 & 26.68 & 29.42 & n.a. \\
S+M c) & 33.67 & 26.98 & 31.43 & 7.43
\end{tabular}



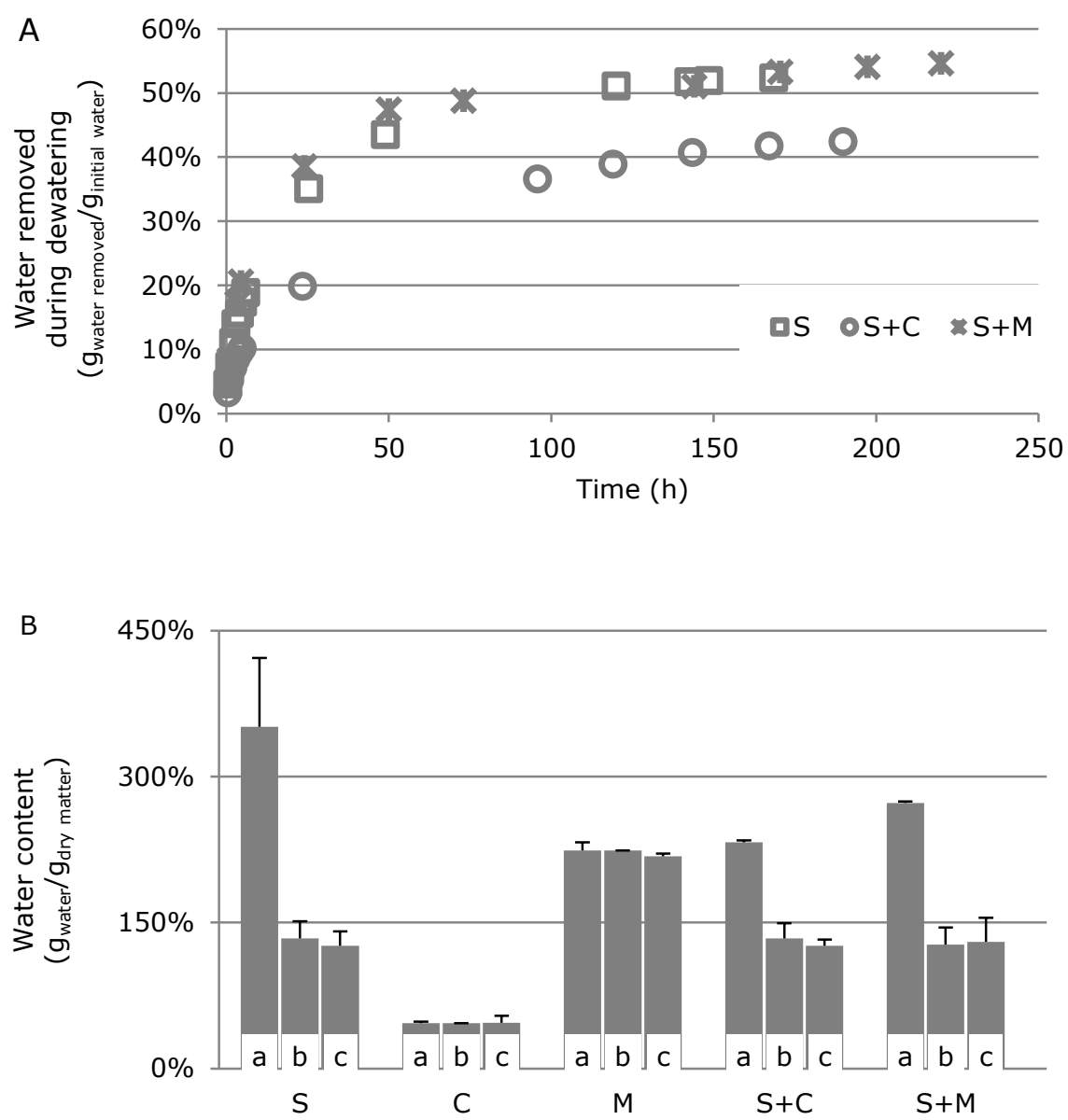

Figure 3-6: A) Water removed from the samples during dewatering in relation to the total initial water content of the samples; B) Water content (\% total weight) a) before dewatering; b) after dewatering; c) after biochemical ripening

Dewatering showed that most water was removed from the samples within the initial 48 hours (Figure 3-6A).

$\mathrm{S}+\mathrm{C}$ had less of its total initial water content removed during dewatering than $S$ alone (Figure 3-6A). This was in line with the lower water content of $C$ in relation to $S$ (Figure 3-6B).

From Figure $36 \mathrm{~B}$, dewatering led to a significant loss of total water for $\mathrm{S}, \mathrm{S}+\mathrm{C}$, and $\mathrm{S}+\mathrm{M}$ while during biochemical ripening the water content 
did not significantly change for any sample as the matric potential was set to $100 \mathrm{hPA}$. The water content of $\mathrm{C}$ and $\mathrm{M}$ was not removable with a suction of $100 \mathrm{hPa}$ and therefore these samples were not submitted to dewatering in the suction chambers.

A more detailed water balance to the dewatering process and to the biochemical ripening are in Supplementary Material Tables 3-3 and 3-4. This mass balance is a rough estimation since it considers that the bulk density did not change during the experiment, which is not entirely correct due to the shrinkage behavior of the samples and the differences in the type of organic matter occurring during ripening. Still, the water balance summarized on these tables gives an insight on the little effect of the mixtures on the water holding capacity.

The aggregate stability index of the fraction $2-4 \mathrm{~mm}$ is slightly higher than the fraction 1-2 $\mathrm{mm}$ (Table 3-4).

The addition of $C$ and $M$ to $S$ resulted in significantly higher undrained shear strength (Table 34 ) for $S+C$ and $S+M$ than for $S$. While for $S$ the undrained shear strength after dewatering and biochemical ripening was not enough to sustain cattle or tractors (Table 3-1), for $S+C$ and $S+M$ it was enough. The undrained shear strength could not be determined for samples $C$ and $M$ since these had no structure.

Table 3-4: Aggregate stability ( $\mathrm{g}_{\text {stable aggregates }} / \mathrm{g}_{\text {dry matter }}$ ) and Undrained shear strength $(\mathrm{kPa})$ after biochemical ripening

\begin{tabular}{lccc} 
& $\begin{array}{c}\text { Aggregate stability }(\mathrm{g} / \mathrm{g}) \\
\text { Fraction 1-2 mm }\end{array}$ & $\begin{array}{c}\text { Aggregate stability }(\mathrm{g} / \mathrm{g}) \\
\text { Fraction 2-4 } \mathrm{mm}\end{array}$ & $\begin{array}{c}\text { Undrained shear } \\
\text { strength }(\mathrm{kPa})\end{array}$ \\
\hline $\mathbf{S}$ & 0.97 & 0.99 & 84.3 \\
$\mathbf{S + C}$ & 0.97 & 0.99 & 235.9 \\
$\mathbf{S + M}$ & 0.93 & 0.96 & 266.2
\end{tabular}




\subsection{Discussion}

The total organic carbon (TOC) represents more than $70 \%$ of the total carbon (TC) for all samples, both before dewatering and after biochemical ripening. During biochemical ripening, the TC decreased less for the mixtures $\mathrm{S}+\mathrm{C}$ and $\mathrm{S}+\mathrm{M}$ than for the control $\mathrm{S}$. Both fractions of TC, TOC and MINeral Carbon (MINC), decreased during biochemical ripening and the correlation coefficient between the decrease in TOC and the decrease in MINC is 0.56 , indicating no strong correlation.

The discussion of the results focus on TOC not only because it represents more than $70 \%$ of the TC but also because this is the most reactive fraction to environmental changes such as temperature, moisture, oxygen levels, $\mathrm{pH}$, and nutrients availability (Coleman et al. 2004).

The objective of adding Compost (C) or Manure (M) to Dredged sediments (S) was to double the organic matter content of the sediments and the TOC of $S+C_{a}$ ) and $S+M_{a}$ ) confirms that this was achieved.

The addition of compost to sediments results in higher decrease in TOC than the addition of manure (Figure 3-2), i.e., the addition of compost and manure have different effects on the behavior of sediments during biochemical ripening.

Regarding the $\mathrm{RC}$ and $\mathrm{PC}$, the mixture $\mathrm{S}+\mathrm{C}$ has similar behavior as $\mathrm{S}$ but the mixture $S+M$ results in less decrease in both $R C$ and PC than $S$. Furthermore, RC decreased more for $S+C$ than the estimated from the controls, and PC decreased less for S+M than the estimated from the controls (Figure 3-2). All samples had higher RC (oxidizable organic carbon) than PC (pyrolysable hydrocarbons), both before dewatering and after biochemical ripening. RC represents a more stable fraction of organic carbon than PC. 
Both $\mathrm{S}+\mathrm{C}$ and $\mathrm{S}+\mathrm{M}$ had an increase in $\mathrm{HI}$ and a decrease in $\mathrm{OI}_{\mathrm{RE} 6}$ during biochemical ripening which indicates that the mixtures resulted in the mineralization of organic matter. The mixture $\mathrm{S}+\mathrm{C}$ had smaller decrease in $\mathrm{HI}$ than $\mathrm{S}$ while $\mathrm{S}+\mathrm{M}$ had higher decrease in $\mathrm{HI}$ than $\mathrm{S}$, which indicates that the addition of $M$ to $S$ results in higher rate of mineralization while the addition of $C$ to $S$ results in lower rate of mineralization. Both $\mathrm{S}+\mathrm{C}$ and $\mathrm{S}+\mathrm{M}$ had higher decrease in $\mathrm{OI}_{\mathrm{RE} 6}$ than $\mathrm{S}$ which indicated that both the addition of $C$ and $M$ to $S$ result in higher rates of mineralization of oxygen-bearing compounds (Figure 3-3).

$M_{a}$ had the highest TOC and $\mathrm{HI}$, and lowest $\mathrm{OI}_{\mathrm{RE} 6}$ content before dewatering, indicating that this was the sample with highest content of easily degradable organic matter. During biochemical ripening, $M$ had the smallest decrease in TOC, had a decrease in PC, was the only with an increase in RC, and was the only sample with a decrease in $\mathrm{HI}$ and increase in $\mathrm{OI}_{\mathrm{RE} 6}$, which indicates that humification occurred for the control $\mathrm{M}$.

The mixtures $\mathrm{S}+\mathrm{C}$ and $\mathrm{S}+\mathrm{M}$ resulted in higher $\mathrm{CO}_{2}$ production and $\mathrm{O}_{2}$ consumption per gram of TOC than the controls $S, C$ and $M$, i.e., there was a positive priming effect. The mixture $S+M$ had higher total $\mathrm{CO}_{2}$ production and $\mathrm{O}_{2}$ consumption per gram of TOC than the mixture $\mathrm{S}+\mathrm{C}$, which goes in line with the higher decrease of $\mathrm{HI}$ for $\mathrm{S}+\mathrm{M}$ than $\mathrm{S}+\mathrm{C}$. Both mixtures resulted in higher decrease in PC than could be expected from the emissions of the individual parts. The mixture $S+M$ had significantly higher decrease in PC than estimated from the individual parts. These results are indicative of a positive priming effect, i.e., there is more $\mathrm{CO}_{2}$ production and $\mathrm{O}_{2}$ consumption during the biochemical ripening of the mixtures $S+C$ and $S+M$ than during the biochemical ripening of the controls $S, C$, and $M$. Furthermore, the HI increased much more for $\mathrm{S}+\mathrm{M}$ than estimated from the controls, and the $\mathrm{OI}_{\mathrm{RE} 6}$ decreased more for $\mathrm{S}+\mathrm{C}$ and $\mathrm{S}+\mathrm{M}$ than estimated from the controls 
(Figure 3-3). Therefore, the addition of $M$ to $S$ seems to enhance the increase in hydrocarbons and decrease in oxygen-bearing compounds which is also indicative of a positive priming effect. Other authors found that the magnitude and direction (positive or negative) of the priming effect depend on the soil type, type of organic matter added and also on the period over which measurements are made (Cely et al. 2014, Zimmerman et al. 2011). The results of this research confirm the mixture $S+M$ results in more changes in the type of organic matter than the mixture $\mathrm{S}+\mathrm{C}$. When transferring the sediments, compost and manure to the experimental conditions, the equilibrium of the organic matter of the three amendments is disturbed and transformations occur until a new equilibrium is reached (Coleman et al. 2004). Since the $\mathrm{CO}_{2}$ production and $\mathrm{O}_{2}$ consumption did not achieve a constant rate, a longer experiment could give more information.

The molar ratio $\left[\mathrm{CO}_{2}\right]:\left[\mathrm{O}_{2}\right]$, also designed as respiratory quotient, ranged from 0.63 for $S$ and $M$ to 0.91 for $S+M$, suggesting that aliphatic organic compounds, amino acids, or refractory components containing relatively little oxygen were predominantly mineralized (Dilly 2001).

The determination of the organic matter content of the samples using the loss on ignition (LOI) method did not show a significant change during dewatering and biochemical ripening. This was also observed in previous studies where biochemical ripening of dredged sediments, with similar organic matter content and particle size distribution, was performed for longer periods (Oliveira et al. 2016). The standard deviation of organic matter content determined by the LOI method was used as a confirmation about the homogeneity among the replicates.

TN decreased $18 \%$ for $S+C$ and $22 \%$ for $S+M$, suggesting there was a positive priming effect for $S+C$ and $S+M$ (Kuzyakov et al. 2000), i.e., the mixtures resulted in higher decrease in TN than the controls.. For TP 
and TS, the changes were less than $7 \%$ and therefore can be considered negligible.

The mixture $\mathrm{S}+\mathrm{M}$ had higher $\mathrm{CO}_{2}$ production and $\mathrm{O}_{2}$ consumption per gram of organic matter than the mixture $\mathrm{S}+\mathrm{C}$ which can be related with the higher TN and TP content, indicating the role that nutrients have in microbial activity. This contradicts the hypothesis that the priming effect is lower when nutrients availability is higher (Fontaine et al. 2011).

Some previous studies with soils amended with swine manure found a positive priming effect (Angers et al. 2010, Bernal \& Kirchmann 1992, Kotzerke et al. 2008). Even though, a previous study with a loamy soil with $8 \mathrm{mgc} / \mathrm{g}_{\text {soil }}$ and $0.9 \mathrm{mg} / \mathrm{g}_{\text {soil }}$ amended with swine manure with 263 $\mathrm{mg}_{\mathrm{c}} / \mathrm{g}$ and $27.3 \mathrm{mg}_{\mathrm{N}} / \mathrm{g}$, did not find a significant change in the $\mathrm{CO}_{2}$ dynamics between the control soil and the amended soil (Dendooven et al. 1998), evidencing that different initial $\mathrm{C}$ and $\mathrm{N}$ content result in different priming effects. Different studies have shown that the addition of compost to soils, including soils with organic contaminants, increases the rate of $\mathrm{C}$ and $\mathrm{N}$ mineralization (Borken et al. 2002, Gandolfi et al. 2010, Hupe et al. 1996). The results of this research confirm that the impact of compost and manure is highly variable since it depends on the type of the organic matter, nutrients content and maturity of the material.

The volume of sample lost during dewatering was $41 \%$ for S, $30 \%$ for $\mathrm{S}+\mathrm{C}$ and $40 \%$ for $\mathrm{S}+\mathrm{M}$. All volume lost was due to water removal since no significant decrease in organic matter content was observed. From this result, we can attribute the loss in volume to water loss and compaction and not to organic matter oxidation as reported in a previous study (Schothorst 1977).

Most water was removed within the initial 48 hours. The initial geotechnical water content of $\mathrm{S}$ was more than $350 \%$ (mass of water per mass of dry sample) due to the sampling method and the natural 
dewatering could take several weeks (Vermeulen et al. 2003, Zentar et al. 2011). During biochemical ripening the water content did not significantly change for any sample since a saturated salt solution of $\mathrm{KNO}_{3}$ was used to keep the relative humidity constant and to avoid condensation.

The aggregates formed during biochemical ripening are very stable to water erosion. The fraction 2-4 $\mathrm{mm}$ has slightly more stable aggregates than the fraction 1-2 mm. An explanation for this is that soil aggregates protect occluded organic matter against degradation (Chaplot \& Cooper 2015, van Lützow et al. 2006). Improvement of aggregate stability was confirmed when repeated application of compost and manure to soil increased the aggregate stability (Annabi et al. 2011).

The mixtures $\mathrm{S}+\mathrm{C}$ and $\mathrm{S}+\mathrm{M}$ resulted in an undrained shear strength higher than $S$ alone. While for $S$ the undrained shear strength after dewatering and biochemical ripening was not enough to sustain cattle or tractors (Table 3-1), for $S+C$ and $S+M$ it was enough. Therefore, the addition of $\mathrm{C}$ and $\mathrm{M}$ might also decrease the period between spreading the sediments and re-using the land.

\subsection{Conclusions}

Most volume lost during ripening can be attributed to the loss of water and not to the loss of organic matter, indicating that spreading sediments, compost and manure to agriculture soils is a suitable approach to reverse the process of land subsidence. The results of this research confirm that the impact of compost and manure on the ripening of dredged sediments is highly variable since it depends on the type of the organic matter, nutrients content and maturity of the material. The results for the control manure indicate a humification of the organic matter, with transformation of the organic matter into amorphous humic compounds, while the results for all other samples 
indicate a mineralization of the organic matter, with transformation of organic matter into inorganic compounds. The results indicate that more changes in the type of organic matter occur when sediments are mixed with compost or manure fraction than it could be expected from the changes in the individual parts, which indicated a positive priming effect. Since the $\mathrm{CO} 2$ production and $\mathrm{O} 2$ consumption were still ongoing, a longer duration of the biochemical ripening experiment could give more information about the long term effect of adding compost or manure to sediments. Using suction to dewater the samples, most dewatering occurs within the first 48 hours which allows for short term experiments on a lab scale. After biochemical ripening, the control sample of sediments and the mixtures of sediments and compost or manure are very resistant to water erosion which is indicated by the high aggregate stability of the samples. The mixtures resulted in and undrained shear strength 3 times higher than the measured for the control $\mathrm{S}$ which is an important improvement compared to the regular spreading of sediments on land and reduces the time between application of sediments and reuse of the land.

\section{Acknowledgements}

This research is supported by the Dutch Technology Foundation STW, which is part of the Netherlands Organisation for Scientific Research (NWO), and which is partly funded by the Ministry of Economic Affairs, via the perspective program BioGeoCivil (grant 11344). We would like to express gratitude to Guido Verweij from Hoogheemraadschap van Schieland en de Krimpenerwaard (HHSK) for supporting with sampling of sediments; Adrie Veeken from Attero for providing compost; and Maria Briglia from Aqua Purga for proving the manure fraction. 


\section{Supplementary Material of Chapter 3}

Supplementary Material Table 3-1: Same as Supplementary Material Table 2-1

Supplementary Material Table 3-2: Decrease (\%) in PC, RC, TOC, HI and $\mathrm{OI}_{\text {RE6 }}$ during dewatering and biochemical ripening. $S+C$ estimated and $S+M$ estimated were estimated from S, C, and M, using Eq. 1 and Eq. 2. Negative signal means there was an increase.

\begin{tabular}{llllll} 
& $\mathrm{PC}$ & $\mathrm{RC}$ & $\mathrm{TOC}$ & $\mathrm{HI}$ & $\mathrm{OI}_{\mathrm{RE} 6}$ \\
\hline $\mathbf{S}$ & 30 & 23 & 25 & -16 & 12 \\
$\mathbf{C}$ & 27 & 11 & 17 & 16 & 1 \\
$\mathbf{M}$ & 32 & -6 & 10 & 38 & -36 \\
S+C measured & 28 & 25 & 26 & -1 & 25 \\
S+C estimated & 29 & 18 & 21 & -5 & 10 \\
S+M measured & 5 & 12 & 10 & -46 & 20 \\
S+M estimated & 31 & 11 & 18 & -2 & 7
\end{tabular}

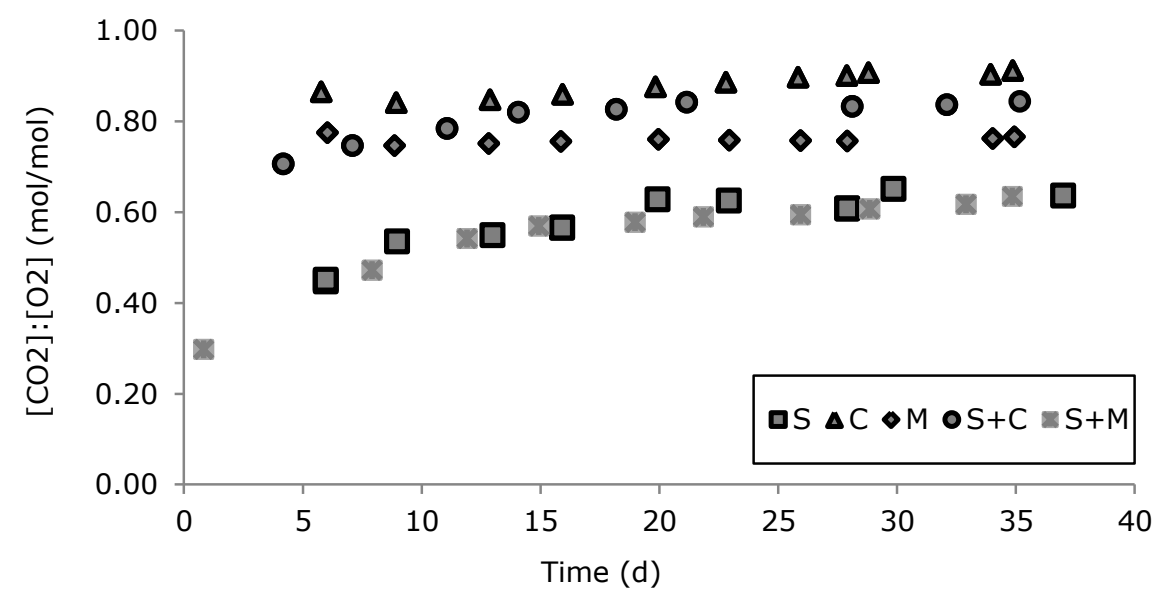

Supplementary Material Figure 3-1: $\left[\mathrm{CO}_{2}\right]:\left[\mathrm{O}_{2}\right](\mathrm{mol} / \mathrm{mol})$ ratio with time. 
Supplementary Material Table 3-3: Water mass balance to the dewatering process

\begin{tabular}{|c|c|c|c|c|}
\hline & & $\mathbf{S}$ & $\mathbf{S}+\mathbf{C}$ & $\mathbf{S}+\mathbf{M}$ \\
\hline Sediments initial & $\mathrm{g}$ & $179.97 \pm 5.71$ & $200.47 \pm 4.65$ & $197.74 \pm 2.71$ \\
\hline Water initial & $g$ & $139.46 \pm 4.43$ & $140.16 \pm 3.25$ & $144.71 \pm 1.98$ \\
\hline Water removed & $\mathrm{g}$ & $73.09 \pm 9.69$ & $59.50 \pm 9.19$ & $79.04 \pm 8.95$ \\
\hline Water removed/Water initial & $\%, g / g$ & $52 \pm 6$ & $42 \pm 7$ & $55 \pm 6$ \\
\hline Water removed/Dry matter initial & $\%, \mathrm{~g} / \mathrm{g}$ & $180 \pm 22$ & $99 \pm 15$ & $149 \pm 16$ \\
\hline Water removed/Total sample initial & $\%, \mathrm{~g} / \mathrm{g}$ & $41 \pm 5$ & $30 \pm 5$ & $40 \pm 4$ \\
\hline
\end{tabular}

Supplementary Material Table 3-4: Water mass balance to the biochemical ripening process

\begin{tabular}{|c|c|c|c|c|c|c|}
\hline & & $\mathbf{s}$ & C & M & $\mathbf{S}+\mathbf{C}$ & $\mathbf{S}+\mathbf{M}$ \\
\hline Sediments initial & $\mathrm{g}$ & $58.55 \pm 4.01$ & $30.04 \pm 4.87$ & $45.47 \pm 3.59$ & $68.32 \pm 1.93$ & $68.15 \pm 2.42$ \\
\hline Water initial & $g$ & $33.38 \pm 2.29$ & $9.54 \pm 1.55$ & $31.44 \pm 2.48$ & $38.15 \pm 1.08$ & $38.89 \pm 1.38$ \\
\hline Sediments final & $\mathrm{g}$ & $57.04 \pm 4.75$ & $29.25 \pm 5.76$ & $46.42 \pm 5.88$ & $66.01 \pm 2.53$ & $66.00 \pm 2.82$ \\
\hline Water final & $\mathrm{g}$ & $31.71 \pm 2.64$ & $9.35 \pm 1.84$ & $31.82 \pm 4.03$ & $37.12 \pm 1.42$ & $36.81 \pm 1.57$ \\
\hline Water removed & $g$ & $1.67 \pm 0.95$ & $0.33 \pm 0.81$ & $-0.38 \pm 2.56$ & $1.03 \pm 0.77$ & $2.08 \pm 0.53$ \\
\hline Water removed/Water initial & $\%, g / g$ & $5 \pm 3$ & $4 \pm 8$ & $-1 \pm 8$ & $3 \pm 2$ & $5 \pm 1$ \\
\hline Water removed/Dry matter initial & $\%, g / g$ & $7 \pm 4$ & $2 \pm 4$ & $-2 \pm 18$ & $3 \pm 3$ & $7 \pm 2$ \\
\hline Water removed/Total sample initial & $\%, g / g$ & $3 \pm 2$ & $1 \pm 3$ & $-1 \pm 6$ & $2 \pm 1$ & $3 \pm 1$ \\
\hline
\end{tabular}





\section{Chapter 4}

\section{Subsidence of organic dredged sediments - mesoscale experiments with different water levels}

This Chapter has been submitted as:

Bruna R. F. Oliveira; Martijn P. J. Smit; Huub H. M. Rijnaarts; Tim Grotenhuis: Subsidence of organic dredged sediments - mesoscale experiments with different water levels 



\section{Abstract}

Purpose: To understand the subsidence behaviour of organic dredged sediments, mesoscale experiments of $1 \mathrm{~m}^{3}$ were performed. As the mesoscale experiments allowed to control the water level of the sediments, two scenarios were tested: upland deposits in which the sediments are allowed to dry; and underwater deposits in which the water level is always $2 \mathrm{~cm}$ above the sediments.

Materials and Methods: Organic sediments dredged from the nature area Wormer- en Jisperveld in The Netherlands were used in these experiments. The parameters analysed were the change in volume occupied by the sediments, the weather conditions, the water drained, the plants present, the organic matter content, the type of organic matter, the nutrients and the undrained shear strength.

Results: The subsidence was similar for both scenarios and was mainly caused by water removal and consequent compaction of the sediments. The water balance indicated that evapotranspiration results in higher loss of water than drainage for the upland deposits. The organic matter content and the nutrients content did not significantly change after 400 days of experiment while the type of organic matter changed in the direction of humification. Furthermore, the undrained shear strength increased with time, however after 400 days the undrained shear strength was not enough to sustain cattle or tractor.

Conclusion: Subsidence was mainly caused by water loss and not organic matter mineralization.

\section{Keywords}

Subsidence; Organic dredged sediments; Wetlands; Sediments deposits; Water level management; Underwater deposits; Upland deposits 


\subsection{Introduction}

Peatlands and organic soils store $30 \%$ of the total carbon in soils while covering only $3 \%$ of Earth's surface and therefore peatlands have an essential role in global carbon cycle and should be preserved (FAO and Wetlands International 2012). Land subsidence as a result of water discharge is occurring in many peatlands worldwide (Dawson et al. 2010, Gebhardt et al. 2010, Kolker et al. 2011, Teatini et al. 2011, van Asselen 2011, Wöppelmann et al. 2013). Subsidence in peatlands is mainly a consequence of drainage that results in shrinkage and oxidation of organic matter (Dawson et al. 2010, Gebhardt et al. 2010). Shrinkage refers to the loss of volume occupied by the water (through vertical and horizontal drainage and evapotranspiration) and rearrangement of the particles (including compaction) when the water is removed (Arnold \& Ghezzehei 2015, Ilnicki 2002, Oleszczuk et al. 2003, Schlotzhauer \& Price 1999). The oxidation of the organic matter may lead to the humification or mineralization (Sanei et al. 2005). Humification can be defined as the transformation of SOM into amorphous humic compounds while mineralization refers to the transformation of organically bound elements $(C, N, P, S)$ into inorganic compounds (Sumner 2000, Zech et al. 1997). The accumulation of carbon in peatlands takes place through the humification of organic matter and through plants photosynthesis. The release of carbon in peatlands occurs through the mineralization of organic matter followed by plants respiration (Langeveld et al. 1997).

The drainage of peatlands is commonly done by dense networks of canals and ditches in order to allow agriculture (Hendriks et al. 2007a, Hoogland et al. 2012). These waterways have to be periodically dredged due to the accumulation of sediments that originate from the surrounding land through water erosion (Tuukkanen et al. 2014) and 
through the horizontal displacement of soft soil due to overburden pressure (Warburton et al. 2004).

A common practice in these areas is to apply the dredged sediments back on the land (Leue \& Lang 2012). When dredged sediments are transferred to upland conditions, the ripening process begins and transforms the waterlogged sediments into an aerated soil (Pons \& Zonneveld 1965). Since many peatlands are now being restored back into wetlands (FAO and Wetlands International 2012) and groundwater level management is one of the strategies used to attenuate or reverse the process of land subsidence in peatlands (Akker et al. 2008, Ballantyne et al. 2013, Berglund \& Berglund 2011, Hoving et al. 2011, Querner et al. 2012), in this study the storage of dredged sediments in upland deposits and in underwater deposits is explored. The underwater deposits are proposed to minimize the aeration of the sediments and therefore minimize the mineralization of organic matter which is thought to be the main cause of subsidence in peatlands (Dawson et al. 2010, Hoogland et al. 2012). Furthermore, it is expected that the buoyancy caused by the higher water level will result in less shrinkage (Alfons et al. 2002). In order to characterize and evaluate the differences in the shrinkage behavior between upland and underwater deposits of sediments, $1 \mathrm{~m}^{3}$ experiments were performed and the monitored parameters were the volume occupied by the sediments, water content, water drained from the system, organic matter content, type of organic matter (Rock-Eval), nutrients, plant growth, and undrained shear strength. 


\subsection{Material and Methods}

\subsubsection{Dredged sediments}

The sediments were dredged in the Wormer- and Jisperveld nature area in the province Noord-Holland, in the Netherlands. According to the World Reference Base for soil resources classification, the soils in the area are classified as histosols (WRB 2014). Currently the area is a protected wetland and is mostly used for animal husbandry and various recreational activities (Natuurmonumenten 2015). The sediments were dredged by the water board Hoogheemraadschap Hollands Noorderkwartier (HHNK) from a small ditch using a crane, placed in four-one cubic meter containers and sent to the laboratory. Within 24 hours after dredging, the sediments were received at the laboratory on March $19^{\text {th }} 2014$ and transferred to the final experimental setup. The sediments were left to settle until March $24^{\text {th }} 2014$, which is considered the day 0 of the experiment. The experiment was monitored for 443 days, until June $10^{\text {th }} 2015$.

The particle size distribution of the mineral fraction of the sediments was determined by first air-drying and then removing the organic matter with $\mathrm{H}_{2} \mathrm{O}_{2}$ and the $\mathrm{CaCO}_{3}$ with $\mathrm{HCl}$. The particle size distribution was determined following the ISO standard ISO/TS 17892-4:2014. Fractions $<2 \mu \mathrm{m}, 2-16 \mu \mathrm{m}$, and $16-50 \mu \mathrm{m}$ were determined by the pipet method and fraction 50-63 $\mu \mathrm{m}$ was determined by wet sieving at the Soil Chemical Biological Soil Laboratory (CBLB) of Wageningen UR. The fractions 63-105 $\mu \mathrm{m}, 105-150 \mu \mathrm{m}, 150-210 \mu \mathrm{m}, 210-420 \mu \mathrm{m}$, and 420$2000 \mu \mathrm{m}$ were determined by dry sieving by the Soil Physics laboratory of Wageningen UR. According to the ISO/TS 17892-4:2014, the sediments can be classified as fine grained and according to the USDA classification system of textural classes the sediments are classified as clay (USDA 1987). 
The fiber content was determined following the standard test method for laboratory determination of the fiber content of peat samples ASTM D1997-91(2008). The fiber content of the sediments is $25,9 \mathrm{mg}_{\text {dry }}$ fibers $/ g_{\text {dry sample. }}$

The $\mathrm{pH}$ of the sediments was determined using a glass electrode without dilution (Soil and Plant Analysis Council Inc. 1999). The pH was 4.28.

\subsubsection{Experimental setup}

The effect of different water tables on the same type of dredged sediments was studied in $1 \mathrm{~m}^{3}$ containers filled with dredged sediments and placed in the open air outside the laboratory.

The containers used for the meso-scale experiments were made of PVC and the top was opened to the atmosphere (Figure 4-1). At the bottom of the containers a drainage system and a stand-pipe were installed. This drainage system consists of a tubing system (internal diameter of $12.5 \mathrm{~cm}$ ) which drains the leachate to a cylindrical deposit $(75 \mathrm{~cm}$ height and $25 \mathrm{~cm}$ diameter). The water level in the leachate deposit was monitored using a Conrad $^{\circledR}$ Overflow protector, version 04/01. The tubing system was covered with a layer of sand of 12 centimeters. To avoid the transfer of fine sediment particles into the sand bed, and therefore the clogging of the drainage system, the sand was covered with a geotextile Polyfelt-TS65 (TENCATE ${ }^{\circledR}$, www.tencate.com). The interface between the sand and sediments is considered as the reference point. 


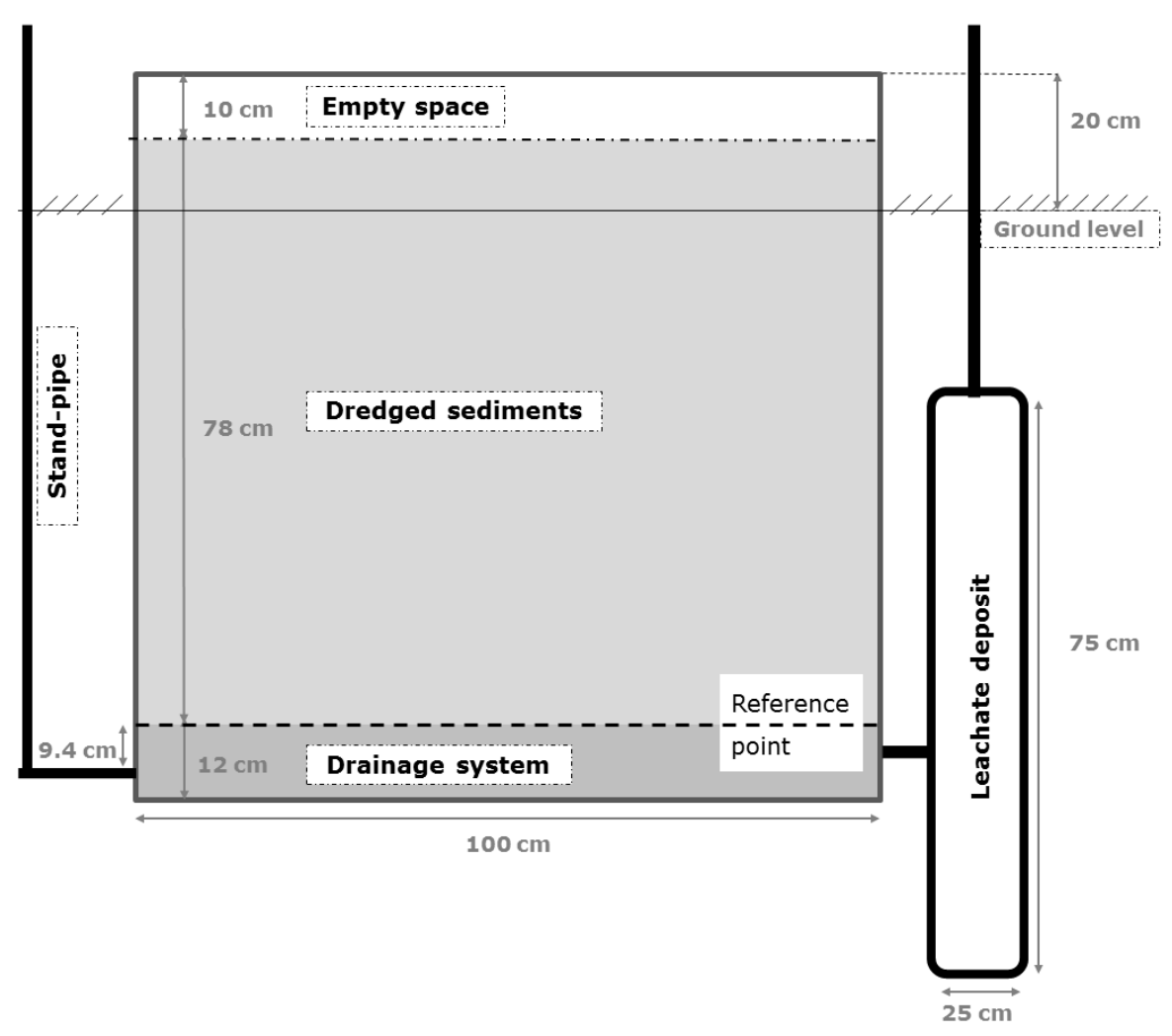

Figure 4-1: Schematic representation of the experimental setup

Four of these $1 \mathrm{~m}^{3}$ containers were prepared corresponding to two different types of deposit: containers $A 1$ and $A 2$ simulate upland deposits of dredged sediments; and containers $B 1$ and $B 2$ simulate underwater deposits. $A 1$ and $A 2$ were allowed to dry throughout the experiment. The leachate deposits of $A 1$ and $A 2$ were emptied 28, 57, $85,124,161$, and 320 days after the start of the experiment to assure that the water level in the leachate deposits was always at least $20 \mathrm{~cm}$ below the top of the sediments. In B1 and B2 a layer of $2 \mathrm{~cm}$ of water was permanently kept above the sediments until day 400 . Between day 400 and day 443 B1 and B2 were allowed to dry. The leachate deposits of $\mathrm{B} 1$ and $\mathrm{B} 2$ were never emptied. 
The setup was placed under the ground and only the top $20 \mathrm{~cm}$ of the container was above the surface. The partial underground position decreases the temperature fluctuation of the sediments, except for the top layer exposed to the atmosphere. The direct sunlight in the deposits was minimal since the setup was placed on the north side of a building at a distance of approximately 2 meters from the building. As the wind direction is mainly from the west, the mesoscale containers were protected from south-west winds. The starting level of the sediments was approximately $10 \mathrm{~cm}$ below the top of the container. The exact level of the sediments was recorded with time to determine the decrease in the volume occupied by the sediments - shrinkage. Due to the underground positioning of the containers, the pressure caused by the heavy load of dredged sediments caused the detachment of the standpipes from the containers during the filling. As a consequence, no results could be obtained from the stand-pipes.

Columns of sediments from top to bottom were sampled on days 52, $129,208,250,320,400$ and 443 after the start of the experiment, using an Eijkelkamp ${ }^{\circledR}$ peat sampler with $54 \mathrm{~mm}$ diameter and $50 \mathrm{~mm}$ length. PVC tubes were used to fill in the space left when a column was taken in order to minimize the impact on the surrounding sediments, especially regarding the oxygen penetration. An effort was made to take samples as far as possible from each other to avoid the interference from previous sampling.

Due to the shrinkage behavior of the sediments it is not possible to follow changes occurring in specific layers with time and therefore it was decided to analyze the sediments from the top to the bottom of the container, in sections of $10 \mathrm{~cm}$. It was decided to refer to the top as 0 because the transformation of waterlogged sediments into aerated soils occurs from top to bottom, due to oxygen penetration. This should be taken in consideration when interpreting the results. 
The weather station De Veenkampen is at a geographic distance of 2.7 $\mathrm{km}$ from the experimental setup. This weather station is managed by the Meteorology and Air Quality Chair Group of Wageningen University and Research Centre, the Netherlands. The average daily precipitation and the average daily temperature $150 \mathrm{~cm}$ above the ground are represented in Figure 4-2.

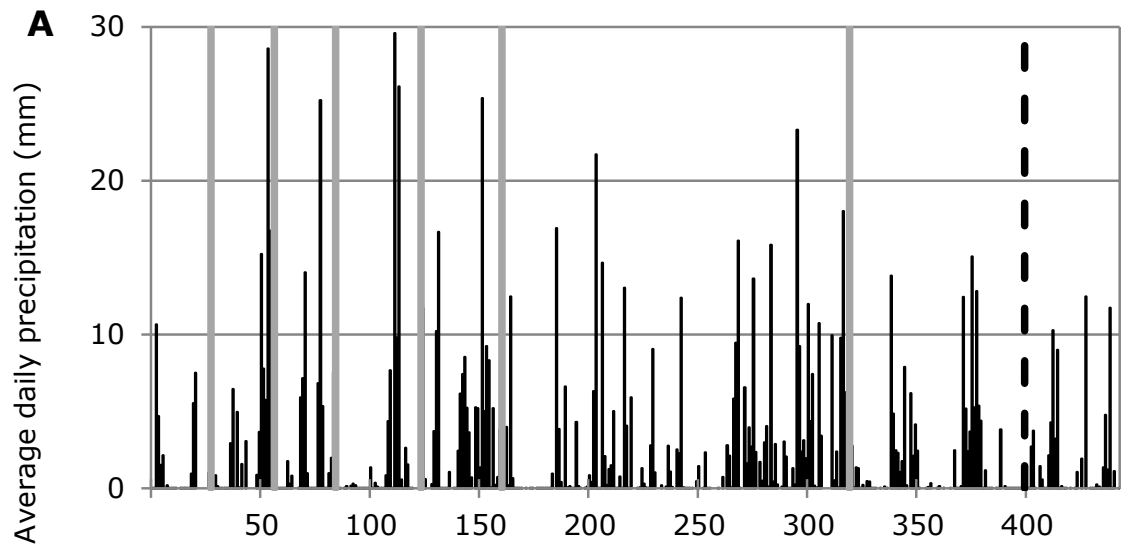

Day

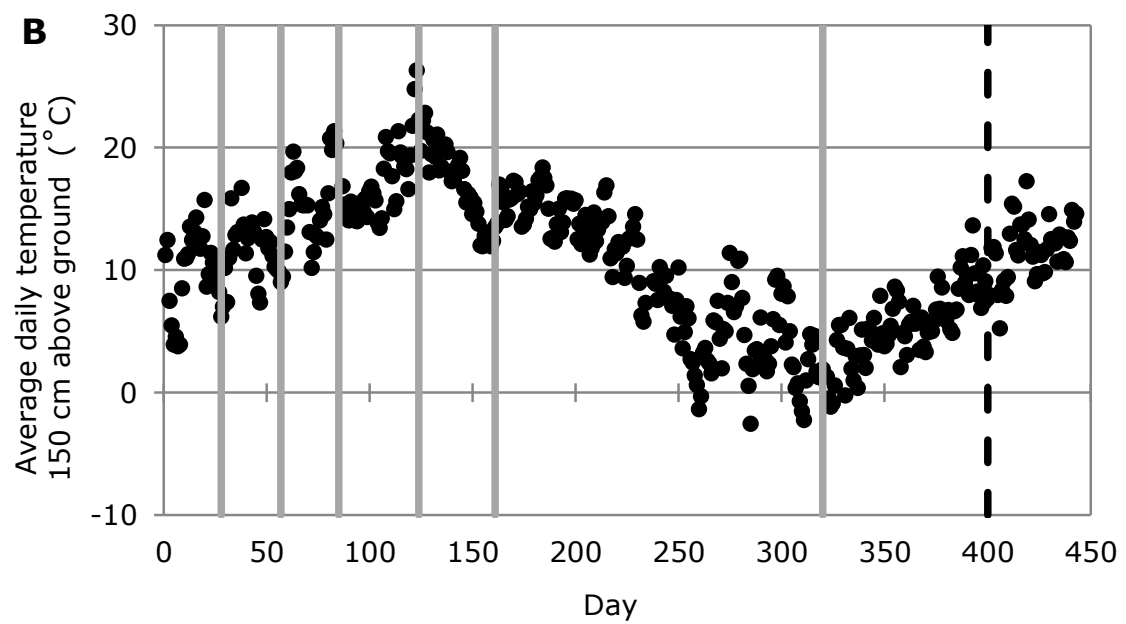

Figure 4-2: A) Average daily precipitation; and B) Average daily temperature $150 \mathrm{~cm}$ above the ground, recorded at De Veenkampen weather station. Vertical grey bars represent the days when the leachate deposits of $A 1$ and $A 2$ were emptied. The vertical dashed black line on day 400 represents the day from which no more water was added on top of the sediments in B1 and B2 


\subsubsection{Analytical methods}

The moisture content and organic matter content were calculated from the oven dry weight of the samples ( 24 hours at $105^{\circ} \mathrm{C}$ ) and the loss on ignition ( $4 \mathrm{~h}$ at $550^{\circ} \mathrm{C}$ ) of the samples (ISO/TS 17892-1:2014). The samples were oven dried at $105^{\circ} \mathrm{C}$ for 24 hours since it is the most common practice in soil sciences (Soil and Plant Analysis Council Inc. 1999, Sumner 2000).

The total C, N, P, and S were determined at the Chemical Biological Soil Laboratory of Wageningen University and Research Centre, The Netherlands. The dredged sediment samples were centrifuged to separate the solid fraction from the supernatant. The supernatant was then filtrated and the colloid fraction collected in the filter was added to the solid fraction. One sub-sample of the solid fraction was digested with the DigiPrep (aquaregia method, according to NEN-69610) and analysed with a Thermo (type iCAP) ICP-AES. Another sub-sample of the solid fraction was used to analyse total organic $\mathrm{C}$ and total $\mathrm{N}$ with a Leco $\mathrm{C} / \mathrm{N}$ analyser. The total $\mathrm{P}$ and total $\mathrm{S}$ of the liquid fraction were analysed with an Varian ICP-AES and the total organic carbon and total nitrogen were analysed with a Skalar Segmented Flow Analyser (SFA).

The type of organic matter was characterized with the Rock-Eval $6^{\circledR}$ method. In the Rock-Eval $6^{\circledR}, 20 \mathrm{mg}$ of sample are heated in pyrolysis and oxidation ovens at a heating rate of $25^{\circ} \mathrm{C} / \mathrm{min}$. The pyrolysis occurs between 100 and $650{ }^{\circ} \mathrm{C}$ under an inert atmosphere of $\mathrm{N}_{2}$. During the pyrolysis, the free hydrocarbons present in the sample and the hydrocarbons released by the thermal cracking of organic matter are detected by the Flame Ionization Detector. Simultaneously, the $\mathrm{CO}$ and $\mathrm{CO}_{2}$ released during thermal cracking of oxygen-bearing organic compounds are measured by Infrared detectors. Following the pyrolysis stage, the sample is transferred to the oxidation oven and heated up to $850^{\circ} \mathrm{C}$ in air, incinerating all the residual organic carbon. The $\mathrm{CO}$ and 
$\mathrm{CO}_{2}$ released during combustion of residual organic carbon are measured by online Infrared detectors (Lafargue et al. 1998). The Total Organic Carbon (TOC) is determined by adding the Pyrolyzed Carbon (PC) to the Residual Carbon (RC). The PC is calculated from the CO released during thermal cracking of the hydrocarbons, pyrolysis up to $500^{\circ} \mathrm{C}$ and the $\mathrm{CO}_{2}$ released during pyrolysis up to $400^{\circ} \mathrm{C}$. The $\mathrm{RC}$ is calculated by summing the $\mathrm{CO}$ and $\mathrm{CO}_{2}$ released during oxidation up to $650^{\circ} \mathrm{C}$. The MINeral Carbon (MINC) is calculated by adding the $\mathrm{CO}_{2}$ released during pyrolysis above $400^{\circ} \mathrm{C}$ (carbonate minerals such as magnesite and siderite) to the $\mathrm{CO}_{2}$ from carbonate decomposition during oxidation phase from $650^{\circ} \mathrm{C}$ to $850^{\circ} \mathrm{C}$ (carbonates such as dolomite and calcite). The Total Carbon (TC) of the sample is the sum of TOC and MINC. The Hydrogen Index ( $\mathrm{HI})$ is calculated from the hydrocarbons released during thermal cracking of hydrocarbons divided by the TOC and therefore represents the amount of hydrogen relative to the amount of organic carbon in the sample. The Oxygen Index (OI) is calculated from the $\mathrm{CO}_{2}$ released during pyrolysis up to $400^{\circ} \mathrm{C}$ and the $\mathrm{CO}$ released during pyrolysis up to $500^{\circ} \mathrm{C}$ and therefore represents the oxygen relative to the amount of the TOC (Lafargue et al. 1998, Sanei et al. 2005). The type of organic matter was determined for the samples at stages a) before dewatering and c) after biochemical ripening. The Rock-Eval $6^{\circledR}$ apparatus from the Dutch Institute Deltares was used.

The evapotranspiration in the setup was calculated using the FAO Penman-Monteith equation, using the net radiation at the crop surface, the soil heat flux density, the mean daily air temperature and wind at 2 $\mathrm{m}$ height, the saturation and actual vapor pressure recorded at the weather station De Veenkampen. This method defines a reference crop as a hypothetical crop with an assumed height of $0.12 \mathrm{~m}$, with a surface resistance of $70 \mathrm{~s} / \mathrm{m}$ and an albedo of 0.23 , resembling a surface of green grass of uniform height actively growing and adequately watered. 
This method is a combination of the original Penman-Monteith equation with aerodynamic surface resistance equations (FAO 1998).

To determine the subsidence of the sediments with time, the height of the sediments was measured at 4 equidistant points in each deposit. Thereafter the volume occupied by the sediments was calculated and compared to the initial volume occupied by the sediments as the relative volume of the sediments.

The dry bulk density was determined after air drying a sample and following the linear measurement method described in the standard ISO 17892-2:2014.

The plants growing in the experimental setup were identified using the (Stichting Flora van Nederland 2014) database.

The undrained shear strength of the remolded $0-10 \mathrm{~cm}$ layer of each container was determined with the fall cone method, following the ISO/TS 17892-6:2004.

\subsubsection{Water balance}

The water drained from the sediments was collected in the leachate deposit and could be quantified [Water drained]. From the geotechnical water content, the volume of water in the sediments could be determined which allows the quantification of the volume of water lost by the sediments throughout the experiment [Water removed from sediments]. Furthermore, during the experiment water was added to the deposits through precipitation [Precipitation] which was recorded at Veenkampen weather station. Therefore, considering that the system did not allow horizontal drainage, the evapotranspiration of the deposits could be estimated:

$[$ Evapotranspiration $]=[$ Water removed from sediments $]+$

$+[$ Precipitation $]-[$ Water drained $]$ 


\subsection{Results}

The relative volume reduction - subsidence - in the upland deposits was $39 \%$ for $\mathrm{A} 1$ and $42 \%$ for $\mathrm{A} 2$, while for the underwater deposits was $35 \%$ for $B 2$ and $37 \%$ for B1 after 400 days of experiment. From day 400 to 443 , no more water was added to the underwater deposits B1 and B2, leading to a subsidence of approximately $40 \%$, which is similar to all containers (Figure 4-3). The settlement period between March $19^{\text {th }} 2014$ (day -5 ) and March $24^{\text {th }} 2014$ (day 0) resulted in a decrease in volume of approximately $10 \%$ for all containers.

Swelling of the sediments was observed after episodes of significant precipitation (Figure 4-2), such as the period between day 50 and 56, and between day 109 and 114 . 


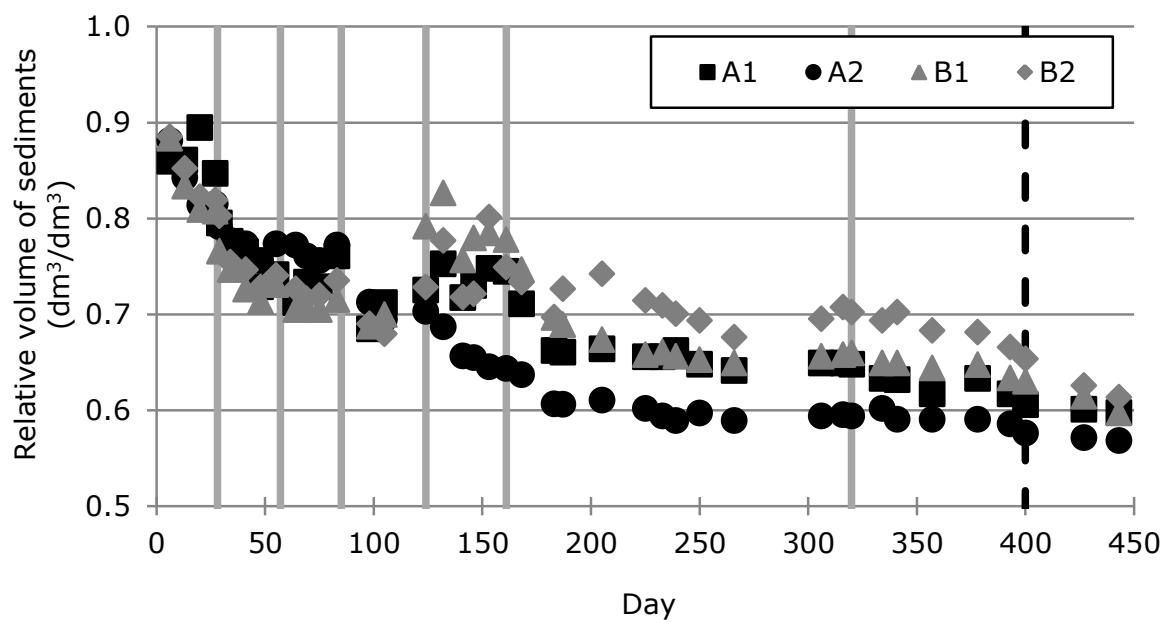

Figure 4-3: Volume of the sediments in relation to the initial volume. Vertical grey bars represent the days when the leachate deposits of $A 1$ and $A 2$ were emptied. The vertical dashed black line on day 400 represents the day from which no more water was added on top of the sediments in B1 and B2

Despite the similar starting conditions of $A 1$ and $A 2$, it could be observed that more water was drained from $A 2$ than $A 1$ (Figure 4-4). Also differences were observed between the drainage of B1 and B2 even though to a less extent. It can also be observed that during the warmer months (Figure 4-2) the cumulative water in the leachate deposits decreases. 


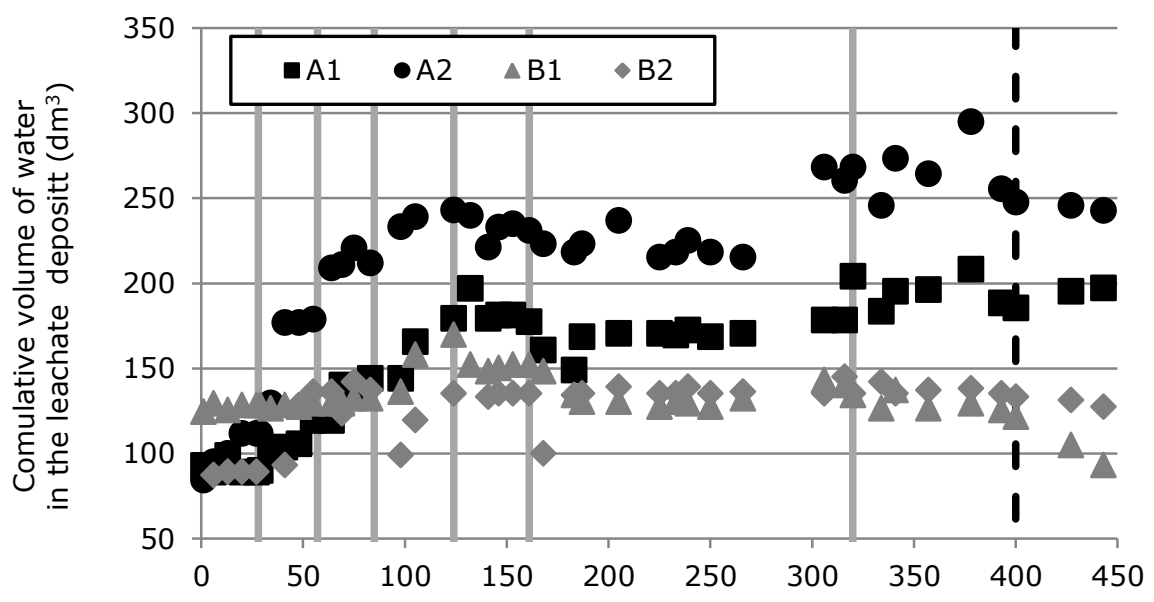

Day

Figure 4-4: Cumulative volume of water in the leachate deposits. Vertical grey bars represent the days when the leachate deposits of $A 1$ and $A 2$ were emptied. The vertical dashed black line on day 400 represents the day from which no more water was added on top of the sediments in B1 and B2

The water content of the sediments on day 0 was on average $898 \%$ $\mathrm{g}_{\text {water }} / \mathrm{g}_{\text {dry matter }}$ for all deposits. The highest decrease in the water content was from day 0 to 52 , with $26 \%$ for $A 1$, and $40 \%$ for $A 2$. $A 1$ and $A 2$ have a vertically homogeneous water content (Figure 4-5).

The water added to maintain the $2 \mathrm{~cm}$ of water on top of the sediments in $B 1$ and $B 2$ had an influence in the water content for all depths (Figure 4-5). A2 had lower geotechnical water content than A1 throughout the experiment which might be related the plants growing in the deposits. 

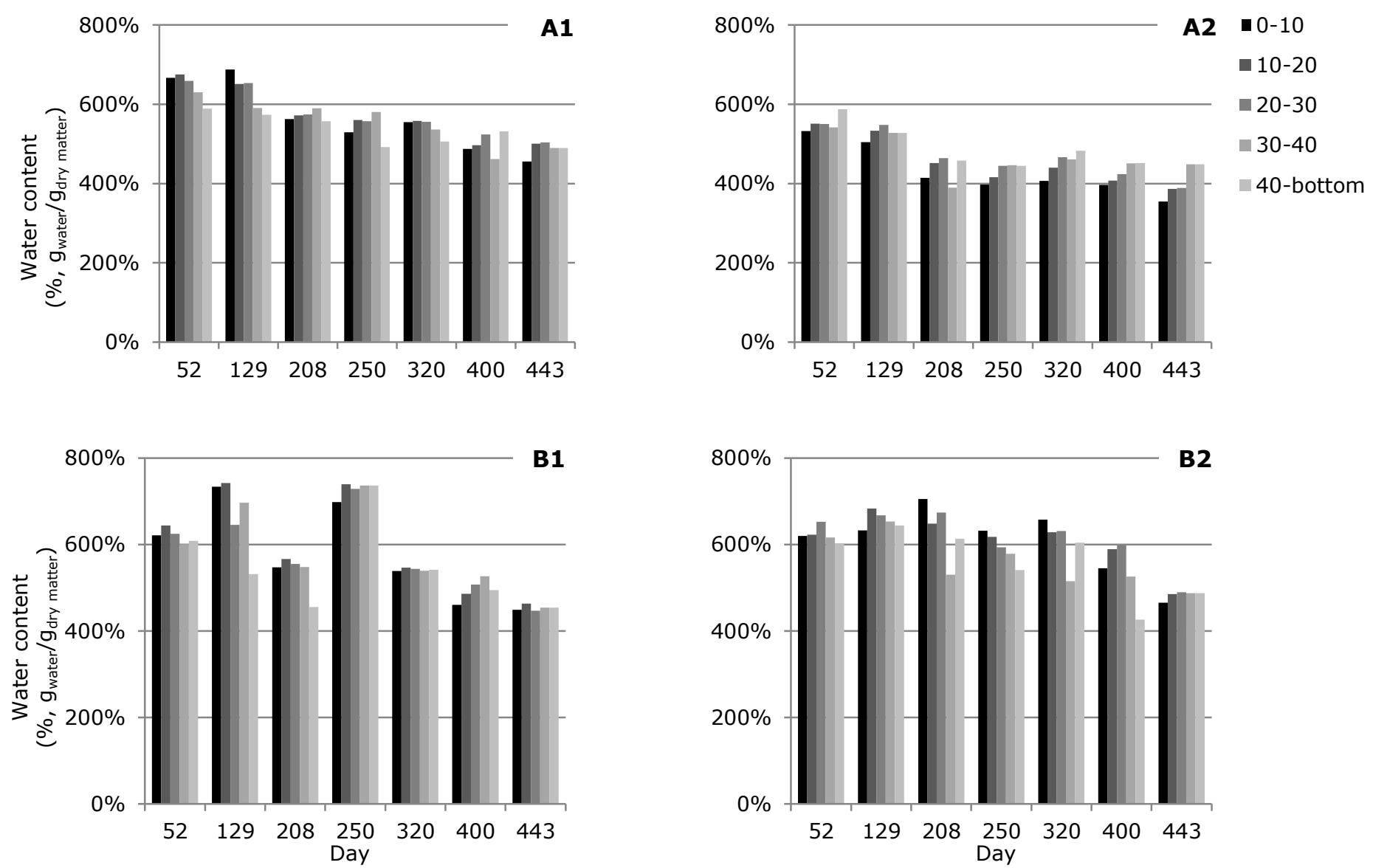

Figure 4-5: Water content $\left(\%, g_{\text {water }} / g_{\text {dry matter }}\right)$ variation in depth with time for $A 1$ and $A 2$ 
The water balance was made for $\mathrm{A} 1$ and $\mathrm{A} 2$. Both containers had similar results, showing that more water was removed through evapotranspiration than through drainage (Table 4-1). Negative values in the water drained mean that the water was transferred back to the sediments deposit, probably due to differences in hydrostatic pressure.

The volume of water added to B1 and B2 was not recorded and therefore the water balance was not made.

Table 4-1: Water balance for experiment A1 and A2: [WRS=Water removed from the sediments $]+[$ PPT $=$ Precipitation $]-[\mathrm{WD}=$ Water drained $]=[\mathrm{ETP}=$ Evapotranspiration $]$

\begin{tabular}{lccccccc} 
Day & \multicolumn{2}{c}{ WRS (I) } & PPT $(I)$ & \multicolumn{2}{c}{ WD (I) } & \multicolumn{2}{c}{ ETP (I) } \\
\hline & A1 & A2 & A1 \& A2 & A1 & A2 & A1 & A2 \\
0 to 52 & 209.4 & 204.3 & 83.3 & 105.8 & 177.0 & 186.9 & 110.6 \\
52 to 129 & 3.6 & 38.5 & 233.6 & 73.6 & 66.1 & 163.6 & 206.0 \\
129 to 208 & 47.2 & 74.7 & 249.1 & -8.8 & -6.2 & 305.1 & 330.0 \\
208 to 250 & 14.0 & 9.4 & 68.7 & -2.0 & -18.6 & 84.7 & 96.7 \\
250 to 320 & 0.1 & -1.4 & 233.6 & 35.5 & 50.1 & 198.2 & 182.1 \\
320 to 400 & 32.7 & 15.2 & 131.5 & -18.6 & -20.6 & 182.8 & 167.3 \\
400 to 443 & 6.9 & 10.8 & 73.9 & 11.8 & -4.9 & 69.0 & 89.6 \\
Cumulative & & & & & & & \\
0 to 443 & 313.9 & 351.5 & 1073.7 & 197.3 & 242.9 & 1190.3 & 1182.3
\end{tabular}

Since no evapotranspiration data is known for the plants growing in the containers (Table 4-2), the evapotranspiration was calculated with the FAO Penman-Monteith equation, using the data recorded at Veenkampen weather station. For the cumulative period from day 0 to 443, the calculated evapotranspiration with the FAO Penman-Monteith method was $730 \mathrm{~mm}$ which underestimates the evapotranspiration determined from the water balance (Table 4-1). 
Table 4-2: General characteristics of the plants. Source: ${ }^{1}$ (Stichting Flora van Nederland 2014) 2 http://plants.usda.gov

\begin{tabular}{|c|c|c|c|c|c|c|c|}
\hline & $\begin{array}{l}\text { Typha } \\
\text { latifolia }\end{array}$ & $\begin{array}{c}\text { Typha } \\
\text { angustifolia }\end{array}$ & $\begin{array}{l}\text { Junkus } \\
\text { effusus }\end{array}$ & $\begin{array}{c}\text { Bolboschoenus } \\
\text { maritimus }\end{array}$ & $\begin{array}{l}\text { Ranunculus } \\
\text { sceleratus }\end{array}$ & $\begin{array}{l}\text { Glyceria } \\
\text { maxima }\end{array}$ & Salix caprea \\
\hline $\begin{array}{l}\text { Height mature } \\
(\max )^{1}\end{array}$ & $2.5 \mathrm{~m}$ & $3 \mathrm{~m}$ & $2.0 \mathrm{~m}$ & $1.5 \mathrm{~m}$ & $0.75 \mathrm{~m}$ & $2 \mathrm{~m}$ & $9 \mathrm{~m}$ \\
\hline Group $^{1}$ & $\begin{array}{l}\text { Aquatic and } \\
\text { marsh plant }\end{array}$ & $\begin{array}{l}\text { Aquatic and } \\
\text { marsh plant }\end{array}$ & $\begin{array}{c}\text { Grass } \\
\text { brassica }\end{array}$ & Grass brassica & $\begin{array}{l}\text { Crowfoot } \\
\text { brassica }\end{array}$ & Grass brassica & $\begin{array}{l}\text { Geranium } \\
\text { and violin } \\
\text { brassica }\end{array}$ \\
\hline Plant form ${ }^{1}$ & Shore plant & Shore plant & Grass & Grass & Shore plant & Grass & Tree \\
\hline $\begin{array}{l}\text { Leaves } \\
\text { (wide) }^{1}\end{array}$ & $3-10 \mathrm{~mm}$ & $1-2 \mathrm{~cm}$ & & $<1 \mathrm{~cm}$ & & $>1 \mathrm{~cm}$ & \\
\hline Leaf shape $^{1}$ & Line-shaped & Line-shaped & $\begin{array}{c}\text { Awl-shaped; } \\
\text { needle } \\
\text { shaped }\end{array}$ & Line-shaped & Incised & Line-shaped & \\
\hline Leaf edge $^{1}$ & Whole & Whole & Whole & Whole & Lobed & Whole & Waved \\
\hline $\begin{array}{l}\text { Underground } \\
\text { parts }^{1}\end{array}$ & Rhizome & Rhizome & Rhizome & $\begin{array}{l}\text { Tuberous } \\
\text { rhizome }\end{array}$ & $\begin{array}{l}\text { Main and } \\
\text { secondary } \\
\text { roots }\end{array}$ & Rhizome & $\begin{array}{l}\text { Mains and } \\
\text { secondary } \\
\text { roots }\end{array}$ \\
\hline Root depth ${ }^{2}$ & $40 \mathrm{~cm}$ & & $60 \mathrm{~cm}$ & $20 \mathrm{~cm}$ & & $1 \mathrm{~m}$ & \\
\hline Stems ${ }^{1}$ & $\begin{array}{c}\text { Erect, } \\
\text { rhizome }\end{array}$ & & $\begin{array}{l}\text { Erect, filled } \\
\text { with marrow }\end{array}$ & $\begin{array}{l}\text { Erects, } \\
\text { triangular }\end{array}$ & $\begin{array}{l}\text { Erect, } \\
\text { smooth }\end{array}$ & Upright & Leaf \\
\hline
\end{tabular}




\section{Chapter 4}

The plant growth was observed at the surface since day 52 in A2, 77 in $A 1,78$ in $B 1$ and 128 in B2. The plants naturally growing (no seeds were added) in the deposits were Typha latifolia, Typha angustifolia, Junkus effuses, Bolboschoenus maritimus, Ranunculus sceleratus, Nasturtium officinale, Glyceria maxima, and Salix caprea (Table 4-2).

The top layer of deposits $\mathrm{A} 1$ and $\mathrm{A} 2$ was exposed to the atmosphere and the plants growing in the 4 deposits transfer oxygen to the system which might lead to oxidation of organic matter. Therefore, also the organic matter quantity and quality were determined.

The organic matter content (OM) in the four deposits varied with time and depth between $40 \%$ and $55 \%$ ( $g_{\text {organic matter }} / g_{\text {dry matter) }}$ (Figure 4-6) and the Total Organic Carbon (TOC) varied with time and depth between

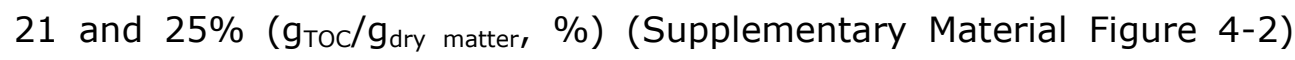
which gives a ratio TOC/OM between 0.43 and $0.53 \mathrm{~g}_{\mathrm{Toc}} / \mathrm{g}_{\text {organic matter }}$ (Figure 4-7). The results for $A 1, B 1$ and B2 show a decrease of the TOC/OM for all depths from day 52 to 320 and a slight increase afterwards. This suggests that the mineralization of organic matter into $\mathrm{CO}_{2}$ was minimal since the variations in the organic matter content can be a consequence of the heterogeneous composition of the sediments. The results obtained for $\mathrm{A} 1$ and $\mathrm{B} 1$ on day 52 suffered from an analysis error, as the samples were in the muffle for 90 minutes instead of 2 hours. The results for the depth $30-40 \mathrm{~cm}$ on day 443 in A2 and B2 reflect a sampling error since some sand from the drainage system was observed in these samples. 

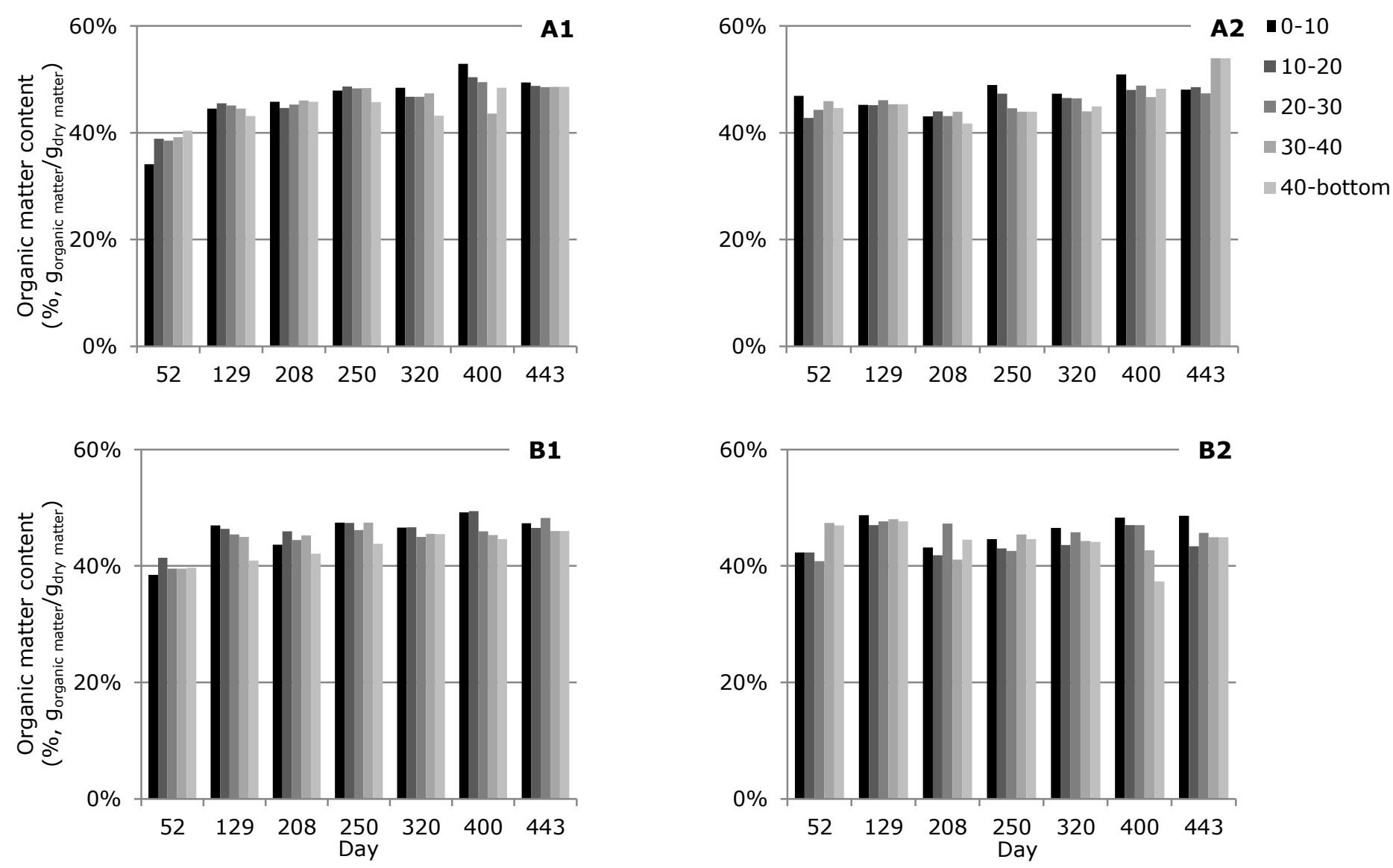

Figure 4-6: Organic matter content $\left(\%, g_{\text {organic matter }} / g_{\text {dry matter }}\right)$ 

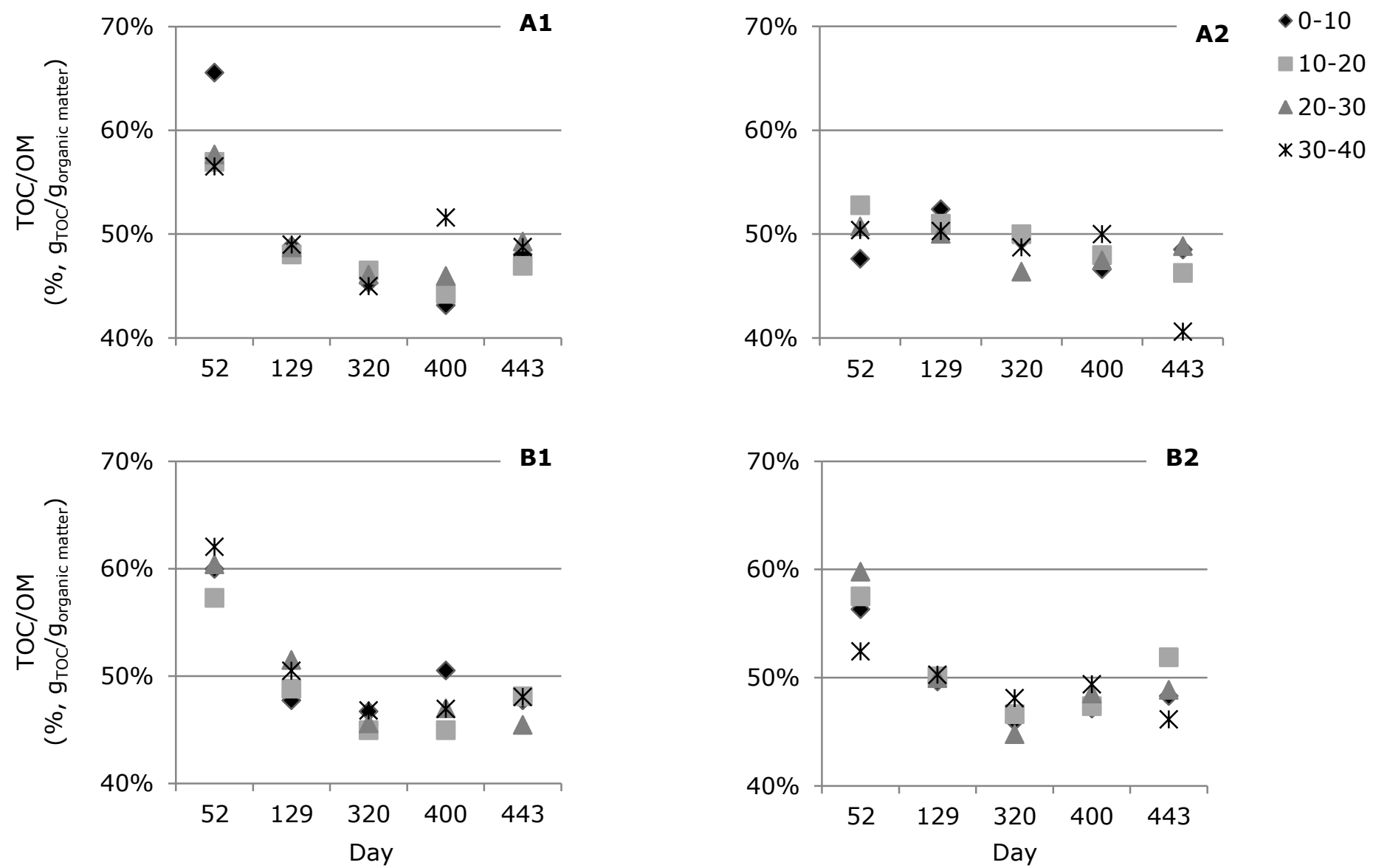

Figure 4-7: Ratio TOC/OM (\%, $\mathrm{g}_{\text {Toc }} / \mathrm{g}_{\text {organic matter }}$ ) 
The average dry bulk density of the sediments on day 0 was determined to be $210 \mathrm{~g} / \mathrm{l}$. From the total volume occupied by the sediments and the water and organic matter content of the sediments, the total mass of water and organic matter on day 0 could be estimated for each container (Table 4-3). Considering the decrease in water content (Figure 4-5) and the decrease in organic matter content (Figure 4-6), it can be considered that the mineralization of organic matter is negligible for the overall decrease in volume (Figure 4-3) of the sediments when compared to shrinkage.

Table 4-3: Estimation of the total mass of water and organic matter in each container on day 0

Volume sediments

Mass sediments

Mass water

Mass of dry matter

Mass of organic matter

\begin{tabular}{lcccc} 
& $\mathrm{A} 1$ & $\mathrm{~A} 2$ & $\mathrm{~B} 1$ & $\mathrm{~B} 2$ \\
\hline $\mathrm{l}$ & 777.3 & 786.6 & 722.5 & 797.4 \\
$\mathrm{~kg}$ & 163.2 & 165.2 & 151.7 & 167.5 \\
$\mathrm{~kg}$ & 141.2 & 139.9 & 130.6 & 144.3 \\
$\mathrm{~kg}$ & 22.0 & 25.3 & 21.1 & 23.2 \\
$\mathrm{~kg}$ & 8.4 & 9.7 & 9.3 & 6.4
\end{tabular}

Even though no significant changes occurred in the organic matter content, the type of organic matter changed with time in all deposits. In general, the Hydrogen Index (HI) decrease and the Oxygen Index $\left(\mathrm{OI}_{\mathrm{RE} 6}\right)$ increase reflect the humification of the organic matter. The major changes in $\mathrm{HI}$ and OI were observed from day 0 to 320 and only slight changes occurred afterwards. No significant difference was observed between the top layer and the bottom layer and also no significant differences were observed between the deposits $A 1$ and $A 2$, and the deposits B1 and B2. In addition, after changing the simulation of underwater deposits to upland deposits after day 400, no significant changes were observed in B1 and B2. This suggests that the root system of the plants could reach the bottom of the deposits and lead to identical changes in the type of organic matter. 


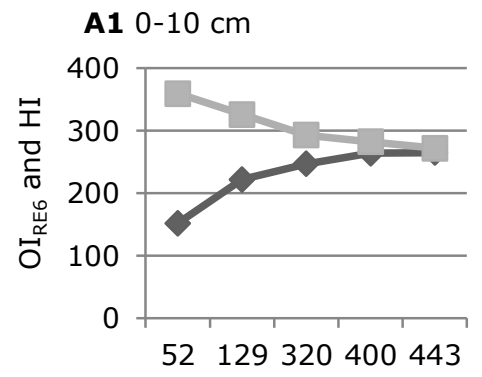

\section{A2 $0-10 \mathrm{~cm}$}

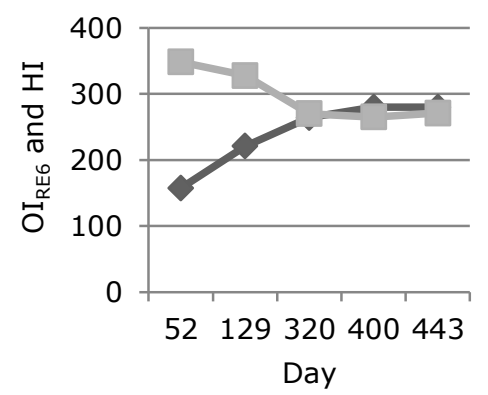

A1 $10-20 \mathrm{~cm}$

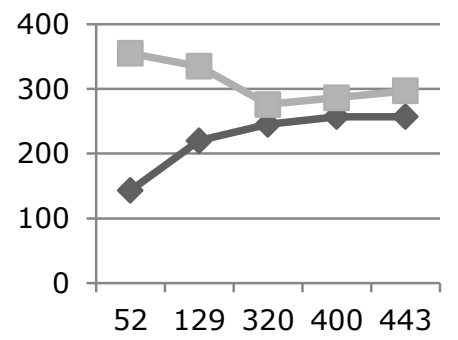

A2 $10-20 \mathrm{~cm}$

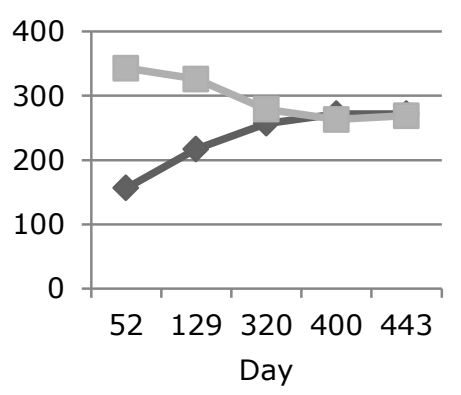

A1 $20-30 \mathrm{~cm}$

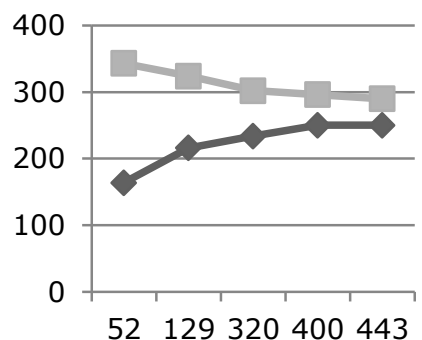

A2 $20-30 \mathrm{~cm}$

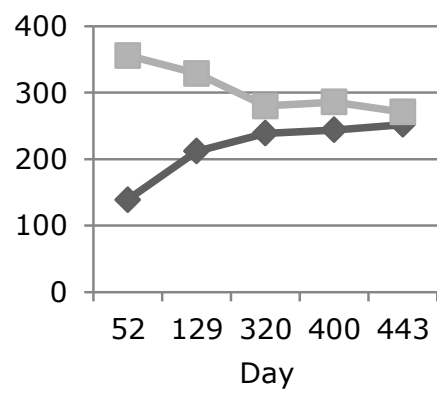

A1 $30-40 \mathrm{~cm}$

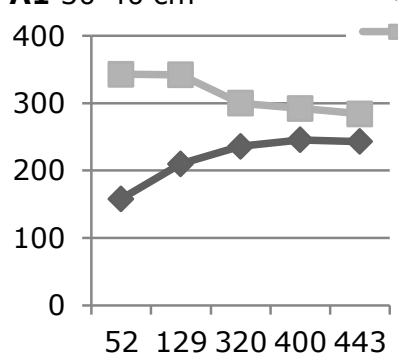

A2 $30-40 \mathrm{~cm}$

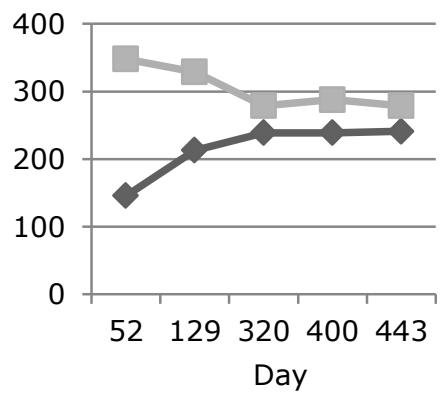

Figure 4-8: Oxygen Index, $\mathrm{OI}_{\mathrm{RE} 6} \mathrm{mg}_{\mathrm{O} 2} / \mathrm{g}_{\mathrm{TOC}}$, and Hydrogen Index, $\mathrm{HI} \mathrm{mg}_{\mathrm{HC}} / \mathrm{g}_{\mathrm{TOC}}$, for $\mathrm{A} 1$ and $\mathrm{A} 2$ 

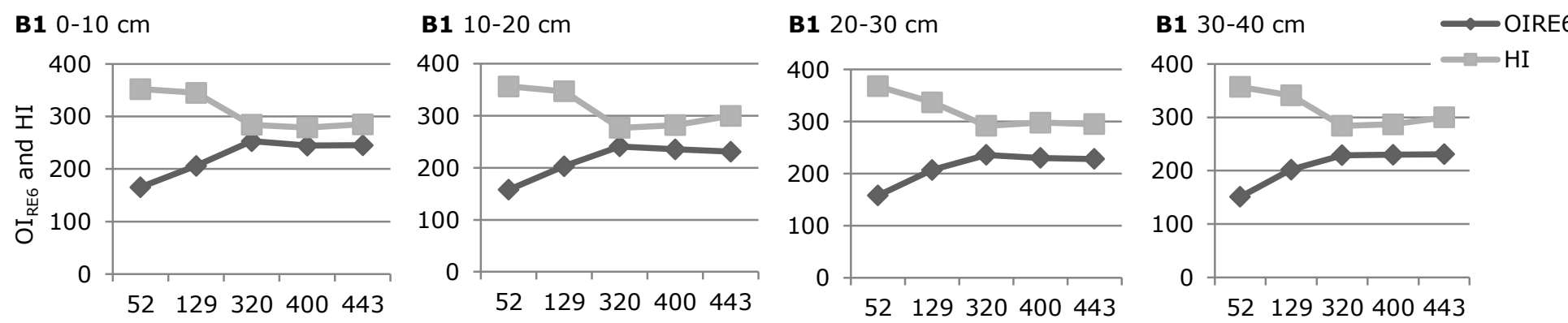

\section{B2 $0-10 \mathrm{~cm}$}

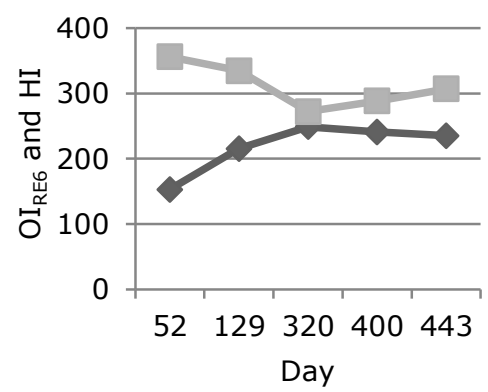

B2 $10-20 \mathrm{~cm}$

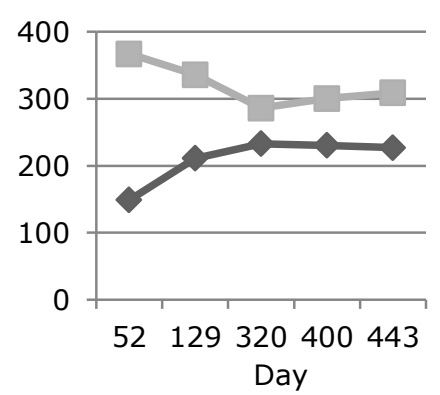

B2 20-30 cm

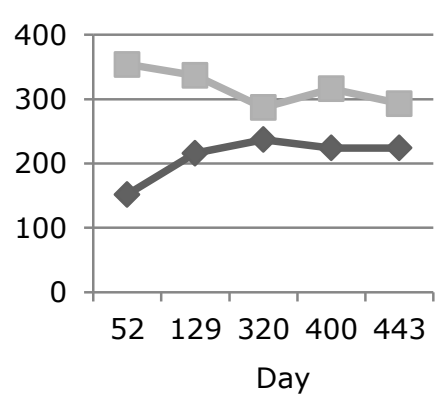

B2 $30-40 \mathrm{~cm}$

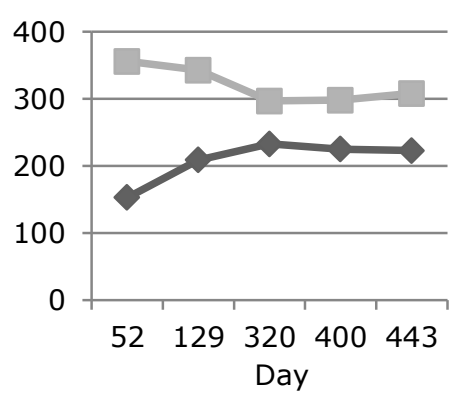

Figure 4-9: Oxygen Index, $\mathrm{OI}_{\mathrm{RE} 6} \mathrm{mg}_{\mathrm{O} 2} / \mathrm{g}_{\mathrm{TOC}}$, and Hydrogen Index, $\mathrm{HI} \mathrm{mg}_{\mathrm{HC}} / \mathrm{g}_{\mathrm{TOC}}$, for $\mathrm{B} 1$ and $\mathrm{B} 2$ 
To further characterize the deposits, the Total Nitrogen (TN), Total Phosphorus (TP) and Total Sulphur (TS) were determined on day 0 and day 443 . On day 0 , a mixed sample representing the average of the four deposits had $14.5 \mathrm{mg} / \mathrm{g}_{\text {dry matter, }} 1.2 \mathrm{mg} / \mathrm{g}_{\mathrm{dry}}$ matter and $23.5 \mathrm{mg} / \mathrm{g}_{\mathrm{dry}}$ matter. The TN, TP and TS variation with depth on day 400 is represented on (Figure 4-10). TN and TP had a vertically homogeneous distribution in the four deposits while the concentration of TS increased with depth, suggesting that sulphur was transported by the water from the top to deeper layers.
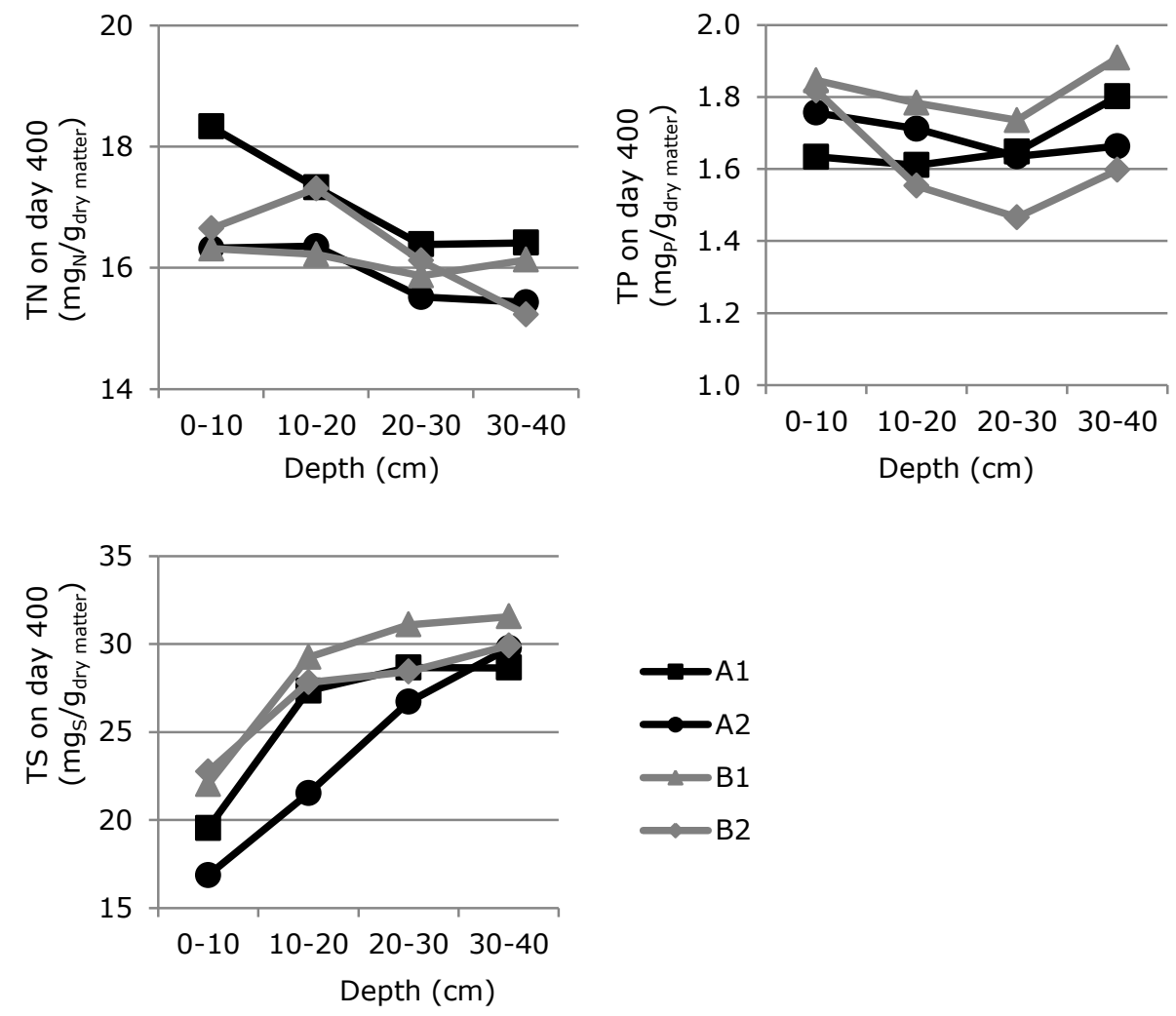

Figure 4-10: Total Nitrogen (TN), Total Phosphorus (TP) and Total Sulphur (TS) on D400

Changes in physical characteristics by measurement of the undrained shear strength showed for the top 0-10 cm layer an increase with time for all deposits (Table 4-3). On D0 the undrained shear strength could 
not be determined since the material had no structure. The undrained shear strength was larger for A2 which was the deposit with a higher density of plants. The deposits B1 and B2, with a higher water level throughout the experiment, had the lowest undrained shear strength.

Table 4-4: Undrained shear strength of the remoulded 0-10 cm layer (cur)

\begin{tabular}{lccc} 
& \multicolumn{3}{c}{$\mathbf{C u r}_{\mathbf{u r}}(\mathbf{k P a})$} \\
Container & Day 250 & Day 400 & Day 443 \\
\hline A1 & 2.61 & 5.63 & 5.83 \\
A2 & 6.65 & 16.00 & 19.29 \\
B1 & 2.86 & 3.39 & 4.18 \\
B2 & 1.08 & 2.82 & 3.09
\end{tabular}

\subsection{Discussion}

The subsidence of the sediments after 400 days was slightly higher for $A 1$ and $A 2$ than for $B 1$ and $B 2$. This suggests that the different water levels studied for organic sediments lead to a lower subsidence as proposed by other authors for peatlands, where subsidence decreased at higher water levels (Hendriks et al. 2007b, Querner et al. 2012, Schouwenaars 2000). Even though, when B1 and B2 were allowed to dry (from day 400 to day 443) the subsidence observed for the 4 containers was similar.

The organic sediments did not shrink continuously as episodes of significant precipitation resulted in the swelling of the sediments which is commonly observed in organic soils (Camporese et al. 2006).

The differences observed in the cumulative water in the leachate deposits are possibly a consequence of the density of plants growing in each container. In addition, since the leachate deposit is in direct connection with the container, the observed decrease of water in the 
leachate deposits is probably consequence of the hydrostatic pressure and the equilibrium of the system.

The subsidence of the sediments is caused by shrinkage, which includes water drained and evapotranspiration, and organic matter mineralization. In this study the quantification of the shrinkage was made with a water balance and the organic matter mineralization was also determined in order to understand the influence of these 2 fractions on subsidence.

The geotechnical water content in A1 and A2 decreased more significantly during the initial 52 days and during the summer than afterwards. This phenomenon is related with the initial sedimentation of the sediment particles that takes place immediately after filling the deposits and has high settling rates (days). The sedimentation is then followed by the consolidation and ripening during which the settling rate of the particles deceases significantly (months) (Vermeulen 2007). Even though the decrease in geotechnical water content followed the same pattern for $A 1$ and $A 2$, the decrease was higher for $A 2$ which might be related with earlier growth of plants. B1 and B2 have a vertically homogeneous geotechnical water content, even after D400. The fluctuation in geotechnical water content in B1 and B2 with depth is a consequence of adding water to maintain the water level $2 \mathrm{~cm}$ above the sediments and therefore the water balance cannot be done for these containers.

The similar subsidence observed for all deposits might be related with the high geotechnical water content observed throughout the experiment which is a consequence of the high water retention capacity of the sediments. Other authors concluded that the geotechnical water content of organic soils cannot be deduced from groundwater levels only, and an important part of the total water storage is caused by swelling/shrinking of the peat (Kellner \& Halldin 2002). A previous study 
with the same sediments gave a very high water retention capacity of $1.12 \mathrm{~cm}^{3}{ }_{\text {water }} / \mathrm{cm}^{3}{ }_{\text {sediments }}$ at $\mathrm{pF}=0$, and $0.71 \mathrm{~cm}^{3}{ }_{\text {water }} / \mathrm{cm}^{3}{ }_{\text {sediments }}$ at $\mathrm{pF}=2$ (Oliveira et al. 2016). This behaviour also explains the decrease in the water drained with time, despite the high geotechnical water content observed for $A 1$ and $A 2$. From the water balance, more water was removed through evapotranspiration (1190.3 I for A1 and 1182.3 I for A2) than through drainage (197.3 I for A1 and 242.9 I for A2) during the 443 days of experiment. The evapotranspiration calculated with the FAO Penman-Monteith equation, using the data recorded at Veenkampen weather station, was $730 \mathrm{~mm}$ for the period from day 0 to day 443 which is smaller than the evapotranspiration determined from the water balance. This difference can be related with an overestimation of the evapotranspiration from the water balance and with the plants growing in the system. The evapotranspiration from the water balance considers the precipitation recorded at the weather station and does not include the attenuation due to the proximity of the deposits to a building (Section 2.2). In addition, the FAO Penman-Monteith equation considers a soil covered with grass and the deposits had different plants growing that can cause higher evapotranspiration than grass. The evapotranspiration is a very difficult parameter to measure or determine accurately (FAO and Wetlands International 2012, STOWA 2009) and therefore the measured water content of the sediment seems to be the most reliable parameter as it is a direct measurement representing the overall result of dewatering by drainage, precipitation and evapotranspiration.

Plants increase the evapotranspiration and play a very important role in wetlands ecology (FAO and Wetlands International 2012). The plants naturally growing in the deposits were Typha latifolia, Typha angustifolia, Junkus effuses, Bolboschoenus maritimus, Ranunculus sceleratus, Nasturtium officinale, Glyceria maxima, and Salix caprea. All plants were observed in the four deposits, i.e., the upland or underwater 
conditions did not affect the diversity and density of plants. Other authors concluded that the water level influences the leaf area and the distribution of plant functional groups which will then influence the evapotranspiration (Moore et al. 2013). Since the four deposits had the same plants, we can expect that the evapotranspiration from B1 and B2 was similar to $A 1$ and $A 2$ and perhaps in a longer experiment differences in the plants would be observed. Still, the container A2 had pants growing earlier than all the others and had the highest subsidence observed. On the opposite side, B2 was the lastest having plants growing and had the lowest subsidence. Therefore, the results indicate that subsidence is influenced by the plants growth.

Regarding the organic matter mineralization fraction of subsidence, the organic matter content in the four deposits varied with time and depth between $40 \%$ and $55 \%$ gorganic matter $/ g_{\text {dry matter }}$ while the Total Organic Carbon (TOC) in the four deposits varied with time and depth between 21 and $25 \% \mathrm{~g}_{\mathrm{Tod}} / \mathrm{g}_{\mathrm{dry}}$ matter. The ratio TOC/OM decreased from D52 to D320 and slightly increased afterwards. This suggests that the mineralization of organic matter into $\mathrm{CO}_{2}$ was minimal since the variations in the organic matter content can be a consequence of the heterogeneous sampling of the sediments. So, it can be concluded that subsidence due to organic matter content mineralization is not significant when compared with the shrinkage. The results for the organic matter and TOC in B1 and B2 were very similar to A1 and A2 despite the different water levels which is opposite to observations in other studies (Ballantyne et al. 2013) and can be related with the geotechnical water content of $\mathrm{A} 1$ and $\mathrm{A} 2$ and a possible consequence of air penetration.

Even though no significant changes occurred in the organic matter content, the type of organic matter changed with time in all deposits. The general decrease in $\mathrm{HI}$ and increase in OI reflect the humification of 
the organic matter. No significant difference was observed between the top layer and the bottom layer which suggests that the roots system of plants could reach the bottom of the deposits and lead to an identical humification of the organic matter during the first 320 days. Also, no significant differences were observed between the replicates $A 1$ and $A 2$, and $B 1$ andB2, and no significant changes were observed in B1 and B2 between days 400 and 443 (when these were allowed to dry).

Other authors found that the shrinkage of organic soils during drying cycles is dependent on the degree of decomposition and on the intensity of drainage (Schwärzel et al. 2002). Since in the present study the organic matter content did not significantly change throughout the experiment, we can expect that the influence of the degree of decomposition of the organic matter had a minimal effect in the overall subsidence.

In order to further characterize the deposits, the Total Nitrogen (TN), Total Phosphorus (TP) and Total Sulphur (TS) were determined. On day 400, TN and TP had a vertically homogeneous distribution in the four deposits while the concentration of TS increased with depth, suggesting that sulphur was transported by the water from the top to deeper layers. The nutrients were not limiting plant growth since other authors found that critical concentrations for plant growth are below 13-14 $\mathrm{mg} / \mathrm{g}_{\mathrm{dry}}$ matter and $0.7 \mathrm{mg} / \mathrm{g}_{\text {dry matter }}$ (Wassen et al. 1995). The microbial diversity in organic soils is characterized by organisms that can cope with the constraining conditions, such as low oxygen availability, cold temperature, acidity and oligotrophy (Andersen et al. 2013). Therefore, it is expected that the microbial activity was not limited by nutrients and microbial diversity was adapted to the conditions.

To know if the deposits of sediments can be used by cattle or tractors, it is necessary to have information about its undrained shear strength. In this experiment the undrained shear strength of the top layer of 
sediments increased with time for all deposits. Even though, the undrained shear strength on day 443 was not enough to sustain cattle (147 kPa/paw) or tractors (118 to $123 \mathrm{kPa} /$ wheel) (Oliveira et al. 2016). A previous lab scale study with the same material has shown an undrained shear strength of $125 \mathrm{kPa}$ after 141 days of biochemical ripening (Oliveira et al. 2016). This difference in results is probably a consequence of the height of the sediments layer since on a lab scale samples had $1.5 \mathrm{~cm}$ in height and in the mesoscale deposits the height went from approximately $78 \mathrm{~cm}$ (Figure 4-1) to approximately $42 \mathrm{~cm}$. This result should have implications in the current practice since it suggests that the land can me more readily used when thin layers of sediments are spread.

This mesoscale setup overcomes the limitations of both laboratory and field experiments. On one hand, the mesoscale experiments are under real weather variations and overcome the boundary conditions of the smaller size laboratory scale. On the other hand, in the mesoscale it is possible to vary the water table while at the same location and under the influence of the same weather conditions, and the water drained from the system can be quantified, which is not possible in the field.

\subsection{Conclusions}

To understand the subsidence behaviour of organic dredged sediments, with the final objective of minimizing it, mesoscale experiments of $1 \mathrm{~m}^{3}$ were performed. The mesoscale experiments allowed to control the water level of the sediments and therefore two scenarios were tested: upland deposits in which the sediments are allowed to dry; and underwater deposits in which the water level is always $2 \mathrm{~cm}$ above the sediments.

The subsidence was similar for both scenarios after 400 days of experiment and most of the volume lost by the sediments corresponded 
to the volume of water collected in the leachate deposit. The similar subsidence observed for all deposits might be related with the high geotechnical water content observed throughout the experiment which is a consequence of the high water retention capacity of the organic sediments.

Together with the possibility of controlling the water level in deposits, another advantage of the mesoscale experiments over field experiments is the possibility to estimate the water balance. The results of the water balance show that more water was lost through evapotranspiration than drainage.

The organic matter content did not significantly change during the experiment while the type of organic matter changed in the direction of humification. The concentration of total nitrogen, phosphorous and sulphur were not limiting plant growth.

Furthermore, the undrained shear strength increased with time but after 400 days it was not enough to sustain cattle or tractor. This result suggests that the land can be more readily used for farming when thin layers of sediments are spread.

Therefore, subsidence was mainly caused by water loss and not organic matter mineralization.

Still, even though patterns can be observed, care should be taken when extrapolating these results to different systems since many variables are involved. 


\section{Chapter 4}

\section{Acknowledgements}

This research is supported by the Dutch Technology Foundation STW, which is part of the Netherlands Organisation for Scientific Research (NWO), and which is partly funded by the Ministry of Economic Affairs, via the perspective program BioGeoCivil (grant 11344). We would like to express gratitude to Karsten Hopman from Hoogheemraadschap Hollands Noorderkwartier (HHNK) for the support with sampling of sediments; Iris de Ronde and Rense Haveman from The Central Government Real Estate Agency - Dutch Ministry of the Interior and Kingdom Relations for the valuable support in the identification of the plants; TenCate ${ }^{\circ}$ for offering the geotextile; Harry Veld from Deltares for the support in the interpretation of the Rock-Eval results; and Leon van Paassen from Technical University of Delft. 


\section{Supplementary Material of Chapter 4}
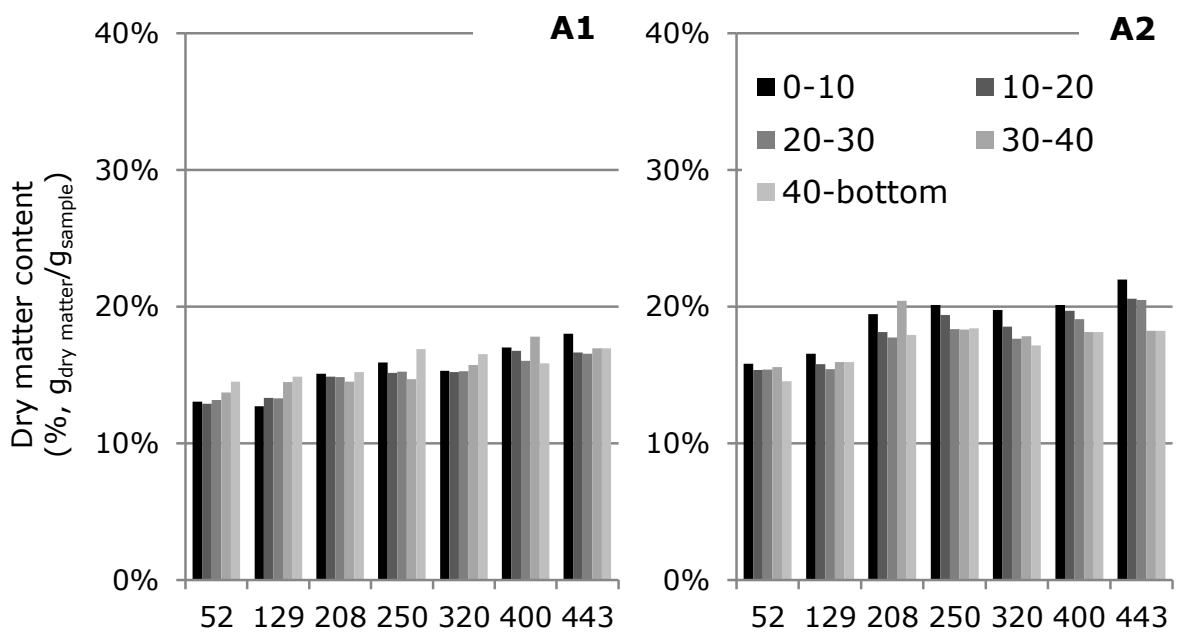

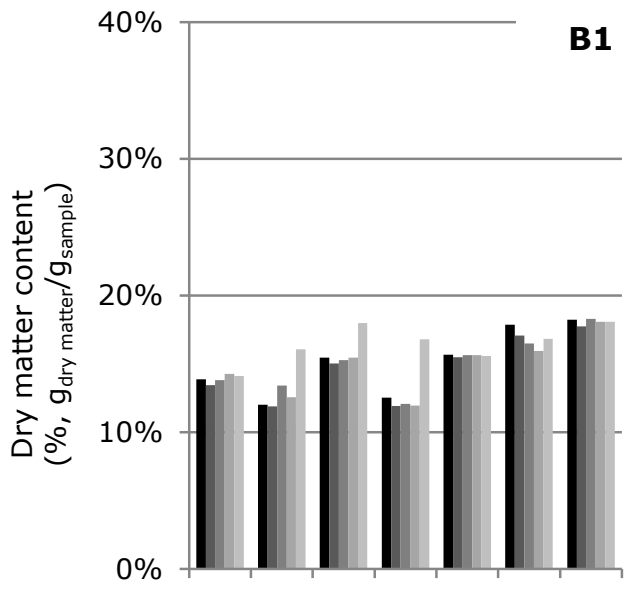

52129208250320400443

Day

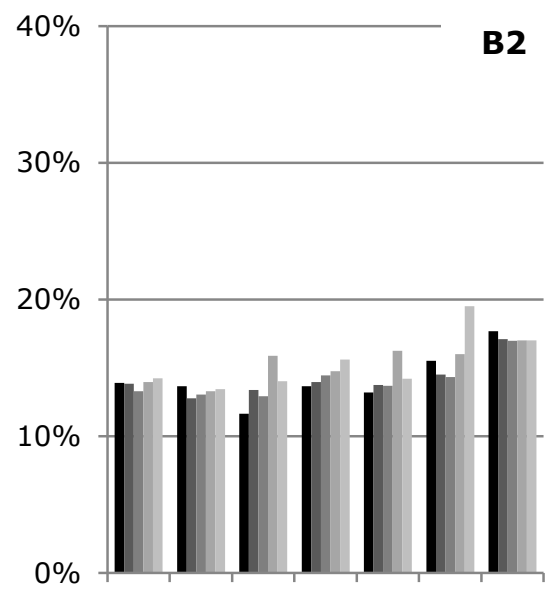

52129208250320400443

Day

Supplementary Material Figure 4-1: Dry matter content $\left(\%, g_{\text {dry matter }} / \mathrm{g}_{\text {sample }}\right)$ 

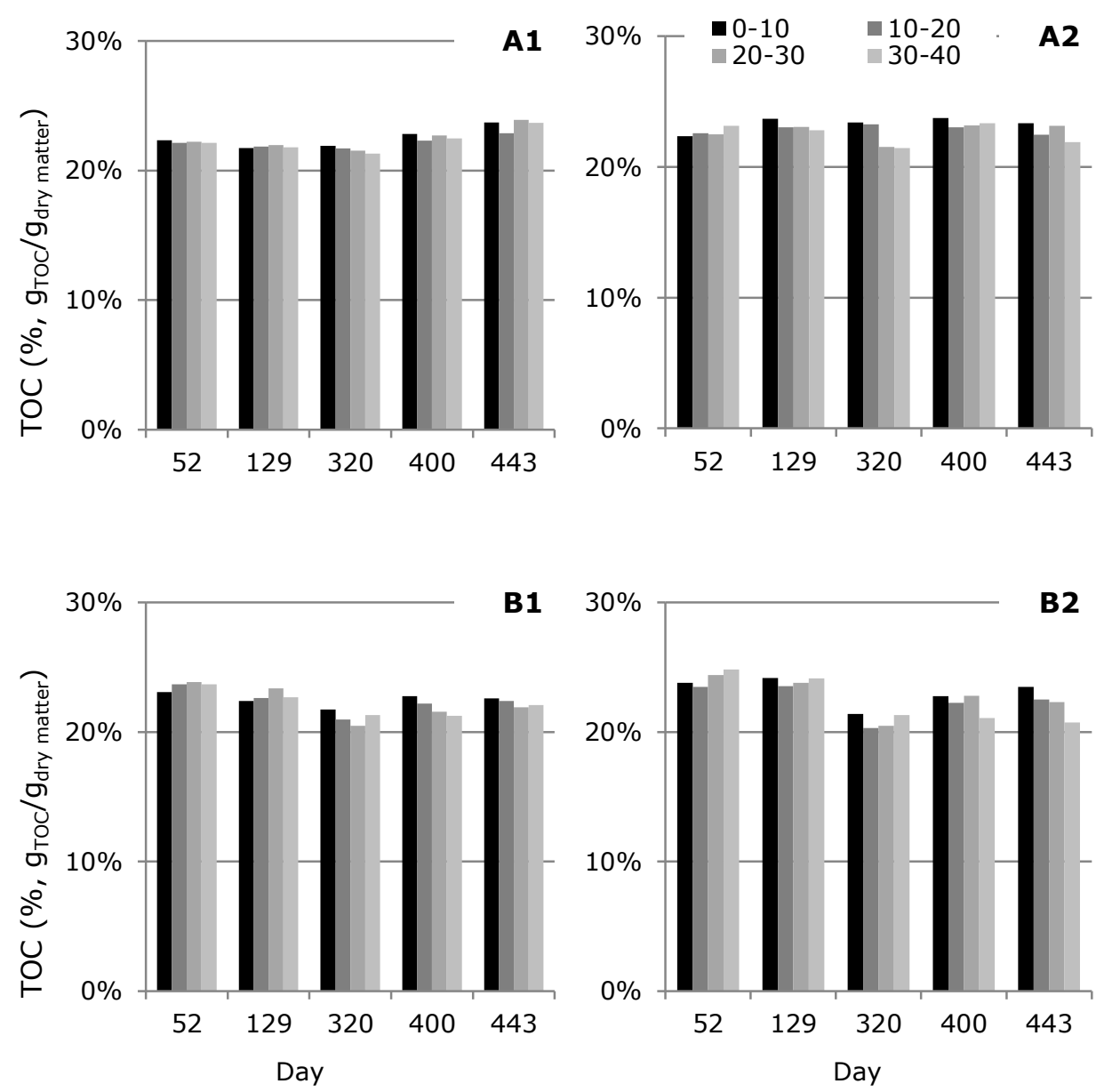

Supplementary Material Figure 4-2: Total Organic Carbon, TOC (\%, $\left.\mathrm{g}_{\text {Toc }} / \mathrm{g}_{\text {dry matter) }}\right)$ 


\section{Chapter 5}

\section{Subsidence of organic dredged sediments in an upland deposit in Wormer- en Jisperveld - North Holland, the Netherlands}

This Chapter has been submitted as:

Bruna R. F. Oliveira; Martijn P. J. Smit; Harry Veld, Leon A. van Paassen; Huub H. M. Rijnaarts; Tim Grotenhuis: Subsidence of organic dredged sediments in an upland deposit in Wormer- en Jisperveld - North Holland, the Netherlands. 



\section{Abstract}

Land subsidence in low-lying peatlands can be caused by shrinkage and organic matter oxidation. When these areas have networks of ditches and canals for drainage purposes, the sediments that accumulate in the waterways can be used to reverse the process of land subsidence. The objective of this study is to understand how dredged sediments can be used to reverse the process of land subsidence by analysing the contribution of shrinkage and organic matter mineralization to the subsidence observed in an upland deposit.

A deposit of dredged sediments in the Wormer- en Jisperveld - North Holland, the Netherlands, was characterized during 17 months in terms of subsidence of the sediments, subsidence of the soil underlying the deposit, water content, organic matter content, type of organic matter, and nutrients. The deposit was filled to a maximum height of $195 \mathrm{~cm}$ and the total subsidence of the sediments was $119 \mathrm{~cm}$. In addition, a subsidence of $19.5 \mathrm{~cm}$ of the underlying soil was observed. Subsidence could be attributed to shrinkage since no significant changes in the organic matter content and total organic carbon were observed. The type of organic matter changed in the direction of humification until winter 2014, stabilized from winter 2014 to spring 2015 and changed in the direction of mineralization after the spring of 2015 .

Considering that the subsidence of dredged sediments in upland deposits is caused by shrinkage during the first 17 months and that the pressure of the deposit on the underlying soil caused an extra subsidence of $19.5 \mathrm{~cm}$, the solution of spreading thinner layers of sediments over the land to decrease the subsidence rates should be explored.

\section{Keywords}

Dredged sediments; Upland deposit; Subsidence; Shrinkage; Organic matter oxidation; Lowlands; Peatlands 


\subsection{Introduction}

The Wormer- en Jisperveld is the largest contiguous peatland in the Netherlands and due to land subsidence and sea level rise, the water level in this peatland was $1.54-1.58 \mathrm{~m}$ below sea in 2011 (Linders 2011).

Land subsidence in these type of peatlands is mainly a consequence of drainage that results in shrinkage due to the loss of volume occupied by the water and rearrangement of the particles when the water is removed (Oleszczuk et al. 2003), and organic matter oxidation (Sanei et al. 2005). The oxidation of the organic matter can result in humification or mineralization. Humification is the transformation of organic matter into amorphous humic compounds and mineralization refers to the transformation of organically bound elements (C, N, P, S) into inorganic compounds (Zech et al. 1997).

The drainage of these low-lying peatlands is necessary to lower the water level especially to maintain the necessary conditions for agriculture and to avoid flooding. For that, dense networks of water courses and pumping stations are needed which is perpetuating the subsidence and becoming increasingly costly (Querner et al. 2012).

In Wormer- en Jisperveld the network of water courses accumulates sediments that have to be dredged to preserve the area (Linders 2011). One of the current practices is to store the dredged sediments in upland deposits of 1 to $2 \mathrm{~m}$ height. Dredged sediments have approximately 0.7 $\mathrm{g}_{\text {water }} / \mathrm{g}_{\text {sediment }}$ and in the upland deposits the sediments are dewatered through runoff (horizontal), drainage (vertical downwards) and evapotranspiration (vertical upwards). Simultaneously to dewatering, also sedimentation, consolidation and ripening occur, transforming the waterlogged sediments into an aerated soil. Sedimentation takes place within hours or days and refers to the settling of the particles. Consolidation is driven by the overburden pressure caused by the weight 
of the overlying layer. Ripening can be sub-divided into physical, chemical and biological ripening. During the physical ripening dehydration and shrinkage occur, the permeability and consistency increase, and cracks are formed. The chemical ripening refers to the oxidation combined with chemical changes that occur due to the improved aeration. Biological ripening refers to the activity of soil fauna and flora (Vermeulen 2007). Dewatering and the overall ripening process are accelerated by crack development (Vermeulen et al. 2003) and evapotranspiration caused by plants (Oliveira et al. submitted-a).

Many other lowlands and delta areas suffer from subsidence (Aich et al. 2013, Hooijer et al. 2012, Pronger et al. 2014, Querner et al. 2012, Wöppelmann et al. 2013) and sediments are a natural resource that can be beneficially used to reverse the process of land subsidence, especially considering that in some areas the sediments and water flow are restrained upstream which limits the natural restoration through sediment accumulation in delta areas (Kolker et al. 2011).

The objective of this study is to understand how dredged sediments can be used to reverse land subsidence by analyzing the contribution of shrinkage and organic matter oxidation to the subsidence observed in an upland deposit. For that, the deposit is characterized in terms of subsidence of the sediments, subsidence of the soil underlying the deposit, water content, organic matter content, type of organic matter, and nutrients.

\subsection{Materials \& Methods}

\subsubsection{Site description}

Between 2001 and 2014, 2.3 million $\mathrm{m}^{3}$ of sediments were dredged from the waterways in the Wormer- en Jisperveld area. The dredged sediments were used to restore waterfronts, raise the surface level of some meadows, and stored in upland deposits. In this research the 
focus was on one of these upland deposits named Deposit X1 $\left(52^{\circ} 31^{\prime} 15.3^{\prime \prime} \mathrm{N} 4^{\circ} 49^{\prime} 53.4^{\prime \prime E}\right)$. Deposit X1 has approximately $145 \mathrm{~m}$ of length and $120 \mathrm{~m}$ width and was formerly used for grazing cattle. The typical lithology in the area is formed by peat from 0.0 to $0.3 \mathrm{~m}$ and from 0.4 to $3.0 \mathrm{~m}$, and clay from 0.3 to $0.4 \mathrm{~m}$ and from 3.0 to $3.5 \mathrm{~m}$ (www.dinoloket.nl/ondergrondgegevens).

To prepare Deposit $\mathrm{X} 1$, approximately $30 \mathrm{~cm}$ of topsoil were removed and this topsoil was used to construct the dikes around the deposit. This resulted in the bottom of Deposit X1 being a mixture of peat and clay. The height from the bottom of the deposit to the top of the dikes was about $215 \mathrm{~cm}$. The deposit was split in two compartments, A and B, separated by a dike which reached a height of about $1.90 \mathrm{~m}$. The Deposit X1 was filled with sediments in two stages: the first stage was from 20/Jan/2014 to 30/Mar/2014; and the second stage was from $1 / \mathrm{Jul} / 2014$ to $16 /$ Oct/2014 (Table $5-1$ ). The filling was done by the water board Hoogheemraadschap Hollands Noorderkwartier (HHNK) in two stages due to two main reasons: during the birds breeding season from 15/Mar/2014 to 15/Jun/2014 no works can be done; and during spring and summer there is a significant reduction in the volume occupied by the sediments and therefore the deposit has space to allocate more sediments after the summer (information provided by the water board HHNK).

Two level gauges were placed in the deposit to monitor subsidence (Figure 5-1). In addition, the water board HHNK monitored the subsidence of the bottom of the deposit by determining the level of the level gauges in relation to a geodetic reference level. At the southern side of the deposit a wooden platform was installed in compartment $A$ to allow sampling of sediments. 


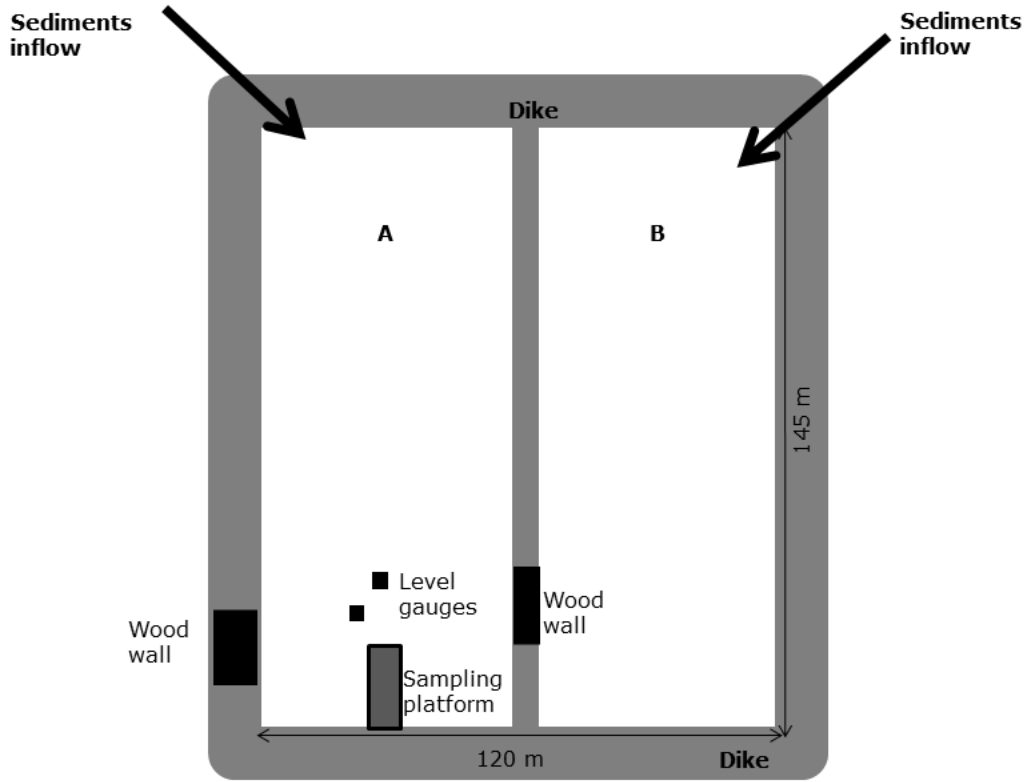

Figure 5-1: Schematic representation of Deposit X1

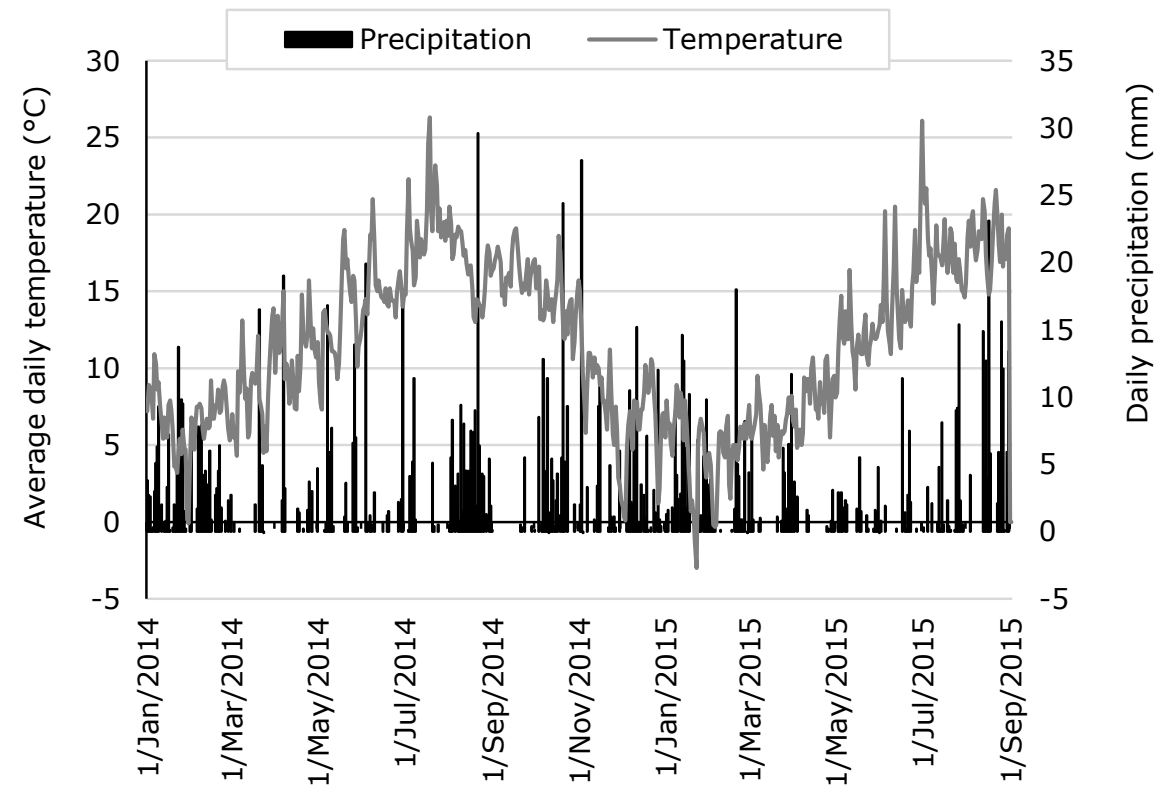

Figure 5-2: Average daily temperature $\left({ }^{\circ} \mathrm{C}\right)$ and daily precipitation $(\mathrm{mm})$ recorded at Wijk aan Zee weather station 
The Deposit X1 also had an adjustable wooden wall on the western side. After settling of the sediments, the wooden wall would be open to allow the horizontal runoff of the clear water to an adjacent ditch (horizontal runoff).

The average daily temperature and the daily precipitation recorded at the nearest weather station which is located in Wijk aan Zee are in Figure 5-2 (KNMI 2016).

\subsubsection{Sampling}

Column samples of sediments were taken using a gouge auger sampler with diameter of $25 \mathrm{~mm}$ (Eijkelkamp Soil \& Water). Sampling was always done from the "platform for sampling" (Figure 5-1). On each sampling day, 3 column samples were taken and mixed. Since the shrinkage characteristics of the deposit could not be quantified, it was chosen to divide the column samples in $10 \mathrm{~cm}$ sections where 0 is the interface between sediments and the soil underlying the sediments. The $10 \mathrm{~cm}$ sections were separated in the field and stored in air-tight glass jars. In the lab the samples were stored at $4^{\circ} \mathrm{C}$ and later sub-divided for the different analysis.

\subsubsection{Analytical methods}

The subsidence of the sediments and settlement of the underlying soil were determined from the readings of the level gauges.

The water content and organic matter content were calculated from the oven dry weight of the samples ( 24 hours at $105^{\circ} \mathrm{C}$ ) and the loss on ignition ( $4 \mathrm{~h}$ at $550^{\circ} \mathrm{C}$ ) of the samples (ISO/TS 17892-1:2014 (Soil and Plant Analysis Council Inc. 1999, Sumner 2000). These two parameters were determined for each $10 \mathrm{~cm}$ section. 
Table 5-1 : Sampling dates and parameters analyzed. $\mathrm{Y}$ - measured; N - not measured

\begin{tabular}{|c|c|c|c|c|c|}
\hline Date & Action & $\begin{array}{c}\text { Water } \\
\text { content }\end{array}$ & $\begin{array}{c}\text { Organic } \\
\text { content }\end{array}$ & $\begin{array}{l}\text { tter } \\
\text { type }\end{array}$ & $\begin{array}{c}\text { Total } \\
\mathrm{N}, \mathrm{P} \text {, and } \mathrm{S}\end{array}$ \\
\hline 20/Jan/2014 & Start filling stage 1 & & & & \\
\hline 30/Mar/2014 & Sampling 1 & Y & Y & $\mathrm{N}$ & $\mathrm{N}$ \\
\hline 30/Mar/2014 & End filling stage 1 & & & & \\
\hline 8/Apr/2014 & Sampling 2 & Y & Y & $\mathrm{N}$ & N \\
\hline 3/Jun/2014 & Sampling 3 & Y & Y & Y & Y \\
\hline $1 / \mathrm{Jul} / 2014$ & Start filling stage 2 & & & & \\
\hline $1 / \mathrm{Jul} / 2014$ & Sampling 4 & Y & Y & Y & $\mathrm{N}$ \\
\hline 8/Sep/2014 & Sampling 5 & Y & Y & Y & $\mathrm{N}$ \\
\hline 9/Oct/2014 & Sampling 6 & Y & Y & $\mathrm{N}$ & $\mathrm{N}$ \\
\hline 16/Oct/2014 & End filling stage 2 & & & & \\
\hline $13 /$ Nov/2014 & Sampling 7 & Y & Y & Y & Y \\
\hline 28/Jan/2015 & Sampling 8 & Y & Y & Y & Y \\
\hline 26/Mar/2015 & Sampling 9 & Y & Y & Y & Y \\
\hline 4/Jun/2015 & Sampling 10 & Y & Y & Y & Y \\
\hline 9/Jul/2015 & Sampling 11 & Y & Y & $Y$ & Y \\
\hline 27/Aug/2015 & Sampling 12 & Y & Y & $Y$ & $Y$ \\
\hline
\end{tabular}

The total N, P, and S were determined at the Chemical Biological Soil Laboratory of Wageningen University and Research Centre, The Netherlands. The dredged sediments samples were oven-dried for 24 hours at $105^{\circ} \mathrm{C}$. One sub-sample was digested with the DigiPrep (aquaregia method, according to NEN-69610) and analyzed with a Thermo (type ICAP) ICP-AES for $\mathrm{P}$ and $\mathrm{S}$. The other sub-sample was used to analyze total organic $\mathrm{N}$ with a Leco $\mathrm{C} / \mathrm{N}$ analyser. The analysis of $\mathrm{N}, \mathrm{P}$, and $\mathrm{S}$ were done in two batches: column samples 3 and 7-10 were done in the first batch, and column samples 11-12 in the second batch. $\mathrm{N}, \mathrm{P}$, and $\mathrm{S}$ were analyzed for each $20 \mathrm{~cm}$ section.

The type of organic matter was characterized with the Rock-Eval $6^{\circledR}$ method, described in (Oliveira et al. 2016). The Rock-Eval ${ }^{\circledR}$ analysis of columns 3-5 and 7-10 were done in one batch, and the analysis of 
columns 11-12 were done in a second batch. The Rock-Eval $6^{\circledR}$ analysis was done for each $20 \mathrm{~cm}$ section.

\subsection{Results}

A subsidence of $50 \mathrm{~cm}$ was observed between the end of the first filling stage and the start of the second filling stage (122 days). To achieve the same $50 \mathrm{~cm}$ of subsidence after the second filling stage, it took 259 days (Figure 5-3). The total subsidence of the sediments between the end of the second filling stage and the last day of sampling (322 days) was $69 \mathrm{~cm}$.

When the sediments settled and a clear layer of water could be observed on top of the sediments layer, the wooden wall would be open to allow the horizontal runoff and this is reflected in the fast drop of the sediments level in consecutive days such as $11-17 / \mathrm{Feb} / 2014$ and 320/Mar/2014 (Figure 5-3).

After the first filling stage the subsidence of the underlying soil (Figure 5-4) reached a steady state at $-10 \mathrm{~cm}$. With the second filling stage the subsidence of the soil underlying the deposit increased to $-19.5 \mathrm{~cm}$.

The water content of the top layer of the deposit had the highest variation with time (Figure 5-5). The layers between the bottom of the deposit and $90 \mathrm{~cm}$ had the smallest changes in the water content and followed a similar pattern of variation with time. The increase in the water content due to the second filling stage was observed later for the deeper layers than for the upper layers, due to the resistance to water percolation. The sample taken on 4/Mar/2014 (first sample) had higher water content than all subsequent samples, even than the samples taken during the second filling stage. On 27/Aug/2015 the water content was similar for all depths, with an average of $616 \pm 36 \%$. 


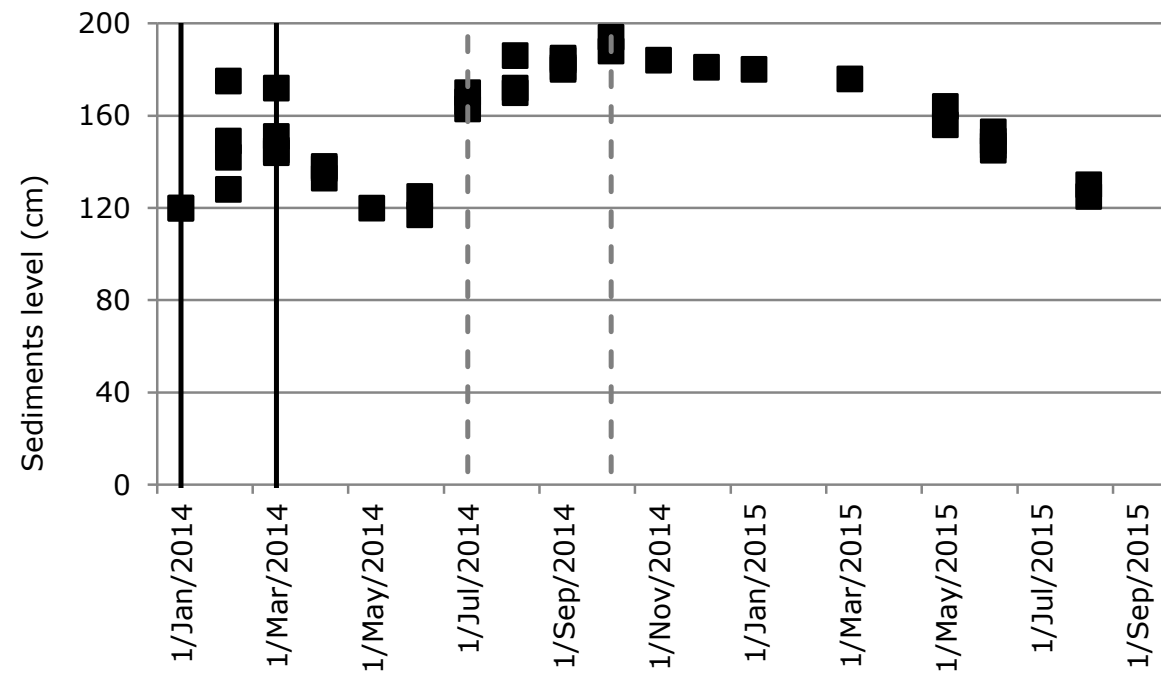

Figure 5-3: Sediments level $(\mathrm{cm})$. Black vertical bars correspond to the first filling stage and grey-dashed vertical bars correspond to the second filling stage

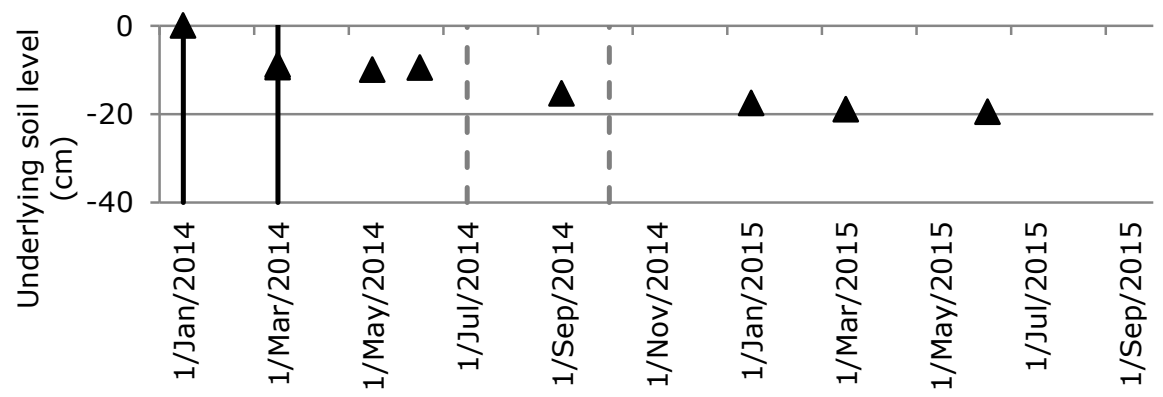

Figure 5-4: Level of the underlying soil $(\mathrm{cm})$. Black vertical bars correspond to the first filling stage and grey-dashed vertical bars correspond to the second filling stage 


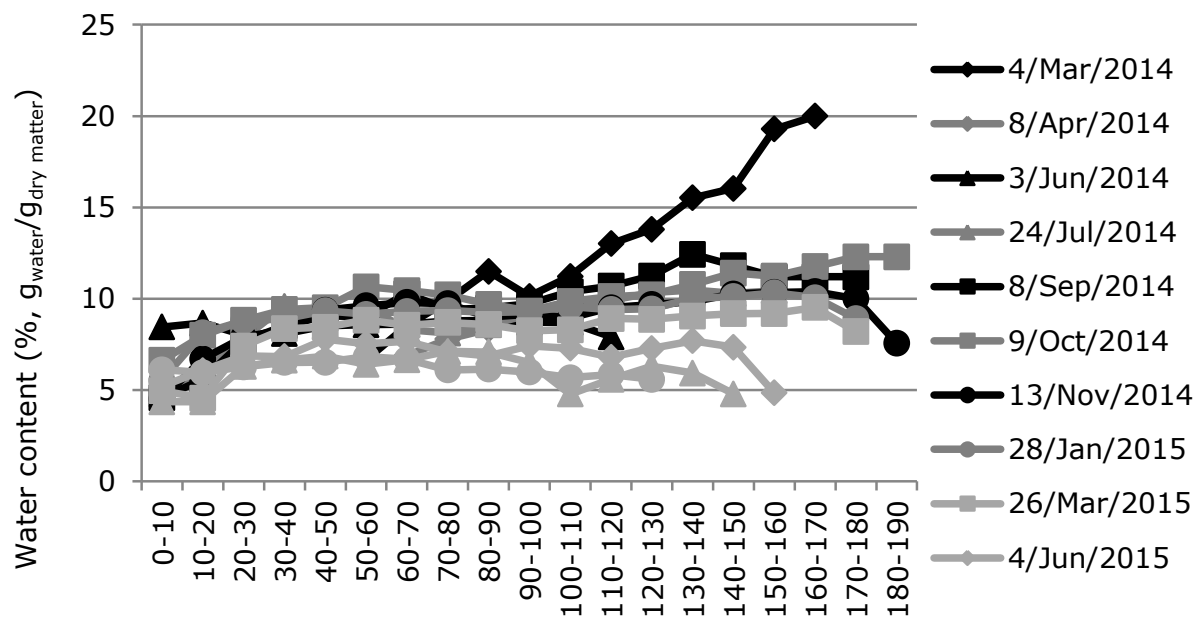

Figure 5-5: Water content ( $\left.\%, g_{\text {water }} / g_{\text {dry matter }}\right)$ for A) 0 to $60 \mathrm{~cm}$ depth, B) 60 to $120 \mathrm{~cm}$ depth, and C) 120 to $180 \mathrm{~cm}$ depth. Black vertical bars correspond to the first filling stage and grey-dashed vertical bars correspond to the second filling stage

The organic matter content (Figure 5-6) and the total organic carbon (Figure 5-7) did not significantly change throughout the monitoring period. The variation observed in the measurements can be attributed to the heterogeneity of the Deposit X1.

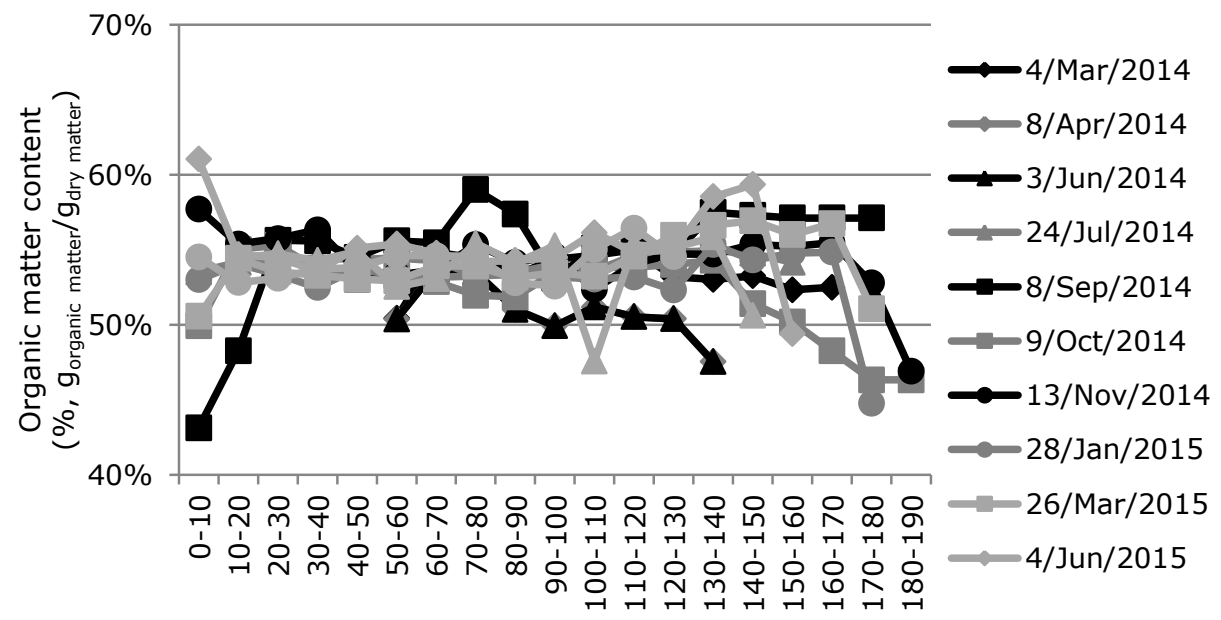

Figure 5-6: Organic matter content (\%, $\left.g_{\text {organic matter }} / g_{\text {dry matter }}\right)$ 


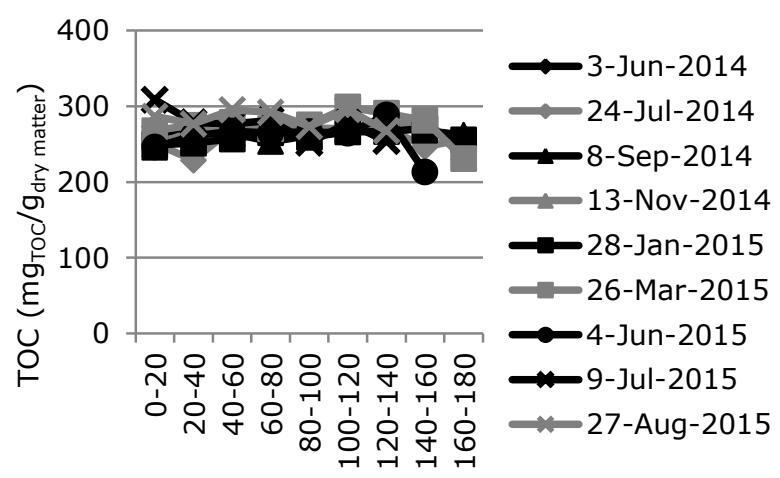

Figure 5-7: Total Organic Carbon $\left(\mathrm{mg}_{\mathrm{Toc}} / \mathrm{g}_{\text {dry matter }}\right)$

The Hydrogen Index $(\mathrm{HI})$ and Oxygen Index $\left(\mathrm{OI}_{\mathrm{RE} 6}\right)$ varied with time showing that even though there were no significant changes in the quantity of organic matter there were changes in the quality of the organic matter (Figure 5-8). $\mathrm{HI}$ and $\mathrm{OI}_{\mathrm{RE} 6}$ had more significant fluctuations at the top of the deposit than for deeper layers. Before the start of the second filling stage, the $\mathrm{HI}$ was decreasing and the $\mathrm{OI}_{\mathrm{RE} 6}$ increasing for all depths. The second filling stage resulted in higher $\mathrm{HI}$ and lower $\mathrm{OI}_{\mathrm{RE} 6}$ down to $60 \mathrm{~cm}$ height which is related with the addition of freshly dredged sediments on top of the deposit. After the end of the second filling period the $\mathrm{HI}$ decreased and the $\mathrm{OI}_{\mathrm{RE}}$ increased slightly until $13 / \mathrm{Nov} / 2014$. From $13 / \mathrm{Nov} / 2014$ to $4 / \mathrm{Jun} / 2015$ the $\mathrm{OI}_{\mathrm{RE} 6}$ and the $\mathrm{HI}$ did not change significantly and after 4/Jun/2015 the HI increased and the $\mathrm{OI}_{\mathrm{RE} 6}$ decreased for all depths.

The Total N, P and $\mathrm{S}$ are homogeneous with depth and the changes observed from 3/Jun/2014 to 4/Jun/2015 might be related with the heterogeneity of the Deposit $X 1$. The samples from 9/Jul/2015 and 27/Aug/2015 seem to divert from the previous samples (Figure 5-9). 

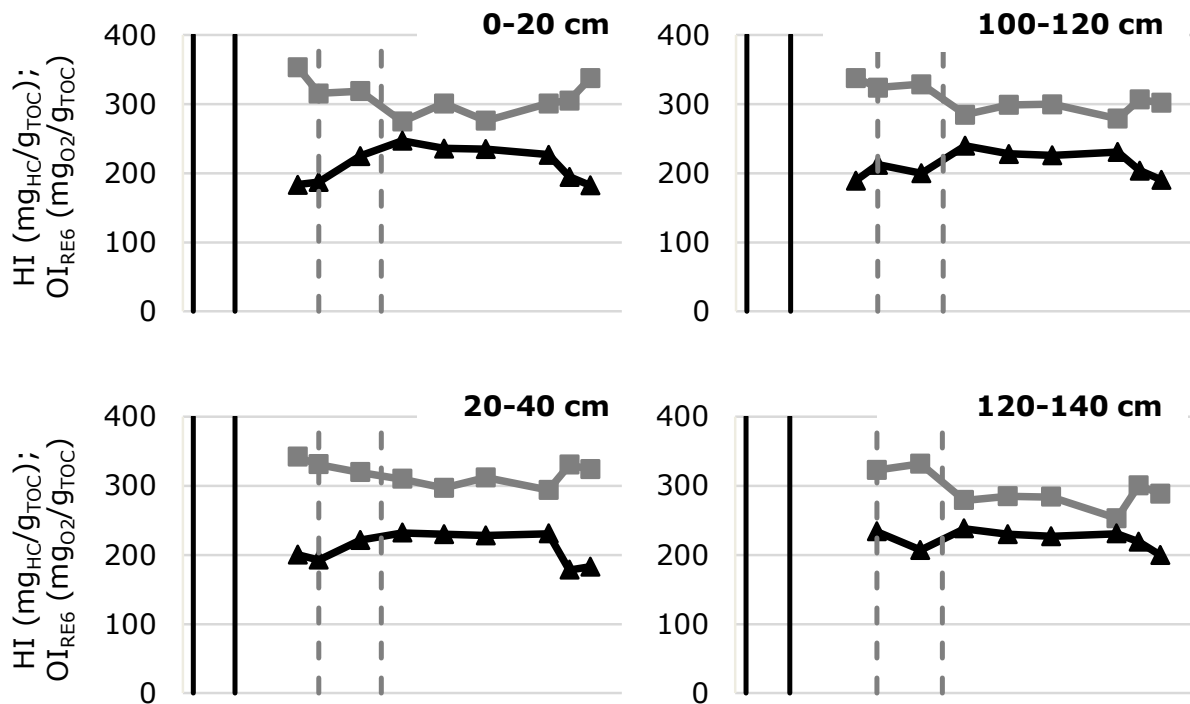

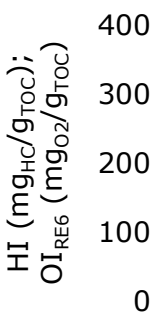
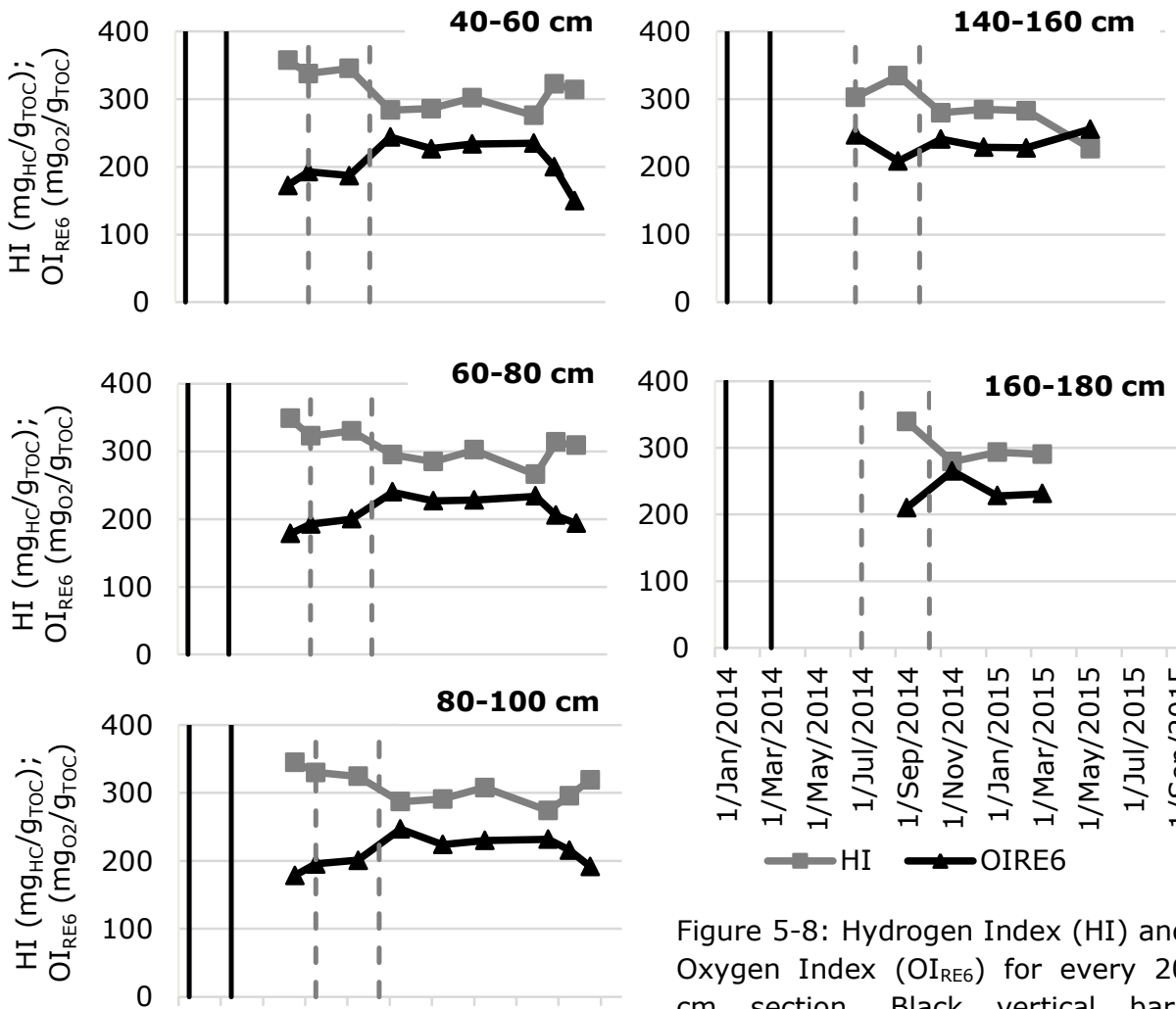

80-100 cm

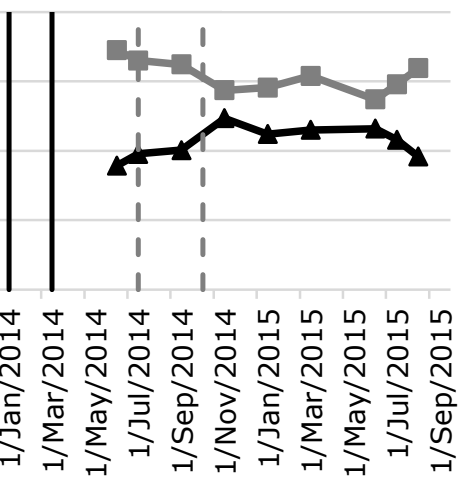

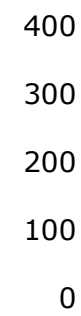

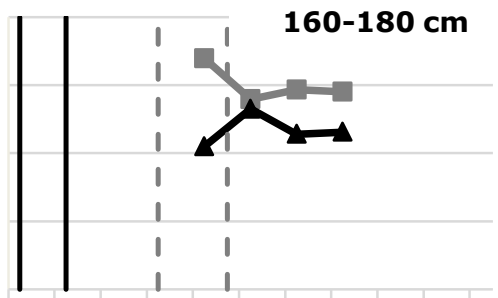

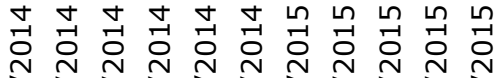

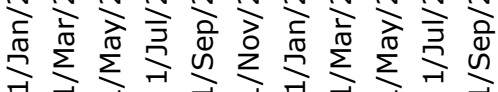

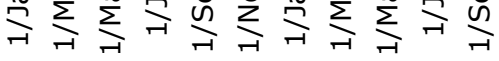
$-\mathrm{HI} \longrightarrow$ OIRE6

Figure 5-8: Hydrogen Index (HI) and Oxygen Index $\left(\mathrm{OI}_{\mathrm{RE} 6}\right)$ for every 20 $\mathrm{cm}$ section. Black vertical bars correspond to the first filling stage and grey-dashed vertical bars correspond to the second filling stage 

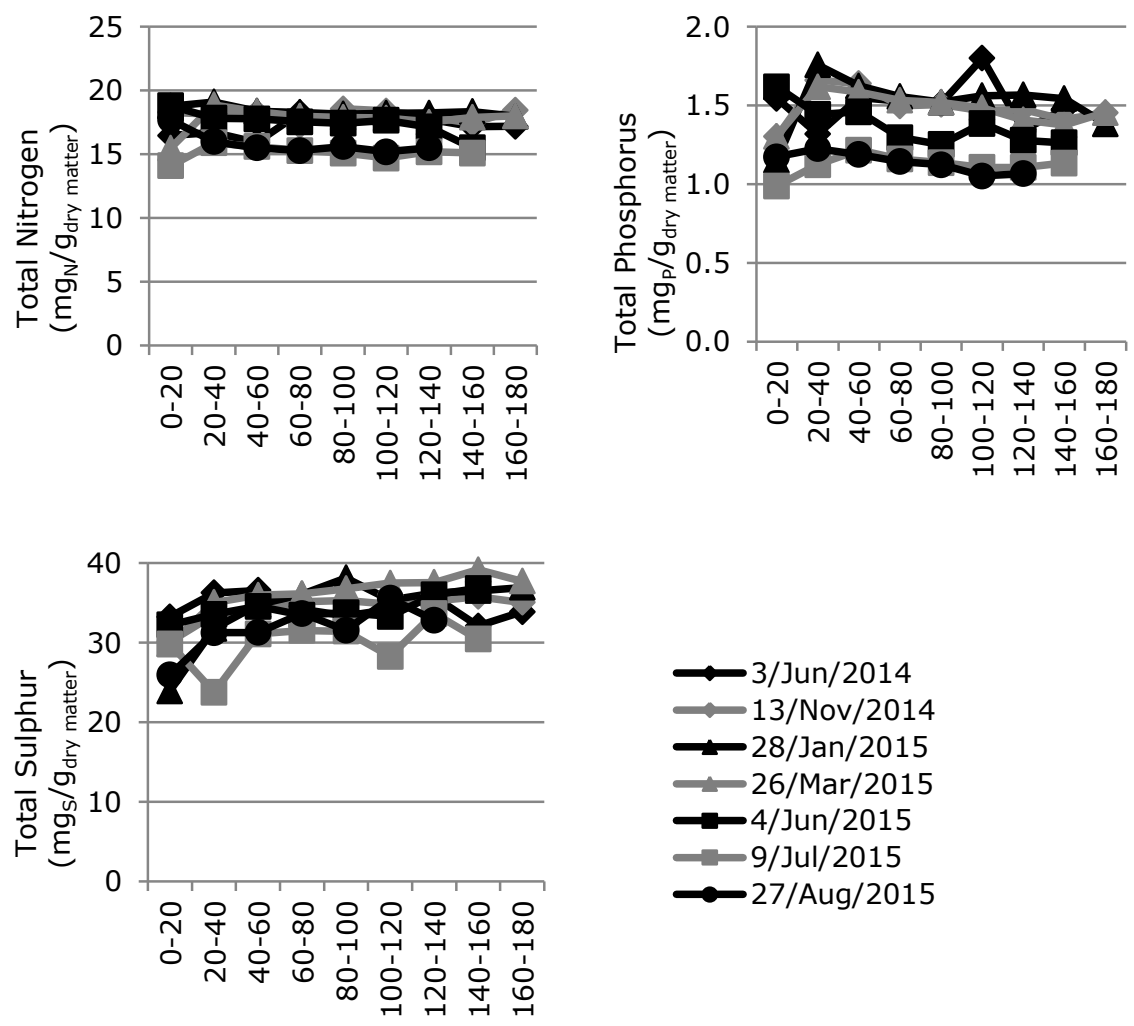

Figure 5-9: Total Nitrogen $\left(\mathrm{mg}_{\mathrm{N}} / \mathrm{g}_{\mathrm{dry}}\right.$ matter $)$, Total Phosphorus $\left(\mathrm{mg}_{\mathrm{p}} / \mathrm{g}_{\mathrm{dry}}\right.$ matter $)$, and Total Sulphur $\left(\mathrm{mg}_{\mathrm{s}} / \mathrm{g}_{\text {dry matter }}\right)$. Black vertical bars correspond to the first filling stage and greydashed vertical bars correspond to the second filling stage

\subsection{Discussion}

A subsidence of $50 \mathrm{~cm}$ was observed after the first filling stage and a subsidence of $69 \mathrm{~cm}$ was observed after the second filling stage until the end of the experiment, giving a total subsidence of $119 \mathrm{~cm}$.

The first filling stage ended in the spring while the second filling stage ended in the autumn and the subsidence results reflect the effect that the weather conditions have on the behavior of the deposit, both due to the addition of water through precipitation and through the influence on 
plant growth (and consequence evapotranspiration). In addition, ripening of dredged sediments results in the increase of the water potential (Vermeulen 2007), and the decomposition and humification of the organic matter result in the degradation of the soil structure, a reduction in the soil capacity to store, retain and transmit water, and a higher propensity to shrink with increasing water potentials (Kechavarzi et al. 2010). The different subsidence rates observed with time can be related with this as well as with the weather conditions since subsidence rates are higher in the warmer months of spring and summer than during the cooler months of autumn and winter. Previous studies have shown that plants have an important role in the hydrology of wetlands (Berglund \& Berglund 2011, Oliveira et al. submitted-a) and therefore the higher subsidence in warmer months can be related with evapotranspiration.

After the first filling stage the subsidence of the underlying soil reached a steady state at $-10 \mathrm{~cm}$. With the second filling stage the subsidence increased to $-19.5 \mathrm{~cm}$. Since below the deposit anaerobic conditions prevail, the subsidence of the underlying soil is mainly shrinkage due to the overburden pressure, as also reported by (van Asselen 2011). A characteristic of peatlands is the capacity of changing volume to store water (a phenomenon called mire breathing) and therefore peatlands can swell and shrink as a response to different water contents (Kellner \& Halldin 2002, Price \& Schlotzhauer 1999). Therefore, it can be expected that at least part of the subsidence of the underlying soil is reversible if the overburden pressure is removed and the peat is re-wetted (Gebhardt et al. 2010).

The water content of the surface layer had the highest variation with time which is initially related with the horizontal removal of water through the adjustable wooden walls and later with the weather conditions and evapotranspiration by plants. The relatively small 
decrease in water content for the deeper layers can be related with the settling of the sediments and the ongoing compaction and shrinkage which can turn the underlying layers impermeable (Dawson et al. 2010) thus limiting dewatering and ripening of the dredged sediments.

The increase in the water content due to the second filling stage had a delayed effect for the deeper layers $0-60 \mathrm{~cm}$ which can be related with lower hydraulic conductivity caused by the ongoing shrinkage. This delayed response was also observed by (Holden \& Burt 2002).

On the last sampling date, the water content of Deposit X1 was similar for all depths, with an average of $616 \pm 36 \%$, reflecting the high water holding capacity of the sediments. A previous study with sediments dredged from the same location showed that the water retention capacity varies from $0.71 \mathrm{~cm}^{3}{ }_{\text {water }} / \mathrm{cm}^{3}$ dry matter before ripening to 1.02 after ripening for a $\mathrm{pF}=2$ (Oliveira et al. 2016).

Since the top layers are exposed to evapotranspiration and the bottom layers have the effect of the overburden pressure, it could be expected the top and the bottom layers of the deposit would be drier than the middle layers. However, this was not observed (Figure 5-5).

For a more in depth analysis of specific layers in time, extensive modelling is required to correct the results for the shrinkage rate of each layer. This will be described elsewhere.

The organic matter content and the total organic carbon did not significantly change throughout the monitoring period and the variation observed in the measurements can be attributed to the heterogeneity of the Deposit $X 1$. This is also in line with previous observations on lab scale (Oliveira et al. 2016) and meso scale experiments (Oliveira et al. submitted-a) using sediments dredged from the same location.

The Hydrogen Index ( $\mathrm{HI})$ and Oxygen Index ( $\left.\mathrm{OI}_{\mathrm{RE} 6}\right)$ had more fluctuations for the surface layers than for deep layers since the top 
layers are directly exposed to weather conditions and also to aerobic conditions. Before the start of the second filling stage, the HI was decreasing and the $\mathrm{OI}_{\mathrm{RE}}$ increasing for all depths, i.e., the changes in the type of organic matter are indicating progressive humification with depth (Albrecht et al. 2015, Disnar et al. 2003). The second filling period resulted in higher $\mathrm{HI}$ and lower $\mathrm{OI}_{\mathrm{RE} 6}$ up to the top $60 \mathrm{~cm}$ of the deposit which is related with the addition of freshly dredged sediments on top of the deposit. After the end of the second filling stage and until $13 / \mathrm{Nov} / 2014$ there was a second period of humification. From $13 / \mathrm{Nov} / 2014$ to $4 / \mathrm{Jun} / 2015$ the $\mathrm{OI}_{\text {REG }}$ and the $\mathrm{HI}$ did not change significantly and after 4/Jun/2015 there was a decrease in $\mathrm{OI}_{\text {RE6 }}$ and an increase in $\mathrm{HI}$, indicating mineralization of the organic matter (Albrecht et al. 2015, Disnar et al. 2003).

On the last sampling date, the decrease in water content was still ongoing and no significant decrease in organic matter content or total organic carbon was observed, even though oxidation changed from humification to mineralization. Some authors report that initial subsidence in newly drained areas is mainly due to shrinkage and after a certain period oxidation becomes the main cause of subsidence (Hooijer et al. 2012, Pronger et al. 2014). In this case, the high water content of the sediments can be protecting the organic matter from mineralization.

The Total N, P and S was homogeneous with depth and the changes observed from 3/Jun/2014 to 4/Jun/2015 might be related with the heterogeneity of the Deposit $X 1$. The samples from 9/Jul/2015 and 27/Aug/2015 seem to divert from the previous samples which might be related with an analytical difference since the last two samples were analyzed in a second batch.

One solution to avoid such high subsidence rates is to spread thin layers of sediments over the field. This solution would decrease not only the subsidence due to the overburden pressure but could also protect higher 
extensions of peatland from aerobic conditions since the sediments have a high water retention capacity. Laboratory scale experiments with samples of $1.5 \mathrm{~cm}$ height of the same sediments have shown that after 141 days at $20^{\circ} \mathrm{C}$ the organic matter mineralization was negligible and the samples had enough undrained shear strength to sustain cattle and tractors (Oliveira et al. 2016). The solution of thinner layers would not only limit air penetration due to the high water retention capacity but also allow shallower groundwater tables which is a complementary measure to reduce land subsidence (Dawson et al. 2010, Querner et al. 2012).

\subsection{Conclusions}

After 17 months of monitoring an upland deposit of dredged sediments, a total subsidence of $138.5 \mathrm{~cm} \mathrm{~cm}$ was observed being $119 \mathrm{~cm}$ attributed to the sediments subsidence and $19.5 \mathrm{~cm}$ to the underlying soil subsidence.

The observed subsidence was due to shrinkage since no significant decrease in organic matter content or total organic carbon was observed. Despite that, there was a period of organic matter humification followed by a period of mineralization of the organic matter, indicating that the conditions might change on a long term since when the last column sample was taken also shrinkage and subsidence were still ongoing.

The results suggest that spreading thinner layers of sediments could result in less subsidence due to the overburden pressure and protection of the underlying soil from aerobic conditions, and therefore this alternative to upland deposit should be explored. 


\section{Acknowledgements}

This research is supported by the Dutch Technology Foundation STW, which is part of the Netherlands Organisation for Scientific Research (NWO), and which is partly funded by the Ministry of Economic Affairs, via the perspective program BioGeoCivil (grant 11344). We would like to express gratitude to Karsten Hopman from Hoogheemraadschap Hollands Noorderkwartier (HHNK) and to Roderick Tollenaar for the vital support with the field experiment 


\section{General Discussion}

Future perspectives and opportunities for the beneficial use of dredged sediments to

reverse land subsidence 



\subsection{Introduction}

\subsubsection{What this thesis is about and why}

Land subsidence as a result of drainage is occurring in many peatlands and delta areas worldwide (Dawson et al. 2010, Gebhardt et al. 2010, Kolker et al. 2011, Teatini et al. 2011, van Asselen 2011, Wöppelmann et al. 2013). As an example, about 35\% of the Netherlands is below sea level mostly as a consequence of land drainage and at some locations the subsidence rate reaches $1 \mathrm{~cm} /$ year (Hoogland et al. 2012). The drainage of these lands was started by farmers that needed land for agriculture and husbandry and found that these were rich in organic matter and nutrients. Drainage of the land first started with digging small ditches to where the water accumulated in the field would drain. This practice resulted in land subsidence due to shrinkage and organic matter oxidation (Dawson et al. 2010, Gebhardt et al. 2010). Shrinkage refers to the loss of volume occupied by the water (through vertical and horizontal drainage and evapotranspiration) and rearrangement of the particles (including compaction) when the water is removed (Arnold \& Ghezzehei 2015, IInicki 2002, Oleszczuk et al. 2003, Schlotzhauer \& Price 1999). The drainage of the land increases the aerated zone of the soil which then increases organic matter oxidation. The organic matter oxidation can be in the direction of the humification or in the direction of mineralization (Sanei et al. 2005). Humification can be defined as the transformation of SOM into amorphous humic compounds while mineralization refers to the transformation of organically bound elements (C, N, P, S) into inorganic compounds (Sumner 2000, Zech et al. 1997).

So, draining the land with small ditches caused land subsidence which therefore increased the need to lower the water level. For that, windmills were introduced to extract the water from the ditches. A selfperpetuating cycle of drainage-subsidence-drainage was created and 
nowadays dense networks of waterways and diesel pumps are needed to maintain the land use. This situation has significant environmental impacts, such as the possibility of salt water intrusion (and salinization of drink water) and upward seepage of brackish, nutrient-rich, groundwater (Hoogland et al. 2012), and greenhouse gas emissions due to organic matter oxidation. It has been reported that peatlands with a subsidence of $1 \mathrm{~cm} / \mathrm{yr}$ result in the emission of about 22 tonnes $\mathrm{CO}_{2} /$ ha/yr of (Akker et al. 2008), and the soil nitrogen being converted into $\mathrm{N}_{2} \mathrm{O}$ canl result in an emission of 1.8 tonnes $\mathrm{CO}_{2}$-eq/ha/yr (Mosier et al. 1998). Still, other authors reported that $\mathrm{CO}_{2}$ and $\mathrm{N}_{2} \mathrm{O}$ emissions do not necessarily increase with deeper drainage (Berglund \& Berglund 2011).

The dense networks of waterways used to drain the land accumulate sediments and have to be periodically dredged to maintain their function. In the past years there has been a growing interest on possible beneficial uses of dredged sediments within the water basin from where these originate. Spreading the sediments on the land can be more sustainable and cost-effective than the current practice of storing in upland deposits or dispose at sea. Furthermore, when contaminants are present, the risk posed to the environment and public health should be assessed considering the background concentrations of the contaminants and its bioavailability. 


\subsubsection{Concise answers to the research questions as presented in Chapter 1}

To answer the research questions formulated in 1.6, the main findings in this research, can be summarizes as:

Subsidence is mainly attributed to shrinkage and no significant mineralization of organic matter occurred (Chapters 2, 3, 4 and 5).

Where bio-wastes are available, these can be added to dredged sediments to further reverse land subsidence but in this case special attention should be given to the potential priming effect (Chapter 3 ).

The water level in the mesoscale experiments did not cause differences in the shrinkage of the sediments (Chapter 4).

After 17 months of monitoring an upland deposit of dredged sediments, the subsidence of the sediments was $88 \mathrm{~cm}$ and the subsidence of the underlying soil (compaction) was $19.5 \mathrm{~cm}$. Still, a height of $87.5 \mathrm{~cm}$ remained after the 17 months (Chapter 5).

In conclusion, these findings support that dredged sediments have the potential to reverse land subsidence.

\subsection{Relevant parameters to answer the research questions}

To answer the research questions and have consistent results that could be comparable with each other, the parameters in Table were addressed.

\subsubsection{Role of organic matter and organic amendments in subsidence of dredged sediment}

Even though spreading dredged sediments has been a common practice by farmers for many years, and is naturally done in flood plains, there are not many reports, and even less scientific research, about the use of sediments on land. Further, within this limited number of papers, there 
is a lack on extensive characterization of the sediments and soils formed after ripening, which can be useful to evaluate the proper application of specific sediments (Chapter 1 ).

Table 6-1: Parameters assessed in each Chapter

\begin{tabular}{lcccc} 
& \multicolumn{5}{c}{ Chapter } \\
\cline { 2 - 5 } Parameter & 2 & 3 & 4 & 5 \\
\hline Water content & $\sqrt{ }$ & $\sqrt{ }$ & $\sqrt{ }$ & $\sqrt{ }$ \\
Water holding capacity & $\sqrt{ }$ & & & \\
$\mathrm{O}_{2}$ consumption/ $\mathrm{CO}_{2}$ production & $\sqrt{ }$ & $\sqrt{ }$ & & \\
Organic matter content & $\sqrt{ }$ & $\sqrt{ }$ & $\sqrt{ }$ & $\sqrt{ }$ \\
Type of organic matter & $\sqrt{ }$ & $\sqrt{ }$ & $\sqrt{ }$ & $\sqrt{ }$ \\
Fibers content & $\sqrt{ }$ & & $\sqrt{ }$ & $\sqrt{ }$ \\
Particle size distribution & $\sqrt{ }$ & $\sqrt{ }$ & $\sqrt{ }$ & $\sqrt{ }$ \\
pH & $\sqrt{ }$ & $\sqrt{ }$ & $\sqrt{ }$ & \\
Total N, P and S & $\sqrt{ }$ & $\sqrt{ }$ & $\sqrt{ }$ & $\sqrt{ }$ \\
Dry bulk density & $\sqrt{ }$ & & $\sqrt{ }$ & \\
Undrained shear strength & $\sqrt{ }$ & $\sqrt{ }$ & $\sqrt{ }$ & \\
Aggregate stability & $\sqrt{ }$ & $\sqrt{ }$ & & \\
\hline
\end{tabular}

The absence of scientific studies led to misconceptions such as most land subsidence is caused by organic matter oxidation.

When sediments are transferred from waterways to upland conditions, the ripening process begins, which transforms the waterlogged sediments into an aerated soils (Pons \& Zonneveld 1965). During ripening, the previously anaerobic dredged sediments become aerobic which induces the oxidation of organic matter (Vermeulen et al. 2007). The oxidation of the organic matter can go in the direction of the humification or mineralization (Sanei et al. 2005). Humification can be defined as the transformation of SOM into amorphous humic compounds 
while mineralization refers to the transformation of organically bound elements ( C, N, P, S) into inorganic compounds (Sumner 2000, Zech et al. 1997) (Chapter 3).

In this research, the type of organic matter changed during biochemical ripening in all experiments (Chapters 2, 3, 4 and 5), even though the quantity of organic matter did not significantly change. In laboratory and mesoscale experiments, the type of organic matter changed in the direction of humification (Chapters 2, 3, and 4). In the upland deposit the type of organic matter changed in the direction of humification during the first warm season, stabilized during the cold season and changed in the direction of mineralization during the second warm season (Chapter 5).

The recycling of organic amendments, such as dredged sediments, compost and manure, in agricultural soils can improve plant growth and thus crop yield, soil carbon content, and microbial biomass and activity (Thangarajan et al. 2013). There are studies reporting that the addition of organic amendments to soil can induce the mineralization of the more stable fraction of the soil organic matter and reduce the overall carbon content. This induced mineralization of the soil organic matter is called priming effect and is mainly due to the increase of decomposing microorganisms which sustain after the initial organic amendment input is exhausted, and then survive on the remaining soil organic matter (Fontaine et al. 2004). Still, there are also studies reporting a negative priming effect, i.e., the native soil organic matter mineralization can be reduced (Kuzyakov et al. 2000) when organic amendments are added to soil. The positive or negative priming effect is mostly determined by the soil microbial biomass response to the addition of different substances (Kuzyakov et al. 2000). Priming effects were found not only for carbon but also for nitrogen (Dempster et al. 2012, Fontaine et al. 2011, 
Masayna et al. 1985), phosphorus (Kuzyakov et al. 2000) and sulphur (O'Donnell et al. 1994).

Therefore, recycling dredged sediments, compost and manure in soils can have varying impacts, depending mainly on the soil type, composition of the organic amendment, climate conditions and period over which measurements are made (Cely et al. 2014, Zimmerman et al. 2011). Even though there are many scientific references regarding the addition of compost and manure to soils, no literature was found regarding the mixture of compost and manure with dredged sediments.

In this research it was found that mixtures of dredged sediments with compost or manure resulted in a positive priming effect, i.e., the $\mathrm{CO}_{2}$ produced by the mixtures was higher than the sum of the individual parts (Chapter 3).

For further research, it is recommended that these organic amendments and its mixtures are mixed with soil to assess the changes in the type of organic matter and the potential priming effect.

\subsubsection{Role of water loss in subsidence of dredged sediment drainage, evapotranspiration, evaporation by plants}

Subsidence in peatlands is mainly a consequence of drainage that results in shrinkage and oxidation of organic matter (Dawson et al. 2010, Gebhardt et al. 2010). Shrinkage refers to the loss of volume occupied by the water (through vertical and horizontal drainage and evapotranspiration) and rearrangement of the particles (including compaction) when the water is removed (Arnold \& Ghezzehei 2015, Ilnicki 2002, Oleszczuk et al. 2003, Schlotzhauer \& Price 1999).

Many peatlands are being restored back into wetlands (FAO and Wetlands International 2012) and groundwater level management is one of the strategies used to attenuate or reverse land subsidence in peatlands (Akker et al. 2008, Ballantyne et al. 2013, Berglund \& 
Berglund 2011, Hoving et al. 2011, Querner et al. 2012). One of the strategies used in peatlands where dredged sediments have to be stored is the use of underwater deposits. In principle, the underwater deposit of sediments minimize the aeration of the sediments and therefore minimize the mineralization of organic matter which is thought to be the main cause of subsidence in peatlands (Dawson et al. 2010, Hoogland et al. 2012). Furthermore, it is expected that the buoyancy caused by the higher water level will result in less shrinkage (Alfons et al. 2002).

On one hand, the effect of different water levels on the shrinkage of the sediments could not easily be determined on the small laboratory since it would be very complex to simulate the pressure of the top layers of sediments on the bottom layers, the plant growth and the weather conditions. On the other hand to determine the effect of different water tables on a field scale would have to be done either at different locations or at different seasons, which would then implicate different initial characteristics of the dredged sediments and weather conditions. Therefore, mesocosm containers of $1 \mathrm{~m}^{3}$ were chosen to perform these experiments since the water table can be manipulated, a water balance can be done, the weather conditions are close to real (even though these are in the open-air, there is the influence of a nearby building), and plants characteristic from the place of origin of the sediments can grow.

In the mesoscale experiments the scenarios of upland conditions and underwater conditions were assessed for the same sediments and under the same environmental conditions. The results show similar subsidence for the two scenarios which might be related with the high geotechnical water content observed throughout the experiment which is a consequence of the high water retention capacity of the sediments (as measured for S5 in Chapter 2). This is in line with the results of other authors who concluded that the geotechnical water content of organic 
soils cannot be deduced from groundwater levels only, and an important part of the total water storage is caused by swelling/shrinking of the peat (Kellner \& Halldin 2002).

Upland or underwater conditions did not affect the diversity and density of plants. The water balance indicates that evapotranspiration results in higher loss of water than vertical drainage (Chapter 4) which is consistent with plants increasing the evapotranspiration and playing a very important role in wetlands ecology (FAO and Wetlands International 2012).

The mesoscale experiments (Chapter 4) showed to be an effective way to simulate different scenarios for the beneficial use of dredged sediments to reverse land subsidence that cannot be easily tested on laboratory or field scale. Still, when trying to extrapolate the results to the field scale, some limitations should be considered such as the height of the sediments used in these experiments, the possible limitations on the plants (especially roots) growth, and the weather conditions of the specific location.

\subsubsection{Complementary properties}

In this research not only the biological changes were analyzed, such as transformation in the organic matter quantity and quality, but also physical parameters such as aggregate stability and undrained shear strength. By having a soil formed from sediments with very stable aggregates stability (Chapters 2, 3), the resistance to erosion of this new soil will be high and therefore the sediments being leached to the waterways will decrease. Less erosion will be translated on a lower periodicity for dredging. In addition to this, the overburden pressure of an upland deposit on the underlying soil (Chapter 5) causes the "squeezing" of the peat which will then end in the waterways, increasing the need to dredge. 
The undrained shear strength is of major importance when considering the use of the land for cattle and heavy machinery like tractors. From practice it is known that it is only possible to walk on upland deposits of $1 \mathrm{~m}$ thickness after 2-3 years of ripening. In this research, the undrained shear strength of the soils formed in Chapter 2 was enough to sustain cattle and tractors and in Chapter 3 it was observed that the addition of bio-wastes significantly increased the undrained strength. These experiments supported therefore the preference for spreading of thin layers over the land instead of using upland deposits of sediments.

\subsection{Data analysis limitations}

Before formulating the research questions of this thesis, two water boards and four end-users were consulted. All said that most changes occurring in upland deposits of dredged sediments were caused by organic matter oxidation. Having that in mind, the published literature about the use of dredged sediments was carefully read and it was found that most studies lack a detailed characterization of the dredged sediments used. Adding to that, the scientific literature regarding the use of dredged sediments on land, as topsoil or similar, is very scarce (Appendix 1). Still, the published literature together with the practical knowledge provided by the water boards and end users was the base to design the experiments and to decided the most important parameters that should be monitored to answer the research questions.

When the first laboratory experiments were designed - Chapter 2 - care was taken to select samples with varying organic matter content and particle size distribution in order to have results representative for different types of dredged sediments.

At that stage it could not be foreseen that the dredged sediments with very high organic matter and clay content would have such a special 
behavior and that shrinkage had much higher contribution to subsidence than organic matter oxidation.

When analyzing the data and interpreting the results of the laboratory scale experiments (Chapters 2 and 3 ) it was recognized that more parameters should have been determined, such as, for example, wet bulk density and pore space. Still, since the laboratory experiments had already been performed and the meso and field scale experiments were already ongoing, the available data had to be analyzed consistently for all the chapters. This thesis gives a good overview of the processes taking place during dewatering and ripening of sediments on laboratory, meso and field scale, that can support further studies. It is strongly recommended that future research takes in consideration the very high water holding capacity or organic sediments as well as its shrinkage behavior.

\subsection{Opportunities for the beneficial use of dredged sediments to reverse land subsidence}

\subsubsection{Introduction}

The industrialization and population growth around waterways in the 20th century led to the contamination of sediments with heavy metals, oils and grease, pesticides, PCBs and hydrocarbons from domestic and industrial sources (von Gunten et al. 1997). As a consequence, some European countries classify dredged sediments as a waste (Apitz 2010) and contaminated sediments were isolated from the environment in confined land disposal areas which were generally located near the dredging projects as the most economical alternative (Walsh 1977). This also resulted on a negative public perception regarding dredged sediments and its use on land. 
Nowadays there are many Directives, Conventions, Regulations and country-specific policies that apply to dredged sediments and complicate the scenario (Mink et al. 2006), starting by the classification of dredged sediments as a waste or a resource (Apitz 2010, Mink et al. 2006). Still, with the decrease in sources of pollution, the development of remediation and treatment technologies (Förstner \& Salomons 2010, Rulkens 2005), and the current policies demanding more sustainable and environmental friendly practices for sediment management (International Maritime Organization 1972, The European Parliament and The Council of the European Union 2008), there are increasing possibilities for the beneficial use of dredged sediments.

In recent years, also a new approach is being developed of looking for opportunities in nature to answer engineering challenges which can cope with changing conditions such as sea level rise and climate change has emerged, which is in line with the Green Adaptation (EU, UNEP, FAO, WWF, and Conservation International) (EEA 2013). This approaches if referred to as, for example, "Working with Nature" (PIANC 2011), or "Engineering with nature" (Banks et al. 2013). In the case of sediments, these concepts are translated as the management of dredged sediments within the water basin as a resource, and as engineered changes in hydrodynamics and natural processes to manage the sediments without the need to dredge (for example, in flood-induced inundations) (de Vriend \& van Koningsveld 2012).

Both scientific literature and European policies favor the beneficial use of sediments to reverse land subsidence. To further improve the public perception on the use of sediments, some terms attributed to sediments, such as sludge and spoil, should be avoided. Further it is recommended to emphasize the positive properties of dredged sediment in all kind of nature based engineering applications, such as increase of 
safety against flooding, nature development, redevelopment of city harbors and the reverse of land subsidence.

\subsubsection{Future research and consultants}

The main findings of this research give a new insight on the changes occurring during dewatering and biochemical ripening of dredged sediments alone or mixed with bio-wastes.

The obtained results provide to the end-users, water boards and other researchers a different perspective on the traditional practice of upland deposits of sediments and on the beneficial use of dredged sediments to reverse land subsidence. The design of dredging plans should have a clear knowledge about the cycle of sediments and ecosystem dynamics so that a coherent plan can be made that tackles not only the functioning of the waterways but also the land subsidence and coastal defence (prevention of flooding due to sea level rise by increasing the land level). By determining how the sediments and bio-wastes, as a resources, can be used to achieve the goals of all involved stakeholders, the common practice can be changed in the direction of more sustainable and cost-effective practices.

For instance, some end users involved in this project are already testing the underwater deposits for restauration of wetlands, such as De Zaag in Rotterdam, the Netherlands (Rijkswaterstaat 2016) and development of new natural areas, such as in the Merwehaven-Vierhavens in Rotterdam, the Netherlands (Stadshavens Rotterdam 2009).

Still, the communication between the scientific community and the stakeholders involved in dredging and managing dredged sediments seems to be a challenge. 


\subsubsection{Development of new policies}

It seems that the European regulations and Directives are already open to include the beneficial use of dredged sediments. In the particular case of the Netherlands, a new environmental code is expected to start in 2018, which integrates 26 Laws in the area of water, soil, sediment and air. This includes topics such as: construction, environment, water management, spatial planning, heritage and nature. The old laws are usually focused on the construction sector and no longer fit in with the current needs With this environmental code, the government wants to significantly improve the legal system (www.omgevingswet.nl). Biowastes such as compost and manure should also be integrated in the new environmental code to increase the possibilities of integration in new beneficial uses.

\subsubsection{Role of bio-wastes}

\subsubsection{Compost}

In the Netherlands the compost has a negative market value (personal communication by Adrie Veeken, Attero) which results in difficulties in application of compost. In March 2016 there was a campaign in which Attero gave $5500 \mathrm{~m}^{3}$ of compost for free to the citizens who separated the biodegradable waste that ends as compost (Attero 2016). Therefore, the search for innovative application has to be explored. In this research it was concluded from the laboratory experiments that compost can be mixed with dredged sediments to reverse the land subsidence (Chapter $3)$, which can now be explored on a larger scale.

\subsubsection{Manure}

In the Netherlands in 2014 there were about 4.1 million cows, 1 million sheep, 430 thousand goats, 12 million pigs, and 130 million chickens, which resulted in the production of approximately 74.1 billion $\mathrm{kg}$ of 
manure (Rijksoverheid 2015) that also has to be managed. AquaPurga used a method for separating the liquid and solid fraction of manure. The solid fraction is in principle rich in organic matter and fibers and poor in nutrients since most nutrients go to the liquid fraction. In this research we assessed the use of the solid fraction of pig manure mixed with sediments to reverse land subsidence and the results show that this is a feasible destination for the solid fraction of manure.

\subsubsection{Impact to the Water boards}

From monitoring the upland deposit (Chapter 5) it was observed that the pressure that the deposit of $125-195 \mathrm{~cm}$ of sediments exerted over the underlying soils caused a subsidence of 19.5 of the underlying soil. Furthermore, the pressure of the sediments cause the "squeezing" of the underlying soil which then ends in the waterways as sediments that have to be dredged. Therefore, the results of this research suggest that new approaches for the management of the sediments should be tested. Even though it might seem that the initial investment of spreading thinner layers of sediments over larger areas will have increased costs at short time, it might be more advantageous when the complete cycle of the sediments is considered. 
References 

Aich S, McVoy CW, Dreschel TW, Santamaria F (2013): Estimating soil subsidence and carbon loss in the Everglades Agricultural Area, Florida using geospatial techniques. Agr Ecosyst Environ 171, 124-133

Akker JJHvd, P.J. Kuikman, Vries Fd, Hoving I, Pleijter M, Hendriks RFA, Wolleswinkel RJ, Simões RTL, Kwakernaak. C (2008): Emission of CO2 from agricultural peat soils in the Netherlands and ways to limit this emission, Proceedings of the 13th International Peat Congress After Wise Use - The Future of Peatlands, Vol. 1 Oral Presentations, Tullamore, Ireland, 8 - 13 june 2008. - Jyväskylä, Finland : International Peat Society, Proceedings of the 13th International Peat Congress, Tullamore, Ireland, 2008-06-08/ 2008-06-13

Albrecht R, Sebag D, Verrecchia E (2015): Organic matter decomposition: bridging the gap between Rock-Eval pyrolysis and chemical characterization (CPMAS 13C NMR). Biogeochemistry 122, 101-111

Alfons JPS, Hilde BMT, Leon PML, Lomans BP, Jan GMR (2002): Peat Bog Restoration by Floating Raft Formation: The Effects of Groundwater and Peat Quality. Journal of Applied Ecology 39, 391-401

Amézketa E (1999): Soil Aggregate Stability: A Review. J Sustain Agriculture 14, 83-151

Andersen R, Chapman SJ, Artz RRE (2013): Microbial communities in natural and disturbed peatlands: A review. Soil Biology and Biochemistry $57,979-994$

Angers DA, Chantigny MH, MacDonald JD, Rochette P, Côté D (2010): Differential retention of carbon, nitrogen and phosphorus in grassland soil profiles with long-term manure application. Nutr $\mathrm{Cycl}$ AgroEcoSys $86,225-229$ 
Annabi M, Le Bissonnais Y, Le Villio-Poitrenaud M, Houot S (2011): Improvement of soil aggregate stability by repeated applications of organic amendments to a cultivated silty loam soil. Agr Ecosyst Environ $144,382-389$

Aouad G, Laboudigue A, Gineys N, Abriak NE (2012): Dredged sediments used as novel supply of raw material to produce Portland cement clinker. Cement and Concrete Composites 34, 788-793

Apitz S (2010): Waste or resource? Classifying and scoring dredged material management strategies in terms of the waste hierarchy. Journal of Soils and Sediments 10, 1657-1668

Apitz SE (2008): Is risk-based, sustainable sediment management consistent with European policy? Journal of Soils and Sediments 8, 461466

Arnold CL, Ghezzehei TA (2015): A method for characterizing desiccation-induced consolidation and permeability loss of organic soils. Water Resour. Res. 51, 775-786

Attero (2016): Vijfeneenhalfduizend kuub gratis compost van Attero Augustin LN, Heilman DJ, Rocha DD (2011): Restoring estuarine habitat in Galveston west bay through beneficial use of dredged sediments. In: Wang P, Rosati JD, Roberts TM (Hrsg.), The proceeding of the Coastal Sediments 2011

Ayuke FO, Brussaard L, Vanlauwe B, Six J, Lelei DK, Kibunja CN, Pulleman MM (2011): Soil fertility management: Impacts on soil macrofauna, soil aggregation and soil organic matter allocation. Appl Soil Ecol 48, 53-62

Baldock JA, Skjemstad JO (2000): Role of the soil matrix and minerals in protecting natural organic materials against biological attack. Organic Geochem 31, 697-710 
Ballantyne DM, Hribljan JA, Pypker TG, Chimner RA (2013): Long-term water table manipulations alter peatland gaseous carbon fluxes in Northern Michigan. Wetlands Ecology and Management 22, 35-47

Banks CJ, Fredette TJ, Suedel BC, Bridges TS (2013): Implementing Engineering With Nature within the Corps: A Workshop, Engineering With Nature: Designing Navigation Infrastructure for Greater Environmental Sustainability, Charleston, South Carolina

Barnes GE (2000): Soil mechanics - Principles and practice. PALGRAVE

Bedell J-P, Briant A, Delolme C, Perrodin Y (2003): Evaluation of the phytotoxicity of contaminated sediments deposited "on soil". I. Impact of water draining from the deposit on the germination of neighbouring plants. Chemosphere 50, 393-402

Berg B, Laskowski R (2005): Decomposers: Soil Microorganisms and Animals, Advances in Ecological Research. Academic Press, pp. 73-100

Berglund Ö, Berglund K (2011): Influence of water table level and soil properties on emissions of greenhouse gases from cultivated peat soil. Soil Biology and Biochemistry 43, 923-931

Bernal MP, Kirchmann H (1992): Carbon and nitrogen mineralization and ammonia volatilization from fresh, aerobically and anaerobically treated pig manure during incubation with soil. Biol Fert Soils 13, 135-141

Bolte K, Hartmann P, Fleige H, Horn R (2011): Determination of critical soil water content and matric potential for wind erosion. Journal of Soils and Sediments 11, 209-220

Borken W, Muhs A, Beese F (2002): Application of compost in spruce forests: effects on soil respiration, basal respiration and microbial biomass. Forest Ecol Manag 159, 49-58

Bortone G, Arevalo E, Deibel I, Detzner H-D, de Propris L, Elskens F, Giordano A, Hakstege P, Hamer K, Harmsen J, Hauge A, Palumbo L, van 
Veen J (2004a): Synthesis of the sednet work package 4 outcomes. Journal of Soils and Sediments 4, 225-232

Bortone G, Arevalo E, Deibel I, Detzner H-D, Propris L, Elskens F, Giordano A, Hakstege P, Hamer K, Harmsen J, Hauge A, Palumbo L, Veen J (2004b): Synthesis of the sednet work package 4 outcomes. Journal of Soils and Sediments 4, 225-232

Bossuyt H, Six J, Hendrix PF (2005): Protection of soil carbon by microaggregates within earthworm casts. Soil Biology and Biochemistry $37,251-258$

Brady NC, Weil RR (2008): The Nature and Properties of Soils. Pearson/Prentice Hall; Fourteenth Edition

Bramley RGV, Rimmer DL (1988): Dredged materials-problems associated with their use on land. J Soil Sci 39, 469-482

Brils J, de Boer P, Mulder J, de Boer E (2014): Reuse of dredged material as a way to tackle societal challenges. Journal of Soils and Sediments, 1-4

Brose DA, Hundal LS, Oladeji OO, Kumar K, Granato TC, Cox A, Abedin Z (2016): Greening a Steel Mill Slag Brownfield with Biosolids and Sediments: A Case Study. Journal of Environmental Quality 45, 53-61

Brouns K, Eikelboom T, Jansen PC, Janssen R, Kwakernaak C, van den Akker JJH, Verhoeven JTA (2015): Spatial Analysis of Soil Subsidence in Peat Meadow Areas in Friesland in Relation to Land and Water Management, Climate Change, and Adaptation. Environmental Management 55, 360-372

Camporese M, Ferraris S, Putti M, Salandin P, Teatini PCW (2006): Hydrological modeling in swelling/shrinking peat soils. Water Resour. Res. $42, n / a-n / a$ 
Canet R, Chaves C, Pomares F, Albiach R (2003): Agricultural use of sediments from the Albufera Lake (eastern Spain). Agr Ecosyst Environ 95, 29-36

Carpenter SR (2005): Eutrophication of Aquatic Ecosystems: Bistability and Soil Phosphorus. Proceedings of the National Academy of Sciences of the United States of America 102, 10002-10005

Cely P, Tarquis AM, Paz-Ferreiro J, Méndez A, Gascó G (2014): Factors driving the carbon mineralization priming effect in a sandy loam soil amended with different types of biochar. Solid Earth 5, 585-594

Chaplot V, Cooper M (2015): Soil aggregate stability to predict organic carbon outputs from soils. Geoderma 243-244, 205-213

Chiang K-Y, Chien K-L, Hwang S-J (2008): Study on the characteristics of building bricks produced from reservoir sediment. Journal of Hazardous Materials 159, 499-504

Coleman D, D CJ, Hendrix P (2004): Fundamentals of Soil Ecology. Elsevier Academic, Amsterdam, NL

COM (2008): Green Paper On the management of bio-waste in the European Union In: Communities CotE (Hrsg.), Brussels

Comoss EJ, Kelly DA, Leslie HZ (2002): Innovative erosion control involving the beneficial use of dredge material, indigenous vegetation and landscaping along the Lake Erie Shoreline. Ecol Eng 19, 203-210

Coulet W, Kearney S, Ekkelenkamp H, Hunte T 2014: An Assessment of the Feasibility of Stabilising Dredged Highly Organic Sediment and Use in Floodbank Construction in Norfolk, UK, Promoting Integrated Sediment Management - PRISMA, a report by the Broads Authority

d'Errico G, Giovannelli D, Montano C, Milanovic V, Ciani M, Manini E (2013): Bioremediation of high organic load lagoon sediments: Compost addition and priming effects. Chemosphere 91, 99-104 
Dang TA, Kamali-Bernard S, Prince WA (2013): Design of new blended cement based on marine dredged sediment. Constr Build Mater 41, 602611

Dawson Q, Kechavarzi C, Leeds-Harrison PB, Burton RGO (2010): Subsidence and degradation of agricultural peatlands in the Fenlands of Norfolk, UK. Geoderma 154, 181-187

de Vriend H, van Koningsveld M (2012): Building with Nature: Thinking, acting and interacting differently. EcoShape, Building with nature, Dordrecht, the Netherlands

Delaune RD, Reddy CN, Patrick Jr WH (1981): Organic matter decomposition in soil as influenced by $\mathrm{pH}$ and redox conditions. Soil Biology and Biochemistry 13, 533-534

Dempster DN, Gleeson DB, Solaiman ZM, Jones DL, Murphy DV (2012): Decreased soil microbial biomass and nitrogen mineralisation with Eucalyptus biochar addition to a coarse textured soil. Plant Soil 354, 311-324

Dendooven L, Bonhomme E, Merckx R, Vlassak K (1998): Injection of pig slurry and its effects on dynamics of nitrogen and carbon in a loamy soil unter laboratory conditions. Biol Fert Soils 27, 5-8

Deviren Saygın S, Cornelis WM, Erpul G, Gabriels D (2012): Comparison of different aggregate stability approaches for loamy sand soils. Appl Soil Ecol 54, 1-6

Dilly O (2001): Microbial respiratory quotient during basal metabolism and after glucose amendment in soils and litter. Soil Biology and Biochemistry 33, 117-127

Disnar JR, Guillet B, Keravis D, Di-Giovanni C, Sebag D (2003): Soil organic matter (SOM) characterization by Rock-Eval pyrolysis: scope and limitations. Organic Geochem 34, 327-343 
EEA 2013: Adaptation in Europe - Addressing risks and opportunities from climate change in the context of socio-economic developments

Eek E, Godoy A, Aagaard P, Breedveld GD (2007): Experimental determination of efficiency of capping materials during consolidation of metal-contaminated dredged material. Chemosphere 69, 719-728

Elmholt S, Schjønning P, Munkholm LJ, Debosz K (2008): Soil management effects on aggregate stability and biological binding. Geoderma 144, 455-467

EPA \& USEPA 2007: Role of the Federal Standard in the Beneficial Use of Dredged Material from US Army Corps of Engineers New and Maintenance Navigation Projects - Beneficial Uses of Dredged Materials, Environmental Protection Agency \& United States Army Corps of Engineers (EPA \& USACE)

European Soil Portal (2012): Glossary of soil terms, Europehan Soil Portal - Soil Data and Information Systems, European Comission, Joint Research Centre, Institute for Environmenta and Sustainability, Land Resource Management Unit,

FAO (1998): Crop evapotranspiration - Guidelines for computing crop water requirements - FAO Irrigation and drainage paper 56. In: Allen RG, Pereira LS, Raes D, Smith M (Hrsg.). FAO - Food and Agriculture Organization of the United Nations, Rome

FAO and Wetlands International (2012): Peatlands - guidance for climate change mitigation through conservation, rehabilitation and sustainable use. Mitigation of Climate Change in Agriculture (MICCA) Programme. Food and Agriculture Organization of the United Nations and Wetlands International 
Fonseca R, Barriga FJAS, Fyfe WS (1998): Reversing desertification by using dam reservoir sediments as agriculture soils. Episodes 21, 218224

Fontaine S, Bardoux G, Abbadie L, Mariotti A (2004): Carbon input to soil may decrease soil carbon content. Ecol Lett 7, 314-320

Fontaine S, Henault C, Aamor A, Bdioui N, Bloor JMG, Maire V, Mary B, Revaillot S, Maron PA (2011): Fungi mediate long term sequestration of carbon and nitrogen in soil through their priming effect. Soil Biology and Biochemistry 43, 86-96

Förstner U, Salomons W (2010): Sediment research, management and policy. Journal of Soils and Sediments 10, 1440-1452

French JR, Burningham H (2009): Restoration of an eroded estuarine foreshore using cohesive dredge material, Orwell Estuary, UK. Journal of Coastal Research SI 56 (Proceedings of the 10th International coastal symposium,Lisbon, Portugal), 1444-1448

Gandolfi I, Sicolo M, Franzetti A, Fontanarosa E, Santagostino A, Bestetti $G$ (2010): Influence of compost amendment on microbial community and ecotoxicity of hydrocarbon-contaminated soils. Bioresource Technol $101,568-575$

Garcia Navarro P (2010): Management of dredged material in the port of Huelva, Spain. Proceedings of the Institution of Civil Engineers-Maritime Engineering 163, 171-177

Gebhardt S, Fleige H, Horn R (2010): Shrinkage processes of a drained riparian peatland with subsidence morphology. Journal of Soils and Sediments 10, 484-493

Gilmanov TG et al. (2007): Partitioning European grassland net ecosystem $\mathrm{CO} 2$ exchange into gross primary productivity and ecosystem 
respiration using light response function analysis. Agr Ecosyst Environ $121,93-120$

Giulio Bernstein A, Bonsembiante E, Brusatin G, Calzolari G, Colombo P, Dall'Igna R, Hreglich S, Scarinci G (2002): Inertization of hazardous dredging spoils. Waste Manage 22, 865-869

Gruhn P, Goletti F, Yudelman M (2000): Integrated nutrient management, soil fertility, and sustainable agriculture: current issues and future challenges. Intl Food Policy Res Inst

Guenet B, Juarez S, Bardoux G, Abbadie L, Chenu C (2012): Evidence that stable $C$ is as vulnerable to priming effect as is more labile $C$ in soil. Soil Biology and Biochemistry 52, 43-48

Gui Y, Cao J, Song ZG, Zhang Q (2011): Evaluation of Undrained Shear Strength of Converting Dredged Material to Agricultural Soil. Applied Mechanics, Materials and Engineering Applications 147, 191-196

Hamza MA, Anderson WK (2005): Soil compaction in cropping systems: A review of the nature, causes and possible solutions. Soil Till Res 82, 121-145

Harmsen J (2007): Measuring Bioavailability: From a Scientific Approach to Standard Methods All rights reserved. No part of this periodical may be reproduced or transmitted in any form or by any means, electronic or mechanical, including photocopying, recording, or any information storage and retrieval system, without permission in writing from the publisher. Journal of Environmental Quality 36, 1420-1428

Harmsen J, Rietra RPJJ, Groenenberg JE, Lahr J, Toorn Avd, Zweers HJ 2012: Verspreiden van bagger op het land in klei- en veengebieden, Alterra - Wageningen UR

Harmsen J, Naidu R (2013): Bioavailability as a tool in site management. Journal of Hazardous Materials 261, 840-846 
Hendriks DMD, van Huissteden J, Dolman AJ, van der Molen MK (2007a): The full greenhouse gas balance of an abandoned peat meadow. Biogeosciences 4, 411-424

Hendriks RFA, Wollewinkel R, Akker JJHvd (2007b): Predicting soil subsidence and greenhouse gas emission in peat soils depending on water management with the SWAP-ANIMO model, Proceedings of the First International Symposium on Carbon in Peatlands, pp. 583-586

Holden J, Burt TP (2002): Infiltration, runoff and sediment production in blanket peat catchments: implications of field rainfall simulation experiments. Hydrological Processes 16, 2537-2557

Hoogland T, van den Akker JJH, Brus DJ (2012): Modeling the subsidence of peat soils in the Dutch coastal area. Geoderma 171-172, 92-97

Hooijer A, Page S, Jauhiainen J, Lee WA, Lu XX, Idris A, Anshari G (2012): Subsidence and carbon loss in drained tropical peatlands. Biogeosciences 9, 1053-1071

Hoving IE, Akker JJHvd, Pleijter M, Houwelingen Kv 2011: Hydrologische en landbouwkundige effecten toepassing onderwaterdrains in polder Zeevang. - Hydraulic an Agricultural effects of applying 'submerged drains' in the Zeevang polder. Rapport 449, Wageningen UR Livestock Research

Hupe K, Lüth JC, Heerenklage J, Stegmann R (1996): Enhancement of the biological degradation of soils contaminated with oil by the addition of compost. Acta Biotechnol 16, 19-30

IADC (1999): From hand-drag to Jumbo: A millennium of dredging. Terra et Aqua, 5-48

IADC, IAPH 2010: Dredging for development 
Ibáñez C, Day JW, Reyes E (2014): The response of deltas to sea-level rise: Natural mechanisms and management options to adapt to high-end scenarios. Ecol Eng 65, 122-130

Ilnicki P (2002): Agricultural production systems for organic soil conservation. In: Parent L-E, Ilnicki P (Editors), Organic soils and peat materials for sustainable agriculture

International Maritime Organization 1972: Convention on the Prevention of Marine Pollution by Dumping of Wastes and Other Matter

ISO 17402:2008 (2008): Soil quality - Requirements and guidance for the selection and application of methods for the assessment of bioavailability of contaminants in soil and soil materials, Technical Committee ISO/TC 190, Soil quality, Subcommittee SC 7, Soil and site assessment.

Jacobs CMJ, Jacobs AFG, Bosveld FC, Hendriks DMD, Hensen A, Kroon PS, Moors EJ, Nol L, Schrier-Uijl A, Veenendaal EM (2007): Variability of annual CO2 exchange from Dutch grasslands. Biogeosciences 4, 803816

Jacobs P, Förstner U (2001): Managing contaminated sediments. Journal of Soils and Sediments 1, 205-212

Kechavarzi C, Dawson Q, Leeds-Harrison PB (2010): Physical properties of low-lying agricultural peat soils in England. Geoderma 154, 196-202

Kellner E, Halldin S (2002): Water budget and surface-layer water storage in a Sphagnum bog in central Sweden. Hydrological Processes $16,87-103$

Kemper WD, Rosenau RC (1986): Aggregate stability and size distribution. In: Klute A (Editor), Methods of soil analysis. Part 1 Physical and mineralogical methods. Second Edition. American Society 
of Agronomy, Inc. and Soil science Society of America, Inc. Madison, Wisconsin USA, USA, pp. 425-442

Kirkby CA, Kirkegaard JA, Richardson AE, Wade LJ, Blanchard C, Batten G (2011): Stable soil organic matter: A comparison of C:N:P:S ratios in Australian and other world soils. Geoderma 163, 197-208

Kirkby CA, Richardson AE, Wade LJ, Batten GD, Blanchard C, Kirkegaard JA (2013): Carbon-nutrient stoichiometry to increase soil carbon sequestration. Soil Biology and Biochemistry 60, 77-86

Kirkby CA, Richardson AE, Wade LJ, Passioura JB, Batten GD, Blanchard C, Kirkegaard JA (2014): Nutrient availability limits carbon sequestration in arable soils. Soil Biology and Biochemistry 68, 402-409

Kirkels FMSA, Cammeraat LH, Kuhn NJ (2014): The fate of soil organic carbon upon erosion, transport and deposition in agricultural landscapes - A review of different concepts. Geomorphology 226, 94-105

Klute A, Dirksen C (1986): Water retention: Laboratory methods. In: Klute A (Editor), Methods of soil analysis. Part 1 - Physical and mineralogical methods. 2nd Edition. American Society of Agronomy, Inc. and Soil science Society of America, Inc. Madison, Wisconsin USA, Wisconsin, USA, pp. 635-686

Knicker H (2011): Soil organic N - An under-rated player for C sequestration in soils? Soil Biology and Biochemistry 43, 1118-1129

Knoblauch C, Beer C, Sosnin A, Wagner D, Pfeiffer E-M (2013): Predicting long-term carbon mineralization and trace gas production from thawing permafrost of Northeast Siberia. Glob Change Biol 19, 1160-1172

Kolker AS, Allison MA, Hameed S (2011): An evaluation of subsidence rates and sea-level variability in the northern Gulf of Mexico. Geophys. Res. Lett. 38, L21404 
Koorevaar P, Dirksen C, Menelik G (1983): Elements of soil physics. Developments in soil science 13. Elsevier, Amsterdam, Netherlands

Kotzerke A, Sharma S, Schauss K, Heuer H, Thiele-Bruhn S, Smalla K, Wilke B-M, Schloter M (2008): Alterations in soil microbial activity and $\mathrm{N}$-transformation processes due to sulfadiazine loads in pig-manure. Environ Poll 153, 315-322

Kramer MG, Sollins P, Sletten RS, Swart PK (2003): N Isotope Fractionation and Measures of Organic Matter Alteration during Decomposition. Ecology 84, 2021-2025

Kronvang B, Laubel A, Larsen SE, Friberg N (2003): Pesticides and heavy metals in Danish streambed sediment. Hydrobiologia 494, 93-101

Krull ES, Baldock JA, Skjemstad JO (2003): Importance of mechanisms and processes of the stabilisation of soil organic matter for modelling carbon turnover. Funct Plant Biol 30, 207-222

Kuzyakov Y, Friedel JK, Stahr K (2000): Review of mechanisms and quantification of priming effects. Soil Biology and Biochemistry 32, 1485-1498

Lafargue E, Marquis F, Pillot D (1998): Rock-Eval 6 Applications in Hydrocarbon Exploration, Production, and Soil Contamination Studies. Oil Gas Sci Technol 53, 421-437

Lafrenz MD, Bean RA, Uthman D (2013): Soil ripening following dam removal. Phys Geogr 34, 124-135

Lal R (2008): Promise and limitations of soils to minimize climate change. J Soil Water Conserv 63, 113A-118A

Langeveld CA, Segers R, Dirks BOM, van den Pol-van Dasselaar A, Velthof GL, Hensen A (1997): Emissions of $\mathrm{CO} 2, \mathrm{CH} 4$ and $\mathrm{N} 2 \mathrm{O}$ from pasture on drained peat soils in the Netherlands. Eur J Agron 7, 35-42 


\section{References}

Leue M, Lang F (2012): Recycling soil nutrients by using channel deposits as fertilizers? Nutr Cycl AgroEcoSys 93, 75-88

Lewis KC, Zyvoloski GA, Travis B, Wilson C, Rowland JCF (2012): Drainage subsidence associated with Arctic permafrost degradation. J. Geophys. Res. 117, n/a-n/a

Limeira J, Agullo L, Etxeberria M (2012): Dredged marine sand as a new source for construction materials. Materiales De Construccion 62, 7-24

Linders JA 2011: Baggerplan Wormer- en Jisperwater - Dredging plan for Wormer- en Jisperwater (in Dutch), Hoogheemraadschap Hollands Noorderkwartier

Lohrer AM, Wetz JJ (2003): Dredging-induced nutrient release from sediments to the water column in a southeastern saltmarsh tidal creek. Marine Pollution Bulletin 46, 1156-1163

Madigan MT, Martinko JM, Stahl DA, Clark DP (2010): Brock Biology of Microorganisms (13th Edition)

Malasavage N, Jagupilla S, Grubb D, Wazne M, Coon W (2012): Geotechnical Performance of Dredged Material-Steel Slag Fines Blends: Laboratory and Field Evaluation. Journal of Geotechnical and Geoenvironmental Engineering 138, 981-991

Masayna W, Kai H, Kawaguchi S (1985): Nitrogen behavior in tropical wetland rice soils. 2 . The efficiency of fertilizer nitrogen, priming effect and A-values. Fert Res 6, 37-47

Mattei P, Cincinelli A, Martellini T, Natalini R, Pascale E, Renella G (2016): Reclamation of river dredged sediments polluted by PAHs by cocomposting with green waste. Science of The Total Environment 566$567,567-574$ 
Mezencevova A, Yeboah NN, Burns SE, Kahn LF, Kurtis KE (2012): Utilization of Savannah Harbor river sediment as the primary raw material in production of fired brick. J Environ Manage 113, 128-136

Mink F, Dirks W, Gerard VR, Hugo dV, Russell M (2006): Impact of European Union environmental law on dredging. Terra et Aqua 104, 310

Miraoui M, Zentar R, Abriak N-E (2012): Road material basis in dredged sediment and basic oxygen furnace steel slag. Constr Build Mater 30, 309-319

Moore PA, Pypker TG, Waddington JM (2013): Effect of long-term water table manipulation on peatland evapotranspiration. Agricultural and Forest Meteorology 178-179, 106-119

Mosier A, Kroeze C, Nevison C, Oenema O, Seitzinger S, van Cleemput $\mathrm{O}$ (1998): Closing the global $\mathrm{N}_{2} \mathrm{O}$ budget: nitrous oxide emissions through the agricultural nitrogen cycle. Nutr Cycl AgroEcoSys 52, 225248

Munkholm LJ (2011): Soil friability: A review of the concept, assessment and effects of soil properties and management. Geoderma 167-168, 236-246

Naidu R, Channey R, McConnell S, Johnston N, Semple KT, McGrath S, Dries $V$, Nathanail P, Harmsen J, Pruszinski A, MacMillan J, Palanisami T (2015): Towards bioavailability-based soil criteria: past, present and future perspectives. Environmental Science and Pollution Research 22, 8779-8785

Natuurmonumenten (2015): Natuurmonumenten - Wormer- en Jisperveld. Over dit natuurgebied 
Netzband A (2007): Sediment Management: An essential element of River Basin Management Plans. Journal of Soils and Sediments 7, 117132

O'Donnell AG, Wu J, Syers JK (1994): Sulphate-S amendments in soil and their effects on the transformation of soil sulphur. Soil Biology and Biochemistry 26, 1507-1514

Ohimain EI, Andriesse W, van Mensvoort MEF (2004): Environmental impacts of abandoned dredged soils and sediments. Journal of Soils and Sediments 4, 59-65

Oleszczuk R, Bohne K, Szatylowicz J, Brandyk T, Gnatowski T (2003): Influence of load on shrinkage behavior of peat soils. Journal of Plant Nutrition and Soil Science 166, 220-224

Oliveira BRF, Smit MPJ, van Paassen LA, Grotenhuis TC, Rijnaarts HHM (2016): Functional properties of soils formed from biochemical ripening of dredged sediments-subsidence mitigation in delta areas. Journal of Soils and Sediments, 1-13

Oliveira BRF, Smit MPJ, Rijnaarts HHM, Grotenhuis T (submitted-a): Subsidence of organic dredged sediments - mesoscale experiments with different water levels. Journal of Soils and Sediments

Oliveira BRF, Smit MPJ, Veld H, Rijnaarts HHM, Grotenhuis T (submittedb): Subsidence of organic dredged sediments in an upland deposit in Wormer- en Jisperveld - North Holland, the Netherlands. Wetlands Ecology and Management

Owens P (2005): Conceptual Models and Budgets for Sediment Management at the River Basin Scale (12 pp). Journal of Soils and Sediments 5, 201-212 
Palumbo L (2007): Sediment management of nations in Europe. In: Bortone G (Editor), Sediment and dredged material treatment, pp. 1158

Parson LE, Swafford R (2012): Beneficial Use of Sediments from Dredging Activities in the Gulf of Mexico. Journal of Coastal Research, 45-50

Perrodin Y, Babut M, Bedell J-P, Bray M, Clement B, Delolme C, Devaux A, Durrieu C, Garric J, Montuelle B (2006): Assessment of ecotoxicological risks related to depositing dredged materials from canals in northern France on soil. Environment International 32, 804814

Perrodin Y, Donguy G, Bazin C, Volatier L, Durrieu C, Bony S, Devaux A, Abdelghafour M, Moretto R (2012): Ecotoxicological risk assessment linked to infilling quarries with treated dredged seaport sediments. Science of the Total Environment 431, 375-384

PIANC 1992: Beneficial uses of dredged material - a practical guide, PIANC - The World Association for Waterborne Transport Infrastructure

PIANC 2011: Working with nature - position paper, PIANC - THE World Association for Waterborne Transport Infrastructure; First published October 2008; revised January 2011

Pons LJ, Zonneveld IS 1965: Soil ripening and soil classification : initial soil formation of alluvial deposits with a classification of the resulting soils, Publication 13, International Institute for Land Reclamation and Improvement

PreSens 2012: VisiSens AnalytiCal 3 software manual VA3.10, PreSens Precision Sensing $\mathrm{GmbH}$, Germany 
PreSens 2013: Oxygen sensor foil for imaging SF-RPSu4 - Instructions manual. Document name: IM_SF-RPSu4_dv2, PreSens - Precision Sensing $\mathrm{GmbH}$, Germany.

Price JS, Schlotzhauer SM (1999): Importance of shrinkage and compression in determining water storage changes in peat: the case of a mined peatland. Hydrological Processes 13, 2591-2601

Pronger J, Schipper LA, Hill RB, Campbell DI, McLeod M (2014): Subsidence Rates of Drained Agricultural Peatlands in New Zealand and the Relationship with Time since Drainage. Journal of Environmental Quality 43

Pulleman MM, Six J, Van Breemen N, Jongmans AG (2005): Soil organic matter distribution and microaggregate characteristics as affected by agricultural management and earthworm activity. European Journal of Soil Science 56, 453-467

Querner EP, Jansen PC, van den Akker JJH, Kwakernaak C (2012): Analysing water level strategies to reduce soil subsidence in Dutch peat meadows. J Hydrol 446-447, 59-69

Reine K, Clarke D, Ray G, Dickerson C (2013): Fishery resource utilization of a restored estuarine borrow pit: A beneficial use of dredged material case study. Marine Pollution Bulletin 73, 115-128

Rijksoverheid (2015): Ontwikkeling veestapel op landbouwbedrijven, 1980-2014

Rijkswaterstaat (2016): De Zaag: nieuwe natuur onder de rook van Rotterdam. Rijkswaterstaat - Ministerie van Infrastructuur en Milieu Ritzema HP, Stuyt LCPM (2015): Land drainage strategies to cope with climate change in the Netherlands. Acta Agriculturae Scandinavica, Section B - Soil \& Plant Science 65, 80-92 
RIVM 2012: Advice on implementing bioavailability in the Dutch soil policy framework - User protocols for organic contaminants, National Institute for Public Health and the Environment, Ministry of Health, Welfare and Sport (Rijksinstituut voor Volksgezondheid en Milieu RIVM), The Netherlands

Rousk J, Brookes PC, Båăth E (2010): Investigating the mechanisms for the opposing $\mathrm{pH}$ relationships of fungal and bacterial growth in soil. Soil Biology and Biochemistry 42, 926-934

Rulkens W (2005): Introduction to the Treatment of Polluted Sediments. Reviews in Environmental Science and Bio/Technology 4, 213-221

Salomons W (2008): Linking soils, sediments and catchment ecosystems. Journal of Soils and Sediments 8, 67-68

Samara M, Lafhaj Z, Chapiseau C (2009): Valorization of stabilized river sediments in fired clay bricks: Factory scale experiment. Journal of Hazardous Materials 163, 701-710

Sanei H, Stasiuk LD, Goodarzi F (2005): Petrological changes occurring in organic matter from Recent lacustrine sediments during thermal alteration by Rock-Eval pyrolysis. Organic Geochem 36, 1190-1203

Schlotzhauer SM, Price JS (1999): Soil water flow dynamics in a managed cutover peat field, Quebec: Field and laboratory investigations. Water Resour. Res. 35, 3675-3683

Schmidt MWI, Torn MS, Abiven S, Dittmar T, Guggenberger G, Janssens IA, Kleber M, Kogel-Knabner I, Lehmann J, Manning DAC, Nannipieri P, Rasse DP, Weiner S, Trumbore SE (2011): Persistence of soil organic matter as an ecosystem property. 478, 49-56

Schothorst CJ (1977): Subsidence of low moor peat soils in the western Netherlands. Geoderma 17, 265-291 
Schouwenaars JM (2000): Water levels in the Echten polder: improving agriculture and reducing land subsidence risks, International Conference on "Agricultural Effects on Ground and Surface Waters: Research at the Edge of Science and Society". IAHS Publication no. 273, Wageningen, The Netherlands

Schrier-Uijl AP, Kroon PS, Hendriks DMD, Hensen A, Van Huissteden J, Berendse F, Veenendaal EM (2014): Agricultural peatlands: towards a greenhouse gas sink \&ndash; a synthesis of a Dutch landscape study. Biogeosciences 11, 4559-4576

Schwärzel K, Renger M, Sauerbrey R, Wessolek G (2002): Soil physical characteristics of peat soils. Journal of Plant Nutrition and Soil Science $165,479-486$

Semple KT, Morriss AWJ, Paton GI (2003): Bioavailability of hydrophobic organic contaminants in soils: fundamental concepts and techniques for analysis. European Journal of Soil Science 54, 809-818

Sheehan C, Harrington J, Murphy JD (2009): Dredging and Dredged Material Beneficial Use in Ireland. Terra et Aqua 115, 3-14

Sheehan C, Harrington J, Murphy JD (2010a): A technical assessment of topsoil production from dredged material. Resour Conserv Recy 54, 1377-1385

Sheehan C, Harrington J, Murphy JD (2010b): An environmental and economic assessment of topsoil production from dredge material. Resour Conserv Recy 55, 209-220

Shiklomanov NI, Streletskiy DA, Little JD, Nelson FECGL (2013): Isotropic thaw subsidence in undisturbed permafrost landscapes. Geophys. Res. Lett. 40, 6356-6361 
Six J, Conant RT, Paul EA, Paustian K (2002): Stabilization mechanisms of soil organic matter: Implications for C-saturation of soils. Plant Soil 241, 155-176

Six J, Bossuyt H, Degryze S, Denef K (2004): A history of research on the link between (micro)aggregates, soil biota, and soil organic matter dynamics. Soil Till Res 79, 7-31

Slobbe E, Vriend HJ, Aarninkhof S, Lulofs K, Vries M, Dircke P (2013): Building with Nature: in search of resilient storm surge protection strategies. Natural Hazards 65, 947-966

Smit MP 2009: Contaminant release from sediments: a mass flux approach, Wageningen University, Wageningen, The Netherlands

Soil and Plant Analysis Council Inc. 1999: Soil analysis handbook of reference methods, CRC Press LLC

Stadshavens Rotterdam 2009: Pionieren aan de Maas, Gebiedsplan concept - Merwehaven-Vierhavens, Rotterdam, the Netherlands (in Dutch)

Stichting Flora van Nederland (2014): Flora van Nederland - wilde planten en hun omgeving online (in Dutch)

STOWA 2009: Verbetering bepaling actuele verdamping voor het strategisch waterbeheer (in Dutch)

Sumner ME (2000): Handbook of soil science. CRC Press, Boca Raton, Fla

Teatini P, Tosi L, Strozzi T (2011): Quantitative evidence that compaction of Holocene sediments drives the present land subsidence of the Po Delta, Italy. J Geophys Res 116, B08407

Terzaghi K, Peck RB, Mesri G (1996): Soil mechanics in engineering practice. Wiley-Interscience 
Thangarajan R, Bolan NS, Tian G, Naidu R, Kunhikrishnan A (2013): Role of organic amendment application on greenhouse gas emission from soil. Science of The Total Environment 465, 72-96

The European Parliament and The Council of the European Union (2008): Waste Framework Directive, Directive 2008/98/EC. Official Journal of the European Union, L312/3 - L312/30

The Innovative Reuse Committee 2007: Innovative reuse of dredged material, Report to the Executive Committee of Maryland's dredged material management program

Tichý R 1998: Bioleaching of metals from soils or sediments using the microbial sulfur cycle, Wageningen Agricultural University, Wageningen, $\mathrm{NL}, 139 \mathrm{pp}$

Torres P, Manjate RS, Fernandes HR, Olhero SM, Ferreira JMF (2009): Incorporation of river silt in ceramic tiles and bricks. Ind Ceram 29, 5-12 Tuukkanen T, Marttila H, Kløve B (2014): Effect of soil properties on peat erosion and suspended sediment delivery in drained peatlands. Water Resour. Res. 50, 3523-3535

Urbanek E, Smucker AJM, Horn R (2011): Total and fresh organic carbon distribution in aggregate size classes and single aggregate regions using natural ${ }^{13} \mathrm{C} /{ }^{12} \mathrm{C}$ tracer. Geoderma $164,164-171$

USACE 1987: Engineering and Design - Beneficial uses of dredged material, USACE - U. S. Army Corps of Engineers

USACE 2008: Dredged Material Management Plan for the Port of New York and New Jersey - Update, USACE - United States Army Corps of Engineers - New York District

USDA 1987: Soil Mechanics Level 1, Module 3 - USDA Textural Classification Study Guide, National Employee Development Staff, Soil conservation Service, United States Department of Agriculture 
van Asselen S (2011): The contribution of peat compaction to total basin subsidence: implications for the provision of accommodation space in organic-rich deltas. Basin Res 23, 239-255

van der Wal D, Forster RM, Rossi F, Hummel H, Ysebaert T, Roose F, Herman PMJ (2011): Ecological evaluation of an experimental beneficial use scheme for dredged sediment disposal in shallow tidal waters. Marine Pollution Bulletin 62, 99-108

van Lützow M, Kögel-Knabner I, Ekschmitt K, Matzner E, Guggenberger G, Marschner B, Flessa H (2006): Stabilization of organic matter in temperate soils: mechanisms and their relevance under different soil conditions - a review. European Journal of Soil Science 57, 426-445

van Roon MR (2012): Wetlands in The Netherlands and New Zealand: Optimising biodiversity and carbon sequestration during urbanisation. J Environ Manage 101, 143-150

van Slobbe E, Lulofs K (2011): Implementing "Building with nature" in complex governance situations. Terra et Aqua 124, 16-23

Vandecasteele B, De Vos B, Tack FMG (2002): Heavy metal contents in surface soils along the Upper Scheldt river (Belgium) affected by historical upland disposal of dredged materials. Science of the Total Environment 290, 1-14

Vellinga T, Eisma M (2005): Management of contaminated dredged material in the port of Rotterdam. Managing European Coasts. In: Vermaat J, Salomons W, Bouwer L, Turner K (Editors). Environmental Science. Springer Berlin Heidelberg, pp. 315-322

Vermaat J, Harmsen J, Hellmann F, Harm vdG, Jeroen dK, Kosten S, Smolders F, Verhoeven J 2012: Zwaveldynamiek in het WestNederlandse laagveengebied, Sectie Aarde en Economie, Faculteit Aarden Levenswetenschappen, Vrije Universiteit Amsterdam, Amsterdam 
Vermeulen J, Grotenhuis T, Joziasse J, Rulkens W (2003): Ripening of clayey dredged sediments during temporary upland disposal a bioremediation technique. Journal of Soils and Sediments 3, 49-59

Vermeulen J, van Dijk SG, Grotenhuis JTC, Rulkens WH (2005): Quantification of physical properties of dredged sediments during physical ripening. Geoderma 129, 147-166

Vermeulen J 2007: Ripening of PAH and TPH polluted sediments Determination and quantification of bioremediation parameters., Wageningen University and Research Centre, Wageningen, The Netherlands, 166 pp

Vermeulen J, van Gool MPM, Dorleijn AS, Joziasse J, Bruning H, Rulkens WH, Grotenhuis JTC (2007): Biochemical ripening of dredged sediments. Part 1. Kinetics of biological organic matter mineralization and chemical sulfur oxidation. Environ Toxicol Chem 26, 2530-2539

Vidal R (2006): Dredging in Spanish Coastal Waters In: (ed.) DE (Editor), Dredging in coastal waters. Taylor \& Francis/Balkema, Leiden, The Netherlands, pp. 125-138

von Gunten HR, Sturm M, Moser RN (1997): 200-Year Record of Metals in Lake Sediments and Natural Background Concentrations. Environmental Science \& Technology 31, 2193-2197

Wagner RJ (2000): Houston-Galveston Navigation Channel: Blueprint for the Beneficial Uses of Dredge Material. Coastal Management 28, 337352

Walsh MR (1977): Dredged material as a natural resource. J. WATERW. PORT COASTAL \& OCEAN DIV.: PROC. ASCE 103, 309-319

Wang D, Wang H, Chen W (2011): Reinforcement Mechanism of Cement/lime-fly ash Treated Sediments as Road Construction Materials. 
In: Zhou XJ (Editor), Architecture and Building Materials, Pts 1 and 2. Applied Mechanics and Materials, pp. 924-927

Wang DX, Abriak NE, Zentar R, Xu W (2012): Solidification/stabilization of dredged marine sediments for road construction. Environ Technol 33, 95-101

Warburton J, Holden J, Mills AJ (2004): Hydrological controls of surficial mass movements in peat. Earth-Science Reviews 67, 139-156

Wassen MJ, Harry GMOV, Evalyne OAMdS (1995): Nutrient Concentrations in Mire Vegetation as a Measure of Nutrient Limitation in Mire Ecosystems. Journal of Vegetation Science 6, 5-16

Wei H, Guenet B, Vicca S, Nunan N, Asard H, AbdElgawad H, Shen W, Janssens IA (2014): High clay content accelerates the decomposition of fresh organic matter in artificial soils. Soil Biology and Biochemistry 77, 100-108

Weinstein MP, Weishar LL (2002): Beneficial use of dredged material to enhance the restoration trajectories of formerly diked lands. Ecol Eng $19,187-201$

Winfield LE, Lee CR 1999: Dredged material characterization tests for beneficial use suitability, U.S. Army Engineer Research and Development Center, Vicksburg, MS

Wöppelmann G, Le Cozannet G, de Michele M, Raucoules D, Cazenave A, Garcin M, Hanson S, Marcos M, Santamaría-Gómez A (2013): Is land subsidence increasing the exposure to sea level rise in Alexandria, Egypt? Geophys. Res. Lett. 40, 2953-2957

WRB IWG 2014: World Reference Base for Soil Resources 2014. International soil classification system for naming soils and creating legends for soil maps., World Soil Resources Reports No. 106. FAO, Rome. 
Yozzo DJ, Wilber P, Will RJ (2004): Beneficial use of dredged material for habitat creation, enhancement, and restoration in New York-New Jersey Harbor. J Environ Manage 73, 39-52

Zech W, Senesi N, Guggenberger G, Kaiser K, Lehmann J, Miano TM, Miltner A, Schroth G (1997): Factors controlling humification and mineralization of soil organic matter in the tropics. Geoderma 79, 117161

Zentar R, Abriak NE, Dubois V, Miraoui M (2009): Beneficial use of dredged sediments in public works. Environ Technol 30, 841-847

Zentar R, Miraoui M, Abriak NE, Benzerzour M (2011): Natural Dewatering of Marine Dredged Sediments. Dry Technol 29, 1705-1713

Zimmerman AR, Gao B, Ahn M-Y (2011): Positive and negative carbon mineralization priming effects among a variety of biochar-amended soils. Soil Biology and Biochemistry 43, 1169-1179 
Appendices 

Supplementary Material Table A1: Summary of case studies of beneficial use of dredged sediments

\begin{tabular}{|c|c|c|c|c|}
\hline $\begin{array}{l}\text { Use \& } \\
\text { Reference }\end{array}$ & $\begin{array}{l}\text { Source of } \\
\text { sediments }\end{array}$ & $\begin{array}{l}\text { Type of sediments } \\
\text { and contamination }\end{array}$ & $\begin{array}{l}\text { Parameters of } \\
\text { sediments }\end{array}$ & $\begin{array}{l}\text { Parameters for assessment } \\
\text { of success }\end{array}$ \\
\hline $\begin{array}{l}\text { Blended cement } \\
\text { (Dang et al. 2013) }\end{array}$ & Marine & $\begin{array}{l}\text { - Median particle size } \\
\text { is } 25 \mu \mathrm{m} \\
\text { - } 2.84 \mathrm{~g} \mathrm{chloride} / \mathrm{l} \text { of } \\
\text { sediment }\end{array}$ & 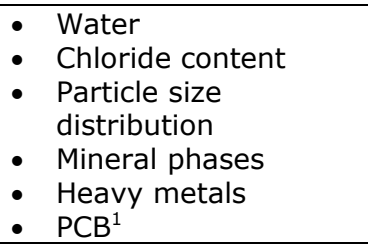 & $\begin{array}{l}\text { - Apparent density } \\
\text { - Porosity } \\
\text { - Intrinsic permeability } \\
\text { - Elastic modulus; } \\
\text { - Compressive strength } \\
\text { - Class strength }\end{array}$ \\
\hline $\begin{array}{l}\text { Cement clinker } \\
\text { (Aouad et al. 2012) }\end{array}$ & River & $\begin{array}{l}\text { - Only particles than } 2 \\
\text { mm were crushed to } \\
\text { reach a particle size } \\
\text { smaller than } 100 \mu \mathrm{m} \\
\text { - Cadmium, Zinc } \\
\end{array}$ & $\begin{array}{ll}\text { - } & \text { Mineralogical } \\
& \text { composition } \\
\text { - } & \text { Chemical composition }\end{array}$ & $\begin{array}{ll} & \text { Chemical composition } \\
\text { - } & \text { Reactivity } \\
\text { - } & \text { Microstructure } \\
& \text { Compressive strength }\end{array}$ \\
\hline $\begin{array}{l}\text { Bricks production } \\
\text { (Mezencevova et al. 2012) }\end{array}$ & Harbour & $\begin{array}{l}\text { - } 8-26 \% \text { sand } \\
\text { - } 29-43 \% \text { silt } \\
\text { - } 32-63 \% \text { clay }\end{array}$ & $\begin{array}{ll}\text { - } & \text { Particle size } \\
& \text { distribution } \\
\text { - } & \text { Plasticity } \\
\text { - } & \text { Specific gravity } \\
\text { - } & \text { Oxide analysis } \\
\text { - } & \text { Crystalline minerals } \\
\text { - } & \text { Metal content } \\
\text { - } & \text { pH }\end{array}$ & $\begin{array}{l}\text { - } \text { Particle size } \\
\text { - Plasticity } \\
\text { - } \text { Specific gravity } \\
\text { - } \text { Oxide and metal content } \\
\text { - } \text { Freezressive strength } \\
\text { - } \text { Mineralogical composition } \\
\text { - } \text { Water absorption } \\
\text { - } \text { Bulk density } \\
\text { - Apparent porosity } \\
\text { Apparent specific gravity }\end{array}$ \\
\hline
\end{tabular}

${ }^{1}$ PCB - Polychlorinated Biphenyls 


\begin{tabular}{|c|c|c|c|c|}
\hline $\begin{array}{l}\text { Use \& } \\
\text { Reference }\end{array}$ & $\begin{array}{l}\text { Source of } \\
\text { sediments }\end{array}$ & $\begin{array}{l}\text { Type of sediments } \\
\text { and contamination }\end{array}$ & $\begin{array}{l}\text { Parameters of } \\
\text { sediments }\end{array}$ & $\begin{array}{l}\text { Parameters for assessment } \\
\text { of success }\end{array}$ \\
\hline $\begin{array}{l}\text { Bricks production } \\
\text { (Samara et al. 2009) }\end{array}$ & River & $\begin{array}{l}\text { - } 60 \% \text { sand } \\
\text { - } 38 \% \text { silt } \\
\text { - } 2 \% \text { clay } \\
\text { - } 15 \% \text { organic matter } \\
\text { (dw) was calcinated. } \\
\text { - Organic pollutants } \\
\text { - Heavy metals }\end{array}$ & $\begin{array}{ll}\text { - } & \text { Heavy metals } \\
\text { - } & \text { Organic matter } \\
\text { - } & \text { Particle density } \\
\text { - } & \text { Particle size distribution }\end{array}$ & $\begin{array}{ll}\text { - } & \text { Porosity } \\
\text { - } & \text { Water absorption } \\
\text { - } & \text { Compressive strength } \\
\text { - } & \text { Permeability } \\
\text { - } & \text { Mineralogy } \\
\text { - } & \text { Freeze and thaw resistance } \\
\text { - } & \text { Heavy metal leaching }\end{array}$ \\
\hline $\begin{array}{l}\text { Glass ceramic material } \\
\text { (Giulio Bernstein et al. 2002) }\end{array}$ & $\begin{array}{l}\text { Venice } \\
\text { lagoon }\end{array}$ & $\begin{array}{l}\text { DM considered toxic } \\
\text { waste due to heavy } \\
\text { metals and organic } \\
\text { pollutants. DM was } \\
\text { vitrified at } 1200- \\
1300^{\circ} \mathrm{C}\end{array}$ & - Chemical composition & 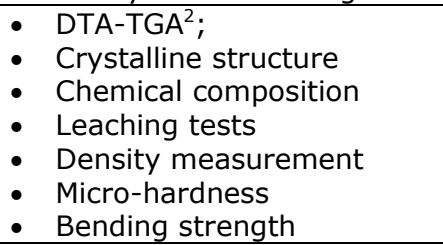 \\
\hline $\begin{array}{l}\text { Ceramic tiles and bricks } \\
\text { (Torres et al. 2009) }\end{array}$ & River & $\begin{array}{l}\text { - } 38 \% \text { sand } \\
\text { - } 58 \% \text { silt } \\
\text { - } \quad 4 \% \text { clay }\end{array}$ & $\begin{array}{ll}\text { - } & \text { True density } \\
\text { - } & \text { Particle size distribution } \\
\text { - } & \text { Chemical composition } \\
\text { - } & \text { Mineral composition }\end{array}$ & $\begin{array}{l}\text { - } \quad \text { Differential and gravimetric } \\
\text { - } \quad \text { Atterberbal analysis } \\
\text { - } \quad \text { Bending strength } \\
\text { - } \quad \text { Water absorption } \\
\text { - } \quad \text { Christaline phases } \\
\text { - Linear shrinkage }\end{array}$ \\
\hline $\begin{array}{l}\text { Road construction } \\
\text { (Wang et al. 2011) }\end{array}$ & Marine & $\begin{array}{l}\text { - } 4.4 \% \text { organic matter } \\
\text { - } 14.5 \% \text { clay } \\
\text { - } 74.7 \% \text { silt } \\
\text { - } 10.8 \% \text { sand }\end{array}$ & $\begin{array}{ll}\text { - } & \text { Organic matter content } \\
\text { - } & \text { Methylene blue } \\
\text { - } & \text { Absolute density } \\
\text { - } & \text { Particle size distribution } \\
\text { - } & \text { Atterberg limits } \\
\text { - } & \text { Mineral composition }\end{array}$ & $\begin{array}{l}\text { - } \text { Atterberg limits } \\
\text { - } \text { Ccompressive strength } \\
\text { - } \text { Proctor compaction } \\
\text { - Indirect tensile strength } \\
\text { - } \text { I-CBR }^{3} \\
\text { - Max. tensile strength } \\
\text { - } \quad \text { Young modulus }\end{array}$ \\
\hline
\end{tabular}

${ }^{2}$ DTA-TGA - Differential Thermal Analysis coupled with Thermo-Gravimetric Analysis

${ }^{3}$ I-CBR - Immediate California Bearing Ratio 


\begin{tabular}{|c|c|c|c|c|}
\hline $\begin{array}{l}\text { Use \& } \\
\text { Reference }\end{array}$ & $\begin{array}{l}\text { Source of } \\
\text { sediments }\end{array}$ & $\begin{array}{l}\text { Type of sediments } \\
\text { and contamination }\end{array}$ & Parameters of sediments & $\begin{array}{l}\text { Parameters for assessment } \\
\text { of success }\end{array}$ \\
\hline $\begin{array}{l}\text { Road construction } \\
\text { (Miraoui et al. 2012) }\end{array}$ & Marine & $\begin{array}{l}\text { - } \quad 6.8 \% \text { organic matter } \\
\text { - } 2.5 \% \text { sand } \\
\text { - } 80 \% \text { silt } \\
\text { - } 8.5 \% \text { clay }\end{array}$ & $\begin{array}{ll}\text { - } & \text { Particle size distribution } \\
\text { - } & \text { Water content Atterberg } \\
\text { - } & \text { Absolute density } \\
\text { - } & \text { Loss on ignition } \\
\text { - } & \text { Mineral composition } \\
\text { - } & \text { Proctor index } \\
\text { - } & \text { CBR index } \\
\text { - } & \text { Heavy metal and } \\
& \text { chlorides }\end{array}$ & $\begin{array}{ll}\text { - } & \text { Atterberg limits } \\
\text { - } & \text { Absolute density } \\
\text { - } & \text { Packing density } \\
\text { - } & \text { Mineralogical composition } \\
\text { - } & \text { Proctor test } \\
\text { - } & \text { CBR }^{4} \\
\text { - } & \text { Tensile strength } \\
\text { - } & \text { Elasticity modulus } \\
\text { - Heavy metals; } \\
\text { - Soluble chlorures, } \\
\text { - } \text { fluorures, cyanuresand } \\
\text { - } \text { MBIfates DBT, } \mathrm{TBT}^{5} \text {. }\end{array}$ \\
\hline $\begin{array}{l}\text { Landfill cover } \\
\text { (Brose et al. 2016) }\end{array}$ & n.a. & n.a. & $\begin{array}{ll} & \mathrm{pH} ; \mathrm{EC} \\
\text { - } & \text { Organic C } \\
\text { - } & \mathrm{TKN} \\
\text { - } & \mathrm{NH}_{4} \\
\text { - } & \mathrm{NO}_{2}+\mathrm{NO}_{3} \\
- & \mathrm{K} \\
- & \mathrm{SO}_{4} \\
- & \mathrm{Cd}, \mathrm{Cr}, \mathrm{Cu}, \mathrm{Fe}, \mathrm{Mn}, \mathrm{Mo}, \\
& \mathrm{Ni}, \mathrm{Pb}, \mathrm{Zn} \\
\end{array}$ & $\begin{array}{l}\text { - Turfgrass tissue: } \mathrm{N}, \mathrm{P}, \mathrm{K} \text {, } \\
\mathrm{Mn}, \mathrm{Zn}, \mathrm{Cd}, \mathrm{Cr}, \mathrm{Cu}, \mathrm{Mo}, \\
\mathrm{Ni}, \mathrm{Pb} \text {; } \\
\text { Soil: } \mathrm{pH}, \mathrm{EC} \text {, Organic C, } \\
\mathrm{TKN}^{6}, \mathrm{NO}_{3}, \text { Total-P, } \mathrm{NH}_{3}, \\
\mathrm{Cd}, \mathrm{Ni}, \mathrm{Cu}, \mathrm{Cr}, \mathrm{Pb}, \mathrm{Zn} \text {; } \\
\text { - Groundwater: } \mathrm{pH}, \mathrm{EC} \text {, } \\
\mathrm{TKN}, \mathrm{NH}_{3}, \mathrm{NO}_{3}, \text { Total-P. }\end{array}$ \\
\hline
\end{tabular}

\footnotetext{
${ }^{4} \mathrm{CBR}$ - California Bearing Ratio

${ }^{5} \mathrm{MBT}, \mathrm{DBT}, \mathrm{TBT}$ - Organotin Compounds Tributyltin (TBT), Dibutyltin (DBT), and Monobutyltin (MBT)

${ }^{6}$ TKN - Total Kjeldahl Nitrogen
} 
Use \&.

Reference

Flood Embankments

(Coulet et al. 2014)
Source of sediments

River
Type of sediments and contamination

- $17 \%$ gravel

- $74 \%$ sand

- $8.5 \%$ silt

- $0.5 \%$ clay

- 26-36\% organic matter
Parameters of sediments

- Loss on ignition

- Particle size distribution

- Atterberg limits

- Maximum dry density

- Linear shrinkage
Parameters for assessment of success

- Liquid and plastic limits

- Liquidity and plasticity index

- Bulk and dry density

- Undrained shear strength

- Displacement

- Hydraulic conductivity

- Leaching test (organic and inorganic contaminants

\begin{tabular}{|c|c|c|c|c|}
\hline $\begin{array}{l}\text { Habitat creation, enhancement } \\
\text { and restoration } \\
\text { (Yozzo et al. 2004) }\end{array}$ & n.a. & n.a. & n.a. & n.a. \\
\hline $\begin{array}{l}\text { Wetland restoration } \\
\text { (Weinstein \& Weishar 2002) }\end{array}$ & n.a. & n.a. & n.a. & n.a. \\
\hline $\begin{array}{l}\text { Estuary restoration } \\
\text { (French \& Burningham 2009) }\end{array}$ & Port & $\mathrm{d}_{50} \approx 30 \mu \mathrm{m}$ & n.a. & $\begin{array}{ll}\text { - } & \text { Topographic surveys } \\
\text { - } & \text { Ecological surveys } \\
\text { - } & \text { Tidal level } \\
\text { - } & \text { Waves } \\
\text { - } & \text { Suspended Sediments } \\
\text { - } & \text { Particle size distribution } \\
\text { - } & \text { Density } \\
\text { - } & \text { Shear strength }\end{array}$ \\
\hline
\end{tabular}




\begin{tabular}{|c|c|c|c|c|}
\hline $\begin{array}{l}\text { Use \& } \\
\text { Reference }\end{array}$ & $\begin{array}{l}\text { Source of } \\
\text { sediments }\end{array}$ & $\begin{array}{l}\text { Type of sediments } \\
\text { and contamination }\end{array}$ & $\begin{array}{l}\text { Parameters of } \\
\text { sediments }\end{array}$ & $\begin{array}{l}\text { Parameters for assessment } \\
\text { of success }\end{array}$ \\
\hline $\begin{array}{l}\text { Pit restoration for fishery } \\
\text { (Reine et al. 2013) }\end{array}$ & $\begin{array}{l}\text { Bay (salt } \\
\text { water) }\end{array}$ & $\begin{array}{l}\text { - } 59-82.7 \% \text { clay/silt } \\
\text { - } 24 \mu \mathrm{m} \text { mean grain size }\end{array}$ & $\begin{array}{l}\text { Particle size } \\
\text { distribution }\end{array}$ & $\begin{array}{l}\text { - Water: dissolved oxygen, } \\
\text { temperature and salinity } \\
\text { - } \quad \text { Benthic community } \\
\text { - } \quad \text { Fishery resource occupation } \\
\text { - } \quad \text { Fish assemblage taxonomic } \\
\text { composition }\end{array}$ \\
\hline $\begin{array}{l}\text { Quarry fill } \\
\text { (Perrodin et al. 2012) }\end{array}$ & Harbour & $\begin{array}{l}\text { - Polluted with heavy } \\
\text { metals, } \mathrm{PAH}^{7} \text { and } \mathrm{TBT}^{8}\end{array}$ & n.a. & $\begin{array}{ll}\text { - } & \mathrm{pH} \\
\text { - } & \text { Conductivity } \\
\text { - } & \text { RedOx potential } \\
\text { - } & \mathrm{NH}_{4}^{+} \\
\text {- } & \text { Chlorides } \\
\text { - } & \text { Heavy metals } \\
\text { - } & \mathrm{TBT} \\
\text { - } & \text { PAH } \\
\text { - } & \text { Lateral runoff } \\
\text { - } & \text { Ecotoxicological tests }\end{array}$ \\
\hline $\begin{array}{l}\text { Habitat remediation in an } \\
\text { eroding intertidal flat } \\
\text { (van der Wal et al. 2011) }\end{array}$ & Estuary & $\begin{array}{l}\text { - } 1.32 \%<63 \mu \mathrm{m} \\
\text { - } 1.69 \% 63-125 \mu \mathrm{m} \\
\text { - } 49.98 \% 125-250 \mu \mathrm{m} \\
\text { - } 45.74 \% 250-500 \mu \mathrm{m} \\
\text { - } 1.25 \% 500-1000 \mu \mathrm{m} \\
\end{array}$ & $\begin{array}{l}\text { - Granulometric } \\
\text { analysis }\end{array}$ & $\begin{array}{l}\text { - } \text { Granulometric analysis } \\
\text { - } \text { Macrobenthic analysis - } \\
\text { biomass, density and species } \\
\text { richness } \\
\text { - Height }\end{array}$ \\
\hline $\begin{array}{l}\text { Synthetic fill material } \\
\text { (Malasavage et al. 2012) }\end{array}$ & & $\begin{array}{l}\text { - } 11.76 \% \text { org. matter; } \\
\text { - } 2.58 \text { specific gravity; } \\
\text { - } 1.2 \% \text { sand } \\
\text { - } 98.8 \%<75 \mu \mathrm{m} \text {. }\end{array}$ & $\begin{array}{ll}- & \text { Water and } \\
& \text { organic matter } \\
& \text { content } \\
\text { - } & \text { Specific gravity } \\
\text { - } & \text { Particle size } \\
& \text { distribution } \\
\end{array}$ & $\begin{array}{ll}\text { - } & \text { Shear strength } \\
\text { - } & \text { Hydraulic conductivity } \\
\text { - } & \text { One-dimensional consolidation }\end{array}$ \\
\hline
\end{tabular}

$7 \mathrm{PAH}$ - Polycyclic aromatic hydrocarbons

${ }^{8}$ TBT - Tributyltin 


\begin{tabular}{|c|c|c|c|c|c|}
\hline $\begin{array}{l}\text { Use \& } \\
\text { Reference }\end{array}$ & $\begin{array}{l}\text { Source of } \\
\text { sediments }\end{array}$ & $\begin{array}{l}\text { Type of sediments } \\
\text { and contamination }\end{array}$ & Parameters of sedim & ents & $\begin{array}{l}\text { Parameters for assessment } \\
\text { of success }\end{array}$ \\
\hline $\begin{array}{l}\text { Habitat restoration } \\
\text { (Augustin et al. 2011) }\end{array}$ & Bay & $\begin{array}{l}\text { - Fine, loose sand; } \\
\text { - Silt/clay } 10-30 \% \text {. }\end{array}$ & n.a. & $\begin{array}{ll}\cdot & \mathrm{E} \\
\cdot & \mathrm{S} \\
\cdot & \mathrm{S} \\
\end{array}$ & $\begin{array}{l}\text { evation } \\
\text { ttlement rates } \\
\text { diments slopes and volumes } \\
\text { ater depth }\end{array}$ \\
\hline $\begin{array}{l}\text { Harbour concrete pavement } \\
\text { (Limeira et al. 2012) }\end{array}$ & Marine & $\begin{array}{l}\text { - } 63 \mu \mathrm{m}<89 \%<250 \\
\mu \mathrm{m} ; \\
\text { - } \text { Density } 2.63 \mathrm{~kg} \cdot \mathrm{dm}^{-3} \text {; } \\
\text { - } 0.76 \% \text { organic } \\
\text { matter; } \\
\text { - } \text { Contamination level } \\
\text { negligible }\end{array}$ & $\begin{array}{ll}\text { - } & \text { Particle size } \\
& \text { distribution } \\
\text { - } & \text { Mineralogical } \\
& \text { characterization; } \\
\text { - } & \text { Absorption; } \\
\text { - } & \text { Heavy metals } \\
\text { - } & \text { Soluble chlorides } \\
\text { - } & \text { Sulphates } \\
\text { - } & \text { PCB }\end{array}$ & 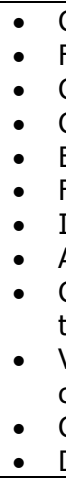 & $\begin{array}{l}\text { nsistency } \\
\text { didity } \\
\text { hesion } \\
\text { mpressive strength } \\
\text { astic modulus } \\
\text { exural tensile strength } \\
\text { direct tensile strength } \\
\text { sorption and capillary suction } \\
\text { acking strength, tenacity and } \\
\text { nsile residual strength } \\
\text { plume of permeable pores } \\
\text { pillary absorption } \\
\text { apillary absorption coefficient } \\
\text { epth of water penetration }\end{array}$ \\
\hline
\end{tabular}


Appendix 2: Non-invasive determination of $\mathrm{O}_{2}$ and $\mathrm{CO}_{2}$ in laboratorial scale experiments with dredged material ${ }^{9}$

Bruna Oliveira; Martijn Smit; Vinnie de Wilde; Tim Grotenhuis; Huub Rijnaarts

\section{A2.1. Introduction}

In many delta areas, dredged material can potentially be used as filling material to compensate land subsidence. One of the aspects that determine the long term stability of these filling materials is the aerobic degradation of organic matter. A thorough understanding of this degradation is lacking as the process is rather complex due to heterogeneous oxygen transport through cracks and pores and the range of properties of organic matter itself. One way of determining the rate of organic matter degradation in laboratorial scale (lab) experiments with dredged material is to make mass balances of $\mathrm{O}_{2}$ and $\mathrm{CO}_{2}$. In this type of determinations it is important to acquire precise data (in space and time) that can be extrapolated to field conditions. Standard methods to measure $\mathrm{O}_{2}$ and $\mathrm{CO}_{2}$ are invasive and can interfere with the results. For instance, taking a gas sample will decrease the volume of gas in the experimental setup, decreasing the pressure to which the sample is subjected and changing the equilibrium conditions; and using needles to sample the bottom of the sample would carry atmospheric gas and material from the upper layers. To overcome the limitations of the standard methods to measure $\mathrm{O}_{2}$ and $\mathrm{CO}_{2}$ and to acquire high spatial and temporal resolution, alternative methods are needed. VisiSens imaging systems are a possible alternative method.

\footnotetext{
9 This report has been prepared after the participation in the VisiSens contest VisiSens Competition 2013 pH / CO $\mathrm{CO}_{2}$ Imaging. This has not been published elsewhere.
} 
These systems combine an imaging technology (digital camera) with fluorescent chemical optical sensor foils to visualize 2D distributions of $\mathrm{O}_{2}$ and $\mathrm{CO}_{2}$ in heterogeneous samples. The sensor foil is covered with a sensor film that translates the analyte content into a light signal. The light signal is recorded with a digital camera and is processed and evaluated by a software specific for each analyte.

\section{A2.2. Objective}

Objective is to explore the applicability of VisiSens imaging systems to determine the evolution with time of the balance between $\mathrm{O}_{2}$ to $\mathrm{CO}_{2}$ in dredged material with high spatial and temporal resolution without interfering with the system.

\section{A2.3. Materials \& Methods}

Dredged material was sampled from a small ditch in a rural area in the Netherlands. This dredged material was classified as non-contaminated according to Dutch policies. The particle size distribution was $8 \%$ clay, $25 \%$ silt and $63 \%$ sand and the organic matter content was $4 \%$. Before the experiment, samples were dewatered to a matric potential of 100 $\mathrm{hPa}$.

Experiments were performed in weck bottles $(1000 \mathrm{ml})$ with modified lids allowing sampling of the headspace. Sensor foils were glued in the middle of the bottom of the bottles. 3 bottles had $\mathrm{CO}_{2}$ sensor foils SFMT1R glued with Kwik-sil silicone glue and 3 bottles had $\mathrm{O}_{2}$ sensor foils SF-RPSU4 glued with regular silicone glue. After placement of the sample on top of the sensor foil, bottles were closed to allow for individual determination of balance between $\mathrm{O} 2$ consumption and $\mathrm{CO}_{2}$ formation. Initial gas composition was normal atmospheric gas composition. The setup was kept at $21.5 \pm 1.5{ }^{\circ} \mathrm{C}$ throughout the experiment and day 1 corresponds to the day when the bottles were 
closed and the first image was taken 2 hours after closing the bottle. Images were recorded on days $1,2,5,6,7$ and 8 .

Two weeks after the start of the experiment, the SF-MT1R sensor foils had to be replaced by SF-CD1R, due to the concentration range. For this, the Kwik-sil silicone glue left from SF-MT1R sensor foils had to be removed. Part of the glue was removed by scraping with a metalspatula. Then, to clean all the residues of glue, acetone, petroleum ether $\left(40-60^{\circ} \mathrm{C}\right)$, and dichloromethane were individually tested. None of these chemicals was successful in removing the glue, even when left soaking for 24 hours. The acquisition of new bottles would take more time than the available for the contest. As a result, the SF-CD1R sensor foils were glued on top of some residues of Kwik-sil silicone glue.

For the calibration of the SF-CD1R sensor foils, a bottle of the same material, but smaller in size $(200 \mathrm{ml})$, was used. Calibration was multipoint using gas mixtures with different concentrations of $\mathrm{CO}_{2}$ (range between $1 \%$ and $25 \%$ ) and $\mathrm{N}_{2}$. To saturate the gas with $\mathrm{H}_{2} \mathrm{O}$, it was flushed through a bottle with ultra-pure water. Gas was flushed during 15 minutes for each $\mathrm{CO}_{2}$ concentration. Bottles were allowed to equilibrate for 2 hours at $21.5 \pm 1.5{ }^{\circ} \mathrm{C}$ before the concentration of $\mathrm{CO}_{2}$ was determined using a Gas-Chromatographer (GC) and the VisiSens AnalytiCal 3 (PreSens 2012).

For the calibration of SF-RPSU4 sensor foils, the same procedure was followed but with $\mathrm{O} 2$ instead of $\mathrm{CO} 2$ and with the VisiSens AnalytiCal 1 (PreSens 2013). 


\section{A2.4. Results}

\section{Calibration $\mathrm{CO}_{2}$ and $\mathrm{O}_{2}$}

Calibration results for $\mathrm{CO}_{2}$ are summarized in Tables A2.1 (rubber stoppers) and A2.2 (Viton stoppers). Pictures can be seen in the annex movies "CO2 calibration rubber stoppers" and "CO2 calibration Viton stoppers" for the respective experimental conditions.

Table A2.1: Calibration of $\mathrm{CO}_{2}$ sensor foil: $\mathrm{CO}_{2}$ concentration in the bottle determined with Gas-Chromatographer (GC), Ratio-value given by AnalytiCal 3 calibration dialog and temperature of the setup with rubber stoppers

\begin{tabular}{lll}
{$\left[\mathrm{CO}_{2}\right]_{\mathrm{GC}} \%$} & Ratio-value & Temperature, ${ }^{\circ} \mathrm{C}$ \\
\hline 25.0 & 4.72 & 23.0 \\
20.1 & 4.56 & 21.4 \\
11.9 & 5.76 & 22.0 \\
11.7 & 4.77 & 21.6 \\
6.9 & 3.92 & 23.0 \\
3.5 & 2.64 & 22.4 \\
1.2 & 4.04 & 22.8
\end{tabular}

Table A2.2: Calibration of $\mathrm{CO}_{2}$ sensor foil: $\mathrm{CO}_{2}$ concentration in the bottle determined with Gas-Chromatographer (GC), Ratio-value given by AnalytiCal 3 calibration dialog and temperature of the setup with Viton stoppers

\begin{tabular}{lll}
{$\left[\mathrm{CO}_{2}\right]_{\mathrm{GC}}, \%$} & Ratio-value & Temperature, ${ }^{\circ} \mathrm{C}$ \\
\hline 19.3 & 3.04 & 20.4 \\
12.9 & 1.51 & 21.0 \\
3.6 & 3.21 & 20.7
\end{tabular}

As can be seen in Table A2.1, no correlation between $\mathrm{CO}_{2}$ concentration and Ratio-values could be observed. The software does not accept the values for calibration (because a decrease of $\mathrm{CO} 2$ should imply a decrease in Ratio-value).

One possible cause was the use of rubber stoppers that can release sulphur compounds that, according to the foils description, might influence the results. To exclude the interference with sulphur 
compounds, a new trial was done using Viton stoppers.

As can be seen in Table A2.2, the ratio values were lower compared to the experiment with rubber stoppers but still no correlation between $\mathrm{CO}_{2}$ concentration and the measured Ratio-value could be observed.

As can be seen in the pictures a pattern of $\mathrm{CO}_{2}$ concentration where no sensor foil was present. This might be induced by the scattering of light by the bottle itself but we did not explore this possibility as time was limited.

The calibration results for $\mathrm{O}_{2}$ are summarized in Table A2.3.

Table A2.3: Calibration of $\mathrm{O}_{2}$ sensor foil: $\mathrm{O}_{2}$ concentration in the bottle determined with Gas-Chromatographer (GC); input $\mathrm{O}_{2} \%$ ( converted to the scale of the AnalytiCal 1 ), Ratio-value given by AnalytiCal 1 calibration dialog and temperature of the setup with rubber stoppers

\begin{tabular}{llll}
{$\left[\mathrm{O}_{2}\right]_{\mathrm{GC}}, \%$} & Input $\mathrm{O}_{2,} \%$ & Ratio-value & Temperature, ${ }^{\circ} \mathrm{C}$ \\
\hline 0.2 & $0 \%$ & 4.72 & 23.0 \\
19.8 & $79 \%$ & 4.56 & 21.4 \\
21.9 & $100 \%$ & 5.76 & 22.0
\end{tabular}

According to VisiSens AnalytiCal 1 manual, atmospheric concentration of oxygen $(21.9 \%)$ corresponds to the $100 \%$ calibration point of the software. Attending to that, the concentration of $\mathrm{O} 2$ given by GC was converted to the software scale. Pictures can be seen in the annex movie "O2 calibration".

$\underline{\mathrm{O}}_{2}$ and $\mathrm{CO}_{2}$ evolution in dredged material

The time-series of $\mathrm{O}_{2}$ concentration underneath the samples are presented in the movies "O2 samples bottle 1" and "O2 samples bottle 2 ". Bottle 3 was discarded due to the displacement of the sample during its handling. Interestingly, higher concentrations of $\mathrm{O}_{2}$ were detected in the middle of the sample while lower concentrations of $\mathrm{O}_{2}$ were seen at the edges of the sample. This might be a result of $\mathrm{O}_{2}$ being trapped 


\section{Appendix 2}

when the sample was first placed in the bottle and either the consumption was higher in the edges of the sample or compaction occurred and $\mathrm{O}_{2}$ was expelled from the edged and then gradually consumed in the middle. 7 Days after the start of the experiment most $\mathrm{O}_{2}$ was consumed. The results show that the method used was capable in detecting variations of $\mathrm{O}_{2}$ concentrations at small distances at different times. The method is therefore potentially useful to be applied in research on $\mathrm{O}_{2}$ consumption in dredged materials.

We did not achieve good results for the calibration of $\mathrm{CO}_{2}$. Therefore we cannot provide results on $\mathrm{CO}_{2}$ production during the degradation of organic matter in the samples.

\section{A2.5. Conclusions}

VisiSens AnalytiCal 1 proved to be a potentially good system for noninvasive determination of $\mathrm{O}_{2}$ concentration in lab experiments with dredged material. A high spatial resolution was obtained regarding the $\mathrm{O}_{2}$ concentration below the samples. Although we could not validate the (absolute) $\mathrm{O}_{2}$ concentrations due to lacking reference methods, relevant insights on consumption patterns can be obtained.

VisiSens AnalytiCal 3 did not prove to be suitable for determination of $\mathrm{CO} 2$ concentration under the described experimental conditions. Especially the absence of any correlation between $\mathrm{CO}_{2}$ concentration and Ratio-value makes the use of this method at this moment unsuitable. 
Summary 

In this thesis, the beneficial use of dredged sediments to reverse land subsidence in lowlands and delta areas is explored. The major constraints for beneficial use of sediments are the contaminant concentrations, and the proper managing of supply and demand of sediments (Chapter 1 ).

When sediments are transferred from waterways to upland conditions, a series of processes take place that transform the waterlogged sediments into aerated soils, a process known as ripening. To understand the relation between the sediments and the soils formed, physical/chemical and biological processes were studied at three scales: laboratory scale, mesoscale, and field scale. The knowledge obtained with these experiments can provide guidelines to effectively use dredged sediments to reverse land subsidence.

In the laboratory experiments, the environmental conditions were controlled, leading to constant water content and optimal oxygen concentration for biological processes. In the mesoscale experiment, the environmental parameters such as wind, precipitation and temperature, were not controlled as the $1 \mathrm{~m}^{3}$ containers used for these experiments were placed outside, in open air conditions. Still, the water level could be monitored and controlled, and the subsidence of the dredged sediment could be monitored. In the field experiment, the environmental and filling conditions could not be controlled but the changes occurring in the deposit were monitored.

In the first laboratory experiment (Chapter 2) the behaviour of dredged sediments with varying particle size distribution and organic matter content was studied. The dredged sediments were dewatered using suction chambers and then submitted to biochemical ripening during 141 days. The five types of dredged sediments had similar overall behaviour. The most significant observation was that most volume lost during dewatering and biochemical ripening was due to shrinkage and 
not to organic matter mineralization. Furthermore, the type of organic matter changed in the direction of humification, i.e., more stable compounds were formed. The soils formed from biochemical ripening of dredged sediments had very stable aggregates and the load-bearing capacity was enough to sustain cattle and tractors.

The second laboratory experiment (Chapter 3) was designed to investigate the influence of mixing compost and the solid fraction of swine manure (low in nutrients) with dredged sediments on dewatering and biochemical ripening. When the supply of dredged sediments is too low to compensate for land subsidence, bio-wastes, such as compost and manure, can be mixed with the sediments to reverse land subsidence. The results of this experiment confirm that most volume lost during ripening was due to shrinkage and not due to organic matter mineralization. Adding compost or the solid fraction of manure to the dredged sediments enhances the changes in the type of organic matter and $\mathrm{CO}_{2}$ production, i.e., the addition results in increased rates of organic matter mineralization which is described in the literature as the priming effect. In addition, the undrained shear strength of the mixtures of sediments with compost or manure was three times higher than the measured values for the sediments alone, meaning that organic amendments will improve the characteristics of the soil formed from ripening of sediments.

The mesoscale experiment (Chapter 4) was performed during 400 days in $1 \mathrm{~m}^{3}$ containers which allowed to control the water level. Two scenarios were tested: upland deposits in which the sediments are allowed to dry; and underwater deposits in which the water level is always $2 \mathrm{~cm}$ above the sediments. It was expected that the upland deposit conditions would lead to a higher subsidence than the underwater conditions. However, subsidence of the sediments was very similar for the two scenarios. Also in these experiments it was observed 
that most subsidence could be attributed to shrinkage and not organic matter mineralization, and the type of organic matter changed in the direction of humification. Furthermore, the water balance indicated that evapotranspiration results in higher loss of water than drainage. Still, in this case the undrained shear strength after 400 days of experiment was not enough to sustain cattle or tractors even though it increased with time.

The monitored field scale upland deposit of dredged sediments (Chapter 5 ) is located in the Wormer- en Jisperveld area - North Holland, the Netherlands. The deposit was filled in two stages reaching a maximum height of sediments of $195 \mathrm{~cm}$. After 17 months of monitoring, the subsidence of the sediments was $119 \mathrm{~cm}$ to which an extra subsidence of $19.5 \mathrm{~cm}$ of the underlying soil due to the overburden pressure was added. The results observed in the upland deposit are in line with the laboratory and mesoscale results since subsidence could also be attributed to shrinkage and no significant changes in the organic matter content were observed. However, in the case of the upland deposit, the type of organic matter changed in the direction of humification during the first 8 months (March to November), then stabilized during 7 months (November to June), and changed in the direction of mineralization afterwards.

The outcomes of this research indicate that dredged sediments have the potential to reverse land subsidence. This statement is supported by the consistent results showing that the decrease in volume of dredged sediments is caused by shrinkage and not to organic matter mineralization as traditionally reported (Chapters 2, 3, 4, and 5).

In addition, in places where composted and stable bio-wastes are available, these can be added to dredged sediments to further reverse land subsidence. Still, in this case special attention should be given to the potential priming effect (Chapter 3 ). 


\section{Summary}

Finally it is recommended to adapt the current practices of disposal of dredged sediments in upland deposits, since $19.5 \mathrm{~cm}$ of subsidence observed for the underlying soil in the upland deposit (Chapter 5), was caused by the overburden pressure of the dredged sediment. From the point of view of avoiding/reversing land subsidence it is recommended to spread thin layers (in the order of $\mathrm{cm}$ ) of sediments over the land, although this might lead to an increase in the time and costs for the stakeholders involved in dredging and in managing the water boards. 


\section{Nederlandse Samenvatting}

In dit proefschrift is het nuttige gebruik van gebaggerd sediment nader onderzocht op geschiktheid voor het tegengaan van bodemdaling in laag gelegen en in delta gebieden. De belangrijkste belemmeringen voor nuttig hergebruik van sediment worden zijn de hoge concentraties aan verontreinigingen en het juist managen van vraag en aanbod van gebaggerd sediment (Hoofstuk 1).

Zodra sediment wordt overgebracht vanuit het water naar een bovengrondse locatie, starten een aantal processen, waarbij waterverzadigd sediment wordt omgezet in geaereerde grond. Deze transformatie wordt aangeduid als rijping van sediment. Om de relaties tussen sediment en de uiteindelijke gevormde grond beter te kunnen begrijpen, zijn fysisch/chemische en biologische processen onderzocht op drie verschillende schaalgroottes: laboratorium-, meso- en veld schaal.

De kennis die met deze experimenten zijn verkregen, kunnen gebruikt worden voor het opstellen van richtlijnen om sediment effectief in te kunnen zetten bij het tegengaan van bodemdaling.

In de laboratorium experimenten, onder gecontroleerde milieucondities, heerste een constant watergehalte en een optimale zuurstofconcentratie voor biologische processen. In het meso schaal experiment, konden de milieu parameters als wind, neerslag en temperatuur, niet gecontroleerd worden omdat de $1 \mathrm{~m}^{3}$ containers buiten geplaatst waren, in de open lucht. Onder deze omstandigheden kon het water niveau gemonitord en gecontroleerd worden en kon de daling van het gebaggerde sediment gemonitord worden. In het veld experiment kon de vul periode van het depot niet gecontroleerd worden, maar bodemdaling in en van het depot kon worden gemonitord onder praktijkomstandigheden. 
In de eerste laboratorium experimenten (Hoofdstuk 2) is het gedrag van gebaggerd sediment bestudeerd met een variatie in deeltjesgrootte verdeling en in organisch stof gehalte. Het gebaggerde sediment werd na ontwatering in een onderdruk cel onderzocht voor biochemische rijping gedurende 141 dagen. De vijf onderzochte type gebaggerd sediment hadden een overeenkomstig gedrag. De meest significante observatie was dat de meeste volume reductie optrad tijdens de ontwatering samen met biochemische rijping door krimp en niet door de mineralisatie van organische stof. Tevens veranderde de samenstelling van de organische stof in de richting van humificatie, hetgeen leidde tot een de vorming van meer stabiele verbindingen. De bodem die na biochemische rijping gevormd is, bleek zeer stabiel te zijn en vertoonde een grote draagkracht capaciteit zodat vee en tractoren de bodem zonder probleem kunnen belasten.

Het tweede laboratorium experiment (Hoofdstuk 3) was ontworpen om de invloed van organische toeslagstoffen als stabiele compost en de vaste fractie uit varkensmest (laag in nutriënten) op het gedrag van sediment te onderzoeken met betrekking tot ontwatering en biochemische rijping. Indien het aanbod van gebaggerd sediment te laag is om bodem daling te compenseren kunnen biologisch afvalstromen als compost en mest (fracties) mogelijk bij gemengd worden om bodemdaling tegen te gaan.

De resultaten van dit experiment bevestigen dat de volume reductie werd veroorzaakt door krimp en niet door de mineralisatie van organische stof. Toevoeging van compost of de 'vaste nutriënten-arme fractie' van mest aan het gebaggerde sediment versterken de veranderingen in het type organische stof en de $\mathrm{CO}_{2}$ productie, $\mathrm{nl}$. de toevoegingen leidden tot een versnelde organische stof mineralisatie, die in de literatuur beschreven wordt als priming effect. Daarnaast bleek de draag kracht (undrained shear strength) van de mengsels van 
sediment met compost of de stabiele mest fractie drie maal hoger te zijn in vergelijking met alleen sediment. Hetgeen betekent dat de organische toeslagstoffen de karakteristieken van de nieuw gevormde bodem verbeteren.

Het meso-schaal experiment (Hoofdstuk 4) is uitgevoerd gedurende 400 dagen in $1 \mathrm{~m}^{3}$ containers, waarin het water niveau gecontroleerd kon worden. twee scenario's zijn onderzocht: bovengrondse opslag waarin het sediment kon drogen; en onder water opslag waarin het water niveau altijd $2 \mathrm{~cm}$ boven het sediment niveau lag. De verwachting was dat de bovengrondse opslag zou leiden tot een grotere bodemdaling dan bij de onder water opslag. Echter, de bodemdaling in beide scenario's was vergelijkbaar. Ook in deze experimenten bleek dat de bodemdaling vooral werd veroorzaakt door krimp en niet door de oxidatie van organische stof, en het bleek dat het type organische stof veranderde in de richting van humificatie. Daarnaast bleek uit de waterbalans, dat evapotranspiratie belangrijker was in de water afname dan drainage. Toch, bleek in de mesocosms dat de draagkracht na 400 dagen niet groot genoeg was om vee en tractoren te kunnen dragen.

Het veldschaal experiment met de bovengrondse opslag van gebaggerd sediment (Hoofdstuk 5) lag in het Wormer-Jisperveld in Noord-Holland, Nederland. De opslag werd in twee perioden gevuld tot een maximum hoogte van $195 \mathrm{~cm}$. Na 17 maanden monitoren bleek het sediment oppervlaak $119 \mathrm{~cm}$ gekrompen te zijn en bleek dat daarnaast he gehele depot $19.5 \mathrm{~cm}$ in de oorspronkelijke bodem is gezonken door het gewicht van het sediment zelf (overburden). De waarnemingen in de bovengrondse opslag komen in feite overeen met de resultaten van de lab-schaal en meso-schaal experimenten, omdat de bodemdaling voornamelijk door krimp veroorzaakt wordt en dat er vrijwel significante afname in het organische stof gehalte wordt waargenomen. Toch veranderde de samenstelling van het organisch materiaal in de eerste 8 
maanden (maart tot november) in de richting van humificatie, daarna stabiliseerde de samenstelling gedurende 7 maanden (november tot juni) en veranderde daarna weer in de richting van humificatie.

De uitkomsten van dit onderzoekgeven aan dat gebaggerd sediment potentie heft om bodemdaling tegen te gaan. Dit wordt onderbouwd met de consistente resultaten op verschillende schaalgrootten waarin wordt waargenomen dat de afname van het sediment volume vooral wordt veroorzaakt door krimp en niet door de oxidatie van organische stof (Hoofdstukken 2, 3, 4 en 5). Daarnaast, als er in de nabijheid gecomposteerde biologische afvallen beschikbaar zijn, kunnen deze worden toegevoegd aan gebaggerd sediment om de bodem daling verder tegen te gaan. Hierbij moet echter wel aandacht gegeven worden aan het potentiële priming effect (Hoofdstuk 3).

Tot slot wordt aanbevolen om de huidige praktijk van het bergen van sediment in bovengrondse opslag aan te passen, immers in het veldschaal experiment daalde het gehele depot $19.5 \mathrm{~cm}$ in de onderliggende bodem (Hoofdstuk 5). Deze daling werd veroorzaakt door het gewicht van het sediment (overburden). Vanuit het oogpunt van het voorkomen dan wel tegengaan van bodemdaling wordt aanbevolen om gebaggerd sediment te verspreiden in dunne lagen (ca. enkele $\mathrm{cm}$ ), hoewel dit kan leiden tot een toename in de benodigde tijd en kosten voor baggerwerkzaamheden. 


\section{Resumo em Português}

Nesta tese, o uso benéfico de sedimentos dragados para reverter a subsidência de solos em zonas abaixo do nível do mar e em deltas é explorado. As principais restrições para o uso benéfico de sedimentos são a contaminação e a corrdenação entre procura e oferta de sedimentos (Capítulo 1).

Quando os sedimentos são transferidos dos canais de água para o solo, uma série de transformaçòes que transformam os sedimentos saturados em água em solos arejados ocorrrem, um processo que se chama de maturação. Para compreender a relação entre os sedimentos e os solos formados após maturação, as transformações físicas, químicas e biológicas foram estudadas em três escalas: laboratorial, mesoescala e campo. O conhecimento resultante pode gerar guias para efectivamente utilizar sedimentos dragados para reverter a subsidência de zonas abaixo do nível do mar.

Nas experiências laboratoriais, as condições ambientais foram controladas de forma a que a temperature o teor de água se mantivemse constantes e a concentração de oxigénio fosse óptima para processos biológicos. Nas experiências a mesoescala, condições ambientais como o vento, precipitação e temperatura, não foram controlados pois os contentores de $1 \mathrm{~m}^{3}$ utilizados para as experiências foram colocados no exterior, ao ar livre. Contudo, o nível da água nos contentores foi controlado e a subsidência dos sedimentos foi monitorizada. $\mathrm{Na}$ experiência de campo nem as condições ambientais nem as condições de enchimento do depósito foram controladas mas as transformações a ocorrer no depósito foram monitorizadas.

Foram feitas duas experiências laboratoriais. Na primeira experiência laboratorial (Capítulo 2) o comportamentos de cinco tipos de 
sedimentos, com texturas e teor de matéria orgânica diferentes, foi estudados. O excesso de água dos sedimentos foi primeiro removido com recurso a câmaras de sucção e de seguida as amostras foram submeditas a maturação bioquímica durante 141 dias. Os cinco tipos de sedimentos tiveram comportamentos semelhantes. A observação mais significativa foi que grande parte do volume perdido durante a remoção do excesso de água e maturação bioquímica foi devido a remoção de água e rearranjo das partículas e não mineralização da matéria orgânica. Além disso, o tipo de matéria orgânica mudou no sentido da humificação, ou seja, formaram-se compostos orgânicos mais estáveis, e os solos formados apresentam agregados muito estáveis e capacidade de suportar gado e tratores.

A segunda experiência laboratorial (Capitulo 3) foi desenhada para investigar a influência de misturar composto e a fração sólida de estrume de suínos (baixa em nutrientes) com sedimentos nos processos de remoção de água e maturação bioquímica. Quando a oferta de sedimentos dragados não é suficiente para compensar a subsidência das terras baixas, composto e estrume podem ser misturas com os sedimentos para aumentar o volume. Os resultados desta experiência confirmam que grande parte do volume perdido durante a maturação bioquímica foi devido a remoção de água e rearranjo das partículas e não mineralização da matéria orgânica. Adicionar composto ou estrume aos sedimentos aumenta as transformações no tipo de matéria orgânica e a produção de dióxido de carbono, ou seja, a mistura resulta em maiores taxas de mineralização da matéria orgânica que é conhecido como priming effect. Ainda assim, a capacidade de suportar cargas aumenta significamente quando composto ou estrume são misturados com os sedimentos.

A experiência a mesoescala (Capítulo 4) foi realizada durante 400 dias e dois cenários foram testados: depósito em zona alta (acima do nível da 
água subterrânea), o qual permite que os sedimentos percam o escesso de agua; e depósito debaixo de água no qual o nível da água é mantido sempre $2 \mathrm{~cm}$ acima do nível dos sedimentos. Era esperado que as condições de depósito alto resultassem numa maior subsidência do que nas condições de depósito debaixo de água. Contudo, os dois cenários tiveram comportamentos semelhantes a nível de subsidência. Também nesta experiência foi observado que grande parte do volume perdido durante a maturação bioquímica foi devido a remoção de água e rearranjo das partículas e não mineralização da matéria orgânica e que o tipo de matéria orgânica mudou na direcção da humificação. O balanço á água no sistema mostrou que mais água foi removida devido a evapotranspiração do que drenagem. No caso da capacidade de suportar cargas, após 400 dias de experiência os solos ainda não tinham capacidade de suportar gado e tratores, apesar de ser observado o aumento da capacidade com o tempo.

A experiência de campo (Capítulo 5) consistiu na monitorização de um depósito de sedimentos acima do nível da água. O depósito monitorizado localiza-se na província Norte da Holanda nos Países Baixos. O depósito foi enchido em dois períodos, atinindo uma altura máxima de sedimentos de $195 \mathrm{~cm}$. Após 17 meses de monitorização, a subsidência dos sedimentos foi de $119 \mathrm{~cm}$ aos quais se adicionam 19.5 de subsidência do solo que suporta o depósito devido à pressão exercida pelo depósito. Os resultados observados na experiência de campo são consistentes com os observados nas experiências de laboratório e mesoescala pois também nesta a maior parte da subsidência pode ser atribuida à remoção de água e rearranjo das partículas e não mineralização da matéria orgânica. Contudo, neste caso as alterações no tipo de matéria orgânica foram na direção da humificação durante os primeiros 8 meses (Março a Novembro), estabilizou durante os 7 meses 


\section{Resumo em Português}

da época fria (Novembro a Junho) e alterou na direção da mineralização no restante período.

Os resultados desta tese indicam que os sedimentos dragados de cursos de água têm potencial para reverter a subsidência de terra em zonas abaixo do nível do mar. Esta afirmação é suportada pelos resultados consitentes das experiências detalhadas nos Capítulos 2 a 5 . Além disso, em zonas onde composto e estrume estão disponíveis, estes podem ser aidcionados aos sedimentos para aumentar o volume de material disponível para reverter a subsidência da terra, embora neste caso devam ser tomadas precauções em relação ao priming effect (Chapter 3).

Finalmente, é recomendado adaptar as práticas actuais de colocação de sedimentos dragados em depósitos acima do nível da água visto ter sido obervada uma susbidência de $19.5 \mathrm{~cm}$ do solo que suporta o depósito (Capítulo 5). Do ponto de vista de reverter a subsidência dos solos em terras abaixo do nível do mar, é recomendado espalhar camadas finas de sedimentos (na ordem dos $\mathrm{cm}$ ) no solo, embora esta prática possa levar a um aumento de tempo e custos a curto prazo. 


\section{Publications and communication of the results}





\section{List of Publications}

- Bruna R.F. Oliveira; Martijn P. J. Smit; Leon A. van Paassen; Tim Grotenhuis; Huub H.M. Rijnaarts (2016): Functional properties of soils formed from biochemical ripening of dredged sediments - subsidence mitigation in delta areas. Journal of Soils and Sediments, 17(1), 286298, doi: 10.1007/s11368-016-1570-7.

- Bruna R.F. Oliveira; Krisjan van Laarhoven; Martijn P. J. Smit; Huub H.M. Rijnaarts; Tim Grotenhuis (2016): Impact of compost and manure on the ripening of dredged sediments. Journal of Soils and Sediments, 17(2), 567-577, doi: 10.1007/s11368-016-1571-6.

- Bruna R.F. Oliveira; Martijn P. J. Smit; Huub H.M. Rijnaarts; Tim Grotenhuis (submitted): Subsidence of organic dredged sediments mesoscale experiments with different water levels

- Bruna R. F. Oliveira; Martijn P. J. Smit; Harry Veld, Leon A. van Paassen; Huub H.M. Rijnaarts; Tim Grotenhuis (submitted): Subsidence of organic dredged sediments in an upland deposit in Wormer- en Jisperveld - North Holland, the Netherlands

Workshop co-host

- Weijdeveld, A., Stern, E.A., Oliveira, B. (2015): Reuse of (contaminated) sediments. Initiative by: CEAMaS (an EU INTERREG IVb program), Wageningen University, Viridian Alliance \& Environmental Adaptive Strategies. Workshop included in the 9th International SedNet conference - Solving societal challenges: working with sediments, 2326 September 2015, Krakow, Poland. 
Oral presentations

- Oliveira, B., Smit, M., Grotenhuis, T., Rijnaarts, H.H.M. (2015): Lift up of Lowlands - beneficial use of dredged sediments. Lift up of Lowlands STW project 11433 final workshop, 10 December 2015, Wageningen, The Netherlands.

- Wijdeveld, A., van Paassen, L., Chassagne, C., Tollenaar, R., Oliveira, B. (2015): Lift up of lowlands, looking at the reuse of sediments on peat meadows by looking at the physical, chemical and biochemical properties in relation to the local situation. 9th International SedNet Conference, 23-26 September 2015, Krakow, Poland.

- Oliveira, B, Smit, M., Grotenhuis, T., Rijnaarts, H.H.M. (2015): Beneficial use of dredged material in agricultural land. 9th International SedNet Conference, 23-26 September 2015, Krakow, Poland.

- Oliveira, B. Smit, M., Grotenhuis, T., Rijnaarts, H.H.M. (2015): Upgrading of natural materials and methods for sustainable lift up of low lying polder areas. BiGeoCivil Workshop, 20-21 January 2015, Rockanje, The Netherlands.

- Oliveira, B., Smit, M., Grotenhuis, T., Rijnaarts, H.H.M. (2014): Lift up of Lowlands - general overview. Masterclass Bio-based Geo-and Civil Engineering within Bodem Breed Symposium, 19 November 2014, Lunteren, The Netherlands.

- Oliveira, B. Smit, M., Grotenhuis, T., Rijnaarts, H.H.M. (2013): Lift up of Lowlands - general overview. BiGeoCivil Workshop, 14-15 March 2015, Oegstgeest, The Netherlands. 


\section{Poster presentations}

- Oliveira, B., Smit, M., Grotenhuis, T., Rijnaarts, H.H.M. (2015): Beneficial use of dredged sediments as topsoil. Environmental Technology for Impact 2015, 29-30 April 2015, Wageningen, The Netherlands.

- Oliveira, B., Smit, M., Grotenhuis, T., Rijnaarts, H.H.M. (2013): Noninvasive measurement of $\mathrm{O} 2$ and $\mathrm{CO} 2$ in experiments with dredged sediments. 8th International SedNet conference, 6-9 November 2013, Lisbon, Portugal.

- Oliveira, B., Smit, M., Grotenhuis, T., Rijnaarts, H.H.M. (2013): Dredged materials upgrade to reverse the subsidence of lowlands. AquaConSoil 2013 - 12th International UFZ-Deltares Conference on Groundwater-Soil-Systems and Water Resource Management, 16-19 April 2013, Barcelona, Spain.

\section{SedNet Newsletters}

- Arjan Wijdeveld, Bruna Oliveira, Eric A. Stern, Tristan Debuigne (2016): Workshop on the reuse of (contaminated) sediments. SedNet Newsletter - May 2016. http://sednet.org/news/newsletter/newslettermay-2016

- Bruna Oliveira (2013): Working-Group - Beneficial use of dredged material. SedNet Newsletter - December 2013. http://sednet.org/newsletter/2013-december/ 



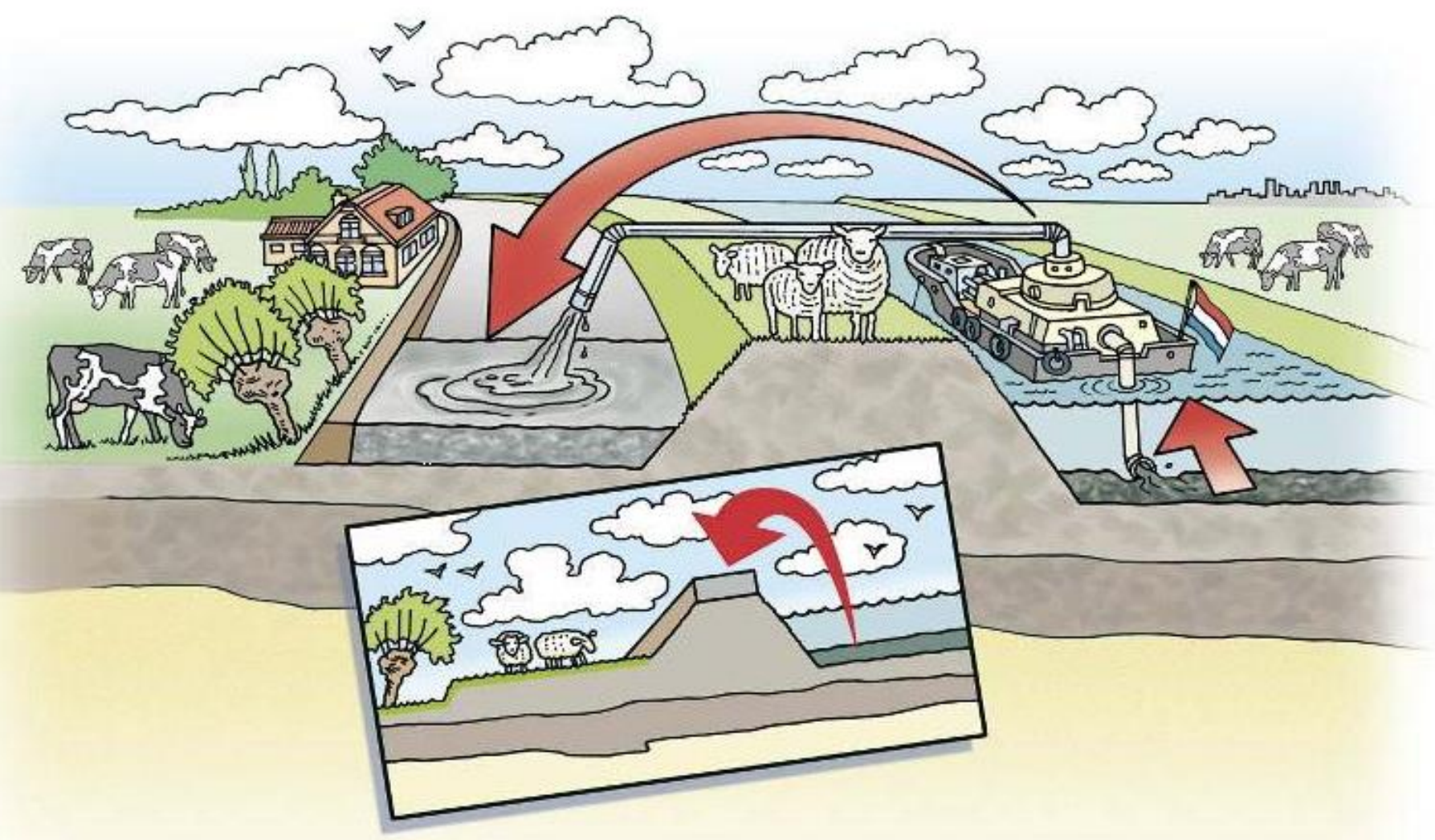





\section{About the author}

Bruna Raquel Figueiredo Oliveira was born August $3^{\text {rd }}, 1986$ in Vale de Cambra, Portugal. In 2009 she graduated with Master's degree in Environmental Engineering in University of Aveiro, Aveiro, Portugal. The MSc thesis was about the impact of burial grounds on groundwater and public health. This work granted her an honour mention for young researcher and 2 years as Research Assistant at CESAM - Centre for Environmental and Marine Studies, University of Aveiro, Portugal. At the same time she was working as teacher in a tutorial centre for students of Environmental Engineering. In 2012, she started as PhD at the department of Environmental Technology at Wageningen University, Wageningen, the Netherlands, on the project Lift up of Lowlands that led to this thesis. 



\section{SENSE}

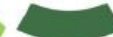

Netherlands Research School for the

Socio-Economic and Natural Sciences of the Environment

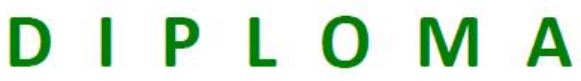

For specialised PhD training

The Netherlands Research School for the

Socio-Economic and Natural Sciences of the Environment

(SENSE) declares that

\section{Bruna Raquel Figueiredo Oliveira}

born on 3 August 1986 in Vale de Cambra, Portugal

has successfully fulfilled all requirements of the

Educational Programme of SENSE.

Wageningen, 15 February 2017

the Chairman of the SENSE board

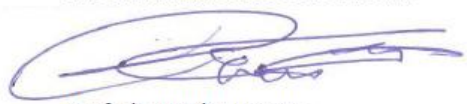

Prof. dr. Huub Rijnaarts the SENSE Director of Education

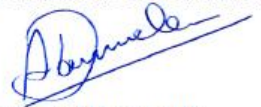

Dr. Ad van Dommelen

The SENSE Research School has been accredited by the Royal Netherlands Academy of Arts and Sciences (KNAW)

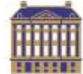

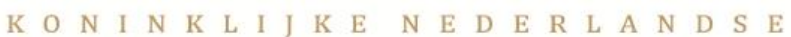

A K A D E M I E V A $N$ W W E T E N S C H A P P E 


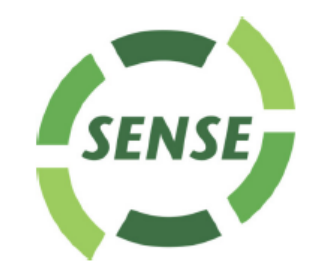

The SENSE Research School declares that Ms Bruna Figueiredo Oliveira has successfully fulfilled all requirements of the Educational PhD Programme of SENSE with a work load of $43.9 \mathrm{EC}$, including the following activities:

\section{SENSE PhD Courses}

- Bayesian Statistics (2012)

- Environmental research in context (2013)

- Research in context activity: 'Co-organising symposium Environmental Technology for Impact', Wageningen (2015)

\section{Other PhD and Advanced MSc Courses}

- Information literacy including EndNote introduction, Wageningen University (2012)

Microbial ecology, Wageningen University (2012-2013)

Model thinking, Coursera online course, University of Michigan (2013)

Interdisciplinary research: Crucial knowledge and skills, Wageningen University (2013)

- Techniques for writing and presenting a scientific paper, Wageningen University (2013)

\section{Management and Didactic Skills Training}

- Supervising BSc student with thesis entitled 'The reuse of dredged material' (2012-2013)

- Assisting practicals of the BSc course 'Introduction Environmental Technology' (2012-2014)

- Supervising two MSc students with thesis entitled 'Dredged sediment treatment, the impact of organic matter addition on priming effect' (2014) and 'Influence of fresh organic matter on the dewatering of dredged sediments' (2015)

- Co-organising the workshop 'Beneficial use of dredged sediments', SedNet conference, Krakow, Poland (2015)

\section{Selection of Oral Presentations}

- Lift up of lowlands - Beneficial use of dredged sediments. Lift up of Lowlands workshop, 10 December 2015, Wageningen, The Netherlands

- Beneficial use of dredged material in agricultural land. $9^{\text {th }}$ International SedNet Conference, 23-26 September 2015, Krakow, Poland

- Upgrading of natural materials and methods for sustainable lift up of low lying polder areas. BioGeoCivil Workshop, 20-21 January 2015, Rockanje, The Netherlands

\section{SENSE Coordinator PhD Education}

Dr. ing. Monique Gulickx 
The research described in this thesis was supported by the Dutch Technology Foundation STW, which is part of the Netherlands Organisation for Scientific Research (NWO), and which is partly funded by the Ministry of Economic Affairs, via the perspective program BioGeoCivil (grant 11344). 
